\title{
Naturalis
}
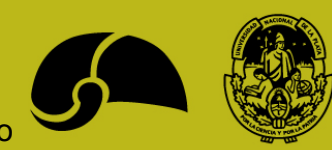

\section{Ecología trófica de cetáceos subantárticos utilizando el análisis de isótopos estables}

\section{Riccialdelli, Luciana}

Doctor en Ciencias Naturales

Dirección: Bastida, Ricardo O.

Co-dirección: Figini, Aníbal J.

Facultad de Ciencias Naturales y Museo

2011

Acceso en:

http://naturalis.fenym.unlp.edu.ar/id/20120126001090

\section{(c) (1) (2) (2) \\ BY NC SA}

Esta obra está bajo una Licencia Creative Commons

Atribución-NoComercial-Compartirlgual 4.0 Internacional

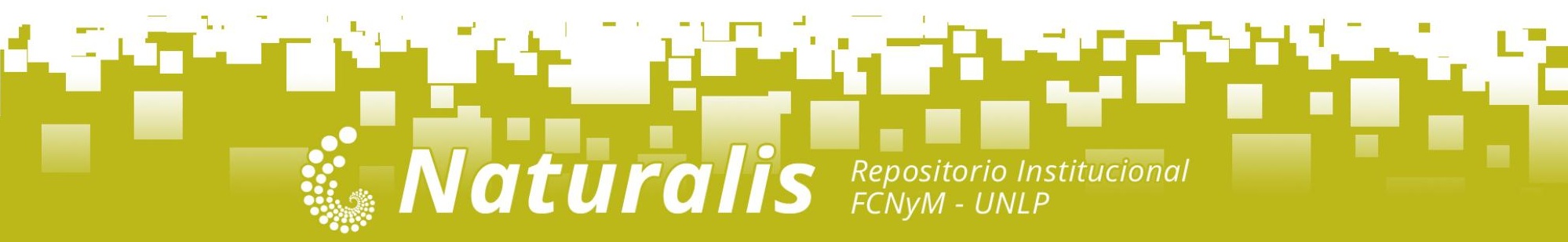




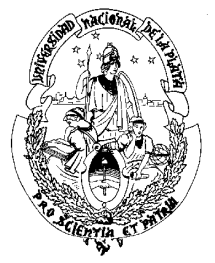

UNIVERSIDAD NACIONAL DE LA PLATA

FACULTAD DE CIENCIAS NATURALES Y MUSEO

\title{
ECOLOGÍA TRÓFICA DE
}

\section{CETÁCEOS SUBANTÁRTICOS UTILIZANDO EL ANÁLISIS DE ISÓTOPOS ESTABLES}

\author{
por \\ LUCIANA RICCIALDELLI
}

Tesis presentada para optar al título de Doctor en Ciencias Naturales

DIRECTOR: RICARDO O. BASTIDA

Codirector: Anibal J. Figini (†)

La Plata, 2011 


\section{ECOLOGÍA TRÓFICA DE CETÁCEOS SUBANTÁRTICOS}

\section{UTILIZANDO EL ANÁLISIS DE ISÓTOPOS ESTABLES}

Resumen. El manejo adecuado de los ecosistemas marinos del Atlántico Sudoccidental requiere una mejor comprensión de su estructura y dinámica. Por ello es fundamental el estudio de la presencia y función trófica de las especies de cetáceos debido a los importantes efectos que ejercen en las tramas tróficas marinas en su rol de predadores de altos niveles tróficos. El objetivo del presente trabajo es evaluar la ecología trófica de ocho especies de cetáceos odontocetos que habitan las aguas subantárticas de Tierra del Fuego.

Se comprobó la utilidad de la variación isotópica del colágeno del hueso para definir el comportamiento trófico principal de seis especies de delfínidos (Lagenorhynchus australis, Cephalorhynchus commersonii, Grampus griseus, Lissodelphis peronii, Pseudorca crassidens y Lagenorhynchus cruciger) y dos especies de focénidos (Phocoena dioptrica y Phocoena spinipinnis). El análisis de isótopos estables en diferentes grupos presa (especies de peces, moluscos cefalópodos y crustáceos) contribuyó a la interpretación ecológica de los valores de $\delta^{13} \mathrm{C}$ y $\delta^{15} \mathrm{~N}$ de los predadores analizados. El uso combinado de $\delta^{13} \mathrm{C}$ y $\delta^{15} \mathrm{~N}$ del colágeno del hueso revela información espacial y de largo tiempo ( $\sim 5$ a 10 años) sobre los hábitos alimentarios y las áreas de alimentación de los cetáceos.

Se encontró un continuo trófico, revelado por estos isótopos, desde la especie más costera con los valores más altos (Lagenorhynchus australis) a las especies más oceánicas y distribuidas más al sur entre aguas del Pasaje de Drake y el Frente Polar (Lagenorhynchus cruciger y Phocoena dioptrica). Los valores de $\delta^{13} \mathrm{C}$ y $\delta^{15} \mathrm{~N}$ de estos consumidores marinos son el reflejo de las variaciones espaciales en los valores de estos isótopos tanto de los productores primarios como de sus especies presas en los diferentes hábitats - costeros, de plataforma patagónica, oceánicos -.

Las evidencias isotópicas sugieren que en hábitats inshore Lagenorhynchus australis y otras dos especies costeras Cephalorhynchus commersonii / Phocoena spinipinnis ocupan diferentes nichos ecológicos. Los altos valores isotópicos de Lagenorhynchus australis son consistentes con consumidores costeros de niveles tróficos altos. Los valores medios de $\delta^{13} \mathrm{C}$ y $\delta^{15} \mathrm{~N}$ y las varianzas isotópicas en Cephalorhynchus commersonii y 
Phocoena spinipinnis indican el uso de recursos costeros y de plataforma con una dieta principalmente ictiófaga. En regiones offshore las similitudes encontradas en las firmas isotópicas de Grampus griseus, Lissodelphis peronï y Pseudorca crassidens indican nichos ecológicos similares. No obstante, Pseudorca crassidens exhibe una acotada variación isotópica indicativa de una mayor especialización en su dieta, presumiblemente teutófaga. Los valores de Grampus griseus y Lissodelphis peronii intermedios entre especies ictiófagas (Lagenorhynchus australis, Cephalorhynchus commersonii, Phocoena spinipinnis) y teutófagas (Pseudorca crassidens) sugiere una dieta basada en peces y calamares. Las similitudes isotópicas que estas especies (Grampus griseus y Lissodelphis peronii) mantienen con especies inshore sugerirían el uso de recursos de plataforma patagónica por parte de éstos. La distribución isotópica bimodal encontrada entre los individuos de Grampus griseus sugiere la existencia de dos grupos con ecología similar pero de localidades latitudinales diferentes. Los valores de $\delta^{13} \mathrm{C}$ y $\delta^{15} \mathrm{~N}$ más bajos se encontraron en Phocoena dioptrica y Lagenorhynchus cruciger, los cuales se correlacionan con valores empobrecidos del Océano Austral, en particular con valores isotópicos del Pasaje de Drake y el Frente Polar.

El análisis de la variabilidad isotópica intra-específica en Grampus griseus y Cephalorhynchus commersonii sugiere que no existe segregación espacial y/o alimentaria entre individuos de diferente sexo en ambas especies, y entre adultos y subadultos en Grampus griseus. Sin embargo en Cephalorhynchus commersonii los valores más altos de $\delta^{15} \mathrm{~N}$ encontrados en especímenes adultos y de mayor talla podría indicar diferencias en las preferencias de presas $\mathrm{y} / \mathrm{o}$ hábitats respecto a los juveniles. Por último, se detectaron cambios isotópicos temporales en ejemplares de Cephalorhynchus commersonii, Phocoena dioptrica y Lagenorhynchus australis varados o capturados incidentalmente en redes costeras a lo largo de tres décadas. Esto podría estar relacionado con cambios en sus preferencias de presas y/o hábitats o con cambios isotópicos producidos en la base de las redes tróficas.

El presente estudio ofrece una nueva visión en la ecología de estas especies principalmente sobre las que existe escasa información ecológica publicada. Con el avance en el conocimiento de los isótopos estables de las tramas tróficas del Atlántico Sudoccidental, podrán realizarse estudios más detallados sobre la ecología de las especies y mejorar el conocimiento global de los ecosistemas de la región. 


\title{
TROPHIC ECOLOGY OF SUBANTARCTIC CETACEANS USING STABLE ISOTOPES ANALYSIS
}

\begin{abstract}
The appropriate management of the Southwest Atlantic marine ecosystems requires a better understanding of its structure and dynamics. That is why it is of major importance the study of the presence and trophic function of the cetacean species since, given their role as top predator, they exert important effects on marine food webs. The aim of this study is to evaluate the trophic ecology of eight species of toothed whales that inhabit the sub-Antarctic waters of Tierra del Fuego.

This study demonstrated the utility of the isotopic variation of bone collagen to define the main feeding behavior of six species of delphinids (Lagenorhynchus australis, Cephalorhynchus commersonii, Grampus griseus, Lissodelphis peronii, Pseudorca crassidens and Lagenorhynchus cruciger) and two species of phocoenids (Phocoena dioptrica and Phocoena spinipinnis). The stable isotopes analysis on different prey groups (fish, cephalopod mollusk and crustaceans) contributed to the ecological interpretation of the $\delta^{13} \mathrm{C}$ and $\delta^{15} \mathrm{~N}$ values of the predators analyzed. The combined use of $\boldsymbol{\delta}^{13} \mathrm{C}$ and $\delta^{15} \mathrm{~N}$ of bone collagen reveals spatial information on a long time scale ( $\sim 5$ to 10yr) on food habits and foraging areas of the cetaceans.

It was found a trophic continuum, revealed by these isotopes, from the most coastal species with the highest values (Lagenorhynchus australis) to the most oceanic species spread further south between waters of the Drake Passage and the Polar Front (Phocoena dioptrica and Lagenorhynchus cruciger). The $\delta^{13} \mathrm{C}$ and $\delta^{15} \mathrm{~N}$ values of these marine consumers are a reflection of the spatial variations in these isotopes values of the primary producers and their prey species at different habitats - coastal, Patagonian shelf, oceanic -.

The isotopic evidence suggests that in inshore habitats Lagenrohynchus australis and two other coastal species Cephalorhynchus commersonii / Phocoena spinipinnis occupy different ecological niches. The high isotopic values of Lagenorhynchus australis are consistent with coastal consumers of high trophic levels. The main $\delta^{13} \mathrm{C}$ and $\delta^{15} \mathrm{~N}$ values and the isotopic variance in Cephalorhynchus commersonii and Phocoena spinipinnis indicate the use of coastal and shelf resources and mainly an ichthyophagous diet. In offshore regions, the similarities found in the isotopic signatures of Grampus griseus,
\end{abstract}


Lissodelphis peronii and Pseudorca crassidens indicate similar ecological niches. However, Pseudorca crassidens exhibits a constrained isotopic variance which indicates of a greater specialization in their diet, presumably teuthophagous. The intermediate values of Grampus griseus and Lissodelphis peronii, between icthyophagous (Lagenorhynchus australis, Cephalorhynchus commersonii, Phocoena spinipinnis) and teuthophagous species (Pseudorca crassidens) suggests a diet based on fish and squid. The isotopic similarities of these species (Grampus griseus and Lissodelphis peronii) with inshore species suggest the use of Patagonian shelf resources. The bimodal isotope distribution found among Grampus griseus individuals suggests the existence of two groups with similar ecology but at different latitudinal locations. The lowest $\delta^{13} \mathrm{C}$ and $\delta^{15} \mathrm{~N}$ values were found in Phocoena dioptrica and Lagenorhynchus cruciger, correlated with depleted values of the Southern Ocean, in particular with isotopic values from the Drake Passage and the Polar Front.

The analysis of the intra-specific isotopic variability in Grampus griseus and Cephalorhynchus commersonii suggests that there is no spatial and/or food segregation between individuals of different sexes in both species, and between adults and subadults in Grampus griseus. However, the higher $\delta^{15} \mathrm{~N}$ values found in adult specimens and of larger size of Cephalorhynchus commersonii may indicate differences in prey preferences and/or habitats compared to juveniles. Finally, temporal isotopic changes were detected in specimens of Cephalorhynchus commersonii, Phocoena dioptrica and Lagenorhynchus australis which were found stranded or incidentally caught in coastal nets over three decades. This could be related to changes in prey and/or habitats preferences or with changes occurred at the base of the food webs.

This study provides new insight into the ecology of these species mainly for those on which there is little ecological information published. With the advance in the stable isotope knowledge of the food webs of the Southwest Atlantic, we will be able to perform detailed studies on the ecology of the species and improve the global knowledge of the ecosystems of the region. 


\section{DEDICATORIA}

A Ignacio

Me gustaría enseñarte que para los sueños no hay techo, y que todo es cuestión de tu voluntad para que hagas posible lo que quieras en esta vida Que es hermoso ponerse desafíos, y que más allá de los resultados vale la pena vivirlos.

A Santiago

Por amarme y creer en mí cada día

A mi mamá Graciela y mi papá Carlos Por enseñarme que la familia es lo más valioso que poseo

A mis hermanos, Paula y Emiliano Por valorar nuestra amistad ante todo 


\section{AGRADECIMIENTOS}

Agradezco profundamente a mi Directora de Beca, R. Natalie P. Goodall, por brindarme la oportunidad de trabajar a su lado y ofrecerme todo cuanto necesitara desde lo profesional hasta lo personal.

A Ricardo O. Bastida, mi Director de Tesis, por estar siempre presente cuando lo necesité, por darme sus sabios consejos y grandes aportes que han mejorado sustancialmente este trabajo.

A Anibal J. Figini, quien fue mi Codirector de Tesis y de Beca, por ofrecerme generosamente su ayuda y hacerme pensar sobre la problemática de la muestra ósea de estas especies de cetáceos. A Hector O. Panarello, por brindar su apoyo como codirector de beca.

Al equipo del LATyR, Roberto Huarte y Jorge Carbonari, por ayudarme en los ensayos sobre el procesamiento de las muestras óseas. Por seguir estando, aún sin Anibal, ante cualquier consulta o necesidad.

A Seth D. Newsome, por ser una constante sumamente importante en este trabajo, desde sus inicios. Por generarme desafíos intelectuales y ser extremadamente entusiasta y emprendedor.

A Marilyn Fogel, por brindarme el fantástico laboratorio de análisis de isótopos estables. A ambos (Seth y Marilyn) por ofrecerme una oportunidad única para alcanzar los objetivos de este trabajo.

A Augusto Tessone, por brindar su ayuda en el análisis repetido de varias muestras así como el intercambio de protocolos de pretratamiento.

Al Centro Austral de Investigaciones Científicas (CADIC), el Museo Acatushún de Aves y Mamíferos Marinos y al LATyR por ofrecerme un espacio de trabajo.

Al Consejo Nacional de Investigaciones Científicas y Técnicas (CONICET), por el otorgamiento de dos Becas de Postgrado (Tipo I y II) para la realización de este trabajo. A Cetacean Society International (CSI), Sigma-Xi, The Scientific Research Society, Committee On Grants-In-Aid of Research y Conservation, Research and Education Opportunities (CREO) por los subsidios otorgados para el trabajo de la Tesis.

A las autoridades del Carnegie Institution por invitarme al Geophysical Laboratory para realizar los análisis isotópicos. 
A Charles Potter, James Mead y Deen Allen del Smithsonian Institution por brindarme importante ayuda en contactos y en permisos de importación de las muestras a Estados Unidos.

A Anne (Jakcle) y Seth (Newsome), por encontrar en ellos unos grandes amigos. A Will Wurzel por la ayuda técnica en el análisis de isótopos estables, y por los excelentes helados caseros preparados en el laboratorio.

A Santiago Favoretti, Natalia Paso Viola, Santiago Ceballos, Federico Boggino, Antonio Boggino, Mónica Torres por ayudarme durante el trabajo de campo.

A Daniel Fernández, Fabián Vanella, Daniel Aureliano, por facilitarme muestras de presas del área patagónica sur y la Convergencia Antártica.

A mis compañeras de trabajo, Natalia Dellabianca, Mónica Torres y Lida Pimper, por ayudarme siempre e intercambiar ideas para mejorar la Tesis.

A Anne Jackle, Natalia Dellabianca, Sara Montemayor, Guadalupe del Río por sus correcciones y sugerencias en la redacción de la Tesis.

A Rosario Robles, por ser una gran consejera, excelente crítica y gran revisora, aún durante sus campañas o viajes personales. Gracias por preocuparte por la organización de mi trabajo como...desde el primer día de la Facultad. Pero por sobretodo por ser una gran amiga y estar siempre.

En lo personal, agradezco a mis amigas/os por haber crecido con ellos, de pequeña y aún de grande. A los viejos amigos, a los nuevos y a los de toda la vida. Especialmente a Ro, Vicky, Sarín, Naty, Guada, Ceci, Moni, Magda por compartir el inicio de una gran aventura en la biología, en viajes y en sueños. A Mariví, Verito y Vero, que sufrieron mis largas ausencias y para no perder la costumbre aún lo siguen haciendo. A Lore, Guille, Hernán y Gabi, por estar desde siempre. A Merce y Fabi, Nati, Ramón y Mayra, Marcos, los jujeños (Betina y Dardo y ahora Nico!), Enca y Marcos Cister, por haber compartido grandes momentos en esta tierra lejana, y hacerme sentir un poco más en casa.

A mis hermanos, Paula y Emiliano, porque los amo y extraño tanto.

A mis padres, por ensañarme lo grandiosa que puede ser esta vida. Por ofrecerme todo, quererme tanto, apoyar todas mis decisiones. Por criarme... y dejarme libre.

A Santiago, por ser mi gran compañero y construir conmigo un hogar donde quiera que estemos.

A Ignacio, porque me diste la sorpresa más grande de mi vida y después de tanta espera, llegaste! 


\section{Índice DE ConTENIDOs}

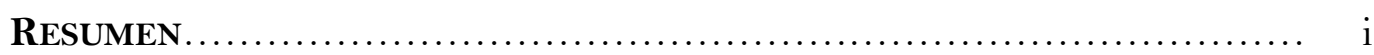

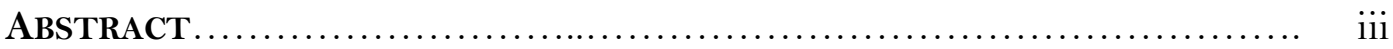

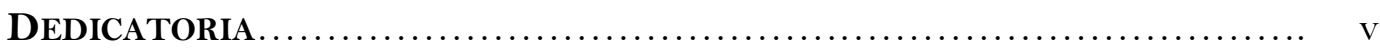

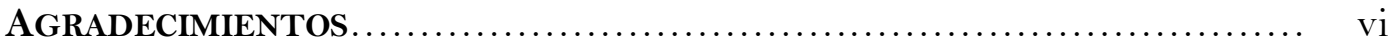

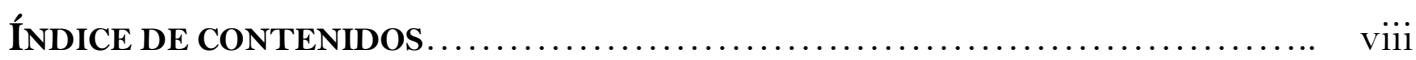

LISTA DE TABLAS Y FIGURAS.................................... xi

CAPÍtulo 1: InTRoducción GenERAL .............................. 1

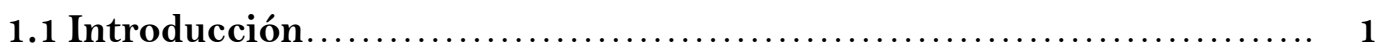

1.2 Objetivos e Hipótesis ......................................... 7

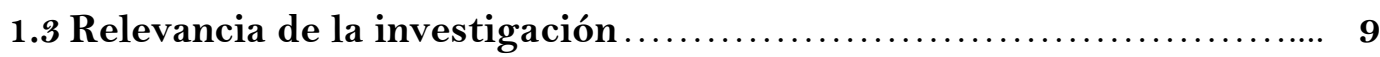

ANEXo I: Descripción de las ESPECIES DE CETÁCEOS ................ 11

Marsopa espinosa (Phocoena spinipinnis) .............................. 11

Marsopa de anteojos (Phocoena dioptrica) .............................. 12

Tonina overa (Cephalorhynchus commersonir) .......................... 13

Delfín austral (Lagenorhynchus australis)............................. 14

Delfín cruzado (Lagenorhynchus cruciger) ............................. 16

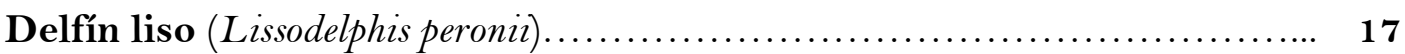

Delfín gris (Grampus griseus) ..................................... 18

Falsa orca (Pseudorca crassidens) ........................................... 19

Anexo II: Principios del AnÁlisis de Isótopos Estables ............ 21

Fraccionamiento isotópico $\ldots \ldots \ldots \ldots \ldots \ldots \ldots \ldots \ldots \ldots \ldots \ldots \ldots \ldots \ldots \ldots \ldots \ldots \ldots \ldots, 22$

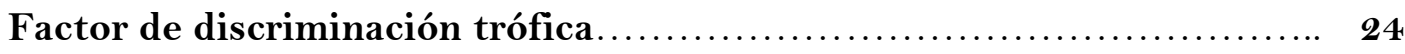

Potenciales substratos para el AIE en mamíferos marinos.............. 25

Características isotópicas del hueso.................................... 26

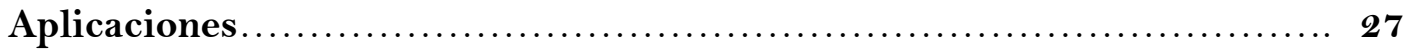

Estimación de los niveles tróficos (NTs) a través del AIE................... 27

Estudio de las preferencias del hábitat a través del AIE..................... 28

Análisis de las fuentes alimentarias a través del AIE....................... 30 
Capítulo 2: Metodología General. 32

2.1 Área de estudio 32

2.2 Procedimientos de investigación 35

2.2.1 Especímenes y colección de muestras............................... 35

2.2.1.1 Cetáceos.................................................... 35

2.2.1.2 Presas....................................................... 38

2.2.2 Procesamiento de las muestras y análisis de isótopos estables.......... 41

2.2.2.1 Procesamiento de las muestras de cetáceos.......................... 41

2.2.2.2 Procesamiento de las muestras de presas........................... 42

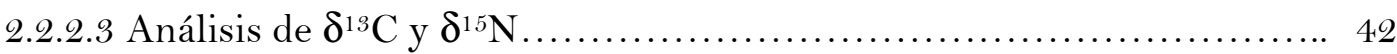

2.2.3 Evaluación de la integridad de las muestras........................ 45

2.2.4 Aspectos para la interpretación de los valores de $\delta^{13} \mathrm{C}$ y $\delta^{15} \mathrm{~N} \ldots \ldots \ldots \ldots 45$

2.2.5 Tratamiento estadístico de los datos............................. 47

2.2.5.1 Análisis de la variación isotópica de presas......................... 47

2.2.5.2 Análisis de la variación isotópica inter-específica en los cetáceos....... 47

2.2.5.2.1 Patrones isotópicos espaciales y/o alimentarios.................. 48

2.2.5.2.2 Estimación de los niveles tróficos............................. 48

2.2.5.2.3 Estimación de la contribución isotópica de las presas al valor isotópico del predador..................................... 49

2.2.5.3 Análisis de la variación intra-específica en la dieta................... 50

2.2.5.4 Análisis de la variación isotópica temporal......................... 50

Capítulo 3: Resultados Generales............................ 56

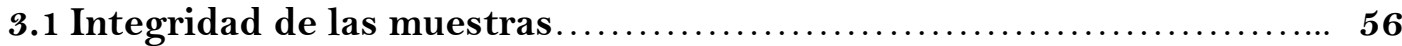

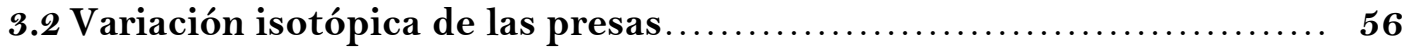

3.3 Variación isotópica inter-específica en los cetáceos estudiados....... 66

3.3.1 Resultados del análisis estadístico general........................... 66

3.3.2 Análisis de cluster............................................ 68

3.3.3 Niveles tróficos y varianza isotópica .............................. 71

3.3.4 Modelos de mezcla - IsoSource ................................. 72

3.4 Variaciones intra-específica en la dieta $\ldots \ldots \ldots \ldots \ldots \ldots \ldots \ldots \ldots \ldots, 81$

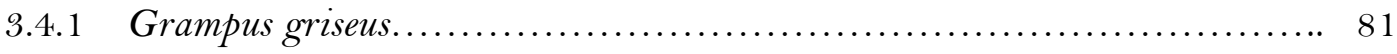

3.4.2 Cephalorhynchus commersonii................................. 83 
3.5 Variación isotópica temporal

Capítulo 4: Discusión General ................................. 91

4.1 Integridad de las muestras.................................. 91

4.2 Variación isotópica de las presas.............................. 92

4.3 Variación isotópica inter-específica en los cetáceos estudiados........ 94

Áreas espaciales de alimentación.............................................. 94

Niveles tróficos y comportamiento alimentario........................... 96

Especies Inshore............................................................. 96

Especies Offshore............................................................. 100

Especies Oceánicas................................................................ 102

4.4 Variaciónes intra-específica en la dieta......................... 104

4.4.1 Grampus griseus........................................................ 104

4.4.2 Cephalorhynchus commersonii.................................. 107

4.5 Variación isotópica temporal ................................. 110

Causas de cambio en las firmas isotópicas ................................ 110

CAPÍtulo 5: Conclusiones Generales......................... 115

Anexo III: Protocolo de Extracción de Muestras de Hueso Para

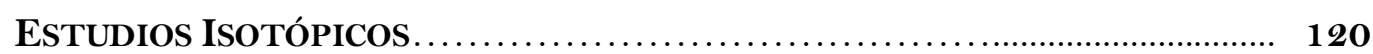

Anexo IV: Protocolo de Pretratamiento de Muestras Óseas Para

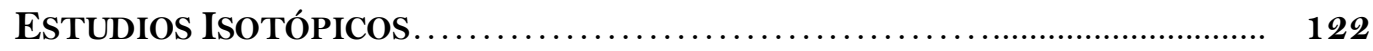

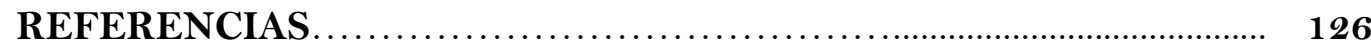




\section{LiSTA DE TABLAS Y FigURAS}

\section{TABLAS}

Tabla 1. Isótopos estables más utilizados en estudios ecológicos.............. 22

Tabla 2. Especies de cetáceos odontocetos analizadas..................... 36

Tabla 3. Especies presas analizadas.................................. 52

Tabla 4. Composición isotópica del colágeno del hueso de los cetáceos

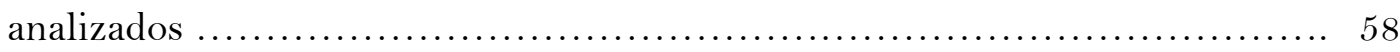

Tabla 5. Composición isotópica de especies presas.......................... 59

Tabla 6. Contribuciones isotópicas de posibles grupos presa - IsoSource....... 75

Tabla 7. Composición isotópica del colágeno del hueso de los ecotipos

de Grampus griseus en relación al sexo y categoría de edad .................. 83

Tabla 8. Composición isotópica del colágeno del hueso de especímenes

de Cephalorhynchus commersonii por clases de edades....

Tabla 9. Resultados del análisis de correlación entre los valores de

$\delta^{13} \mathrm{C}$ y $\delta^{15} \mathrm{~N}$ y los años de varamiento de los cetáceos.

\section{FIGURAS}

Figura 1: Área de estudio.

Figura 2: Sectores de muestreo: A. área Tierra del Fuego y B. área

Convergencia Antártica.

Figura 3. Ubicación de las piezas óseas seleccionadas de los especímenes de cetáceos analizados.

Figura 4. Muestreo de presas....................................... 40

Figura 5. Procesamiento de las muestras y análisis de isótopos estables....... 44

Figura 6. Composición isotópica de grupos de presas del Atlántico

Sudoccidental: (A). valores de $\delta^{13} \mathrm{C}$. (B). valores de $\delta^{15} \mathrm{~N} \ldots \ldots \ldots \ldots \ldots \ldots \ldots \ldots$

Figura 7. Valores de $\delta^{13} \mathrm{C}$ y $\delta^{15} \mathrm{~N}$ ( \pm error estándar) de grupos presa del Atlántico Sudoccidental. 
Figura 8. Valores de $\delta^{13} \mathrm{C}$ y $\delta^{15} \mathrm{~N}$ del colágeno del hueso de los cetáceos analizados

Figura 9. Valores de $\delta^{13} \mathrm{C}$ y $\delta^{15} \mathrm{~N}$ del colágeno del hueso de los

ecotipos de Grampus griseus....

Figura 10. Análisis de cluster (vecino más cercano y distancias euclideanas)

para las especies de cetáceos

Figura 11. Contribuciones isotópicas de 3 grupos presas al valor isotópico de Lagenorhynchus australis

Figura 12. Contribuciones isotópicas de 4 grupos presas al valor isotópico de Cephalorhynchus commersonii

Figura 13. Contribuciones isotópicas de 4 grupos presas al valor isotópico de Phocoena spinipinnis.

Figura 14. Dieta de las especies de cetáceos en base a la segregación de sus firmas isotópicas y la relación establecida con sus presas.

Figura 15. Comportamiento trófico principal de las ocho especies de cetáceos analizados

Figura 16. Valores medios de $\delta^{13} \mathrm{C}$ y $\delta^{15} \mathrm{~N}$ ( \pm desvío estándar) de los ecotipos de Grampus griseus y sus posibles presas.

Figura 17. Variación isotópica intra-específica en Cephalorhynchus commersonii en relación con la edad de los individuos

Figura 18: Variación isotópica intra-específica en Cephalorhynchus commersonii en relación con la longitud total de los individuos.

Figura 19. Variación isotópica temporal en Cephalorhynchus commersonii, Lagenorhynchus australis, Phocoena dioptrica y Grampus griseus. 


\section{CAPÍTULO 1}

\section{INTRODUCCIÓN GENERAL}

\subsection{INTRODUCCIÓN}

La mayoría de las especies de mamíferos marinos ocupan los niveles más altos de las redes tróficas marinas, siendo fundamentales componentes de la estructura y función de los ecosistemas que integran (Estes 1996, Bowen 1997, Merrick 1997, Trites 2002). La crisis global que las pesquerías mundiales están atravesando, advierte la necesidad de reformular el manejo de los ecosistemas marinos (Pauly et al. 2002). La idea del manejo ecosistémico (Pauly \& Christensen 2002) está reemplazando a la gestión pesquera basada sólo en especies blanco, la cual ignora las interacciones ecológicas entre diferentes componentes de las redes tróficas (Christensen \& Pauly 2004). Las decisiones sobre el manejo y conservación de estos ecosistemas deben basarse en información ecológica precisa sobre la estructura y función de los mismos. Para los ecosistemas marinos oceánicos, esta evaluación incluye el desarrollo de una mejor comprensión sobre el rol ecológico de los predadores de los niveles más altos de las redes tróficas, generalmente difíciles de estudiar en su hábitat natural por su gran movilidad.

En este contexto, para lograr comprender globalmente el rol de los mamíferos en su ambiente natural, principalmente en relación al efecto de su posición en la estructura y dinámica de las redes tróficas, es de crucial importancia contar con información sobre sus hábitos tróficos (Trites 2003, Iverson et al. 2004, CarreonMartinez \& Heath 2010). Sin embargo, resulta muy difícil evaluar el estado trófico de un animal, lo que en otras palabras sería definir el nivel que ocupa en la estructura trófica de una comunidad y el subsecuente rol que juega como consumidor (Rau et al. 1983). Si bien, la observación directa puede ser usada para estimar el comportamiento alimentario de algunos organismos, para muchos, entre los cuales se encuentran los cetáceos, esto rara vez es posible. La observación de cetáceos alimentándose en la naturaleza puede ser logísticamente difícil e impráctica. En la mayoría de los casos, los estudios se ven limitados al comportamiento superficial de los animales, y sólo cuando las condiciones meteorológicas lo permiten. Para especies de comportamiento oceánico, estos métodos son aún más complicados, dado que para su seguimiento se 
necesita una buena logística y un importante respaldo económico. Así pocos estudios han sido conducidos por observación directa de animales alimentándose en la naturaleza, ya sea desde embarcaciones, desde tierra o bien desde el aire en el extremo sur del Atlántico Sudoccidental (Würsig et al. 1977, Viddi \& Lescrauwaet 2005, Reyes 2006). En este sentido, debe destacarse la importancia de utilizar métodos indirectos para conocer sus hábitos tróficos (Iverson et al. 2004).

El conocimiento de la ecología trófica de la mayor parte de los cetáceos del Mar Argentino, y en particular los distribuidos en Tierra del Fuego, se basa principalmente en métodos indirectos. Entre estos, el análisis de contenidos estomacales de animales varados o capturados incidentalmente durante maniobras de pesca (Goodall \& Galeazzi 1985, Bastida et al. 1988, Clarke \& Goodall 1994, Goodall \& Schiavini 1995). Algunos estudios basados en datos procedentes del análisis del contenido estomacal de muchos individuos han logrado aportar una substancial información sobre la dieta de varias especies, como la tonina overa (Cephalorhynchus commersonii), el delfín austral (Lagenorhynchus australis) y la falsa orca (Pseudorca crassidens) (Bastida et al. 1988, Schiavini et al. 1997, Koen Alonso et al. 1999).

De este modo, aunque estos estudios aportan importantes datos sobre las preferencias generales de alimentación, el análisis de los contenidos estomacales -en muchos casos- puede resultar poco satisfactorio y presentar serias limitaciones (Rau et al. 1983). En este sentido, el diferente grado de digestión, genera una sobreestimación hacia presas con partes duras (ej. cefalópodos), y una difícil identificación de los restos procedentes de presas de cuerpo blando (Sheffield et al. 2001, Stainland 2002, Sheffield \& Grebmeier 2009), esto genera problemas en la determinación del tamaño de la presa consumida y hasta en su identificación (Iverson et al. 2004). Además, los contenidos estomacales varían considerablemente entre los individuos de una misma especie resultando un reflejo de la comida más reciente ( 24-72hs), brindando una visión instantánea del rol trófico que juega cada especie y posiblemente no representando la dieta a largo plazo (Michener \& Kaufman 2007). El análisis de contenidos estomacales de cetáceos varados genera un problema adicional, debido a que los mismos probablemente corresponden a individuos enfermos que no se han alimentado de sus presas habituales, ni tampoco las han consumido en sus áreas de alimentación tradicionales (Pierce et al. 2004) y en muchos casos, en el proceso de varamiento, regurgitan sus contenidos estomacales. Más aún, algunos estudios se basan en datos de pocos individuos que han varado lejos de su área de distribución geográfica (Fernández et al. 2003), ofreciendo una pobre caracterización de sus 
hábitos tróficos. Por otra parte, teniendo en cuenta que la mayoría de los cetáceos varados presenta sus estómagos vacíos o con poco contenido se necesita un gran número de muestras para representar la variabilidad alimentaria de cada especie, a distintas escalas temporales y espaciales; así como un muy buen conocimiento taxonómico de la mayoría de las presas por parte del investigador (Michener \& Kaufman 2007).

Durante las últimas décadas se han desarrollado técnicas que no dependen de la recuperación de las partes duras resistentes a la digestión y que ofrecen ventajas sobre los métodos tradicionales en el estudio de los hábitos tróficos de estos organismos, entre estos el análisis de isótopos estables (Pierce \& Boyle 1991, Iverson et al. 2004, Pierce et al. 2004, Thiemann et al. 2004, Deagle et al. 2005, Sheppard \& Harwood 2005, Tollit et al. 2006).

El análisis de isótopos estables es una técnica complementaria a los métodos tradicionales sobre el estudio de dieta en el reino animal, y constituye una vía de análisis independiente para el estudio de las preferencias de presas y de hábitat (Newsome et al. 2010). Esta técnica, se adapta muy bien al caso de los mamíferos marinos y se basa en una relación predecible entre la composición isotópica del consumidor y su presa, generalmente referido como discriminación trófica. En general, los valores de $\quad \delta^{13} \mathrm{C} \quad \mathrm{y} \quad \delta^{15} \mathrm{~N}$ se incrementan en $\sim 1-2 \%$ y $3-5 \%$ o respectivamente por cada aumento del nivel trófico en las redes alimentarias (DeNiro \& Epstein 1978, 1981, Minagawa \& Wada 1984). La variación natural de diversos isótopos estables en los sistemas marinos, y en particular la de carbono $\left(\boldsymbol{\delta}^{13} \mathrm{C}\right) \mathrm{y}$ nitrógeno $\left(\boldsymbol{\delta}^{15} \mathrm{~N}\right)$, ha sido aprovechada por diversos estudios aportando nuevas perspectivas sobre las interacciones entre los organismos y su ambiente (Kelly 2000, Rubenstein \& Hobson 2004, Wolf et al. 2009, Newsome et al. 2010). Esta técnica ha sido especialmente útil para el modelado del funcionamiento de las redes tróficas, y para estimar el efecto de los predadores de los niveles más altos de las redes tróficas (control top-down) y de los productores primarios (control bottom-up) en la estructura y funcionamiento de los ecosistemas (Cabana \& Rasmussen 1994, 1996, Hobson \& Sease 1998, Pauly et al. 1998a, Garcia et al. 2006, Porras-Peters et al. 2008, Newsome et al. 2009a).

El análisis de isótopos estables ha sido aplicado ampliamente en los estudios ecológicos de mamíferos marinos para tratar de caracterizar principalmente la dieta y 
sus niveles tróficos (Pauly et al. 1998, Gendron et al. 2001, Niño-Torres et al. 2006). El avance en el conocimiento sobre los factores de discriminación trófica y la tasa de recambio isotópico en los tejidos de los consumidores, así como la incorporación paulatina de los valores isotópicos de sus posibles presas en los estudios ecológicos, ha permitido aportar datos cualitativos de sus dietas y en ciertos casos hasta cuantitativos mediante el uso de diversos modelos de mezcla (Phillips \& Gregg 2001, 2003, Phillips et al. 2005). Los factores de discriminación trófica (o enriquecimiento trófico) indican la diferencia isotópica entre los tejidos de un consumidor y su dieta, y la tasa de recambio isotópico permite conocer el lapso de tiempo que representa esa información. A su vez, debido a la diferente tasa de recambio isotópico de los tejidos, el análisis de isótopos estables sobre diversos tipos de tejidos (como piel, músculo, hueso, dientes, pelos, sangre, hígado) de animales vivos o muertos y hasta fósiles, proporciona una evaluación del comportamiento alimentario a diferentes escalas temporales (Hobson \& Clark 1992a, Sponheimer et al. 2003, Koch 2007). En ciertos casos el uso de tejidos con crecimiento prolongado, como los huesos, y sin remodelación posterior a su depósito, como las barbas de los cetáceos misticetos y los dientes en cetáceos odontocetos, ofrecen un registro temporal que cubre toda o casi toda la vida de los individuos. Esto resulta sumamente valioso para el estudio de los cambios en los hábitos tróficos debidos, a la edad, condiciones ambientales o movimientos migratorios, entre otras causas (Best \& Schell 1996, Newsome et al. 2007a, Knoff et al. 2008, Newsome et al. 2009b).

Los valores de $\delta^{15} \mathrm{~N}$ y $\delta^{13} \mathrm{C}$ de los productores primarios en el océano varían espacial y temporalmente en función de diferentes condiciones físicas y oceanográficas (Koch 2007). Trabajos previos realizados en aguas del norte y centro de Patagonia y en el extremo sur del Atlántico Sur cerca de la Antártida, muestran variaciones significativas en los valores de $\delta^{15} \mathrm{~N}$ y $\delta^{13} \mathrm{C}$ entre las redes tróficas (Forero et al. 2004, Lewis et al. 2006, Ciancio et al. 2008, Drago et al. 2009, Lara et al. 2010), siguiendo los patrones reportados por Rau et al. (1982) y Goericke \& Fry (1994). Así, se ha documentado una declinación negativa en los valores de $\delta^{13} \mathrm{C}$ para el fitoplancton marino, generando gradientes isotópicos a gran escala en los valores de carbono en la base de las redes tróficas a lo largo de los océanos Pacífico y Atlántico desde aguas templadas hacia zonas árticas y antárticas (Rau et al. 1982, Goericke \& Fry 1994). Los valores de $\delta^{13} \mathrm{C}$ del fitoplancton marino también cambian en un gradiente longitudinal desde zonas costeras hacia aguas offshore, con valores más altos de $\delta^{13} \mathrm{C}$ cerca de la 
costa (Michener \& Kaufman 2007). Los patrones espaciales en los valores de $\delta^{15} \mathrm{~N}$ entre los ecosistemas marinos son mucho más complejos, pero también han sido reportadas variaciones latitudinales y longitudinales en el océano Pacífico Norte, en el mar de Bering, Beaufort y Chukchi (Schell et al. 1998, Burton \& Koch 1999, Michener \& Kaufman 2007). En general, la diferencia en los valores de $\delta^{15} \mathrm{~N}$ y $\delta^{13} \mathrm{C}$ de los productores primarios en la base de las redes tróficas son reflejadas en toda la estructura trófica y por consiguiente en los valores isotópicos de los predadores de los niveles más altos de las redes tróficas, permitiendo estudios de movimientos migratorios y usos del hábitat (Schell et al. 1989, Best \& Schell 1996, Burton \& Koch 1999).

A pesar de que existen diversas áreas que aún necesitan ser investigadas en relación a la teoría y experimentación de la técnica (Wolf et al. 2009), se ha generado un gran conocimiento sobre la ecología trófica de los mamíferos marinos mediante el análisis de isótopos estables. La comparación en los valores de $\boldsymbol{\delta}^{15} \mathrm{~N}$ entre individuos o especies es ampliamente usada para estimar sus niveles tróficos (Pauly et al. 1998, Gendron et al. 2001, Post 2002), dato indispensable a la hora de evaluar el rol ecológico que éstos mantienen en la dinámica de sus ecosistemas (Trites 2001, Das et al. 2003). Los valores de $\delta^{13} \mathrm{C}$ son útiles pues brindan información sobre la fuente de carbono en la dieta (DeNiro \& Epstein 1978, Kelly 2000) y también son buenos indicadores del uso del hábitat de los organismos siendo que sus valores isotópicos reflejan la composición isotópica de la base de la red trófica donde se están alimentando (Hobson 2007, Graham et al. 2010, Newsome et al. 2010). De este modo, diversos estudios han aportado gran información sobre dietas modernas, históricas y prehistóricas, sobre el solapamiento/segregación trófica de los organismos, usos del hábitat, diferenciación de stocks poblacionales, estrategias maternales, entre muchos otros (Ames et al. 1996, Best \& Schell 1996, Burton \& Koch 1999, Walker \& Macko 1999, Walker et al. 1999, Bearhop et al. 2004, Lee et al. 2005, Aurioles et al. 2006, Newsome et al. 2006, Knoff et al. 2008, Porras-Peters et al. 2008, Drago et al. 2009, Newsome et al. 2009a, Eder et al. 2010, Kiszka et al. 2010, Pinela et al. 2010).

Por lo expuesto, el estudio sobre hábitos tróficos de cetáceos mediante métodos como la observación directa y análisis de los contenidos estomacales resultan costosos o limitados comparados con la eficacia costo-beneficio de realizar el método 
de análisis de isótopos estables. En este sentido, este último resulta una herramienta útil que ofrece la posibilidad de revelar aspectos novedosos y resolver otros ambiguos, a la vez que aporta y contribuye sustancialmente a los estudios convencionales en la determinación de los hábitos tróficos de una especie (Best \& Schell 1996, Aurioles et al. 2006, Michener \& Kaufman 2007), ofreciendo un campo de investigación muy amplio y relevante en el conocimiento de la ecología de los mamíferos marinos (Hobson \& Sease 1998).

En el sector sudoeste del Atlántico Sur la actividad de las operaciones pesqueras ha aumentado a lo largo de las últimas tres décadas, impactando negativamente a las pesquerías y amenazando a diversas especies de pequeños cetáceos así como a otras especies de mamíferos y aves marinas. El efecto de la mortalidad incidental (Goodall et al. 1994), la explotación directa (Goodall et al. 1994, Lescrauwaet \& Gibbons 1994) y los efectos indirectos de las pesquerías industriales en las aguas patagónicas son extremadamente difíciles de monitorear y por lo tanto han sido muy poco evaluadas (Crespo et al. 1997a). Trabajos previos han sugerido que las costas de Tierra del Fuego experimentaron una menor presión pesquera en comparación con áreas del norte de la plataforma Patagónica (Bertolotti et al. 2001). Sin embargo, las pesquerías artesanales de Tierra del Fuego que históricamente no han sido monitoreadas, representan una constante amenaza para la vida marina. Asimismo, en los recientes años los desembarcos pesqueros aumentaron rápidamente (Isla 2006) con efectos desconocidos para los cetáceos de la zona. Para entender el potencial riesgo directo (ej. mortalidad incidental) y/o indirecto (ej. competencia por explotación) debido a las interacciones con las pesquerías, es importante tener información y conocer las preferencias alimentarias y de hábitat de estos predadores marinos (Reeves et al. 2003).

A pesar de la necesidad de este tipo de información para el éxito de programas de gestión y conservación, los cetáceos no han sido intensamente estudiados en esta región remota del mundo. Como resultado, es insuficiente la información ecológica básica en relación a las preferencias alimentarias y de hábitat de los cetáceos en el Atlántico Sudoccidental. Sumado a esto, resulta difícil la recopilación de datos ecológicos de los cetáceos menores de Tierra del Fuego, especialmente para aquellas especies de hábitos oceánicos, debido a las condiciones meteorológicas extremas y la extensa costa -con muy limitado acceso- que caracterizan a la región. 
De las 23 especies de cetáceos menores citadas para Tierra del Fuego, ocho especies, seis de la familia Delphinidae y dos de la familia Phocoenidae, son consideradas las más importantes y representativas de los distintos ecosistemas marinos de la región: Cephalorhynchus commersonii, Grampus griseus, Lagenorhynchus australis, Lagenorhynchus cruciger, Lissodelphis peronii, Pseudorca crassidens, Phocoena dioptrica y Phocoena spinipinnis (Anexo I). Diversas muestras óseas de estas especies fueron objeto de comparación en términos isotópicos, con el fin de responder a los objetivos planteados.

Dado que cada especie juega un importante rol en la estructura y dinámica de los ecosistemas, estas especies de cetáceos menores pueden tener efectos importantes en las redes tróficas de los ecosistemas donde viven. Por lo tanto, el manejo de estos ambientes requiere una mejor comprensión sobre el rol ecológico de estos predadores.

\subsection{OBJetivos E HiPótesis}

El presente estudio pretende evaluar las principales fuentes alimentarias, áreas de alimentación y relaciones tróficas de algunas especies de cetáceos odontocetos representativas del extremo sur de Sudamérica. El fin último de esta investigación es generar información ecológica importante para la comprensión de la estructura y funcionamiento del ecosistema marino de esta región, con importantes implicaciones para su racional manejo.

El cumplimiento del objetivo general propuesto se logrará a través de los siguientes objetivos parciales:

IInvestigar las áreas de alimentación de los cetáceos odontocetos en términos de su firma isotópica.

Determinar el nivel trófico que ocupan estos mamíferos marinos en las tramas tróficas del Atlántico Sudoccidental mediante estudios isotópicos.

Comparar a los cetáceos odontocetos en términos de su firma isotópica y en cuanto a la relación que establezcan con los valores de sus presas.

다 Comparar y revalidar la dieta de las especies objeto de estudio determinadas por contenidos estomacales mediante técnicas isotópicas. 
A modo de análisis preliminar se proponen los siguientes objetivos parciales a ser investigados en profundidad en un futuro:

I- Analizar la variación isotópica intra-específica en Grampus griseus y Cephalorhynchus commersonii en relación a la edad y el sexo de los animales.

It Analizar la posible existencia de tendencias isotópicas temporales en Cephalorhynchus commersonii, Lagenorhynchus australis y Phocoena dioptrica.

Basados en el conocimiento previo de cada especie, la hipótesis de trabajo planteada en esta Tesis es la siguiente:

Existe una clara diferenciación trófica entre las especies de cetáceos a estudiar en virtud de que ellas poseen distintas áreas de alimentación y ocupan distintos niveles tróficos en los ecosistemas del Atlántico Sudoccidental.

De acuerdo a nuestra hipótesis planteada podrían presentarse diversas alternativas:

Las especies de cetáceos presentan diferencias isotópicas significativas, debido a que ocupan distintos niveles tróficos y se alimentan en diferentes áreas de alimentación.

Las especies de cetáceos que se alimentan cerca de la costa y/o en latitudes bajas se encuentran enriquecidas en los valores de $\delta^{13} \mathrm{C}$ y $\delta^{15} \mathrm{~N}$, mientras que las especies asociadas a áreas oceánicas y/o a latitudes altas se encuentran empobrecidas en los valores de $\delta^{13} \mathrm{C}$ y $\delta^{15} \mathrm{~N}$, reflejando los gradientes espaciales en los valores de los isótopos estables de los productores primarios del Atlántico Sudoccidental y el Océano Austral.

Las especies de cetáceos generalistas, que consumen un amplio rango de tipos de presas y/o se alimentan en diferentes tipos de hábitat (ej. costero, plataforma, talud continental), exhiben una gran variación en los valores isotópicos en comparación con especialistas, que se alimentan de un bajo número de presas y/o en hábitats específicos. 


\subsection{RELEVANCIA DE LA INVESTIGACión}

Los sistemas frontales, entre los que se encuentran las aguas subantárticas adyacentes a la Provincia de Tierra del Fuego, son de especial interés por la magnitud de sus áreas de influencia y la alta producción biológica. Estos sistemas frontales corresponden a la Convergencia Subtropical formada por el encuentro de la Corriente de Brasil y la de Malvinas que ocurre a los $\sim 40^{\circ} \mathrm{S}$ y la Convergencia Antártica formada por el encuentro de las masas de aguas Subantárticas y Antárticas entre los $50^{\circ}$ y $60^{\circ} \mathrm{S}$. La región oceánica al sur de la Convergencia Subtropical hasta el Continente Antártico ha sido considerada en al año 2000 por la Organización Hidrográfica Internacional como el Océano Austral y definida como una conglomeración de grandes partes de los océanos Pacífico, Atlántico e Índico. La Comisión para la Conservación de los Recursos Marinos Antárticos Vivos (CCAMLR) considera que este océano cae al sur de la Convergencia Antártica.

La distribución y evolución de muchas especies de mamíferos y aves marinas están relacionadas con varias zonas oceánicas, tanto al norte como al sur de estas convergencias, sin embargo la mayor diversidad animal ocurre en zonas Subantárticas (Campagna et al. 2006, Bastida et al. 2007).

Las actividades pesqueras desarrolladas en este sector conllevan consecuencias inevitables para el ecosistema, como el incremento en la inestabilidad de las redes tróficas y la incapacidad de mantener una abundante población de organismos de altos niveles tróficos (Trites et al. 2006). Por lo tanto resulta importante la regulación y el control de estas actividades ya que esta región sostiene una gran diversidad faunística, entre la que se hallan las especies de cetáceos aquí estudiadas. Sin embargo, el manejo adecuado de estos ambientes requiere una mejor comprensión de su estructura y dinámica, incluyendo el estudio de la presencia y función trófica que la comunidad de cetáceos mantiene sobre el ecosistema de la región.

Los datos isotópicos presentados en este trabajo representan una importante contribución a la compleja ecología de las especies de cetáceos del extremo sur del Atlántico Sudoccidental. Los resultados aquí presentados rectifican y/o ratifican la dieta de estos cetáceos, definiendo en forma general las áreas de alimentación y los niveles tróficos en los que se ubican, así como el grado de solapamiento/segregación de sus hábitos tróficos. Estos datos son fundamentales para el racional manejo de las pesquerías y elaborar normas para la protección de estos mamíferos marinos del Mar Argentino. 
El presente trabajo constituye el primer proyecto de investigación en Sudamérica sobre diferentes aspectos de la alimentación de cetáceos menores subantárticos mediante estudios isotópicos. 


\section{ANEXO I}

\section{DesCRIPCIÓn De las EsPeCies de CETÁCEOS}

A continuación se destacan los aspectos más importantes de las especies de cetáceos odontocetos estudiados en la presente Tesis y en vinculación con su distribución geográfica y sus hábitos tróficos. La mayoría de la información sobre sus hábitos tróficos proviene de investigaciones recientes realizadas principalmente en Perú, Chile y Argentina sobre especímenes capturados intencionalmente (Reyes \& Van Waerebeek 1995), capturados incidentalmente en redes de pesca o bien de ejemplares varados (Goodall \& Galeazzi 1985, Bastida et al. 1988, Goodall 1994, Goodall \& Schiavini 1995, Goodall et al. 1995a, Goodall et al. 1997a, Koen Alonso et al. 1999, Fernández et al. 2003, Goodall et al. 2008).

Phocoena spinipinnis Burmeister, 1865

\section{Marsopa espinosa o marsopa de Burmeister (Burmeister's porpoise)}

La marsopa espinosa, Phocoena spinipinnis es una especie endémica de las aguas costeras de Sudamérica. Se distribuye a lo largo de la costa Atlántica desde Santa Catarina, sur de Brasil (28 $\left.48^{\circ} \mathrm{S}\right)$ hasta cerca del Cabo de Hornos $\left(56^{\circ} \mathrm{S}\right)$ y asciende por el Pacífico hacia Bahía de Paita, norte de Perú (05º1’S) ((Reyes \& Van Waerebeek 1995, Goodall et al. 1995b). A pesar que se la ha descrito como una especie eminentemente costera (Brownell \& Praderi 1982), fue registrada a $40 \mathrm{~km}$ de la costa en Uruguay, 50km en Argentina y 55km en Perú y Chile (Goodall et al. 1995b), en general en aguas de 30-60m de profundidad para la Provincia de Buenos Aires (Argentina) en el área de Necochea (Corcuera 1991) y aguas con valores máximos de 1.000m de profundidad (Culik 2004).

No existen estimaciones de abundancia de esta especie en todo su rango de distribución y, a pesar del gran número de ejemplares capturados en Perú y Chile, los avistajes son extremadamente raros y en general de pocos individuos (1-4) (Van Waerebeek et al. 2002). Ello puede deberse -en parte- a las dificultades en el registro de estos animales debido a su pequeño tamaño, prolongadas inmersiones y a su tranquilo comportamiento sin manifestaciones aéreas (Würsig et al. 1977). 
Vinculada a masas de agua templado-frías que no superan los $10-15^{\circ} \mathrm{C}$ (Bastida \& Rodríguez 2006), la marsopa espinosa es observada casi exclusivamente en primaveraverano en aguas del norte de Patagonia (Würsig et al. 1977). Esto sugiere movimientos estacionales que pueden ser norte-sur o inshore-offshore, desconociéndose si están relacionados con la temperatura del agua o la disponibilidad de presas. Los avistajes de esta especie realizados en el Canal Beagle la registran todo el año, excepto en los meses de agosto y septiembre, pudiendo corresponder a grupos residentes que permanecen en la zona (Goodall et al. 1995b, Tezanos Pinto et al. 2000). En Perú y Chile no existe evidencia de movimientos estacionales (Van Waerebeek et al. 2002).

Se ha sugerido que las poblaciones del Atlántico y el Pacífico comprenden dos stocks diferentes (Brownell \& Praderi 1982). Dicha hipótesis es consistente con diferencias encontradas en el tamaño entre individuos de ambos sectores (Corcuera et al. 1995), sin embargo los análisis moleculares diferencian un stock poblacional en las costas de Perú y otro distribuido en Chile-Argentina, situación que se repite en otros cetáceos costeros como el delfín oscuro (Lagenorhynchus obscurus) (Rosa et al. 2005).

Existen muy pocos estudios sobre la dieta de esta especie a lo largo de toda su distribución geográfica. Se estudiaron contenidos estomacales de ejemplares en Uruguay (Brownell \& Praderi 1982, 1984), Perú (Reyes \& Van Waerebeek 1995), Chile (Escare \& Oporto 1992), y en Argentina en Necochea, Claromecó y Mar Chiquita (Provincia de Buenos Aires) (Corcuera 1991, Corcuera et al. 1995, Lorenzani \& Junin 1996), y sólo sobre 4 especímenes de Tierra del Fuego que mostraron restos de peces, camarones mísidos y eufásidos (Goodall et al. 1995a). Dichos estudios demuestran que esta especie se alimenta a cierta distancia de la costa, principalmente de peces demersales y pelágicos y también de calamares.

\section{Phocoena dioptrica Lahille, 1912}

\section{Marsopa de anteojos o marsopa de Lahille (Spectacled porpoise)}

La marsopa de anteojos, Phocoena dioptrica fue considerada una de las especies más raras del mundo antes del estudio de ejemplares varados en Tierra del Fuego (Goodall 1978, 1989, Goodall \& Schiavini 1995). Es exclusiva del hemisferio sur, la mayoría de los especímenes conocidos en la actualidad son de Tierra del Fuego, con varamientos y avistajes aislados en Provincia de Buenos Aires (Bastida y Rodríguez 2009), y en el sur de Brasil $\left(32^{\circ} \mathrm{S}\right)$ e islas oceánicas australes: Islas Malvinas, Georgias del Sur, Auckland, Macquarie, Heard, Kergüelen, Tasmania, sur de Australia y Nueva Zelanda (Kemper \& Hill 2001, Goodall 2002a). Según Goodall (2002a) su distribución 
es circumpolar en aguas subantárticas y antárticas, siendo desconocido el grado de contacto entre estas poblaciones. A diferencia del resto de los focénidos, pero similar a la marsopa de Dall (Phocoenoides dalli), parece habitar tanto aguas costeras como oceánicas (Fajardo-Mellor et al. 2006).

Poco es lo que se conoce sobre la biología, distribución, abundancia, comportamiento social y hábitos tróficos de esta especie. Los registros más frecuentes tienen lugar en aguas con temperatura superficial entre $5-10^{\circ} \mathrm{C}$ (Bastida \& Rodríguez 2006), y se las ha visto en grupos muy pequeños de 2-3 individuos (Bastida et al. 2007). A pesar del gran número de especímenes recolectados hasta la fecha en las costas de Tierra del Fuego, sus hábitos tróficos son casi desconocidos, si bien hay sólo dos registros de contenidos estomacales, uno proveniente de un ejemplar macho de 6 años de edad varado en Puerto Madryn, Chubut (Argentina); el mismo estaba constituido por restos de anchoitas (Engraulis sp.) y pequeños crustáceos (Goodall \& Schiavini 1995). El otro registro provine de un espécimen hembra encontrada al sur de Tasmania y que contenía leche en su sistema digestivo (lo cual indicaba que aún estaba en período de lactancia), picos de cefalópodos identificados como Sepia sp. y un pez, Aracana ornata, parcialmente digerido (Kemper \& Hill 2001).

\section{Cephalorhynchus commersonii (Lacépède, 1804)}

\section{Tonina overa o delfín de Commerson (Commerson's dolphin)}

El género Cephalorhynchus, comprende cuatro especies distribuidas exclusivamente en aguas templado-frías del hemisferio sur (C. commersonii, C. eutropia, C. heavisidii y C. hectori). Estas cuatro especies de pequeño tamaño parecen restringirse a ambientes neríticos similares (Pichler et al. 2001) y de las cuales la tonina overa, Cephalorhynchus commersonii, es la de más amplia distribución.

La tonina overa, es uno de los delfines más comunes del litoral Argentino. Presenta una distribución geográfica discontinua en el hemisferio sur. Actualmente por datos morfológicos, de pigmentación y de ADN mitocondrial, estas poblaciones son consideradas subespecies, una de ellas endémica de las costas de Patagonia, $C$. $c$. commersonii, y la otra endémica de las islas Kergüelen en el Océano Índico, $C$. $c$. kerguelenensis (Robineau et al. 2007). La tonina overa es considerada una especie costera que en el Atlántico Sudoccidental se distribuye desde Río Negro, Argentina (40 30’S) hasta cerca del Cabo de Hornos, el Estrecho de Magallanes, Islas Malvinas, Islas de los Estados, Pasaje de Drake e islas Shetland del Sur (61 $\left.{ }^{\circ} 59^{\prime} \mathrm{S}\right)$ (Goodall 1994, Goodall et al. 2008). Cabe mencionar que han ocurrido ciertos registros fuera de estos 
límites de su distribución en las costas de Chile, el sur de Brasil y el sur de Sudáfrica (Best 2007). En la región patagónica es frecuente en zonas estuariales y desembocaduras de rías (Iñíguez \& Tossenberger 2007). En la zona de Tierra del Fuego habita en áreas costeras reparadas, estrechos y zonas con fuertes corrientes marinas (Bastida \& Rodríguez 2006). Aunque raramente se la observa lejos de la costa, existen avistajes en el sector intermedio de la Plataforma Continental Argentina y hasta más allá del talud, en aguas de más de 200m de profundidad (Goodall et al. 1988, Goodall 1994, Pedraza 2007). En las islas Kergüelen, se registra en aguas de menos de 100m de profundidad, con algunos avistajes en el borde de la plataforma ( 200m de profundidad) (Goodall 1994, Robineau et al. 2007).

Generalmente se la observa en pequeños grupos de 2 a 10 individuos, sólo en ciertas ocasiones se han visto grupos numerosos de 100 o más individuos, posiblemente debido a agrupamientos estacionales de alimentación o reproducción (Goodall 1994). Poco se conoce sobre los movimientos estacionales de la tonina overa, aunque durante los meses de invierno parecen dispersarse hacia aguas offshore siguiendo los movimientos de sus presas como el róbalo (Eleginops maclovinus) y la merluza (Merluccius hubbsi) (Goodall 1994), de forma similar al delfín de Héctor (Cephalorhynchus hectori) que exhibe movimientos estacionales en sentido inshoreoffshore y patrones de movimientos diurnos (Slooten et al. 2006, Rayment et al. 2009, 2010).

Varios estudios realizados sobre sus hábitos tróficos en todo el rango de su distribución patagónica (Bastida et al. 1988, Clarke \& Goodall 1994, Berón Vera et al. 2001, Rosero Caicedo 2005) muestran que se trata de una especie oportunista que se alimenta principalmente en aguas costeras de la plataforma, de hábitos más pelágicos al norte de su distribución y con incorporación de componentes bentónicos al sur de la misma (Pedraza 2007). En la parte sur, esta especie basa su dieta principalmente en sardinas fueguinas (Sprattus fuegensis), pejerreyes (Odonthestes spp.), merluza de cola (Macruronus magellanicus), calamares (Loligo gahi) y crustáceos (Bastida et al. 1988, Clarke \& Goodall 1994).

Lagenorhynchus australis (Peale, 1848)

\section{Delfín austral (Peale's dolphin)}

El género Lagenorhynchus comprende seis especies cuya sistemática está bajo revisión debido a nuevos resultados encontrados por análisis de citocromo-b que sostienen que conforman un grupo parafilético (LeDuc et al. 1999). De las tres 
especies de Lagenorhynchus que habitan el hemisferio sur (L. australis, L. cruciger y L. obscurus), la primera es la de más fácil observación y, a su vez, es la más restringida en su distribución geográfica (Goodall et al. 1997b, Viddi \& Lescrauwaet 2005).

El delfín austral, Lagenorhynchus australis habita exclusivamente aguas de Argentina y Chile. Se distribuye por el Océano Pacífico desde Valdivia, Chile $\left(38^{\circ} \mathrm{S}\right)$ hacia el sur del Cabo de Hornos $\left(59^{\circ} \mathrm{S}\right)$, y por el Atlántico Sudoccidental hasta el Golfo San Jorge $\left(44^{\circ} \mathrm{S}\right)$, abarcando también las Islas Malvinas (Goodall 2002b). Sin embargo, existen registros fuera de estos límites a los $33^{\circ} \mathrm{S}$ en Chile, a los $41^{\circ}-32^{\circ} \mathrm{S}$ al

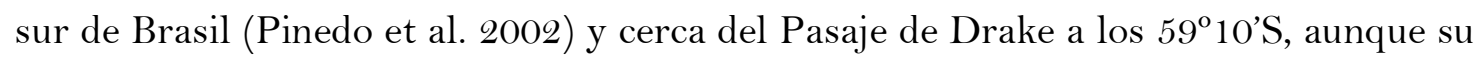
límite offshore sigue siendo desconocido (Goodall et al. 1997b).

Dentro de su rango de distribución en el Atlántico Sudoccidental, el delfín austral habita dos grandes tipos de hábitat: al Sur se lo ha observado frecuentar aguas bien costeras, fiordos y canales protegidos con camas de macroalgas, kelp, de la especie Macrocystis pyrifera (Lescrauwaet 1997, Goodall et al. 1997c, Viddi \& Lescrauwaet 2005), donde parece alimentarse de especies demersales y de fondo (Schiavini et al. 1997). Al Norte adquiere un comportamiento más pelágico y habita costas abiertas frecuentando la plataforma continental (Schiavini et al. 1997). También exiten registros de esta especie en estuarios o desembocaduras de ríos, como en los ríos Santa Cruz y Río Deseado en Argentina y en el Río Douglas en Chile y aún adentrándose en ellos. Se lo ha observado también sobre la Plataforma Continental Argentina, en aguas con influencia de la Corriente de Malvinas y sobre el Banco Burdwood (Goodall et al. 1997b).

El delfín austral parece vivir en simpatría con el delfín oscuro (Lagenorynchus obscurus) -aunque se cree que usan diferentes hábitats- (Crespo et al. 1997b), también con la tonina overa se los ha visto asociarse frecuentemente (de Haro \& Iñíguez 1997, Goodall 2002b), y con la marsopa espinosa (Brownell \& Praderi 1982).

Así como otras especies, nada se conoce sobre sus posibles movimientos estacionales. En el Estrecho de Magallanes y en la Isla de Chiloé se han registrado grupos todo el año (Lescrauwaet 1997). Mientras que en la parte sur de Tierra del Fuego, los animales parecen acercarse más hacia la costa en verano, posiblemente siguiendo a sus presas (Goodall 2002b), como se ha sugerido con la tonina overa (Goodall 1994), la marsopa espinosa (Würsig et al. 1977) y posiblemente el delfín chileno (Cephalorhynchus eutropia) (Goodall et al. 1988). 
Poco es lo que se ha publicado sobre los hábitos alimentarios del delfín austral. Asociado fuertemente a los bosques de Macrocystis pyrifera donde dispone la mayor parte de su tiempo buscando alimento (Lescrauwaet 1997, Viddi \& Lescrauwaet 2005), principalmente presas de fondo y demersales que toman cerca o dentro de los bosques de algas (Schiavini et al. 1997). Los contenidos estomacales de esta especie han sido estudiados en ejemplares de las Islas Malvinas, Tierra del Fuego y Santa Cruz, pudiéndose identificar peces, cefalópodos, bivalvos, crustáceos y salpas (Goodall \& Galeazzi 1985, Iñíguez \& de Haro 1994, Schiavini et al. 1997). Estos trabajos sugieren que el delfín austral se comporta como un predador generalista costero por lo menos al sur de su distribución geográfica y en primavera-verano; sin embargo, su rango de alimentación podría extenderse sobre la plataforma patagónica y presentar una alimentación más pelágica (Schiavini et al. 1997, Goodall 2002b), como se mencionó anteriormente.

Lagenorhynchus cruciger (Quoy \& Gaimard, 1824)

\section{Delfín cruzado (Hourglass dolphin)}

El delfín cruzado, Lagenorhynchus cruciger, es considerado una especie oceánica que se distribuye de forma circumpolar al norte y al sur de la Convergencia Antártica (Goodall 2002c), siendo el único delfín pequeño que se observa al sur de ésta (Bastida et al. 2007). Se distribuye desde los $41^{\circ} 30^{\prime} \mathrm{S}$ hasta los hielos a los $66^{\circ} \mathrm{S}$ (Goodall 2002c). La mayoría de los avistajes se encuentra entre los $54^{\circ} \mathrm{S}$ y los $62^{\circ} \mathrm{S}$ aunque existen registros a los $33^{\circ} 40^{\prime} \mathrm{S}$ al sudoeste de Valparaíso, Chile y a $36^{\circ} 14$ 'S en el Océano Atlántico Sur, con el registro más austral en el Pacífico Sur a los $67^{\circ} 38^{\prime} \mathrm{S}$ (Goodall 1997).

Es una especie frecuente en aguas turbulentas lejos de la costa, con temperaturas entre $0^{\circ}$ a $12^{\circ} \mathrm{C}$, con registros máximos de individuos en aguas con temperaturas entre $3^{\circ}-5^{\circ} \mathrm{C}$, como las de la Convergencia Antártica (Goodall 1997). La mayoría de los avistajes se registraron en el Pasaje de Drake, una de las aguas más turbulentas del mundo (Goodall 2002c).

A pesar de la gran cantidad de avistajes, pocos animales han sufrido eventos de varamiento o capturas, probablemente debido a su comportamiento oceánico, por lo tanto muy poco es lo que se conoce sobre su biología general (Goodall 1997, Goodall et al. 1997a). No existe información sobre aspectos reproductivos de esta especie, longevidad, comportamiento social, patrones de movimiento, mortalidad y dinámica 
poblacional. Suelen observarse en grupos pequeños, en general menos de 8 a 10 animales, aunque se han registrado grupos de 100 individuos (Goodall 1997).

Por ser ejemplares de aguas australes, su alimentación parece basarse en peces mictófidos, calamares y crustáceos (Goodall et al. 1997a, Goodall 2002c). El análisis de dos ejemplares varados en el norte de Patagonia, muy lejos de su rango de distribución normal, permitió identificar restos de merluza común (Merluccius hubbsi), merluza de cola (Macruronus magellanicus), anchoita (Engraulis anchoita), calamares (Loligo gahi, Illex argentinus, Semirossia tenera), y pulpo (Eledone massyae) (Fernández et al. 2003).

Lissodelphis peronii (Lacépède, 1804)

\section{Delfín liso austral (Southern right whale dolphin)}

El género Lissodelphis (Gloger, 1841), cuya historia taxonómica ha sido muy discutida, comprende dos especies: el delfín liso austral (Lissodelphis peronii) y el delfín liso del norte (L. borealis) (Jefferson et al. 1994). La forma del cuerpo del género Lissodelphis es única entre los delfínidos, pues sus cuerpos delgados se caracterizan por la ausencia de aleta dorsal (Newcomer et al. 1996).

Lissodelphis peronii se distribuye de forma circumpolar en las regiones subantárticas, entre $\operatorname{los} 35^{\circ} \mathrm{S}$ y $\operatorname{los} 65^{\circ} \mathrm{S}$, extendiéndose al norte y al sur de la Convergencia Subtropical y Antártica (Jefferson et al. 1994, Newcomer et al. 1996). Es una especie pelágica y netamente oceánica, de aguas frías a templadas entre $1-20^{\circ} \mathrm{C}$ (Jefferson et al. 1994). Sin embargo, puede encontrarse cerca de la costa, en aguas profundas o en zonas de la plataforma altamente productivas (Van Waerebeek et al. 1991, Newcomer et al. 1996). Su rango de distribución se extiende al Norte siguiendo las corrientes frías subantárticas, como la de Humboldt en las costas occidentales de Sudamérica y la de Benguela en África (Newcomer et al. 1996). En la costa este de Sudamérica, esta especie parece ser común en aguas de la Corriente de Malvinas, entre Patagonia y las islas (Culik 2004).

No existen estimaciones de abundancia, aunque se sabe que es una especie gregaria y que forma grupos que pueden superar los 1.000 individuos. Se desconoce sobre sus movimientos migratorios. Existen poblaciones residentes en áreas productivas de Namibia y en las costas chilenas entre los $25^{\circ}$ a $40^{\circ} \mathrm{S}$. Parte de esta última población presenta movimientos migratorios en dirección norte en invierno y primavera cuando las aguas frías de upwelling y el componente costero de la Corriente de Humboldt son fuertes (Van Waerebeek et al. 1991). A pesar de que los varamientos 
de esta especie son pocos comunes (Baker 1981), han ocurrido eventos de este tipo en las costas de Sudamérica, en Argentina (Goodall 1978) y Chile (Van Waerebeek et al. 1991).

Se conocen contenidos estomacales provenientes de ejemplares de Nueva Zelanda, centro de Chile y de las islas Shetland del Sur (Torres \& Aguayo 1979, Baker 1981, Van Waerebeek \& Oporto 1990, Lipsky 2002). El estudio de estos contenidos reportó una amplia variedad de peces y calamares. En Tierra del Fuego, a pesar de haberse estudiado un alto número de individuos ( 50$)$ (Goodall \& Galeazzi 1985), su dieta sigue siendo desconocida.

\section{Grampus griseus (Cuvier, 1812)}

\section{Delfín gris o delfín de Risso (Risso's dolphin)}

El delfín gris, Grampus griseus, es una especie cosmopolita que habita principalmente en los océanos templados y tropicales de todo el mundo (Baird 2002a). Es de hábitos oceánicos, asociado a aguas del talud continental y de la plataforma exterior, especialmente en relación con aguas profundas entre 400 a $1.000 m$ (Baumgartner 1997, Olavarría et al. 2001, Cañadas et al. 2002, Davis et al. 2002). Estas zonas generalmente coinciden con aguas de upwelling y corrientes altamente productivas que ofrecen una gran disponibilidad de presas, generando una abundancia y distribución irregular de sus poblaciones alrededor del mundo (Kruse et al. 1999).

En la parte occidental del Océano Atlántico se distribuye desde Newfoundland $\left(50^{\circ} \mathrm{N}\right)$ hasta el Cabo de Hornos $\left(53^{\circ} \mathrm{S}\right)$ (Leatherwood et al. 1980). En Sudamérica se ha registrado a G. griseus en el Atlántico desde el noreste de Brasil, hasta Tierra del Fuego y por el Pacífico en todos los países (Bastida et al. 2007), incluidas las Islas Galápagos (Smith \& Whitehead 1999). A pesar que se considera poco frecuente el varamiento masivo en esta especie (Baird 2009), en Tierra del Fuego (Argentina) se han registraron 12 eventos de varamientos masivos y 13 simples (Goodall \& Schiavini 1992).

En la mayor parte de su rango de distribución geográfica, el delfín gris parece estar presente todo el año, aunque se han sugerido movimientos en sentido inshoreoffshore en algunas áreas, especialmente cuando la oferta de alimentos es importante (Best 2007). Su presencia en zonas costeras se ha documentado en ciertas épocas del año en el oeste del Atlántico Norte, Inglaterra, sudeste de Sudáfrica, Chile (Olavarría et al. 1999), y en Argentina en aguas del norte de Patagonia (Reyes 2006). 
Grandes concentraciones de individuos puede ocurrir en respuesta a la gran disponibilidad de presas, pero los registros de avistajes indican que comúnmente vive en grupos de 10-30 animales (Baird 2002a), los cuales parecen estar compuestos por individuos del mismo sexo y edad (Baird 2009).

Es una especie principalmente teutófaga, aunque puede complementar su dieta con peces bentopelágicos de la plataforma continental y zonas del talud (Best 2009). En el hemisferio sur, Baker (1974) y Ross (1984) reportaron calamares y peces en los contenidos estomacales de ejemplares de Nueva Zelanda. Sekiguchi et al. (1992) analizaron la dieta de 11 individuos varados en Sudáfrica, encontrando diferentes especies de calamares y peces tanto costeros como oceánicos. De 13 estómagos examinados en Tierra del Fuego, sólo 4 tuvieron contenidos con otolitos y picos de calamares (Goodall, datos no publicados). En el hemisferio norte existen registros de contenidos estomacales de especímenes de España y California, con presencia de restos de diversas especies de cefalópodos (Culik 2004). En base a estudios estomacales, (Cockroft et al. 1993), establecieron que existen diferencias en las preferencias alimentarias entre machos y hembras y hasta entre diferentes clases de edad, sugiriendo una repartición de los recursos entre los subgrupos en los que vive comúnmente el delfín gris.

\section{Pseudorca crassidens (Owen, 1846)}

\section{Falsa orca (False killer whale)}

La falsa orca, Pseudorca crassidens, es una especie cosmopolita comúnmente distribuida en aguas tropicales y templadas (Stacey et al. 1994). Existen numerosos registros de avistajes de esta especie en aguas templado-frías, pero para las aguas subantárticas no había un registro hasta que se produjo un varamiento masivo en el Estrecho de Magallanes en 1989 (Koen Alonso et al. 1999). Este cetáceo habita aguas oceánicas, profundas, aunque en ocasiones también se acerca a la costa.

A pesar de ser una especie gregaria, moviéndose en grupos de 10 a 200 individuos (Culik 2004), se los ha observado también individualmente (Flores et al. 2003). Presenta lazos sociales muy fuertes entre sus individuos, lo que se refleja en sus varamientos masivos. Algunos de ellos han sido con un alto número de ejemplares, como el ocurrido en Mar del Plata en 1946, donde se registraron $\sim 800$ animales (Bastida et al. 2007), y también el ocurrido 1989 en el Estrecho de Magallanes donde vararon 181 individuos. No se conoce bien sobre sus movimientos estacionales, pero para el Pacífico Norte se ha sugerido que, tanto esta especie como Grampus griseus y 
Globicephala melas, migran al sur hacia aguas más cálidas en invierno y al norte hacia aguas más frías en verano (Baird 2002b).

La dieta de esta especie parece ser diversa, tanto en término de especies como en el tamaño de sus presas (Baird 2002b). Se han estudiado contenidos estomacales de especímenes de Brasil, del sur de África, y del varamiento en el Estrecho de Magallanes de 1989 (Ross 1984, Pinedo \& Rosas 1989, Sekiguchi et al. 1992, Koen Alonso et al. 1999). Este último estudio permitió concluir que la falsa orca en el Atlántico Sudoccidental es una especie oportunista, alimentándose principalmente de especies pelágicas, siendo peces y cefalópodos las presas más importantes (Koen Alonso et al. 1999). A pesar de que la falsa orca se alimenta principalmente de peces y cefalópodos, se la ha visto atacar pequeños cetáceos, crías de ballenas jorobadas (Megaptera novaeangliae) y cachalotes (Physeter macrocephalus) (Baird 2002b). 


\section{ANEXO II}

\section{Principios DEL ANÁlisis DE Isótopos EsTABLES}

$\mathrm{El}$ análisis de isótopos estables (AIE) es una técnica cuyo uso se ha incrementado notablemente durante los últimos años en distintos campos de la biología. Los estudios pioneros de DeNiro \& Epstein (1978, 1981) demostraron que las composiciones isotópicas de los tejidos de los organismos reflejan las fuentes nutricionales de los animales. A partir de entonces se ha tratado de definir y caracterizar de una forma más precisa esa relación (Hedges et al. 2005). Las diferencias encontradas en la composición isotópica entre la dieta y los tejidos de los organismos están dadas, en última instancia, por las energías de disociación de las moléculas que dependen de la masa relativa de los elementos que las están formando (Schoeller 1999, Fry 2006, Dawson \& Siegwolf 2007).

Los isótopos (iso: igual, topos: lugar) son diferentes estructuras atómicas de un mismo elemento que se diferencian por su masa, determinada por el número de neutrones y protones en su núcleo (Chang 1992). En términos generales el número de protones define al elemento, el número de neutrones define al isótopo (Fry 2006). A diferencia de los isótopos inestables o radioactivos (como por ejemplo el ${ }^{14} \mathrm{C}$ ) $\operatorname{los}$ isótopos estables (por ejemplo ${ }^{12} \mathrm{C}$ y ${ }^{13} \mathrm{C}$ para el carbono y el ${ }^{15} \mathrm{~N}$ y ${ }^{14} \mathrm{~N}$ para el nitrógeno) de un elemento son aquellos donde el número de partículas subatómicas no se modifica a través del tiempo. El término isótopo pesado y liviano se refiere a la masa de los isótopos de un mismo elemento, como ${ }^{13} \mathrm{C}$ y ${ }^{12} \mathrm{C}$ para el carbono y ${ }^{15} \mathrm{~N} \mathrm{y}$ ${ }^{14} \mathrm{~N}$ para el nitrógeno, respectivamente (Chang 1992, Sulzman 2007). Los isótopos estables más utilizados en estudios ecológicos corresponden al H, C, N, O y S, dada por su gran abundancia en la corteza terrestre y porque toman parte en numerosos procesos naturales. En la Tabla 1 se resume información de estos isótopos estables. 
Tabla 1. Isótopos estables más utilizados en estudios ecológicos

\begin{tabular}{|c|c|c|c|c|c|}
\hline Elemento & $\begin{array}{l}\text { Isótopo } \\
\text { estable }\end{array}$ & $\begin{array}{l}\text { Abundancia } \\
(\%)\end{array}$ & $\begin{array}{l}\text { Proporción } \\
\text { medida }\end{array}$ & Estándar internacional & Aplicaciones \\
\hline Hidrógeno & $\begin{array}{c}{ }^{1} \mathrm{H} \\
{ }^{2} \mathrm{H}(\mathrm{D})\end{array}$ & $\begin{array}{c}99,985 \\
0,015\end{array}$ & $2 \mathrm{H} / 1 \mathrm{H}(\mathrm{D} / \mathrm{H})$ & $\begin{array}{l}\text { Vienna - Standard Mean } \\
\text { Ocean Water (VSMOW) }\end{array}$ & $\begin{array}{l}\text { Migracion, uso del hábitat, dieta, } \\
\text { niveles tróficos }\end{array}$ \\
\hline Carbono & ${ }^{12} \mathrm{C}$ & $\begin{array}{c}98,892 \\
1,108\end{array}$ & $13 \mathrm{C} / 12 \mathrm{C}$ & $\begin{array}{l}\text { Vienna - Pee Dee } \\
\text { Belemnite (VPDB) }\end{array}$ & Dieta, uso del hábitat, migación \\
\hline Nitrógeno & $\begin{array}{l}{ }^{14} \mathrm{~N} \\
{ }^{15} \mathrm{~N}\end{array}$ & $\begin{array}{c}99,635 \\
0,365\end{array}$ & $15 \mathrm{~N} / 14 \mathrm{~N}$ & $\begin{array}{l}\text { Nitrógeno atmosférico } \\
\text { (N2 atm) }\end{array}$ & $\begin{array}{l}\text { Niveles tróficos, dieta, uso del } \\
\text { hábitat, migración, reproducción }\end{array}$ \\
\hline Oxígeno & $\begin{array}{l}{ }^{16} \mathrm{O} \\
{ }^{17} \mathrm{O} \\
{ }^{18} \mathrm{O}\end{array}$ & $\begin{array}{c}99,759 \\
0,037 \\
0,204\end{array}$ & $18 \mathrm{O} / 16 \mathrm{O}$ & $\begin{array}{l}\text { Vienna - Standard Mean } \\
\text { Ocean Water (VSMOW) }\end{array}$ & $\begin{array}{l}\text { Uso del hábitat, migración dieta, } \\
\text { termorregulación, osmoregulación }\end{array}$ \\
\hline Azufre & $\begin{array}{l}{ }^{32} \mathrm{~S} \\
{ }^{33} \mathrm{~S} \\
{ }^{34} \mathrm{~S} \\
{ }^{36} \mathrm{~S}\end{array}$ & $\begin{array}{c}95,000 \\
0,750 \\
4,210 \\
0,014\end{array}$ & $34 \mathrm{~S} / 32 \mathrm{~S}$ & $\begin{array}{l}\text { Vienna Metorito Cañón } \\
\text { Diablo Troilite (VCDT) }\end{array}$ & Uso del hábitat, migración dieta \\
\hline
\end{tabular}

\section{Fraccionamiento isotópico}

A pesar de que los isótopos tienen las mismas propiedades químicas, determinadas por la configuración de la nube de electrones, la leve diferencia en el peso atómico puede causar diferencias químicas y físicas muy sutiles entre los compuestos que contienen elementos que varían en el número de neutrones en el núcleo (Schoeller 1999, Sharp 2007). Las diferencias en las masas de los isótopos generan diferencias en la frecuencia de vibración del núcleo de los átomos, siendo menor en los isótopos pesados respecto a los livianos. Esto lleva a que 1) los isótopos livianos o las moléculas formadas por éstos reaccionen más rápido y requieran menos energía de activación, 2) la fuerza de enlace en las sustancias que contienen isótopos pesados es mayor y por lo tanto se necesita más energía para romperlos (Fry 2006, Dawson \& Siegwolf 2007). En los procesos bioquímicos y físico-químicos esto provoca una separación masa-dependiente de los isótopos, conocido como fraccionamiento isotópico, y es lo que genera las diferencias observadas en las abundancias de los isótopos estables entre los sustratos, haciendo referencia al punto de partida de una reacción química $\mathrm{y}$, en nuestro caso, a la dieta del consumidor y los productos refiriendo al resultado de dicha reacción, en nuestro caso el tejido del consumidor (Schoeller 1999, Dawson et al. 2002).

En general cuando se trabaja a escalas de abundancias isotópicas naturales, las composiciones de los isótopos estables de un elemento se describen mediante una 
unidad específica desarrollada para tal fin denominada con la letra minúscula delta $(\boldsymbol{\delta})$. Básicamente $\delta$ es la proporción de la forma más pesada (y rara) a la forma más ligera (y más abundante) de un isótopo. Debido a que las abundancias absolutas de las proporciones son muy pequeñas, los valores isotópicos están referidos a un valor estándar y multiplicado por mil (\%). El estándar de referencia es un gas de idéntica naturaleza que el gas proveniente de las muestras (ej. $\mathrm{CO}_{2}, \mathrm{~N}_{2}, \mathrm{H}_{2}, \mathrm{SO}_{2}$ ) con composiciones químicas e isotópicas parecidas. El estándar para los isótopos estables de carbono es un pequeño fósil de belemnite de la formación Pee Dee (PDB) situada en Carolina del Sur, E.E.U.U., mientras que para los isótopos estables de nitrógeno el patrón internacional es el $\mathrm{N}_{2}$ atmosférico. La mayoría de los laboratorios trabajan con estándares internos de composición conocida dada la escasez de algunos patrones internacionales, como el PDB que en la actualidad se ha sustituido por el V-PDB.

Por definición, los materiales de referencia tienen un valor de $\delta$ de $0 \%$. Así, un valor de $\delta$ positivo indica que la muestra contiene más isótopo pesado respecto al estándar de referencia, y se dice que la muestra está enriquecida en el isótopo pesado. Mientras que valores negativos de $\delta$ indican que la muestra contiene menor cantidad de isótopo pesado que el estándar, y por lo tanto se dice que está empobrecida en el isótopo pesado (Sharp 2007, Sulzman 2007).

La discriminación de un isótopo X será =

$$
\delta^{h} \mathrm{X}=\left[\left(\mathrm{R}_{\text {muestra }} / \mathrm{R}_{\text {estándar }}\right)-1\right]^{*} 1000
$$

donde $\delta^{\mathrm{h}} \mathrm{X}=\delta^{13} \mathrm{C}$ o $\delta^{15} \mathrm{~N}$ u otra especie isotópica, $\mathrm{R}_{\text {muestra }} \mathrm{y} \mathrm{R}_{\text {estándar }}=$ proporción de la forma isotópica más pesada a la forma más ligera del isótopo $\left({ }^{\mathrm{h}} \mathrm{X} /{ }^{\mathrm{z}} \mathrm{X}\right)$ de la muestra y del estándar de referencia respectivamente, siendo ${ }^{\mathrm{h}} \mathrm{X}$ y ${ }^{\mathrm{z}} \mathrm{X}$ las formas isotópicas pesada y liviana del elemento $\mathrm{X}$, respectivamente $\left(\mathrm{ej} .{ }^{13} \mathrm{C}\right.$ y ${ }^{12} \mathrm{C}$ para el carbono y ${ }^{15} \mathrm{~N}$ y ${ }^{14} \mathrm{~N}$ para el nitrógeno). El principio para medir estas proporciones es el fraccionamiento de masas, fenómeno por el cual los distintos isótopos estables de un elemento se separan unos de otros por una serie de procesos físico-químicos, térmicos o biogeoquímicos. La medición de la cantidad de éstos se lleva a cabo a través de un espectrómetro de masas de relaciones isotópicas, conocido por sus siglas en inglés (IRMS) (Sharp 2007, Sulzman 2007, Mucchio \& Jackson 2009). 


\section{Factor de discriminación trófica}

En los estudios tróficos el fraccionamiento se denomina factor de discriminación trófica $(\Delta)$ conocido también como enriquecimiento trófico y generalmente se describe como la diferencia en los valores isotópicos entre los tejidos del consumidor y su dieta (Vanderklift \& Ponsard 2003, Martinez del Río et al. 2009), mediante la siguiente ecuación:

$$
\Delta^{\mathrm{h}} \mathrm{X}_{\mathrm{A}-\mathrm{B}}=\Delta^{\mathrm{h}} \mathrm{X}_{\mathrm{A}}-\Delta^{\mathrm{h}} \mathrm{X}_{\mathrm{B}}
$$

que denota la diferencia entre la composición isotópica del tejido de un consumidor (A) y su dieta (B), siendo $\Delta^{\mathrm{h}} \mathrm{X}$ la forma isotópica bajo estudio (ej. $\Delta^{13} \mathrm{C}$ o $\Delta^{15} \mathrm{~N}$ ). Debido a que los tejidos del consumidor están enriquecidos en el isótopo pesado $\left({ }^{15} \mathrm{~N}\right.$ o $\left.{ }^{19} \mathrm{C}\right)$ respecto a la dieta, los valores $\Delta^{\mathrm{h}} \mathrm{X}_{\mathrm{A}-\mathrm{B}}$ son positivos. Es importante entender el fraccionamiento existente entre el tejido bajo estudio y la dieta de un animal a la hora de interpretar la información ecológica que aportan estos valores (Newsome et al. 2010).

En general, los valores de los isótopos estables de nitrógeno $\left(\delta^{15} \mathrm{~N}\right)$ y carbono $\left(\boldsymbol{\delta}^{13} \mathrm{C}\right)$ exhiben un enriquecimiento por nivel trófico de $\sim 3-5 \%$ y $\sim 1-2 \%$, respectivamente (DeNiro \& Epstein 1978, 1981, Minagawa \& Wada 1984, Post 2002, McCutchan et al. 2003). Diversos procesos, que tienen lugar durante la asimilación del alimento y el metabolismo del organismo, contribuyen a este enriquecimiento isotópico (McCutchan et al. 2003, Sponheimer et al. 2003, Fry 2006). Los procesos de transaminación y desaminación, que llevan a la formación y excreción de productos nitrogenados enriquecidos en el isótopo ligero de nitrógeno $\left({ }^{14} \mathrm{~N}\right)$, como amonio, urea y ácido úrico, dejan en el cuerpo un pool remanente de aminoácidos enriquecidos en el isótopo pesado $\left({ }^{15} \mathrm{~N}\right)$, generando así un valor positivo de $\Delta^{15} \mathrm{~N}_{\text {tejido-dieta }}$ (Schoeller 1999, Wolf et al. 2009). En el caso del carbono, la pérdida preferencial de ${ }^{12} \mathrm{CO}_{2}$ en la respiración y la captación selectiva de compuestos ${ }^{13} \mathrm{C}$-durante la digestión- es lo que principalmente contribuye al enriquecimiento de ${ }^{13} \mathrm{C}$ en el cuerpo del organismo respecto a la dieta (McCutchan et al. 2003, Wolf et al. 2009).

A la hora de evaluar la dieta de los organismos se pueden encontrar diferentes respuestas a través del uso de diferentes tejidos y hasta diferentes componentes de un mismo tejido, siendo que éstos difieren en sus valores de $\delta^{15} \mathrm{~N}$ y $\delta^{13} \mathrm{C}$ y por lo tanto en la discriminación isotópica entre el tejido-dieta (Hare et al. 1991, Hobson \& Clark 
1992, Caut et al. 2009, Wolf et al. 2009). La diferencia en los valores de $\boldsymbol{\delta}^{15} \mathrm{~N}$ entre los tejidos está generada por la distinta composición de amino ácidos que difieren en su composición isotópica (Wolf et al. 2009). La diferencia en los valores de $\boldsymbol{\delta}^{13} \mathrm{C}$ entre los tejidos está generada tanto por la diferente composición de amino ácidos como por el contenido lipídico de éstos. (Wolf et al. 2009).

Los lípidos están empobrecidos en ${ }^{13} \mathrm{C}$ respecto a otros compuestos bioquímicos, como carbohidratos y proteína, y por lo tanto muestran valores más negativos en $\delta^{13} \mathrm{C}$ ( 6-8\%o) respecto a ellos (DeNiro \& Epstein 1978, Post et al. 2007). Por lo tanto, muestras con alto contenido lipídico mostrarán bajos valores de $\delta^{13} \mathrm{C}$ respecto a muestras con bajo contenido lipídico (McCutchan et al. 2003, Post et al. 2007). Como el contenido lipídico varía en gran medida entre los tejidos y entre las especies, es importante eliminar la variabilidad que generan en los valores de $\delta^{13} \mathrm{C}$. Para esto, pueden aplicarse correcciones matemática sobre los valores de $\delta^{13} \mathrm{C}$, que se basan en relaciones empíricas entre el contenido lipídico, la proporción $\mathrm{C} / \mathrm{N}$ y las diferencias en los valores de $\delta^{13} \mathrm{C}$ generadas por los lípidos. Siendo que este tipo de correcciones se encuentra aún en debate (Logan et al. 2008, Mintenbeck et al. 2008), los lípidos son generalmente extraídos de forma química de las muestras (Pinnegar \& Polunin 1999, Post et al. 2007, Hoffman \& Sutton 2010). Los métodos químicos más utilizados para remover los lípidos se basan en una mezcla de solventes orgánicos polares, generalmente cloroformo:metanol, siguiendo protocolos modificados de los de Folch et al. (1957) y Blight \& Dyer (1959), que remueven la mayor cantidad de lípidos posibles y generan muestras homogéneas para su análisis.

Dada la diversidad de especies que puede analizarse mediante el AIE en estudios de redes tróficas, es difícil mantener un mismo tipo de tejido para el análisis y por consiguiente no se logra evitar la variabilidad lipídica con la que se enfrenta. Por lo tanto, en los procesamientos de las muestras se hace importante la extracción química de lípidos para incrementar la consistencia en los resultados (Sotiropoulos et al. 2004, Post et al. 2007, Hoffman \& Sutton 2010).

\section{Potenciales substratos para el AIE en mamíferos marinos}

El AIE puede aplicarse sobre distintos tejidos como pelos, uñas, glándulas, músculo, piel, dientes, hueso, entre otros. La información ecológica que integra cada tejido depende de su constitución macromolecular, su modo de crecimiento y su tasa 
de renovación o incorporación isotópica (Wolf et al. 2009, Newsome et al. 2010). En virtud de ello, la información trófica puede ser evaluada a diferentes escalas temporales a través del análisis de diferentes tejidos de un mismo organismo, tanto de animales vivos como muertos y hasta fósiles (Koch 2007). Aquellos tejidos, como el hepático o el plasma sanguíneo que presentan altos grados de incorporación isotópica, su composición isotópica refleja la del alimento ingerido recientemente, mientras que otros, como el colágeno del hueso, con bajo grado de incorporación isotópica, reflejan períodos de tiempo mucho más largos (años). Los tejidos como barbas de ballenas, pelos, uñas, plumas en aves y conchas en invertebrados, que son depositados en intervalos definidos de tiempo, su composición isotópica refleja la información de la dieta incorporada durante el periodo de su formación (Wolf et al. 2009). Por lo tanto, según el objetivo y las posibilidades de cada investigación resultará más apropiado uno u otro tejido.

A continuación se hace referencia las características isotópicas del hueso, siendo que éste constituyó el objeto de estudio isotópico de este trabajo con el fin de caracterizar el comportamiento trófico general de diferentes especies de cetáceos odontocetos del Atlántico sudoccidental.

Características isotópicas del hueso

El tejido óseo, al igual que otros tejidos, incluye una rica gama de isótopos para analizar, en particular, ${ }^{13} \mathrm{C},{ }^{15} \mathrm{~N},{ }^{2} \mathrm{H},{ }^{18} \mathrm{O},{ }^{34} \mathrm{~S}$ y ${ }^{44} \mathrm{Ca}$. La matriz ósea está constituida por una matriz orgánica que representa $\sim 20-30 \%$ de la misma y una matriz inorgánica que comprende el $\sim 80-70 \%$ de su peso seco. Algunos de los isótopos encontrados en el tejido óseo se encuentran en ambas fases (orgánica e inorgánica), permitiendo la medición isotópica en ambos componentes (Hedges et al. 2005).

La fracción inorgánica del hueso está formada por depósitos submicroscópicos de un tipo de fosfato cálcico muy parecido -pero no idéntico- al mineral hidroxiapatita $\left(\mathrm{Ca}_{10}\left[\mathrm{PO}_{4}\right]_{6}\left[\mathrm{OH}_{2}\right]_{2}\right)$ y que generalmente se denomina bioapatita (Fawcett 1995, Hedges et al. 2005, Koch 2007). El 90\% de la porción orgánica del hueso está formada por proteínas de colágeno, y otras proteínas no colágenas en menor proporción (Fawcett 1995). Así el colágeno extraído durante el procesamiento de las muestras y sobre el cual se realiza la mayoría de los análisis isotópicos en muestras recientes (<500 años de antigüedad) de este tejido, es en realidad un mezcla de proteínas que es considerada en su mayor parte como colágeno de hueso (Koch 2007). La posibilidad de 
subdividir y analizar de forma individual cada aminoácido del colágeno aumenta la riqueza en la información isotópica que brinda este tejido (Hare et al. 1991, Fogel \& Turros 2002, Hedges et al. 2005).

Las diferentes fracciones del hueso reflejan diferentes componentes de la dieta (routing isotópico) (Hedges et al. 2005). La fracción orgánica es producida principalmente por la porción proteica de ésta, mientras que la fracción inorgánica es producida por una mezcla de proteínas, carbohidratos y lípidos de la dieta (Tykot 2004, Hedges et al. 2005, Koch 2007). Debido a ello, existen diferencias en la discriminación trófica entre las diferentes fracciones del hueso (colágeno y bioapatita) y la dieta. En particular, el colágeno del hueso está enriquecido en $\sim 5 \%$ y $\sim 3,4 \%$ o respecto al carbono y al nitrógeno total de la dieta respectivamente (Hare et al. 1991, Hedges et al. 2005, Koch 2007).

El hueso es un material vivo y dinámico, que crece de forma compleja y se renueva continuamente, durante la vida del individuo (Fawcett 1995, Koch 2007). Durante esta renovación, se produce un patrón dinámico de reabsorción de hueso viejo y deposición de hueso nuevo, que involucra ambas fracciones del mismo (colágeno y bioapatita), por lo que la composición isotópica de una muestra de hueso reflejará un promedio de la dieta durante los últimos años del individuo ( $\sim 5$ a 10 años), dependiendo de la edad del animal (Tykot 2004, Hedges et al. 2005) así como de influencias metabólicas, nutritivas y endócrinas (Fawcett 1995).

\section{Aplicaciones}

Estimación de los niveles tróficos a través del AIE

Calcular los niveles tróficos es un primer paso necesario para cuantificar y entender las interacciones tróficas entre los cetáceos y otras especies del ecosistema marino. Tradicionalmente los niveles tróficos se estiman a través de información colectada de contenidos estomacales pero, desafortunadamente, la dieta de muchas especies de cetáceos son pobremente conocidas debido a una incompleta colección de muestras a través del tiempo y el espacio.

A través del análisis de isótopos estables de nitrógeno $\left({ }^{15} \mathrm{~N} /{ }^{14} \mathrm{~N}\right)$ se puede estimar los niveles tróficos sin la información de la dieta o de los contenidos estomacales de estos animales. Varios estudios encontraron una correlación entre el nivel trófico que los organismos ocupan en las redes tróficas y la composición isotópica de nitrógeno 
$\left(\boldsymbol{\delta}^{15} \mathrm{~N}\right)$ de sus tejidos (DeNiro \& Epstein 1981, Minagawa \& Wada 1984, Vander Zanden \& Rasmussen 1996). Los cetáceos, así como otros animales, acumulan el isótopo pesado $\left({ }^{15} \mathrm{~N}\right)$ en sus tejidos y muestran un enriquecimiento isotópico en relación a los valores de sus presas (Schoeninger \& DeNiro 1984, Kelly 2000). Así, cuando la materia se mueve de un nivel trófico a otro, la proporción de los isótopos cambia en una cantidad que se asume constante (Hedges et al. 2005). A través de experimentos de laboratorio y trabajos a campo, se encontró una discriminación trófica promedio de $\sim 3,4 \%$ o para una gran diversidad de taxa animales (Minagawa \& Wada 1984, Cabana \& Rasmussen 1996, Post 2002). Los niveles tróficos pueden ser calculados dividiendo la diferencia entre la proporción isotópica en los tejidos de los mamíferos marinos y la proporción isotópica de los organismos ubicados en la base de la cadena trófica, por esta diferencia entre niveles tróficos, de acuerdo a la siguiente ecuación:

$$
\mathrm{NT}_{\mathrm{x}}=\left(\left(\boldsymbol{\delta}^{15} \mathrm{~N}_{\mathrm{x}}-\boldsymbol{\delta}^{15} \mathrm{~N}_{\text {línea base }}\right) / \Delta\right)+\mathrm{TL}_{\text {línea base }}\left[{ }^{3}\right]
$$

donde el $\mathrm{NT}_{\mathrm{x}}$ es el nivel trófico del consumidor $\mathrm{X}, \boldsymbol{\delta}^{15} \mathrm{~N}_{\mathrm{x}}$ es la composición de isótopos estables de nitrógeno del consumidor $\mathrm{X}, \mathrm{y} \boldsymbol{\delta}^{15} \mathrm{~N}_{\text {línea base } \mathrm{y}} \mathrm{TL}$ línea base es la composición isotópica de nitrógeno y el nivel trófico de los organismos considerados como línea base de la red trófica y $\Delta$ es el factor de discriminación trófica asumido por nivel trófico $(\sim 3,4 \%$ o).

En general se recomienda calcular los niveles tróficos con valores de $\delta^{15} \mathrm{~N}$ de consumidores secundarios $(\mathrm{NT}=2)$ o próximos, que muestren una baja variabilidad temporal en sus firmas isotópicas. Así los valores de $\delta^{15} \mathrm{~N}$ de los consumidores reflejan diferencias reales de los niveles tróficos y no diferencias temporales en la signatura isotópica de los organismos ubicados en la base de las redes tróficas (Cabana \& Rasmussen 1996).

Estudio de las preferencias del hábitat a través del AIE

Los métodos isotópicos son excelentes para el estudio de las preferencias de hábitat en vertebrados acuáticos, existiendo una gran bibliografía respecto al tema (Hobson 1999, 2007). Se ha determinado que los valores $\delta^{13} \mathrm{C}$ y $\delta^{15} \mathrm{~N}$ de los productores primarios, tanto en las redes tróficas terrestres como marinas, exhiben una importante variación espacial y temporal (Rau et al. 1982, Goericke \& Fry 1994, 
Schell et al. 1998, Michener \& Kaufman 2007). En general, cualquier sistema isotópico que varía espacialmente tiene el potencial de proveer información sobre el movimiento animal (Koch 2007).

Estas variaciones isotópicas se reflejan en toda la estructura trófica, por lo tanto, conociendo cómo los patrones isotópicos cambian espacialmente entre los hábitats es posible inferir las potenciales áreas de alimentación de los consumidores marinos a través de sus firmas isotópicas (Hobson 2007). Una gran cantidad de estudios han utilizado los patrones isotópicos espaciales que exhiben los valores de $\delta^{13} \mathrm{C}$ de los productores primarios para discriminar entre hábitats. Esto es posible cuando se comparan hábitats pelágicos y offshore donde el fitoplancton es la única fuente de materia orgánica con hábitats bentónicos e inshore donde existen otros productores primaros, como macroalgas, que son también importantes fuentes de carbono (France 1995, Graham et al. 2010, Newsome et al. 2010).

Diversos mecanismos modelan la variación en los valores de $\delta^{13} \mathrm{C}$ en los productores primarios marinos (Koch 2007, Graham et al. 2010), tales como: (1) la productividad del sistema, con altos valores de $\delta^{13} \mathrm{C}$ en áreas altamente productivas como zonas inshore y de upwelling y bajas latitudes, y lo opuesto en áreas de baja productividad como regiones offshore y altas latitudes. Estos diferentes valores son el resultado, en parte, del rápido crecimiento del fitoplancton y las concentraciones de $\mathrm{CO}_{2(\mathrm{aq})}$ del agua de mar, las altas tasas de crecimiento consumen rápidamente el $\mathrm{CO}_{2(\mathrm{aq})}$ alterando el fraccionamiento de carbono en la fotosíntesis, generando poca discriminación en contra de ${ }^{13} \mathrm{C}$ y dejando altos valores de $\delta^{13} \mathrm{C}$. La solubilidad del $\mathrm{CO}_{2}$, la cual depende de las condiciones físico-químicas del océano (temperatura y salinidad del agua de mar, que a su vez varía en función de la latitud) y la mezcla estacional de la columna de agua, también juega un importante papel en la determinación de los valores de $\boldsymbol{\delta}^{13} \mathrm{C}$ (Rau et al. 1982, Goericke \& Fry 1994, Dehairs et al. 1997, Newsome et al. 2010); (2) la composición y el tamaño de las especies de la comunidad fitoplanctónica, con diferencias fisiológicas y diferentes vías de fijación de carbono (Rau et al. 1982, Dehairs et al. 1997); (3) la importancia del input derivado por macroalgas y pastos marinos a la red trófica, que presentan valores de $\delta^{13} \mathrm{C} \sim 6 \%$ o más altos que el fitoplancton simpátrico (France 1995).

A diferencia de los isótopos del carbono, el control en los valores de $\delta^{15} \mathrm{~N}$ en la base de la red trófica es sumamente complejo. Varios procesos juegan un rol importante en el fraccionamiento isotópico de nitrógeno entre los productores 
primarios, generando variaciones geográficas en los valores de $\delta^{15} \mathrm{~N}$ (Kelly 2000, Montoya 2007) como: (1) la composición inicial del nitrógeno inorgánico de la zona eufótica, (2) la completa o incompleta toma de este nitrógeno por parte del fitoplancton, (3) la pérdida de nitrógeno por hundimiento de la materia particulada hacia el fondo del mar y la incorporación de este nitrógeno profundo en las áreas de upwelling, (4) los procesos de desnitrificación que ocurren bajo la zona eufótica que remueven preferencialmente ${ }^{14} \mathrm{~N}$, enriqueciendo el pool de nitrógeno ${ }^{15} \mathrm{~N}$, y (5) el grado de fijación de $\mathrm{N}_{2}$ atmosférico llevado a cabo por cianobacterias que tienen lugar en aguas oligotróficas (Dunton et al. 1989, Schell et al. 1998, Montoya 2007).

Análisis de las fuentes alimentarias a través del AIE

Debido a la relación isotópica establecida entre los tejidos de los animales y su dieta (DeNiro \& Epstein 1978, 1981), los isótopos estables son muy utilizados para realizar determinaciones cuantitativas de las contribuciones de varias fuentes presas a la dieta de un predador mediante el uso de modelos de mezcla (Hobson 1999, Phillips 2001, Phillips \& Gregg 2003). En estos modelos se asumen que la composición isotópica de los tejidos del consumidor iguala al promedio de la composición isotópica de los constituyentes de su dieta (Martinez del Río \& Wolf 2005). En general, se pueden utilizar los modelos de mezcla lineares con $n$ isótopos para estimar la contribución de $n+1$ fuentes alimentarias, y llegar a una única solución matemática posible que satisfaga el balance de masa para $n$ isótopos (Phillips \& Gregg 2001, 2003). Así el número de fuentes a utilizar se ve limitada por la cantidad de isótopos estables involucrados. Para dos ítems alimentarios y un isótopo estable la fórmula típica sería:

$$
\delta^{13} \mathrm{C}_{\text {mezcla }}=f_{1} * \delta^{13} \mathrm{C}_{1}+f_{2} * \delta^{13} \mathrm{C}_{2}
$$

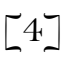

siendo $1=f_{1}+f_{2}$

y donde $\delta^{13} \mathrm{C}_{1}$ y $\delta^{13} \mathrm{C}_{2}$ es la composición isotópica del ítem 1 y 2 de la dieta, siendo $f_{1} \mathrm{y}$ $f_{2}$ las fracciones de cada ítem, respectivamente.

La ecuación [4] puede extenderse para tres ítems presas y dos isótopos estables, para 4 ítems presas y tres isótopos estables y así sucesivamente. Sin embargo, lo más común es que el número de fuentes potenciales exceda $n+1$, evitando encontrar una única solución con estos modelos.

Cuando el número de fuentes presas supera $n+1$, Phillips \& Gregg (2003) describieron un procedimiento que expande el uso de los modelos de mezcla lineares 
descriptos por Phillips (2001), en donde puede utilizarse cualquier número de isótopos estables y de presas posibles. Con el modelo IsoSource propuesto por Phillips \& Gregg (2003), se examinan todas las combinaciones de las contribuciones de cada fuente (O$100 \%$ ) en pequeños incrementos preseleccionados, aceptando como posible soluciones aquellas combinaciones que sumen cerca del valor isotópico de la mezcla. Este modelo utiliza un procedimiento iterativo para determinar límites (superiores e inferiores) para las contribuciones de cada fuente a la mezcla.

$\mathrm{Al}$ igual que los modelos de mezcla lineales, este método asume que las concentraciones y la digestibilidad de $\mathrm{C}$ y $\mathrm{N}$ son las mismas para todas las fuentes presas (Phillips \& Gregg 2003). Con cualquier método, se obtienen buenos resultados cuando las potenciales fuentes presas difieren sustancialmente en sus firmas isotópicas (Phillips \& Koch 2002), de lo contrario se generan amplios rangos de contribuciones para cada fuente. A pesar de las limitaciones que estos modelos presentan (Martinez del Río \& Wolf 2005), aportan una aproximación sobre la constitución de la dieta de los animales cuando otros métodos no son posibles.

En resumen, la composición isotópica del colágeno del hueso de los cetáceos bajo estudio no reflejará meramente sus fuentes nutricionales, el hecho es mucho más complejo y sus valores de $\delta^{13} \mathrm{C}$ y $\delta^{15} \mathrm{~N}$ variarán en relación a diferentes procesos fisiológicos y ambientales, como la composición isotópica de sus presas, las proporciones relativas asimiladas de cada especie presa, del fraccionamiento isotópico tejido-dieta, del recambio isotópico de cada tejido, así como del lugar de alimentación, el nivel trófico que ocupen, y de las propiedades del ecosistema en relación al tipo de productores primarios y, el ciclado de estos isótopos. Sumado a esto, los estudios de laboratorio han comprobado que otros factores pueden estar afectando el balance de dichos isótopos en el cuerpo de los organismos, tales como el estrés hídrico y nutricional, lactancia, gestación, entre otros, generando así modificaciones en sus valores. 


\section{CAPÍTULO 2}

\section{METODOLOGÍA GENERAL}

\section{1 ÁREA DE ESTUdio}

El área de estudio comprende las masas de agua adyacentes al Archipiélago de Tierra del Fuego, en particular las del Atlántico Sudoccidental (Figura 1). El Archipiélago está formado por una red intrincada de canales, senos y bahías, con una isla principal llamada Isla Grande de Tierra del Fuego y numerosas islas de menor extensión (Servicio de Hidrografía Naval 1981).

En su sector norte, Tierra del Fuego está separada del continente por el Estrecho de Magallanes, que une los océanos Atlántico y Pacífico por un brazo principal y tres secundarios. El brazo principal está definido en su boca oriental $\left(\sim 52^{\circ} \mathrm{S}\right)$ por una línea que se extiende desde Cabo Vírgenes (Santa Cruz) a Cabo Espíritu Santo (Tierra del Fuego) y la boca occidental está definida por una línea que va desde el Cabo Pilar en la isla Desolación al Cabo Victoria en la isla Victoria (Chile). En su recorrido el brazo principal sufre estrechamientos (como los de la Primera y Segunda Angostura) y se dirige hacia el S primero y luego hacia el NO para desembocar en el océano Pacífico. Hacia el sur, Tierra del Fuego está separada de las islas Navarino y Hoste (Chile), entre otras islas menores por el Canal Beagle. Este canal se extiende de este a oeste a $\operatorname{los} \sim 55^{\circ} \mathrm{S}$ y tiene una longitud aproximada de $200 \mathrm{~km}$, conectando también los océanos Atlántico y Pacífico Sur (Servicio de Hidrografía Naval 1981, 2006).

Las masas de agua que rodean Tierra del Fuego, en particular las del sector atlántico, corresponden al Área Patagónica Sur del Mar Argentino, que ocurre entre dos convergencias de altas latitudes: la Convergencia Subtropical y la Convergencia Antártica. Las aguas entre ambas convergencias constituye la zona Subantártica (Bujalesky 2007) de aguas templado-frías que caracterizan, desde el punto de vista biogeográfico marino, a la Provincia Magallánica. 


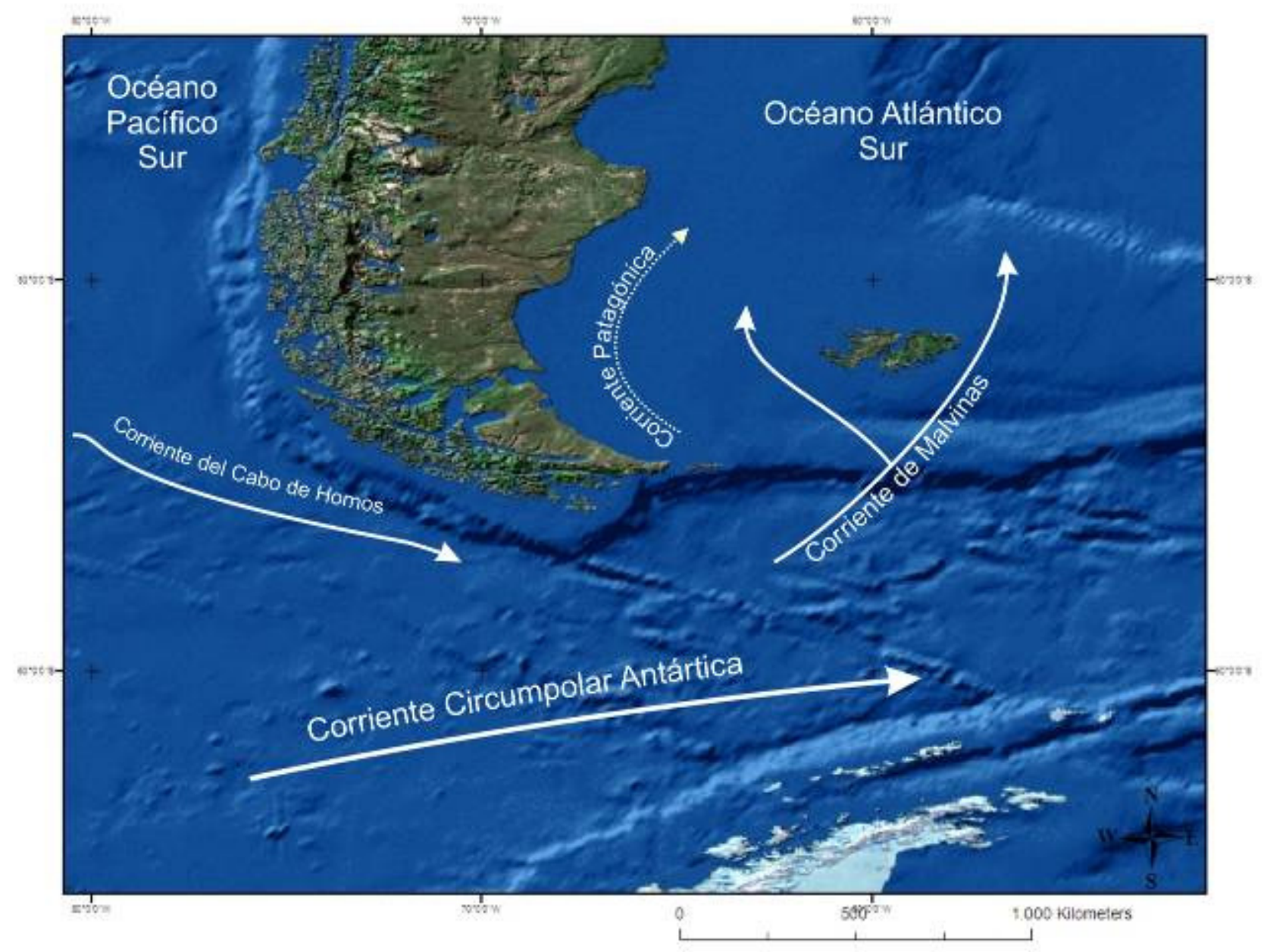

Figura 1. Área de estudio. Se muestran las principales corrientes que dominan en las aguas subantárticas de la región.

Las aguas del sector atlántico de Tierra del Fuego constituyeron el principal sitio de estudio de este trabajo (Figura 1), debido al alto registro de varamientos y/o capturas incidentales de cetáceos menores ocurridos en esta zona con respecto a otras (ej. Canal Beagle y Estrecho de Magallanes). En este sector se definieron dos grandes ecosistemas: el de las aguas costeras y el de las aguas sobre la plataforma patagónica, caracterizados por distintos tipos de masas de agua que influyen en sus ritmos oceanográficos y biológicos.

La costa oriental de Tierra del Fuego, abarca desde la boca del Estrecho de Magallanes hasta el extremo de la Península Mitre y presenta características similares a las del resto de la Patagonia, con grandes amplitudes de mareas y extensas zonas intermareales. Se encuentra influenciada por aguas costeras de la Corriente Patagónica (originada en aguas subantárticas de la deriva oceánica del 
oeste), aguas continentales que llegan a la costa por drenaje superficial y aguas del Estrecho de Magallanes (Cousseau \& Perrota 2000, Campagna et al. 2006). Las aguas costeras exhiben temperaturas de $2^{\circ}$ a $7^{\circ} \mathrm{C}$ y salinidades de $32,7 \%$ o para el sector de Río Grande y Cullen. El régimen de mareas es de tipo semidiurno, con aumento de amplitud de marea desde el Sur hacia el Norte: 2,5m en Bahía Thetis; 4,6m en Cabo San Pablo y Río Grande y 6,6m en Bahía San Sebastián (Servicio de Hidrografía Naval 1981, 2006).

Las aguas sobre la plataforma continental están formadas por una mezcla de aguas de la Corriente de Malvinas, del Estrecho de Magallanes, por los aportes continentales que llegan de la zona costera y por aguas de la Corriente Patagónica. La mezcla de estas aguas genera salinidades entre $33,2 \%$ - 33,8\% y temperaturas de $5^{\circ} \mathrm{C}$ a lo largo del año con un rango de $5^{\circ}-10^{\circ} \mathrm{C}$ en invierno y verano, respectivamente. La Corriente de Malvinas ingresa por el talud continental sobre el sector sur de la plataforma patagónica. Está formada por aguas subantárticas frías, de baja salinidad y ricas en nutrientes que fluyen hacia el norte entre los $55^{\circ} \mathrm{S}$ y $39^{\circ}$ - $36^{\circ} \mathrm{S}$. Es una corriente de aguas superficiales (que no suele superar los $200 \mathrm{~m}$ de espesor) que se origina de la Corriente Circumpolar Antártica, en el sector sudoriental del Pacífico Sur, Pasaje de Drake y áreas vecinas al Banco Burdwood. El núcleo de esta corriente se ubica entre los 150 a $600 \mathrm{~m}$, con temperaturas entre $4^{\circ} \mathrm{y}$ $5^{\circ} \mathrm{C}$ y salinidades entre $34,1 \%$ y $34,2 \%$. En todo su recorrido esta masa de agua interactúa con las aguas de fondo, confiriéndoles características subantárticas de forma casi permanente (Servicio de Hidrografía Naval 1981, 2006, Cousseau \& Perrota 2000, Campagna et al. 2006).

En el Archipiélago de Malvinas, se divide en dos brazos de agua ascendentes, el del oeste se desplaza hacia el norte sobre la plataforma continental, y está constituido por aguas frías y de baja salinidad debido al aporte de aguas continentales provenientes de los canales fueguinos y del Estrecho de Magallanes $(32,3 \%$ ). A su vez, el brazo este rodea a las Islas Malvinas y también se desplaza hacia el norte a lo largo del borde de la plataforma continental, presenta importantes floraciones de fitoplancton. Entre los $36^{\circ}-38^{\circ} \mathrm{S}$ la Corriente de Malvinas se encuentra con la Corriente de Brasil, formada por aguas subtropicales, cálidas $\left(\mathrm{T}>16^{\circ} \mathrm{C}\right)$ y salinas $(\mathrm{S}>35,0 \%$ ) , que fluyen hacia el sur, formando la Convergencia Subtropical Subantártica. A partir de allí, ambas se separan del borde continental y se dirigen hacia el SE para constituir la celda de recirculación anticiclónica del Atlántico Sur. 
Estos frentes oceánicos crean condiciones especiales para la disponibilidad de nutrientes y la productividad primaria, constituyendo áreas de alimentación para muchas especies de peces y moluscos cefalópodos, potenciales presas de varias especies de mamíferos marinos. En el sector de estudio se registran tres grandes áreas con altas concentraciones de nutrientes y con importantes implicancias para todo el ecosistema: 1) los alrededores de las Islas Malvinas y el Banco Burdwood, las surgencias de aguas antárticas aportan alta concentración de nutrientes y alta saturación de oxígeno generando una de las zonas más productivas del Mar Argentino; 2) las capas sub superficiales ( $50 \mathrm{Om})$ de las aguas antárticas del Pasaje de Drake, al norte del Frente Polar, y 3) las aguas costeras entre $\operatorname{los} 50^{\circ}$ y $55^{\circ} \mathrm{S}$, principalmente el sector NE de Tierra del Fuego, donde el gran aporte de aguas continentales que drenan hacia el Estrecho de Magallanes produce una intrusión de aguas de baja salinidad, generando un frente salino que propicia condiciones locales de alta productividad (Cousseau \& Perrota 2000, Campagna et al. 2006).

\subsection{Procedimientos DE INVESTIGACión}

Este trabajo de investigación, Disposición DCyT Nro 04/07, contó con el permiso de la Provincia de Tierra del Fuego para realizar todas las tareas propuestas; incluidas la toma de muestras de cetáceos varados y el muestreo costero de potenciales especies presas (peces e invertebrados varios). Asimismo, se obtuvieron los Permisos de Exportación para realizar el análisis isotópico de las muestras. Estos permisos fueron otorgados por la Dirección de Fauna Silvestre Nación (Secretaría de Ambiente y Desarrollo Sustentable) (permisos N 23351 y 15262) y permiso CITES II (permisos $\mathrm{N}^{\circ}$ 029884 y 029885) de la Dirección Nacional de Recursos Naturales y Conservación de la Biodiversidad.

\subsubsection{Especímenes y colección de muestras}

\subsubsection{Cetáceos}

De las 23 especies de cetáceos menores citadas para Tierra del Fuego (Goodall et al. 2008), en el presente estudio se seleccionaron ocho especies de cetáceos odontocetos, seis de la familia Delphinidae y dos de la familia Phocoenidae, por ser las más importantes y representativas de los distintos ecosistemas marinos de la 
región. De acuerdo a la información disponible en relación a la ecología y distribución de estas especies, se consideran de hábitos principalmente costeros a Lagenorhynchus australis, Cephalorhynchus commersonii y Phocoena spinipinnis, especies de hábitos oceánicos a Lagenorhynchus cruciger, Lissodelphis peronii, Grampus griseus, Pseudorca crassidens y de hábitos costero-oceánico a Phocoena dioptrica (Tabla 2). Para detalles de su ecología trófica y distribución ver Anexo I.

\section{Tabla 2. Especies de cetáceos odontocetos analizadas}

n = número de especímenes analizados, tipo de hábitat (C - costero, O - oceánico) y principales hábitos alimentarios según bibliografía

\begin{tabular}{lllccc|} 
Familia & \multicolumn{1}{c}{ Especie } & Nombre común & N & Hábitat & Hábitos alimentarios \\
Delphinidae & Cephalorhynchus commersonii & Tonina overa & 121 & $\mathrm{C}$ & ictiófago \\
& Grampus griseus & Delfín gris & 48 & $\mathrm{O}$ & teutófago/ictiófago \\
& Lagenorhynchus australis & Delfín austral & 39 & $\mathrm{C}$ & ictiófago \\
& L.cruciger & Delfín cruzado & 5 & $\mathrm{O}$ & ictiófago \\
& Lissodelphis peronii & Delfín liso & 37 & $\mathrm{O}$ & teutófago/ictiófago \\
& Pseudorca crassidens & Falsa orca & 27 & $\mathrm{O}$ & teutófago/ictiófago \\
Phocoenidae & Phocoena dioptrica & Marsopa de anteojos & 87 & $\mathrm{C} / \mathrm{O}$ & ictiófago \\
& P. spinipinnis & Marsopa espinosa & 7 & $\mathrm{C}$ & ictiófago
\end{tabular}

Los especímenes estudiados pertenecen a la colección de RNP (R. Natalie P. Goodall) depositada en el Museo Acatushún de Aves y Mamíferos Marinos Australes, Estancia Harberton (Tierra del Fuego). Los mismos fueron colectados en las costas noreste y sur de la Isla Grande de Tierra del Fuego, Argentina (52-54 ${ }^{\circ} \mathrm{S}$ y $68-69^{\circ} \mathrm{O}$ ) (Figura $2 \mathrm{~A}$ ) y constituyen parte de un proyecto que se lleva a cabo desde el año 1974/75, el cual consiste en revisar periódicamente las playas en búsqueda de ejemplares varados. La mayoría de los ejemplares se encontraron en la costa NE de Tierra del Fuego y representan eventos de varamientos tanto simples como masivos, así como capturas incidentales - especialmente las pequeñas especies - en redes costeras de pesca artesanal (Goodall 1978, Goodall et al. 1994, Goodall et al. 2008).

Se tomaron pequeñas muestras de hueso ( 100 a 500mg), generalmente de la región pterigoidea del cráneo o bien de los huesos chevrones cuando no se pudo tomar craneales (Figura 3). Para más información sobre el Protocolo de extracción de muestras de hueso para análisis isotópico ver Anexo III. 
Cada muestra de hueso se cortó y limpió con un equipo de minitorno (Dremel®) Mod. 395) usando brocas de piedra. Se eliminó una capa superficial muy fina de hueso con el fin de eliminar cualquier tipo de contaminante que se hubiera adherido mientras se mantuvo en depósito.
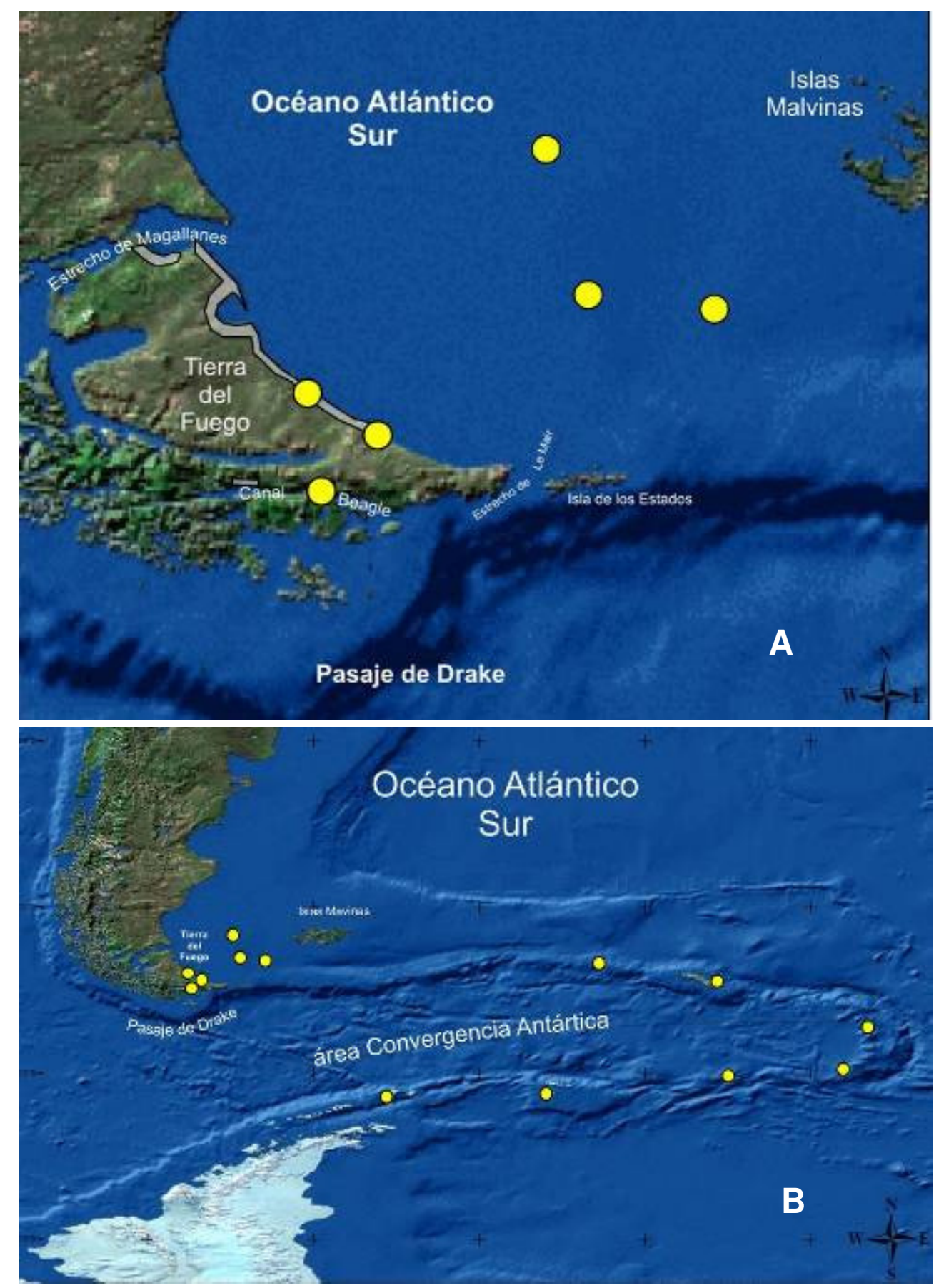

Figura 2. Sectores de muestreo: A. área Tierra del Fuego. B. área Convergencia Antártica. Los círculos amarillos corresponden a los puntos de muestreo de especies presas, las áreas grises representan las zonas de varamientos de los cetáceos analizados. La mayoría de los varamientos han ocurrido en el sector noreste de Tierra del Fuego. 


\subsubsection{Presas}

Se colectaron posibles especies presas de los cetáceos estudiados en áreas costeras y oceánicas de las aguas circundantes a la Provincia de Tierra del Fuego. Los especímenes procedieron de: 1) barcos pesqueros comerciales que operan con redes de arrastre de fondo y media agua, 2 ) redes costeras de enmalle y trasmallo y trampas para peces en las costas noreste y sur de Tierra del Fuego y 3) contenidos estomacales de animales varados (Figura 4).

El esfuerzo de muestreo de presas se concentró en las zonas de mayor representación de especimenes de cetáceos. El área de muestreo se localizó entre los $\sim 51-54^{\circ} \mathrm{S}$ y los $\sim 62^{\circ}-68^{\circ} \mathrm{O}$ (Figura $2 \mathrm{~A}, \mathrm{~B}$ ), cubriéndose así los hábitats costeros $\left(54^{\circ} 17^{\prime} \mathrm{S}-66^{\circ} 41^{\prime} \mathrm{O}, 54^{\circ} 52^{\prime} \mathrm{S}-67^{\circ} 16^{\prime} \mathrm{O}, 53^{\circ} 57^{\prime} \mathrm{S}-67^{\circ} 27^{\prime} \mathrm{O}\right)$ y pelágicos $\left(53^{\circ} 09^{\prime} \mathrm{S}-\right.$ $\left.62^{\circ} 48^{\prime} \mathrm{O}, 53^{\circ} 57^{\prime} \mathrm{S}-67^{\circ} 27^{\prime} \mathrm{O}\right)$ del área patagónica sur y sectores de la Convergencia Antártica (entre $53^{\circ} 22^{\prime} \mathrm{S}$ a $61^{\circ} 22^{\prime} \mathrm{S}$ y entre $26^{\circ} 28^{\prime} \mathrm{O}$ a $55^{\circ} 31^{\prime} \mathrm{O}$ ).

Las presas se ordenaron en siete categorías, en relación a los grupos taxonómicos y sus hábitos ecológicos: peces costero-bentónicos $(\mathrm{CB})$, peces costeropelágicos $(\mathrm{CP})$, peces demerso-pelágicos $(\mathrm{DP})$, calamares $(\mathrm{SQ})$, pulpos $(\mathrm{OQ})$, crustáceos (CR) y zooplancton (ZP) (Tabla 3).

Se tomaron pequeñas muestras $(\sim 1, \mathrm{og})$ de músculo, hueso y picos de cefalópodos de especímenes frescos de los muestreos costeros y oceánicos y muestras de hueso y picos de cefalópodos de ítems de contenidos estomacales. 


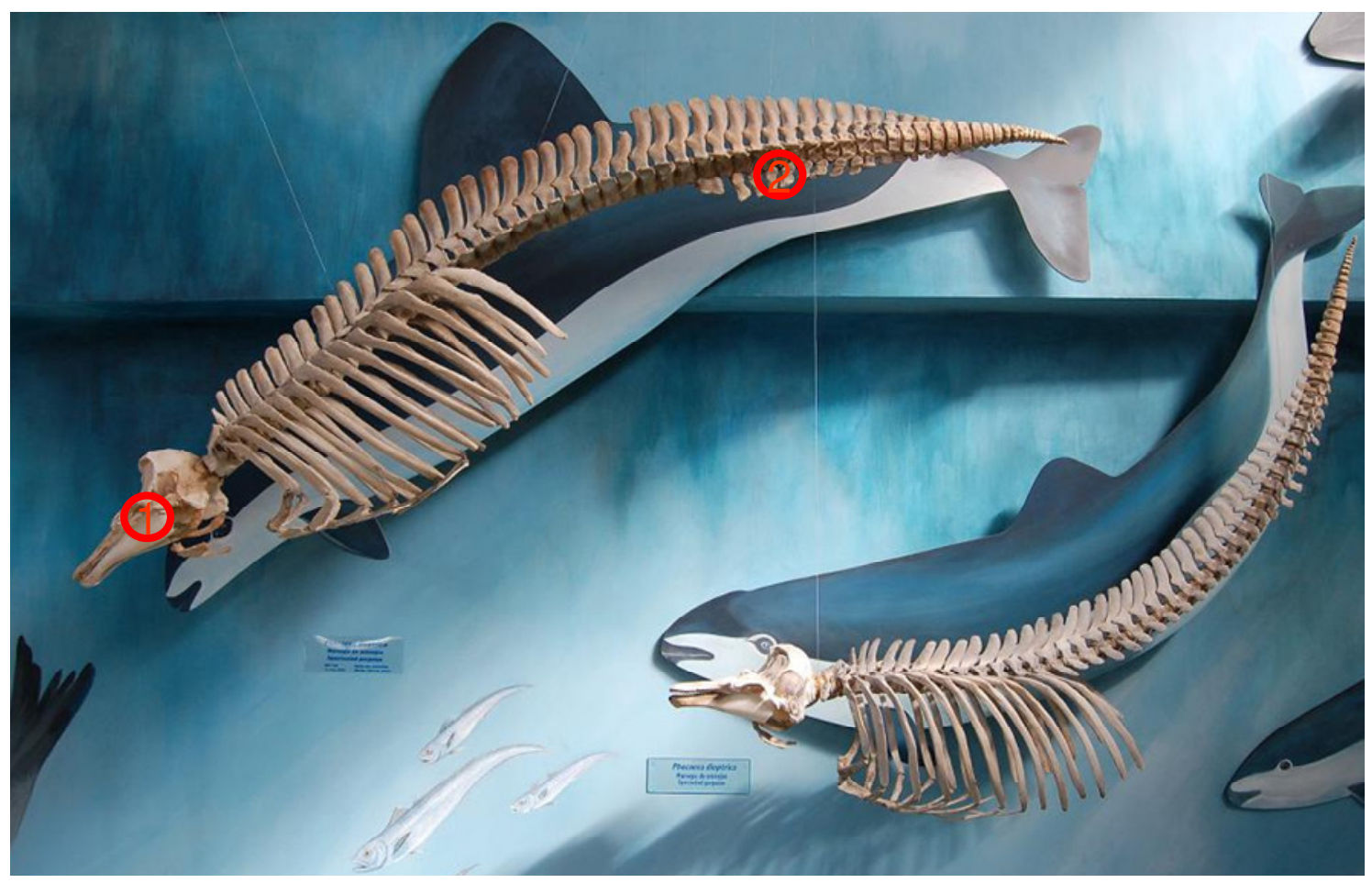

Figura 3. Ubicación de las piezas óseas seleccionadas de los especímenes de cetáceos analizados. Huesos de la región pterigoidea del cráneo y (2) huesos chevrones Especímenes de marsopa de anteojos (Phocoena dioptrica) en exhibición, Museo Acatushún. 


\section{Figura 4. Muestreo de presas}

Fondo, red de arrastre, Bahía Cambaceres (Ea. Harberton)

A - Recolección de peces, Bahía Cambaceres (Ea. Harberton)

B/C - Red agallera y trasmallo, Punta María

D - Recolección de peces, red de arrastre, Bahía Cambaceres (Ea. Harberton)

E/F - Colocación de trampas, Bahía Relegada (E) y Bahía Harberton (F) (Ea. Harberton)

$\mathrm{G} / \mathrm{H}$ - Recolección de peces costeros, Cabo San Pablo

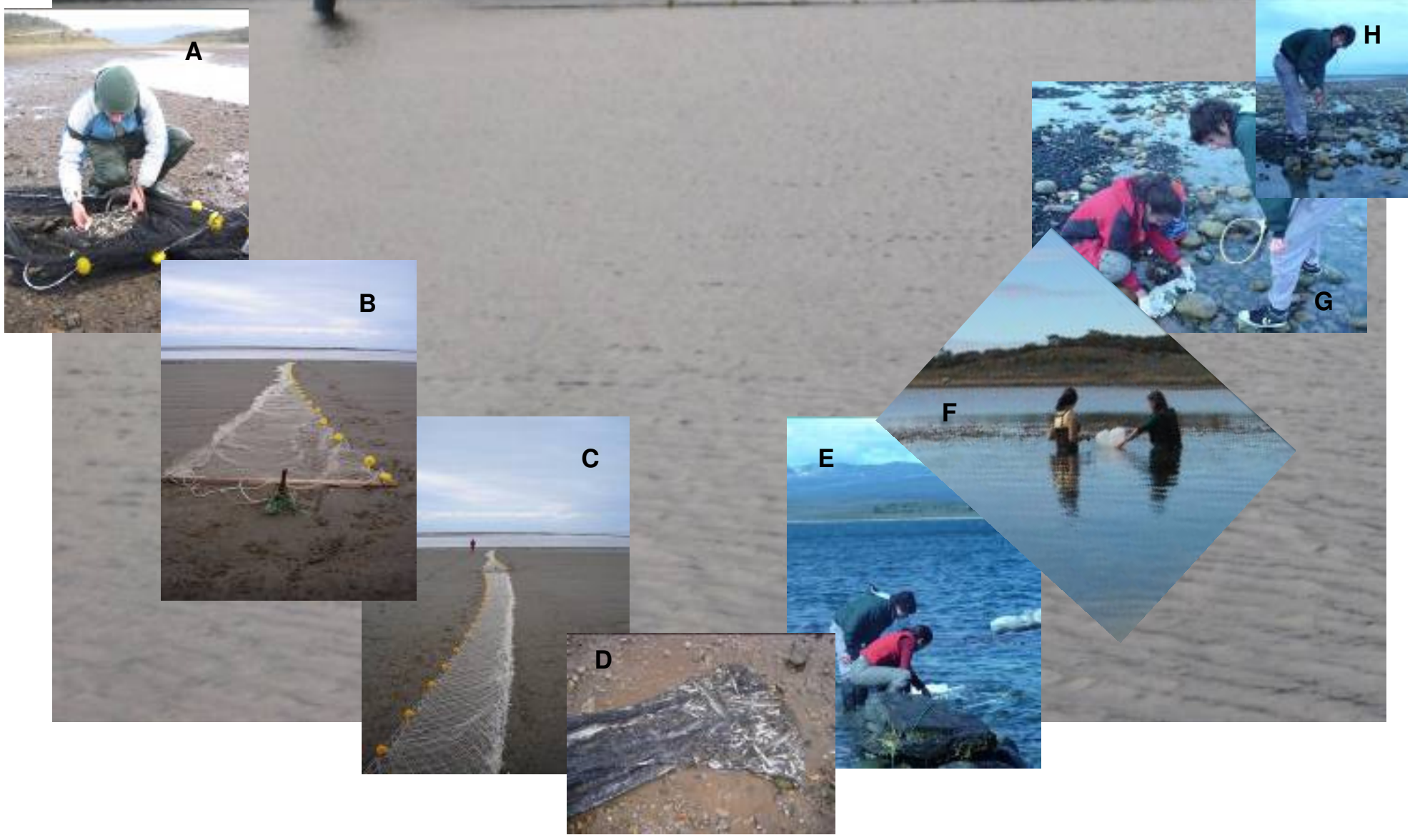

Metodología General 


\subsubsection{Procesamiento de las muestras y análisis de isótopos estables}

El análisis de isótopos estables puede ser abordado a través de distintos procesamientos. Pueden utilizarse una gran variedad de tejidos y analizarse diversos isótopos estables, dependiendo de los objetivos del estudio. Para más detalles sobre el análisis de isótopos estables ver Anexo II.

La consistencia en los procesamientos es importante a fin de generar muestras comparables para el análisis de isótopos estables (Sotiropoulos et al. 2004, Post et al. 2007, Hoffman \& Sutton 2010). Esto adquiere gran relevancia en los estudios de las redes tróficas, donde se analiza una gran diversidad de organismos y distintos tipos de tejidos. La variación en la constitución macromolecular de los tejidos y sus distintas tasas de recambio isotópico generan diferencias en la discriminación trófica entre los tejidos de las presas y los consumidores, complicando la interpretación en los resultados.

En la presente Tesis se analizaron distintos tipos de tejidos y una gran diversidad de organismos que difieren en el contenido lipídico. Con el fin de generar muestras homogéneas para su análisis, el procesamiento químico que se realizó incluyó una primera etapa de desmineralización en ácido débil y una segunda etapa de extracción de lípidos para las muestras óseas. En el caso de muestras de músculo y picos de cefalópodos sólo se realizó la segunda etapa. De esta manera, se midió la proporción de isótopos estables de carbono $\left(\boldsymbol{\delta}^{19} \mathrm{C}\right)$ y nitrógeno $\left(\boldsymbol{\delta}^{15} \mathrm{~N}\right)$ en la fracción proteica de cada muestra. A continuación se detalla el procesamiento realizado.

\subsubsection{Procesamiento de las muestras de cetáceos}

El trabajo (Figura 5) se inició con 100mg de muestra limpia de cada espécimen. Cada muestra se dispuso en un vial de vidrio de $20 \mathrm{ml}$ donde se realizó todo el procesamiento químico: el primer paso consistió en la desmineralización de la muestra ósea en $15 \mathrm{ml}$ de $\mathrm{HCl} 0,2 \mathrm{~N}$ durante $\sim 72-96 \mathrm{hs}$ y a temperatura ambiente, con el fin de obtener el colágeno. La solución ácida se cambió regularmente por una nueva solución durante ese período. En cada recambio de la solución se agitó la muestra durante 10 minutos con agitador magnético (Marca Decalab) y se dejó reposar en el vial destapado hasta su nuevo recambio. Desmineralizada totalmente la muestra, se enjuagó con agua destilada hasta lograr la neutralidad. Siendo que los lípidos se encuentran empobrecidos en ${ }^{13} \mathrm{C}$, el variable contenido lipídico de las muestras de las distintas especies de cetáceos y de sus presas puede generar inconsistencias en las determinaciones isotópicas. Con el fin de que la muestra 
represente sólo el contenido de colágeno, se extrajeron los lípidos de las mismas. Se agregaron 13ml de mezcla de extracción de lípidos, formada por cloroformometanol en proporción 2:1. Las muestras fueron agitadas -con agitador magnéticodurante 30 minutos y se agregaron $4 \mathrm{ml}$ de agua destilada para separar una fase superior de metanol+agua y una inferior de cloroformo+lípidos. Se dejó reposar por $\sim 12 \mathrm{hs}$ a temperatura ambiente y en frasco tapado, hasta que las fases quedaran separadas para eliminar adecuadamente los lípidos. La eliminación del contenido lipídico requirió de 4 a 5 repeticiones para extraer completamente las grasas. Las muestras resultantes se lavaron nuevamente con agua destilada varias veces hasta obtener valores neutros de $\mathrm{pH}$ y se secaron en estufa a $60^{\circ} \mathrm{C}$ por $\sim 24$ hs. Para más detalles sobre el Protocolo de pretratamiento ver Anexo IV.

\subsubsection{Procesamiento de las muestras presas}

Las muestras de músculo, hueso y picos de cefalópodos de especímenes frescos, provenientes de barcos pesqueros y del muestreo costero, fueron preservadas a $-18^{\circ} \mathrm{C}$ hasta su procesamiento. Se usaron muestras de huesos y picos de cefalópodos de contenidos estomacales, preservados en alcohol al 70\%. Previo al procesamiento, las muestras de contenidos estomacales se lavaron varias veces en agua destilada hasta lograr su neutralidad y las de hueso se procesaron de la misma manera que la descrita para los huesos de cetáceos. Previo al procesamiento, las muestras de músculo se secaron en estufa a $60^{\circ} \mathrm{C}$ por $48 \mathrm{hs}$. El procesamiento se inició con 100mg de muestra seca de cada espécimen. Los lípidos se removieron de la misma manera que la descrita anteriormente en la sección 2.2.2.1 y posteriormente se secaron en estufa a $60^{\circ} \mathrm{C}$ por $24 \mathrm{~h}$.

\subsubsection{Análisis de $\delta^{13} \mathrm{C}$ y $\delta^{15} \mathrm{~N}$}

A continuación del procesado se pesó una submuestra seca $(\sim 0,5-0,6 \mathrm{mg})$ en cápsulas de estaño ( 3 x $5 \mathrm{~mm}$ ). Se obtuvo $\mathrm{CO}_{2}$ y $\mathrm{N}_{2}$ por combustión de la muestra a temperaturas muy elevadas y se midieron las relaciones isotópicas de carbono $\left({ }^{13} \mathrm{C} /{ }^{12} \mathrm{C}\right)$ y nitrógeno $\left({ }^{15} \mathrm{~N} /{ }^{14} \mathrm{~N}\right)$ mediante un Analizador Elemental Carlo Erba (EA) acoplado con un espectrómetro de masa DELTAplus XL-Thermo Finnigan y un espectrómetro de masa DELTA Vplus en el Geophysical Laboratory, Carnegie Institution of Washington, Washington D.C. (Figura 5). 
Los resultados son expresados en la notación delta $(\boldsymbol{\delta})$ convencional usando la siguiente ecuación:

$$
\delta^{13} \mathrm{C} \text { or } \delta^{15} \mathrm{~N}=\left[\left(\mathrm{R}_{\text {muestra }} / \mathrm{R}_{\text {estándar }}\right)-1\right] *{ }^{*} 1000 \quad[1]
$$

donde $\mathrm{R}_{\text {muestra }} \mathrm{y} \mathrm{R}_{\text {estándar }}$ corresponden a las proporciones isotópicas de carbono $\left({ }^{13} \mathrm{C}:{ }^{12} \mathrm{C}\right)$ y nitrógeno $\left({ }^{15} \mathrm{~N}:{ }^{14} \mathrm{~N}\right)$ de la muestra y del estándar respectivamente. Debido a que las abundancias absolutas de las proporciones son muy pequeñas, los valores isotópicos se expresan referidos a un valor estándar y multiplicado por mil (ppt. \%o). Los estándares de referencia son el Vienna-Pee Dee Belemnite (V-PDB) para el carbono y el $\mathrm{N}_{2}$ atmosférico para el nitrógeno. 


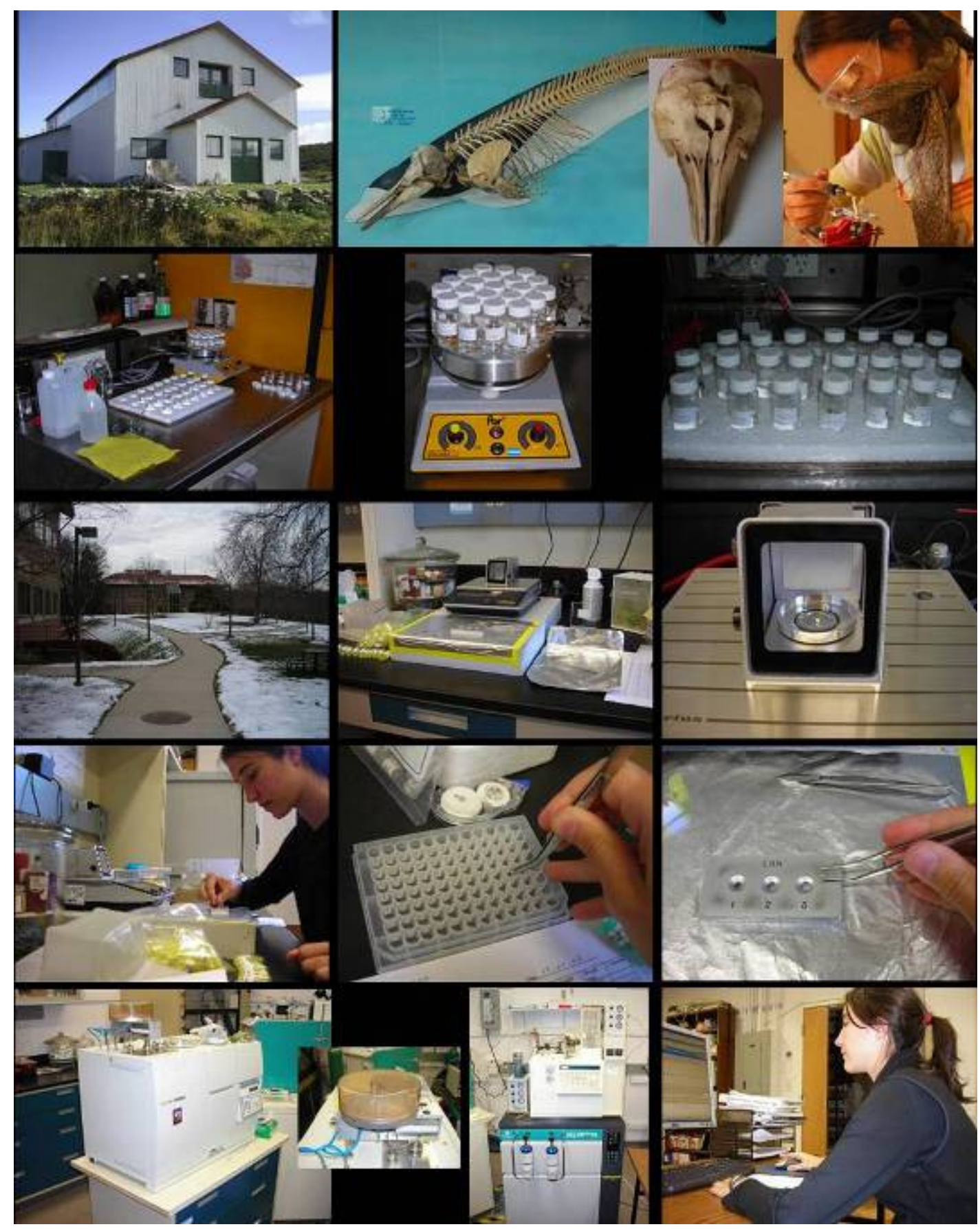

Figura 5. Procesamiento de las muestras y análisis de isótopos estables. Primer línea de fotos: Museo Acatushún, corte y limpieza previa al procesamiento químico. Segunda línea de fotos: Centro Austral de Investigaciones Científicas: procesamiento químico. Tercer, cuarta y quinta línea de fotos: Geophysical Laboratory, Carnegie Institution for Science, pesado final de las muestras procesadas y análisis de isótopos estables de carbono y nitrógeno, equipos utilizados: analizador elemental Carlo Erba y espectrómetro de masa DELTAplus XL-Thermo Finnigan. 


\subsubsection{Evaluación de la integridad de las muestras}

Para evaluar la integridad de las muestras se midió (1) la cantidad de colágeno, expresada como porcentaje del peso recuperado del hueso, y (2) la relación $\mathrm{C} / \mathrm{N}$ sobre el colágeno (Ambrose 1990). Según diversas investigaciones los huesos modernos frescos contienen aproximadamente $22 \%$ en peso de colágeno y el rango de $\mathrm{C} / \mathrm{N}$ considerados normales, de proteína pura, se encuentra entre 2,8 y 3,5 (Ambrose 1990).

Estas mediciones son importantes para evaluar si la muestra presenta algún tipo de degradación proteica generado por el procesamiento aplicado o por otros factores, como el efecto de la acción bacteriana/fúngica y sustancias húmicas que pudieron haber operado sobre las mismas. Dado que los especímenes de los cetáceos analizados en este trabajo quedaron expuestos en la costa posterior a su varamiento y por periodos variables, las inclemencias del clima - además de los factores ya mencionados - pudieron haber degradado la fracción proteica del hueso generando cambios en su composición isotópica.

\subsubsection{Aspectos para la interpretación de los valores de $\delta^{13} \mathrm{C}$ y $\delta^{15} \mathrm{~N}$}

En este estudio, la especie constituyó la unidad de análisis principal para la interpretación de la información isotópica obtenida. Los contrastes isotópicos entre las especies aportan información relacionada con el uso del hábitat y/o tipo de presas consumidas por parte de éstas.

Para evaluar el uso diferencial de los recursos por parte de los cetáceos los valores promedios de $\delta^{13} \mathrm{C}$ y $\delta^{15} \mathrm{~N}$ de cada especie son discutidos en el marco de todo el conjunto de datos, más que de forma individual. Dado que las posibles presas de los cetáceos se encuentran disponibles virtualmente en todo el espacio considerado, la segregación marcada de los datos isotópicos así como el diferente grado de consumo de los tipos de presas costeras vs. oceánicas son la clave para evaluar las áreas de alimentación y las relaciones tróficas de los individuos, ya que se puede relacionar esos recursos con los sectores potenciales de explotación (ej. sector costero, plataforma continental y talud) a través de sus firmas isotópicas, y con ello evaluar el uso del hábitat.

Sin embargo, dado que estas especies de cetáceos son mamíferos marinos con una alta movilidad, el uso de un sector del espacio por parte de éstos, no implica necesariamente la explotación de sus recursos alimentarios. En estos casos, sus firmas isotópicas no registrarán el uso de dichos hábitats. 
Para permitir la comparación directa entre los valores isotópicos de los cetáceos y sus posibles presas se aplicó una corrección trófica a los valores de éstas últimas. Dado que la discriminación trófica varía de acuerdo al tipo de tejido analizado (Hobson \& Clark 1992b, Hobson et al. 1993, Caut et al. 2009, Newsome et al. 2010), se implementaron diferentes correcciones a los valores isotópicos del músculo, hueso y picos de las presas. Para las muestras de músculo de las presas, se implementó una corrección de $+5,0 \%$ y $+3,4 \%$ on los valores de $\delta^{13} \mathrm{C}$ y $\delta^{15} \mathrm{~N}$, respectivamente, para explicar una discriminación trófica y de tejido (Hare et al. 1991, Hedges et al. 2005, Koch 2007). Para los huesos y picos de las presas que sólo requieren una corrección para la discriminación trófica, se implementó una corrección de $+1,0 \%$ o $+3,4 \%$ o en los valores de $\delta^{13} \mathrm{C}$ y $\delta^{15} \mathrm{~N}$, respectivamente (DeNiro \& Epstein 1978, 1981, Minagawa \& Wada 1984, Post 2002).

Para una mejor interpretación de las dietas y las áreas de alimentación, se definieron tres tipos generales de dieta:

- Dieta costera: se incluyen aquí los valores que evidencien un mayor consumo de presas costeras (valores altos de $\delta^{13} \mathrm{C}$ y $\delta^{15} \mathrm{~N}$ ).

- Dieta mixta: se incluyen los valores que evidencien un consumo variable de ambos tipos de presas, costeras y de plataforma (valores intermedios de $\delta^{13} \mathrm{C}$ y $\left.\delta^{15} \mathrm{~N}\right)$.

- Dieta oceánica: se incluyen los valores que evidencien un mayor consumo de presas de plataforma, talud o regiones oceánicas australes (valores bajos de $\delta^{13} \mathrm{C}$ y $\left.\delta^{15} \mathrm{~N}\right)$.

Es importante destacar que el colágeno del hueso, debido a su lenta tasa de renovación isotópica, contiene información ecológica que representa un promedio del alimento ingerido por el organismo durante gran parte de su vida, entre $\sim 5$ a 10 años dependiendo del estadio ontogenético del animal, por lo que es un buen integrador de los datos isotópicos sobre la dieta de largo tiempo (Koch 2007). Además, sus cualidades superiores de preservación en comparación con tejidos blandos (ej. músculo, piel), permiten una investigación post-mortem de las características ecológicas de cada individuo/especie.

Por otra parte, las fluctuaciones esporádicas en los valores de los isótopos estables debido a estrés periódico, nutricional, por enfermedades, por cambios 
recientes en el comportamiento alimentario o por patrones de movimientos, no son reflejados en la composición isotópica del colágeno del hueso como en otros tejidos (como sangre, piel, hígado o músculo), que presentan altas tasas de recambio isotópico (Hedges et al. 2005). Por lo tanto los huesos permiten caracterizar los hábitos tróficos generales de los cetáceos bajo estudio, incluyendo sus preferencias de hábitat, tipos de presas y relaciones tróficas. Para más detalles sobre las características isotópicas del hueso dirigirse al Anexo II.

\subsubsection{Tratamiento estadístico de los datos}

\subsubsection{Análisis de la variación isotópica de presas}

Se compararon las diferentes especies de presas mediante sus valores promedios de $\delta^{13} \mathrm{C}$ y $\delta^{15} \mathrm{~N}$. Se evaluó la normalidad de ambas variables $\left(\boldsymbol{\delta}^{13} \mathrm{C}, \boldsymbol{\delta}^{15} \mathrm{~N}\right)$ mediante el Test de Kolmogorov-Smirnov y la homogeneidad de varianza mediante el Test F. Dado que los datos no cumplieron con los requerimientos para realizar test paramétricos, se compararon los valores de $\delta^{13} \mathrm{C}$ y $\delta^{15} \mathrm{~N}$ entre las especies mediante el test no paramétrico de Kruskal-Wallis (K-W), seguido de comparaciones pareadas mediante el test de la U de Mann-Whitney (U-test). Para todos los cálculos, el nivel de significancia fue de $\alpha=0,05$.

\subsubsection{Análisis de la variación isotópica inter-específica en los cetáceos}

Se compararon las diferentes especies de cetáceos mediante los valores promedios de $\delta^{13} \mathrm{C}$ y $\delta^{15} \mathrm{~N}$, las varianzas isotópicas asociadas, los niveles tróficos (NTs) estimados y la relación establecida de éstos con los valores de sus posibles presas del Atlántico Sudoccidental.

Se evaluó la normalidad de ambas variables $\left(\boldsymbol{\delta}^{13} \mathrm{C}, \boldsymbol{\delta}^{15} \mathrm{~N}\right)$ mediante el Test de Kolmogorov-Smirnov y la homogeneidad de varianza mediante el Test F. Dado que los datos no cumplieron con los requerimientos para realizar test paramétricos, se compararon los valores de $\delta^{13} \mathrm{C}$ y $\delta^{15} \mathrm{~N}$ entre las especies mediante el test no paramétrico de Kruskal-Wallis (K-W), siendo el test más confiable para este caso. Seguido al test de K-W, se realizaron comparaciones pareadas mediante el test de la U de Mann-Whitney (U-test). Se analizó estadísticamente la varianza isotópica en C y $\mathrm{N}$ mediante el Test $\mathrm{F}$ como un método para estudiar el solapamiento/segregación 
trófica entre las especies. Para todos los cálculos, el nivel de significancia fue de $\alpha=$ 0,05 .

\subsection{Patrones isotópicos espaciales y/o alimentarios}

Se realizó un análisis de cluster para discernir patrones isotópicos espaciales entre las especies y determinar las relaciones tróficas generales. Este procedimiento crea un cluster con nueve observaciones asignadas. El cluster es un grupo de observaciones con características similares basadas en los valores $\delta^{13} \mathrm{C}$ y $\delta{ }^{15} \mathrm{~N}$. Se usó el método del vecino más cercano y distancias euclideanas (Nearest Neighbor method y Euclidean distances). Se esperó que el uso de distintos tipos de ambientes (costeros vs. oceánicos) por parte de estas especies, se reflejara en los grupos creados por este análisis, dado que existe una distribución espacial de los valores isotópicos tanto en sentido longitudinal (zonas costeras vs. oceánicas) como latitudinal (latitudes bajas vs. altas).

\subsection{Estimación de los niveles tróficos}

Siguiendo los grupos creados en el análisis de cluster, se estimó el nivel trófico para cada especie de cetáceo utilizando los valores de $\delta^{15} \mathrm{~N}$ de cada espécimen. Debido a que la mayoría de los mamíferos marinos son considerados predadores de altos niveles tróficos, era de suponer que ocuparan el tercer y quinto nivel trófico, como en otras regiones (Pauly et al. 1998a). En este estudio se asumió un factor de discriminación trófica o enriquecimiento trófico $(\Delta)$ de $3,4 \%$ o por nivel trófico (Minagawa \& Wada 1984, Post 2002). Para el cálculo de los niveles tróficos se consideraron dos redes tróficas generales, una en aguas del norte de Patagonia y otra al sur de la región a la altura de Tierra del Fuego. Se consideró como línea base para calcular el nivel trófico el valor promedio de $\delta^{15} \mathrm{~N}$ de eufásidos (Euphausia lucens, $\delta^{15} \mathrm{~N} 7,3 \%$, SD 0,8\%o) reportado por Ciancio et al. (2008) para las aguas del sur de Patagonia, y el valor promedio de $\delta^{15} \mathrm{~N}$ de la anchoita (Engraulis anchoita, $\delta^{15} \mathrm{~N} 16,4 \%$, SD 0,1\%o) reportado por Forero et al. (2004) para las aguas del norte. Se asumió una completa herbivoría por parte de los eufásidos ocupando un nivel trófico de 2,0 (Ciancio et al. 2008), mientras que para la anchoita se asumió un nivel trófico de 3,2 de acuerdo a su ecología (Forero et al. 2004). Los niveles tróficos fueron calculados usando la siguiente ecuación: 


$$
\mathrm{NT}_{\text {cet }}=\left(\left(\boldsymbol{\delta}^{15} \mathrm{~N}_{\text {cet }}-\boldsymbol{\delta}^{15} \mathrm{~N}_{\text {línea base }}\right) / 3,4\right)+\mathrm{NT}_{\text {línea base }}[\mathrm{Q}]
$$

donde el $\mathrm{NT}_{\text {cet }}$ es el nivel trófico de las especies de cetáceos consideradas, $\delta^{15} \mathrm{~N}_{\text {cet }}$ es la composición de isótopos estables de nitrógeno del cetáceo consumidor, y $\delta^{15} \mathrm{~N}_{\text {línea base y }} \mathrm{NT}_{\text {línea base }}$ es la composición isotópica de nitrógeno y el nivel trófico, respectivamente, de la línea base de cada red trófica considerada.

2.2.5.2.3 Estimación de la contribución isotópicas de las presas al valor isotópico del predador

A fin de ayudar en la interpretación de los resultados sobre el solapamiento/segregación de los hábitos tróficos de los cetáceos bajo estudio, se cuantificó la contribución isotópica de diversas fuentes alimentarias al valor estimado de $\delta^{13} \mathrm{C}$ y $\delta^{15} \mathrm{~N}$ de estos predadores, mediante la utilización de modelos de mezcla. Debido a la existencia de varias fuentes potenciales de presas se trabajó con el software IsoSource versión 1.3 (Phillips \& Gregg 2003). Este programa calcula todos los rangos de las contribuciones de las posibles fuentes (= presas) a una mezcla (= colágeno de hueso de los cetáceos) en base al valor de isótopos estables.

Se utilizaron las categorías de presas establecidas a priori de acuerdo a los grupos taxonómicos y sus hábitos ecológicos (sección 2.2.1.2) utilizando sus valores corregidos por discriminación trófica de $\delta^{13} \mathrm{C}$ y $\delta^{15} \mathrm{~N}$ (sección 2.2.4). Para cada consumidor en particular, y a fin de calcular las contribuciones isotópicas relativas a la dieta de cada uno, se priorizaron posibles grupos presas en base al conocimiento previo sobre sus hábitos tróficos y a la proximidad en los valores de los isótopo estables de carbono y nitrógeno. En este modelo, se examinaron todas las posibles combinaciones de las contribuciones de cada fuente presa (0-100\%) en pequeños incrementos (1\%o). Se consideraron como posibles soluciones sólo las combinaciones que sumaron cerca de la signatura isotópica del predador con un rango de tolerancia de $\pm 0,05 \%$, determinándose la frecuencia y el rango de las contribuciones de cada fuente. Cada solución individual representa una combinación de las proporciones de las fuentes que satisfacen el balance de masa isotópico del modelo. 


\subsubsection{Análisis de la variación intra-específica en la dieta}

Se analizó la variación isotópica a nivel intra-específico para aquellas especies (Grampus griseus y Cephalorhynchus commersoniı) con las que se contó con diversa información de sus individuos (ej. edad, sexo).

Se evaluó la normalidad de los datos $\left(\boldsymbol{\delta}^{13} \mathrm{C}, \quad \boldsymbol{\delta}^{15} \mathrm{~N}\right)$ mediante el Test de Kolmogorov-Smirnov y la homogeneidad de varianza mediante el Test F. Se realizaron comparaciones pareadas mediante Test de Student (Test T) cuando los datos cumplieron con requerimientos paramétricos, en caso contrario las comparaciones se realizaron mediante el Test de la U de Mann-Whitney (U-test).

Se analizó estadísticamente la varianza isotópica en $\mathrm{C}$ y $\mathrm{N}$ mediante el Test $\mathrm{F}$ como un método para estudiar el solapamiento/segregación entre los sexos y las clases etarias.

En C. commersonii, se evaluó también la correlación entre los valores de $\delta^{13} \mathrm{C}$ y $\delta^{15} \mathrm{~N}$ del colágeno del hueso con la edad y la longitud total. Como los datos no siguieron una distribución normal se evaluó mediante el coeficiente de correlación de rangos de Spearman. Para todos los cálculos, el nivel de significancia fue de $\alpha=$ 0,05 .

\subsubsection{Análisis de la variación isotópica temporal}

Siendo que algunos especímenes de cetáceos representan muestras históricas, desde el año 1974/75 a la actualidad, se calculó la Corrección Suess para cada espécimen que explica el decrecimiento global en el contenido de ${ }^{13} \mathrm{C}$ del dióxido de carbono atmosférico, generado principalmente por la quema de combustible fósil de hace $\sim 150$ años (Leuenberger et al. 1992, Francey et al. 1999, Idermühle et al. 1999).

Se evaluó la correlación entre los valores de $\delta^{13} \mathrm{C}$ y $\delta^{15} \mathrm{~N}$ del colágeno del hueso y los años de varamiento de los especímenes para cuatro especies: Cephalorhynchus commersonii, Lagenorhynchus australis, Phocoena dioptrica y Grampus griseus. Para el resto de las especies este análisis no fue posible por la baja representatividad de las muestras a lo largo de los años. Previo a los análisis de correlación se aplicó la Corrección de Suess para eliminar la pequeña fracción registrada relacionada con este efecto industrial. Se calculó además el coeficiente de Correlación de Pearson para los datos que siguieron una distribución normal, en caso contrario se evaluó 
mediante el coeficiente de correlación de rangos de Spearman. Para todos los cálculos, el nivel de significancia fue de $\alpha=0,05$. 
Tabla 3. Especies presas analizadas

\# número de especie. Grupo: peces costero-bentónicos $(\mathrm{CB})$, peces costero-pelágicos $(\mathrm{CP})$, peces demerso-pelágicos (DP), calamares (SQ), pulpos (OC), crustáceos $(\mathrm{CR})$ y zooplancton $(\mathrm{ZP})$.

Espécimen: fresco (F) o ítem de contenido estomacal (CE), punto de muestreo (Lat/long), estación colectada (Scol), número (n) y tipo de muestras analizadas (Mtipo)

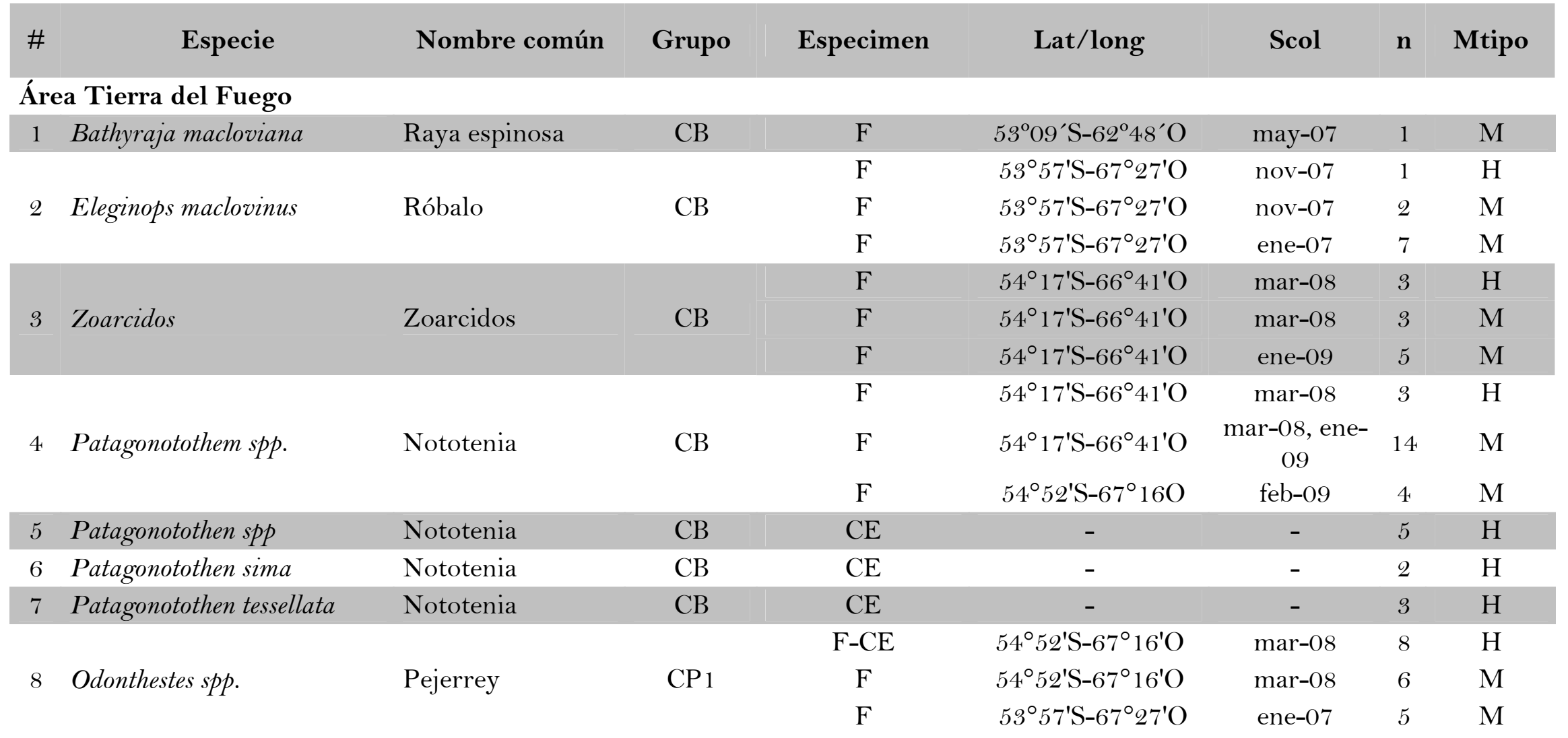




\section{Tabla 3. continuación}

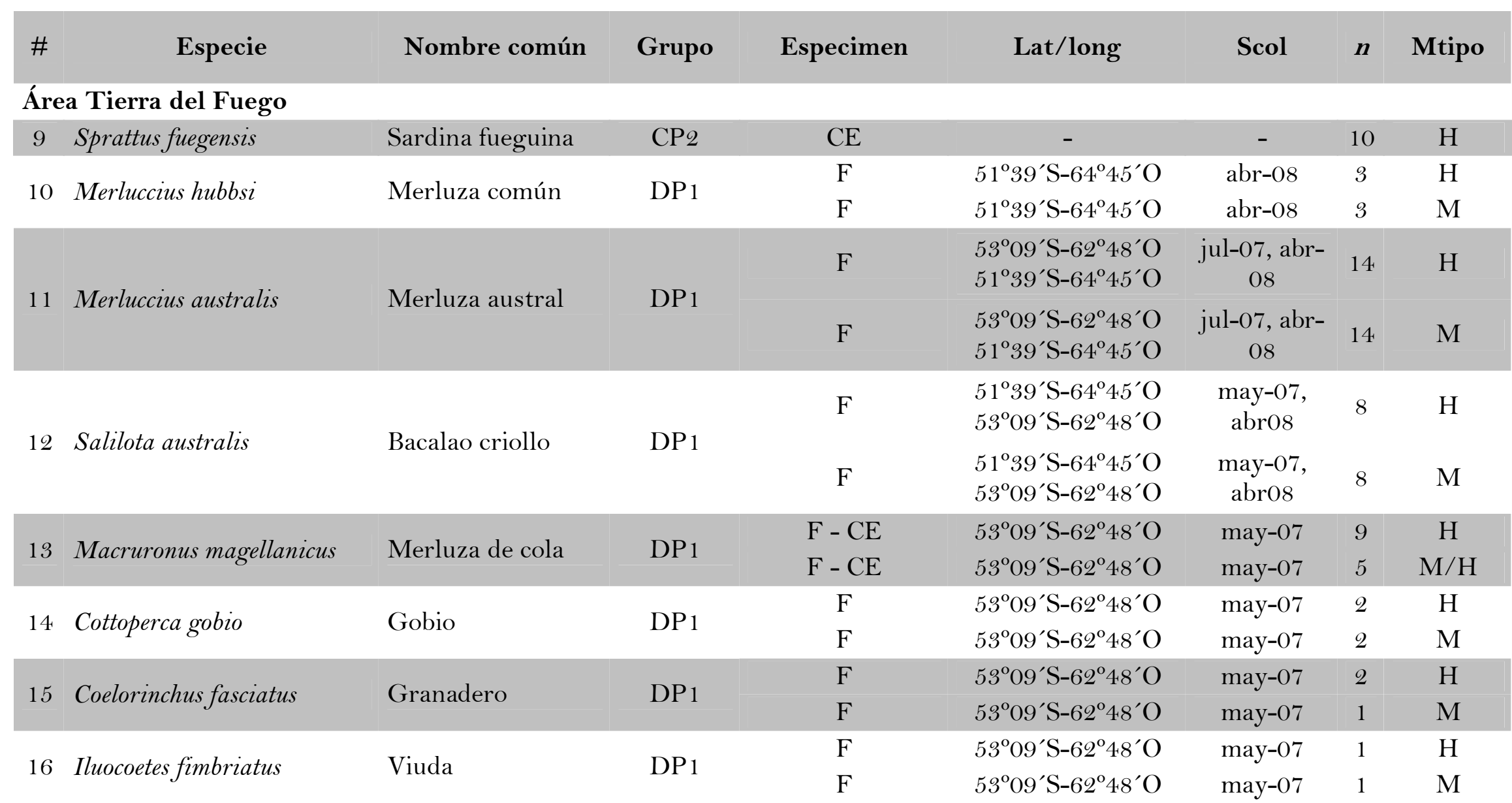


Tabla 3. continuación

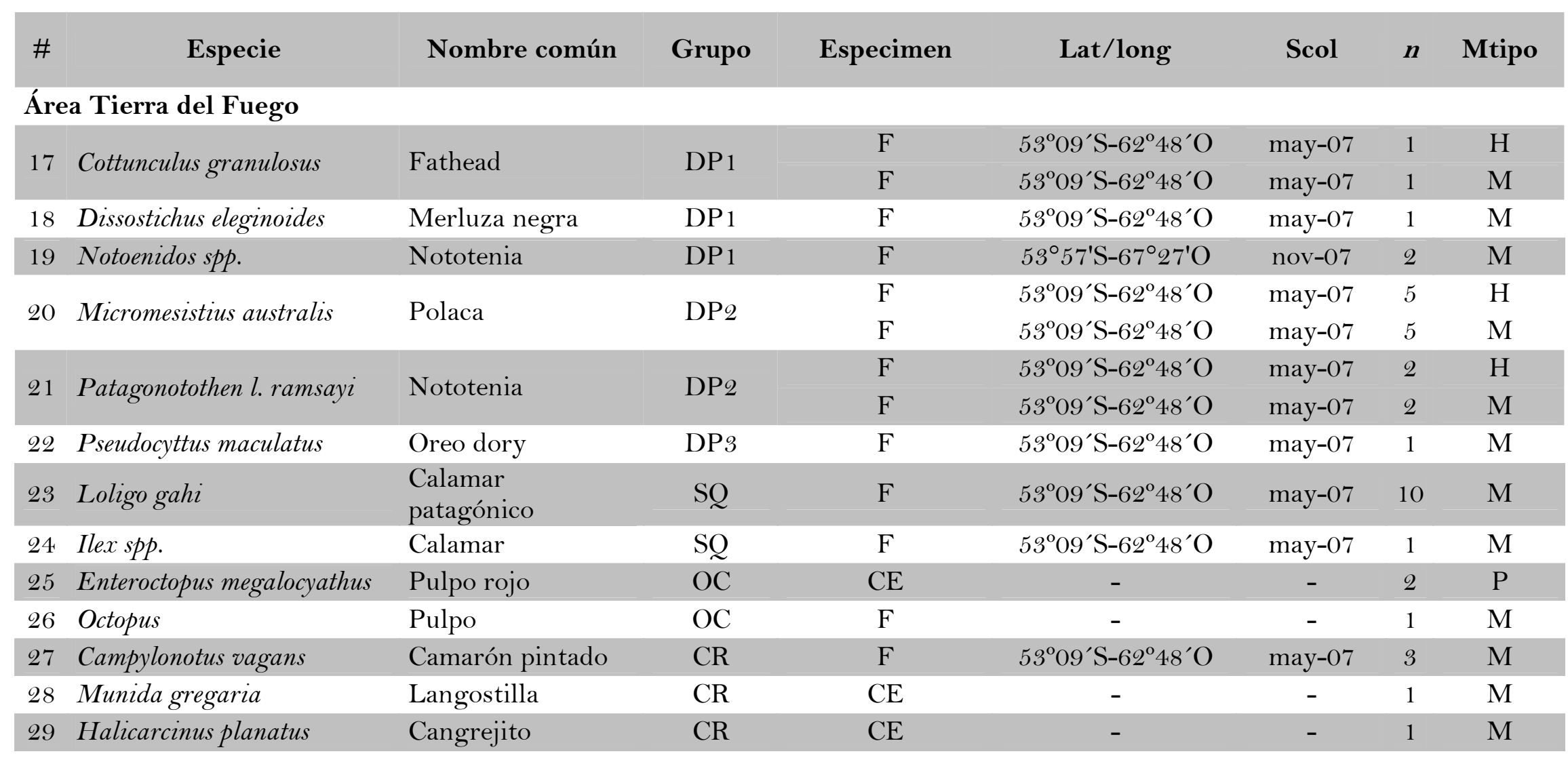




\section{Tabla 3. continuación}

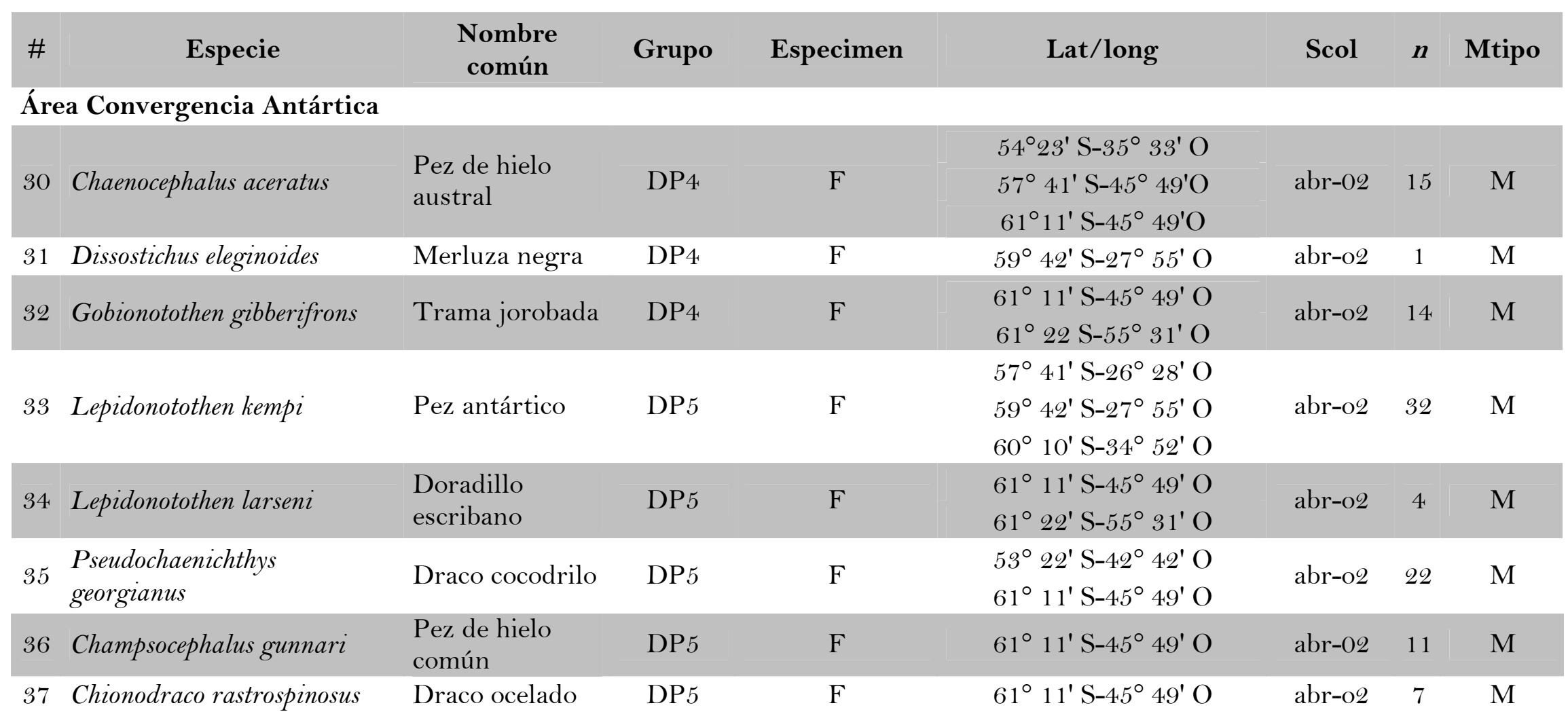




\section{CAPÍtTULO 3}

\section{RESUltados GENERALES}

\subsection{INTEGRIDAD DE LAS MUESTRAS}

Siguiendo los parámetros analizados para determinar la calidad y la preservación de las muestras óseas y evaluar el procedimiento llevado a cabo, el colágeno del hueso de los cetáceos se encuentra bien preservado. En total se recuperó un $22 \%$ ( $\pm 3,3 \mathrm{DE})$ de colágeno del hueso de los cetáceos con valores medios entre 20,5\% y 23,9\% entre las diferentes especies, resultando ser una cantidad de colágeno normal para proteína pura (Ambrose 1990). Los valores de $\mathrm{C} / \mathrm{N}$ se encontraron dentro del rango aceptable, con una media total de $2,9( \pm 0,1$ DE) y medias por especies que variaron entre 2,8 y 2,9 (Tabla 4) (Capítulo 2, sección 2.3.3). Las muestras de presas también mostraron valores de $\mathrm{C} / \mathrm{N}$ dentro del rango aceptable, con una media total de $3,2( \pm 0,5 \mathrm{DE})$ y una media por especies que varió entre 2,6 y 6,4 (Tabla 5).

A su vez, la repetición del análisis del estándar (acetanilo) para el carbono y nitrógeno, mostró una buena reproductibilidad, con una desviación estándar $<0,2 \%$ o para ambos valores de $\delta^{13} \mathrm{C}$ y $\delta{ }^{15} \mathrm{~N}$, evidenciando la precisión de los instrumentos que resultan confiables en los valores isotópicos determinados.

\subsection{VARIACIÓN ISOTÓPICA DE LAS PRESAS}

En el presente trabajo se colectaron y analizaron un total de 300 individuos presa correspondientes a 37 especies (Tabla 5). A su vez, se compararon los resultados obtenidos con valores de isótopos estables de presas colectadas en otros sectores de las aguas Patagónicas (Forero et al. 2004, Lewis et al. 2006, Ciancio et al. 2008, Drago et al. 2009). En la Tabla 5 se presentan los datos isotópicos de las posibles especies presas analizadas. Para la evaluación de las fuentes tróficas de los cetáceos se utilizan valores isotópicos medios para cada grupo de presas consideradas. En la Figura 6 se presentan en forma separada los valores de $\delta^{13} \mathrm{C}$ y 
$\delta^{15} \mathrm{~N}$ de los grupos de presa. Ambos sistemas isotópicos son graficados en forma conjunta para la correcta interpretación de los patrones existentes en la información isotópica aportada por estos recursos en la Figura 7.

En las figuras 6 y 7 los valores isotópicos de las presas se muestran corregidos por la discriminación trófica para permitir la comparación directa entre los datos isotópicos de los consumidores y sus potenciales fuentes alimentarias (Capítulo 2, sección 2.2.4). Los valores isotópicos de las presas varían desde $-23,8 \%$ a $-9,2 \%$ o para $\delta^{13} \mathrm{C}$ y de $2,4 \%$ a $18,6 \%$ para $\delta^{15} \mathrm{~N}$. La comparación de los 7 grupos de presas analizados mostró diferencias significativas en $\delta^{13} \mathrm{C}(\mathrm{K}-\mathrm{W}, \mathrm{P}<0,0001)$ y $\delta^{15} \mathrm{~N}(\mathrm{~K}-$ $\mathrm{W}, \mathrm{P}<0,0001)$. Las presas costeras pelágicas $(\mathrm{CP})$ y demerso-pelágicas (DP) se dividieron en dos $(\mathrm{CP} 1, \mathrm{CP} 2)$ y cinco $(\mathrm{DP} 1, \mathrm{DP} 2, \mathrm{DP} 3, \mathrm{DP} 4, \mathrm{DP} 5)$ grupos, por diferencias significativas entre sus medias, lo que incrementó el número original de grupos presas de 7 a 12. En la Figura 6 se observa una declinación en ambos valores isotópicos, desde presas costeras hacia las más oceánicas. Al graficar ambos sistemas isotópicos $\left(\boldsymbol{\delta}^{13} \mathrm{C}\right.$ y $\left.\delta^{15} \mathrm{~N}\right)$ se muestra una mejor discriminación de los grupos presas costeras, de plataforma/talud y de regiones oceánicas (Figura 7). Las presas costeras-bentónicas $(\mathrm{CB})$ presentan los valores más altos en $\delta^{13} \mathrm{C}$ y $\delta^{15} \mathrm{~N}$, mientras que el grupo del zooplancton $(\mathrm{ZP})$ presenta los valores más bajos para el $\delta^{15} \mathrm{~N}$. Las especies pelágicas $(\mathrm{CP})$ y demerso-pelágicas (DP1 y DP2), incluyendo también a los calamares (SQ), los pulpos (OC) y crustáceos (CR), presentan valores intermedios, mientras que las especies demerso-pelágicas consideradas de regiones oceánicas (DP3, DP4 y DP5) muestran los valores más bajos en $\delta^{13} \mathrm{C}$ y $\delta^{15} \mathrm{~N}$.

Específicamente se encontró una diferencia de $+1,1 \%$ y $+5,2 \%$ en los valores de $\delta^{13} \mathrm{C}$ entre los grupos costeros con respecto a los grupos presa de áreas de plataforma/talud y regiones oceánicas, respectivamente, y una diferencia de $+4,0 \%$ o entre las dos últimas. Para los valores de $\delta^{15} \mathrm{~N}$, también se encontraron diferencias de $+0,5 \%$ o y $+3,9 \%$ o entre el grupo costero con respecto a las presas de áreas de plataforma/talud y oceánicas, respectivamente, y una diferencia de $+3,4 \%$ ontre las dos últimas. Debido al desvío que presentan los valores isotópicos del zooplancton (ZP) y de crustáceos (CR) con respecto al resto de los grupos presa no fueron utilizados para la distinción de los hábitats de la región. Los pulpos (OC) se consideraron dentro del grupo costero y los calamares (SQ) dentro del grupo de plataforma. 
Tabla 4. Composición isotópica del colágeno del hueso de los cetáceos analizados

ID = sigla identificatoria de la especie, $\mathrm{n}=$ número de especimenes analizados, $\mathrm{LN}=$ latitud norte, $\mathrm{LS}=$ latitud sur valores medios de $\delta^{13} \mathrm{C}$ y $\delta^{15} \mathrm{~N}( \pm \mathrm{DE} \%$ ), proporción de $\mathrm{C} / \mathrm{N}$ de cada especie y ecotipo (GG1 y GG2), nivel trófico (NT) estimado, área de forrajeo $(\mathrm{AF})$ y dieta determinada mediante el análisis de isótopos estables de carbono y nitrógeno.

\begin{tabular}{|c|c|c|c|c|c|c|c|c|}
\hline Especie & ID & $\mathbf{n}$ & $\boldsymbol{\delta}^{13} \mathrm{C}( \pm \mathrm{DE})$ & $\boldsymbol{\delta}^{15} \mathbf{N}( \pm \mathrm{DE})$ & $\mathrm{C} / \mathrm{N}$ & NT & AF & Dieta \\
\hline \multicolumn{9}{|l|}{ Delphinidae } \\
\hline Cephalorhynchus commersonii & $\mathrm{CC}$ & 121 & $-12,7(1,3)$ & $17,2(0,7)$ & 2,9 & 4,9 & costero/plataforma & ictiófago \\
\hline \multirow[t]{3}{*}{ Grampus griseus } & GG & 48 & & & & & & \\
\hline & ecotipo GG 1 & $(23)$ & $-11,6(0,5)$ & $19,5(1,3)$ & 2,8 & 4,1 & talud continental $(\mathrm{LN})$ & teutófago - ictiófago \\
\hline & ecotipo GG2 & $(25)$ & $-13,9(0,9)$ & $15,5(1,4)$ & 2,9 & 4,4 & talud continental (LS) & teutófago - ictiófago \\
\hline Lagenorhynchus australis & LA & 39 & $-10,8(1,2)$ & $19,3(1,6)$ & 2,8 & 5,5 & costero & ictiófago \\
\hline L. cruciger & $\mathrm{LC}$ & 5 & $-17,2(1,0)$ & $10,2(0,8)$ & 2,8 & nd & oceánico (LS) & nd \\
\hline Lissodelphis peronii & LP & 37 & $-12,9(0,9)$ & $15,3(2,4)$ & 2,8 & 4,3 & talud continental & teutófago - ictiófago \\
\hline Pseudorca crassidens & PS & 27 & $-12,8(0,4)$ & $13,1(0,7)$ & 2,8 & 3,7 & talud continental & teutófago \\
\hline \multicolumn{9}{|l|}{ Phocoenidae } \\
\hline Phocoena dioptrica & $\mathrm{PD}$ & 87 & $-17,9(1,2)$ & $10,1(0,9)$ & 2,9 & nd & oceánico (LS) & nd \\
\hline P. spinipinnis & PS & 7 & $-13,0(1,0)$ & $17,9(0,7)$ & 2,9 & 5,1 & costero/plataforma & ictiófago \\
\hline
\end{tabular}


Tabla 5. Composición isotópica de especies presas

Valores de isótopos estables de carbono $\left(\boldsymbol{\delta}^{13} \mathrm{C}\right)$ y nitrógeno $\left(\boldsymbol{\delta}^{15} \mathrm{~N}\right)$ de muestras de hueso $(\mathrm{H})$, músculo $(\mathrm{M})$ y picos $(\mathrm{P})$ de posibles presas de cetáceos del Atlántico sudoccidental. \# número de especie. Grupo: peces demerso-pelágicos (DP1, DP2, DP3, DP4, DP5), peces costero-bentónicos $(\mathrm{CB})$, peces costero-pelágicos (CP1, CP2), calamares (SQ), pulpos (OC), crustáceos (CR) y zooplancton (ZP). Medias de $\delta^{13} \mathrm{C}$ y $\delta^{15} \mathrm{~N}$ y desvío estándar ( $\pm \mathrm{DE} \%$ ), proporción de $\mathrm{C} / \mathrm{N}$, número (n) y tipo de muestras (Mtipo), nd = no disponible Datos isotópicos obtenidos en esta Tesis y de Ciancio et al. (2008).

\begin{tabular}{|c|c|c|c|c|c|c|c|c|c|c|c|}
\hline \multirow{2}{*}{$\#$} & \multirow{2}{*}{ Especies } & \multirow{2}{*}{$\begin{array}{l}\text { Nombre } \\
\text { común }\end{array}$} & \multirow{2}{*}{ Grupo } & \multicolumn{2}{|c|}{$\delta^{13} \mathrm{C}(\% o)$} & \multicolumn{2}{|c|}{$\delta^{15} \mathbf{N}(\% o)$} & \multirow{2}{*}{$\mathrm{C} / \mathrm{N}$} & \multirow{2}{*}{$\mathbf{n}$} & \multirow{2}{*}{ Mtipo } & \multirow{2}{*}{ Referencia } \\
\hline & & & & Media & $\pm \mathrm{DE}$ & Media & $\pm \mathrm{DE}$ & & & & \\
\hline \multicolumn{12}{|c|}{ Área Tierra del Fuego } \\
\hline 1 & Bathyraja macloviana & Raya & $\mathrm{CB}$ & $-23,8$ & 0,5 & 9,2 & 0,1 & 3,2 & 7 & M & Esta Tesis \\
\hline \multirow{4}{*}{2} & \multirow{4}{*}{ Eleginops maclovinus } & \multirow{4}{*}{ Róbalo } & \multirow{4}{*}{$\mathrm{CB}$} & $-15,4$ & nd & 13,9 & nd & 2,9 & 1 & $\mathrm{H}$ & Esta Tesis \\
\hline & & & & $-17,2$ & 0,8 & 15,1 & 0,6 & 3,1 & 2 & M & Esta Tesis \\
\hline & & & & $-12,9$ & 1,4 & 18,0 & 0,5 & 3,1 & 7 & M & Esta Tesis \\
\hline & & & & $-14,9$ & 0,3 & 17,2 & 0,4 & - & 6 & $\mathrm{M}$ & Ciancio et al. (2008) \\
\hline \multirow{3}{*}{3} & \multirow{3}{*}{ Zoarcidos } & \multirow{3}{*}{ Zoarcidos } & \multirow{3}{*}{$\mathrm{CB}$} & $-9,2$ & 1,1 & 17,5 & 0,2 & 3,1 & 3 & $\mathrm{H}$ & Esta Tesis \\
\hline & & & & $-10,4$ & 0,9 & 18,1 & 0,2 & 3,1 & 3 & $\mathrm{M}$ & Esta Tesis \\
\hline & & & & $-12,5$ & 0,8 & 18,6 & 0,5 & 3,5 & 5 & M & Esta Tesis \\
\hline \multirow{3}{*}{4} & \multirow{3}{*}{ Patagonotothem spp. } & \multirow{3}{*}{ Nototenia } & \multirow{3}{*}{$\mathrm{CB}$} & $-11,6$ & 0,3 & 17,5 & 0,7 & 3,3 & 3 & $\mathrm{H}$ & Esta Tesis \\
\hline & & & & $-11,7$ & 0,8 & 18,0 & 0,5 & 3,3 & 14 & $\mathrm{M}$ & Esta Tesis \\
\hline & & & & $-15,5$ & 0,5 & 17,3 & 1,0 & 3,2 & 4 & M & Esta Tesis \\
\hline 5 & Patagonotothen spp & Nototenia & $\mathrm{CB}$ & $-12,8$ & 3,2 & 16,3 & 1,1 & 3,0 & 5 & $\mathrm{H}$ & Esta Tesis \\
\hline 6 & Patagonotothen sima & Nototenia & $\mathrm{CB}$ & $-12,5$ & 2,0 & 15,7 & 0,5 & 2,8 & 2 & $\mathrm{H}$ & Esta Tesis \\
\hline
\end{tabular}


Tabla 5. Continuación

\begin{tabular}{|c|c|c|c|c|c|c|c|c|c|c|c|}
\hline \multirow{2}{*}{$\#$} & \multirow{2}{*}{ Especies } & \multirow{2}{*}{$\begin{array}{l}\text { Nombre } \\
\text { común }\end{array}$} & \multirow{2}{*}{ Grupo } & \multicolumn{2}{|c|}{$\delta^{13} \mathrm{C}(\%$ oo) } & \multicolumn{2}{|c|}{$\delta^{15} \mathbf{N}(\%)$} & \multirow{2}{*}{$\mathbf{C} / \mathbf{N}$} & \multirow{2}{*}{$\mathbf{n}$} & \multirow{2}{*}{ Mtipo } & \multirow{2}{*}{ Referencia } \\
\hline & & & & Media & $\pm \mathrm{DE}$ & Media & $\pm \mathrm{DE}$ & & & & \\
\hline \multicolumn{12}{|c|}{ Área Tierra del Fuego } \\
\hline 7 & $\begin{array}{l}\text { Patagonotothen } \\
\text { tessellata }\end{array}$ & Nototenia & $\mathrm{CB}$ & $-15,2$ & 1,9 & 16,4 & 0,6 & 3,4 & 3 & $\mathrm{H}$ & Esta Tesis \\
\hline \multirow{4}{*}{8} & \multirow{4}{*}{ Odonthestes spp. } & \multirow{4}{*}{ Pejerreyes } & \multirow{4}{*}{$\mathrm{CP}_{1}$} & $-12,8$ & 0,4 & 15,2 & 1,3 & 3,0 & 8 & $\mathrm{H}$ & Esta Tesis \\
\hline & & & & $-13,9$ & 1,0 & 15,7 & 1,6 & 3,2 & 6 & M & Esta Tesis \\
\hline & & & & $-15,3$ & 0,5 & 17,3 & $\mathrm{O}, 1$ & 3,2 & 5 & M & Esta Tesis \\
\hline & & & & $-14,0$ & 0,8 & 16,7 & 0,2 & nd & 6 & M & Ciancio et al. (2008) \\
\hline \multirow{2}{*}{9} & \multirow{2}{*}{ Sprattus fuegensis } & \multirow{2}{*}{$\begin{array}{l}\text { Sardina } \\
\text { fueguina }\end{array}$} & \multirow{2}{*}{$\mathrm{CP}_{2}$} & $-15,0$ & 0,9 & 14,5 & 1,0 & 3,1 & 10 & $\mathrm{H}$ & Esta Tesis \\
\hline & & & & $-20,2$ & 1,0 & 13,1 & 0,9 & nd & 25 & M & Ciancio et al. (2008) \\
\hline & \multirow{3}{*}{ Merluccius hubbsi } & \multirow{3}{*}{ Merluza común } & \multirow{3}{*}{$\mathrm{DP}_{1}$} & $-14,6$ & 1,0 & 16,8 & 1,3 & 2,9 & 3 & $\mathrm{H}$ & Esta Tesis \\
\hline & & & & $-16,6$ & 0,2 & 17,7 & 0,3 & 3,2 & 3 & M & Esta Tesis \\
\hline & & & & $-18,2$ & 0,9 & 17,0 & 0,1 & nd & 6 & $\mathrm{M}$ & Ciancio et al. (2008) \\
\hline \multirow{3}{*}{\multicolumn{2}{|c|}{11 Merluccius australis }} & \multirow{3}{*}{ Merluza austral } & \multirow{3}{*}{$\mathrm{DP}_{1}$} & $-14,0$ & 0,7 & 16,8 & 1,0 & 2,8 & 14 & $\mathrm{H}$ & Esta Tesis \\
\hline & & & & $-15,9$ & 0,5 & 17,7 & 0,7 & 3,1 & 14 & $\mathrm{M}$ & Esta Tesis \\
\hline & & & & $-17,4$ & 1,0 & 15,6 & 0,6 & nd & 3 & $\mathrm{M}$ & Ciancio et al. (2008) \\
\hline \multirow{3}{*}{\multicolumn{2}{|c|}{12 Salilota australis }} & \multirow{3}{*}{ Bacalao criollo } & \multirow{3}{*}{$\mathrm{DP}_{1}$} & $-13,6$ & 0,6 & 15,8 & 0,6 & 2,8 & 8 & $\mathrm{H}$ & Esta Tesis \\
\hline & & & & $-16,9$ & 0,7 & 15,9 & 0,4 & 3,1 & 8 & M & Esta Tesis \\
\hline & & & & $-17,7$ & 0,2 & 15,3 & 0,3 & nd & 3 & M & Ciancio et al. (2008) \\
\hline
\end{tabular}


Tabla 5. Continuación

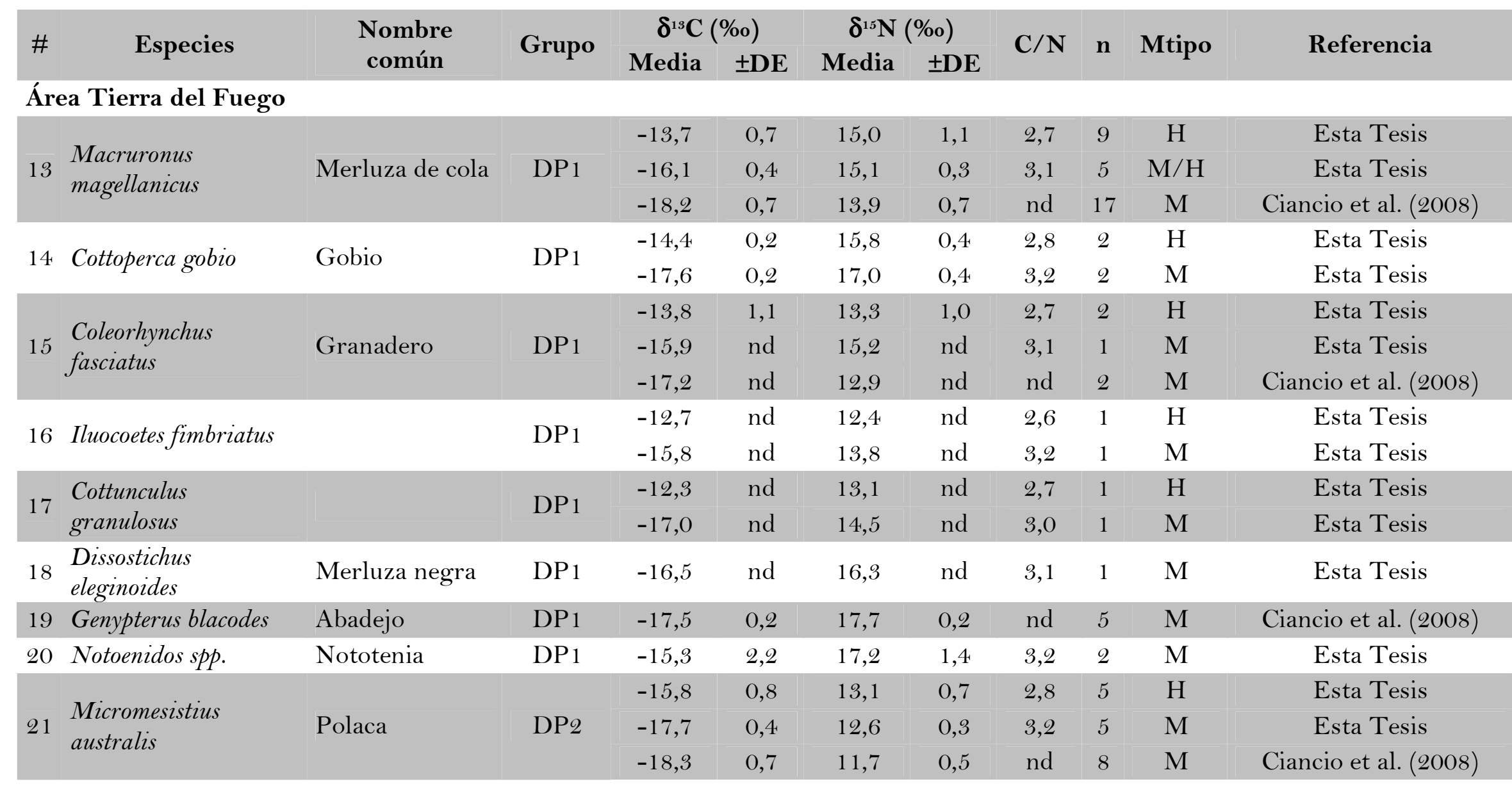


Tabla 5. Continuación

\begin{tabular}{|c|c|c|c|c|c|c|c|c|c|c|c|}
\hline \multirow{2}{*}{$\#$} & \multirow{2}{*}{ Especies } & \multirow{2}{*}{ Nombre común } & \multirow{2}{*}{ Grupo } & \multicolumn{2}{|c|}{$\delta^{13} \mathrm{C}(\%)$} & \multicolumn{2}{|c|}{$\delta^{15} \mathbf{N}(\% o)$} & \multirow{2}{*}{$\mathrm{C} / \mathrm{N}$} & \multirow{2}{*}{$\mathbf{n}$} & \multirow{2}{*}{ Mtipo } & \multirow{2}{*}{ Referencia } \\
\hline & & & & Media & $\pm \mathrm{DE}$ & Media & $\pm \mathrm{DE}$ & & & & \\
\hline \multicolumn{12}{|c|}{ Área Tierra del Fuego } \\
\hline \multirow{3}{*}{22} & \multirow{3}{*}{$\begin{array}{l}\text { Patagonotothen } l . \\
\text { ramsayi }\end{array}$} & \multirow{3}{*}{ Nototenia } & \multirow{3}{*}{$\mathrm{DP} 2$} & $-14,2$ & 0,3 & 13,0 & 0,4 & 2,7 & 2 & $\mathrm{H}$ & Esta Tesis \\
\hline & & & & $-16,9$ & 0,2 & 14,1 & 0,1 & 3,1 & 2 & M & Esta Tesis \\
\hline & & & & $-19,3$ & 0,6 & 14,8 & 1,0 & nd & 5 & M & Ciancio et al. (2008) \\
\hline 23 & Pseudocythus maculatus & & $\mathrm{DP} 3$ & $-19,8$ & nd & 10,3 & nd & 3,2 & 1 & $\mathrm{M}$ & Esta Tesis \\
\hline 24 & Mictophids & Mictófidos & $\mathrm{DP} 3$ & $-21,9$ & 0,7 & 11,7 & 0,9 & nd & 5 & M & Ciancio et al. (2008) \\
\hline \multirow{2}{*}{25} & \multirow{2}{*}{ Loligo gahi } & \multirow{2}{*}{$\begin{array}{l}\text { Calamar } \\
\text { patagónico }\end{array}$} & \multirow{2}{*}{ SQ } & $-17,5$ & 0,3 & 13,3 & 0,5 & 3,2 & 10 & $\mathrm{M}$ & Esta Tesis \\
\hline & & & & $-19,0$ & 0,6 & 13,6 & 0,7 & nd & 10 & M & Ciancio et al. (2008) \\
\hline 26 & Semirrosia tenera & & SQ & $-20,4$ & nd & 12,3 & nd & nd & 1 & M & Ciancio et al. (2008) \\
\hline 27 & Ilex spp. & Calamar & SQ & $-16,6$ & nd & 14,9 & nd & 3,3 & 1 & $\mathrm{M}$ & Esta Tesis \\
\hline 28 & Illex argentinus & Calamar & SQ & $-18,1$ & 0,3 & 13,1 & 0,9 & nd & 12 & $\mathrm{M}$ & Ciancio et al. (2008) \\
\hline 29 & Moroteuthis ingens & Lurión común & SQ & $-18,7$ & 0,4 & 13,5 & 1,1 & nd & 2 & M & Ciancio et al. (2008) \\
\hline 30 & $\begin{array}{l}\text { Enteroctopus } \\
\text { megalocyathus }\end{array}$ & Pulpo rojo & $\mathrm{OC}$ & $-15,9$ & 2,7 & 10,5 & 3,8 & 3,3 & 2 & $\mathrm{P}$ & Esta Tesis \\
\hline 31 & $\begin{array}{l}\text { Enteroctopus } \\
\text { megalocyathus }\end{array}$ & Pulpo rojo & $\mathrm{OC}$ & $-15,2$ & nd & 17,5 & nd & nd & 2 & $\mathrm{M}$ & Ciancio et al. (2008) \\
\hline 32 & Octopus & Pulpo & $\mathrm{OC}$ & $-15,5$ & nd & 13,5 & nd & 3,1 & 1 & M & Esta Tesis \\
\hline 33 & Campylognathus vagans & Camarón & $\mathrm{CR}$ & $-17,2$ & 0,4 & 13,6 & 0,5 & 3,2 & 3 & $\mathrm{M}$ & Esta Tesis \\
\hline
\end{tabular}




\section{Tabla 5. Continuación}

\begin{tabular}{|c|c|c|c|c|c|c|c|c|c|c|}
\hline \multirow{2}{*}{ \# $\quad$ Especies } & \multirow{2}{*}{ Nombre común } & \multirow{2}{*}{ Grupo } & \multicolumn{2}{|c|}{$\delta^{13} \mathrm{C}(\%$ oo) } & \multicolumn{2}{|c|}{$\delta^{15} \mathbf{N}(\%)$} & \multirow{2}{*}{$\mathbf{C} / \mathbf{N}$} & \multirow{2}{*}{$\mathbf{n}$} & \multirow{2}{*}{ Mtipo } & \multirow{2}{*}{ Referencia } \\
\hline & & & Media & $\pm \mathrm{DE}$ & Media & $\pm \mathrm{DE}$ & & & & \\
\hline \multicolumn{11}{|l|}{ Área Tierra del Fuego } \\
\hline \multirow{2}{*}{ 34. Munida gregaria } & \multirow{2}{*}{ Bogavante } & \multirow{2}{*}{$\mathrm{CR}$} & $-16,9$ & nd & 12,2 & nd & 5,2 & 1 & M & Esta Tesis \\
\hline & & & $-16,6$ & 0,4 & 7,9 & 0,7 & nd & 4 & M & Ciancio et al. (2008) \\
\hline 35 Halicarcinus planatus & Cangrejo & $\mathrm{CR}$ & $-16,9$ & nd & 2,4 & nd & 6,4 & 1 & M & Esta Tesis \\
\hline 36 Calanus australis & Copépodos & $\mathrm{ZP}$ & $-20,0$ & 1,8 & 9,27 & 1,1 & nd & 7 & M & Ciancio et al. (2008) \\
\hline 37 Themisto gaudichaudii & Anfípodos & $\mathrm{ZP}$ & $-20,9$ & 1,5 & 10,5 & 1,8 & nd & 17 & M & Ciancio et al. (2008) \\
\hline 38 Euphausia lucens & Eufáusidos & $\mathrm{ZP}$ & $-19,8$ & 0,7 & 7,3 & 0,8 & nd & 7 & M & Ciancio et al. (2008) \\
\hline \multicolumn{11}{|c|}{ Área Convergencia Antártica } \\
\hline 39 Chaenocephalus aceratus & $\begin{array}{l}\text { Pez de hielo } \\
\text { austral }\end{array}$ & $\mathrm{DP}_{4}$ & $-20,0$ & 1,3 & 12,4 & 0,1 & 3,2 & 15 & M & Esta Tesis \\
\hline 40 Dissostichus eleginoides & Merluza negra & $\mathrm{DP} 4$ & $-19,9$ & nd & 13,3 & nd & 3,1 & 1 & M & Esta Tesis \\
\hline 41 Gobionotothen gibberifrons & Trama jorobada & $\mathrm{DP} 4$ & $-19,5$ & 1,8 & 12,6 & 0,1 & 3,2 & 14 & M & Esta Tesis \\
\hline 42 Lepidonotothen kempi & Pez antártico & DP5 & $-23,1$ & 1,0 & 11,6 & 0,3 & 3,3 & 32 & M & Esta Tesis \\
\hline 43 Lepidonotothen larseni & $\begin{array}{l}\text { Doradillo } \\
\text { escribano }\end{array}$ & DP5 & $-22,0$ & 2,6 & 12,4 & 0,0 & 3,3 & 4 & M & Esta Tesis \\
\hline 44. $\begin{array}{l}\text { Pseudochaenichthys } \\
\text { georgianus }\end{array}$ & Draco cocodrilo & DP5 & $-21,7$ & 1,9 & 10,8 & 0,1 & 3,2 & 22 & M & Esta Tesis \\
\hline 45 Champsocephalus gunnari & $\begin{array}{l}\text { Pez de hielo } \\
\text { común }\end{array}$ & DP5 & $-23,5$ & 0,6 & 9,6 & 0,2 & 3,2 & 11 & $\mathrm{M}$ & Esta Tesis \\
\hline 46 Chionodraco rastrospinosus & Draco ocelado & DP5 & $-23,8$ & 0,5 & 9,2 & 0,1 & 3,2 & 7 & $\mathrm{M}$ & Esta Tesis \\
\hline
\end{tabular}



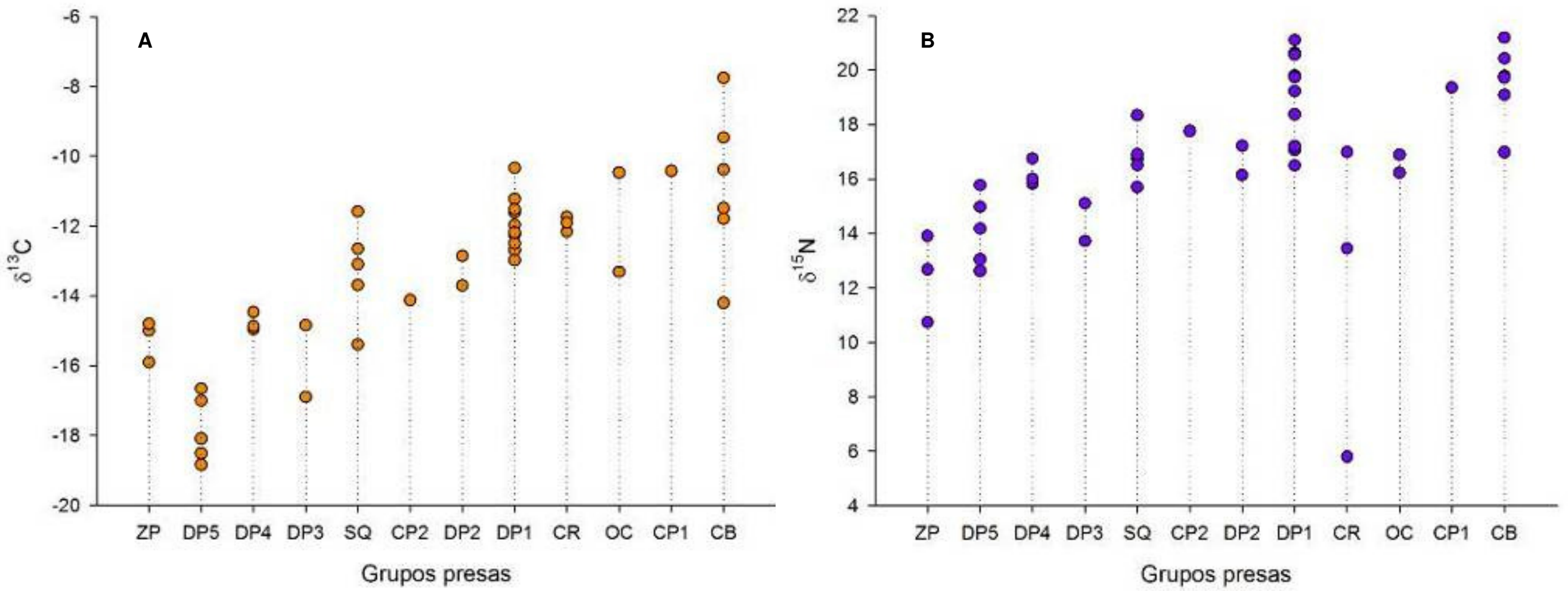

Figura 6. Composición isotópica de grupos de presas del Atlántico Sudoccidental: (A) valores medios de $\delta^{13} \mathrm{C}$. (B) valores medios de $\boldsymbol{\delta}^{15} \mathbf{N}$. Se observa una declinación en $\delta^{13} \mathrm{C}$ y $\boldsymbol{\delta}^{15} \mathrm{~N}$ desde presas costeras hacia las presas más oceánicas. Zooplancton (ZP), peces demersopelágicos neríticos (DP1, DP2), peces demerso-pelágicos oceánicos (DP3, DP4, DP5), calamares (SQ), crustáceos (CR), pulpos (OC), peces costero-pelágicos $(\mathrm{CP} 1, \mathrm{CP} 2)$, peces costero-bentónicos $(\mathrm{CB})$. Los valores se muestran corregidos por la discriminación trófica. 


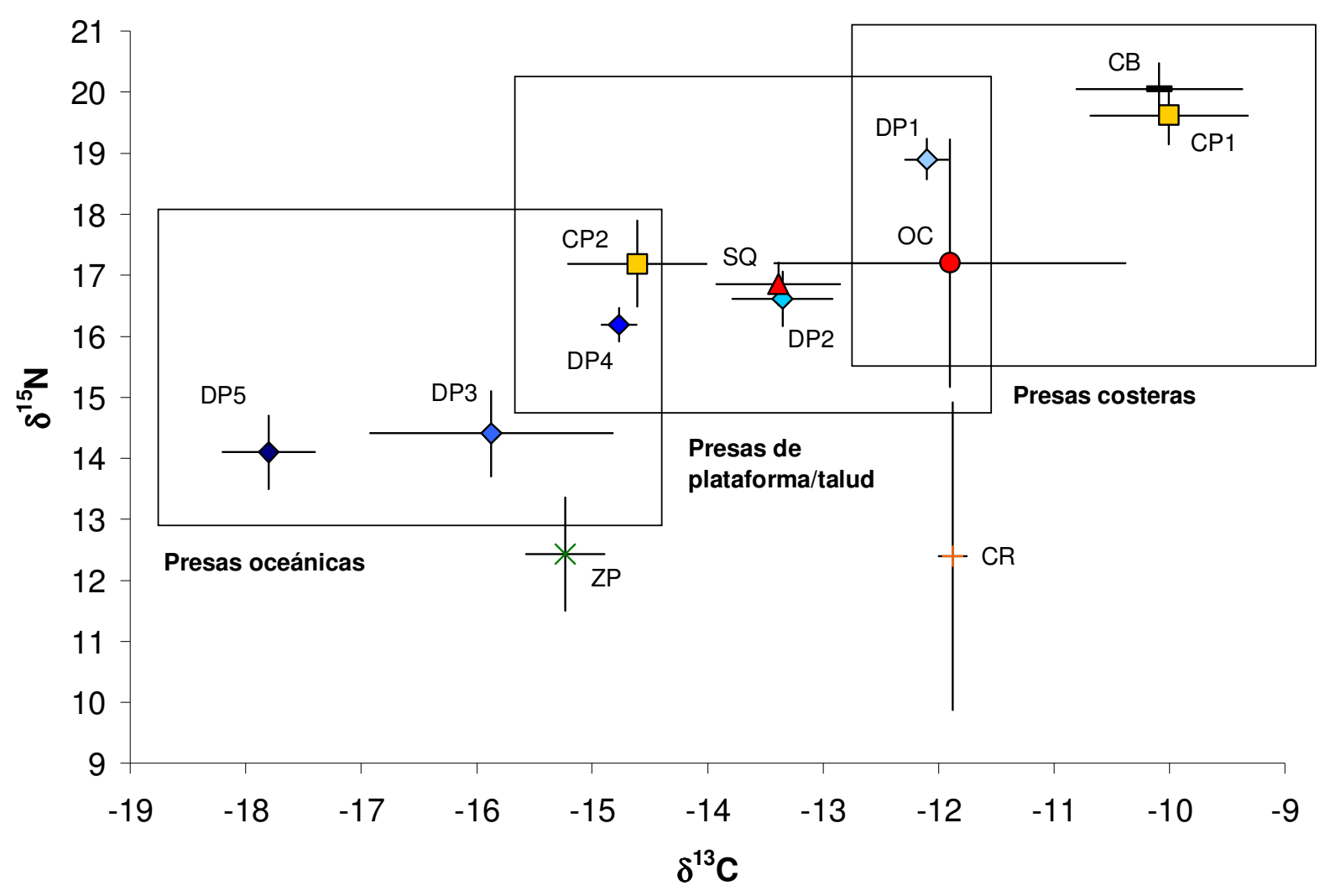

Figura 7. Valores de $\delta^{13} \mathbf{C}$ y $\delta^{15} \mathbf{N}$ ( \pm error estándar) de grupos presa del Atlántico Sudoccidental. La declinación conjunta de ambos valores isotópicos permite definir tres grupos principales de presas que caracterizan distintos hábitats: presas costeras con altos valores de $\delta^{13} \mathrm{C}$ y $\delta^{15} \mathrm{~N}$, presas de plataforma/talud con valores isotópicos intermedios y presas oceánicas con bajos valores. A pesar de que las áreas definidas pueden distinguirse isotópicamente, se observa un solapamiento de las mismas generada por la variabilidad en los valores de $\delta^{13} \mathrm{C}$ y $\delta^{15} \mathrm{~N}$ de los tres grupos principales de presas -costero, plataforma/talud, oceánico-. Grupo costero: peces costero-bentónicos $(\mathrm{CB})$, peces costero-pelágicos $(\mathrm{CP} 1, \mathrm{CP} 2)$ y pulpos (OC). Grupo plataforma/talud: peces demerso-pelágicos plataforma (DP1, DP2) y calamares (SQ). Grupo oceánico: peces demerso-pelágicos oceánicos (DP3, DP4, DP5). El grupo del zooplancton (ZP) y el de crustáceos (CR) no son utilizados para la distinción de los hábitats de la región debido al desvío que presentan con respecto al resto de los grupos. Los valores se muestran corregidos por la discriminación trófica. 


\subsection{VARIACIÓN ISOTÓPICA INTERESPECÍFICA EN LOS CETÁCEOS ESTUDIADOS}

\subsubsection{Resultados del análisis estadístico general}

Se analizó un total de 371 especímenes de cetáceos correspondientes a seis especies de delfínidos y dos especies de marsopas. Cuatro de ellas, Grampus griseus $(\mathrm{n}=48)$, Lageonrhynchus cruciger $(\mathrm{n}=5)$, Lissodelphis peronii $(\mathrm{n}=37)$, y Pseudorca crassidens $(\mathrm{n}=27)$ se consideraron previamente especies de hábitos oceánicos o especies offshore. Las otras tres especies, Cephalorhynchus commersonii $(\mathrm{n}=121)$, Lagenorhynchus australis $(\mathrm{n}=39)$ y Phocoena spinipinnis $(\mathrm{n}=7)$ se consideraron como costeras o inshore. Por último Phocoena dioptrica $(\mathrm{n}=87)$ se ha considerado como especie de hábitos costero-oceánico. Los datos isotópicos para las especies de cetáceos se resumen en la Tabla 4.

La comparación de los valores promedios de los isótopos estables de estas ocho especies de cetáceos mostró diferencias significativas en $\delta^{13} \mathrm{C}(\mathrm{K}-\mathrm{W}, \mathrm{P}<0,0001)$ y $\delta^{15} \mathrm{~N}(\mathrm{~K}-\mathrm{W}, \mathrm{P}<0,0001)$ (Figura 8); con un alto grado de variación inter-específica, con valores desde $-22,8 \%$ a $-6,7 \%$ para $\delta^{13} \mathrm{C}$ y de $7,6 \%$ a $22,1 \%$ o para $\delta^{15} \mathrm{~N}$. Los valores más altos de $\delta^{13} \mathrm{C}$ y $\delta^{15} \mathrm{~N}$ pertenecen a $L$. australis, una especie costera. Se encontró diferencias significativas entre L. australis y el resto de las especies en los valores de $\delta^{13} \mathrm{C}$ y $\delta^{15} \mathrm{~N}$ (Test-U, $\left.\mathrm{P}<0,05\right)$. Otras dos especies costeras, $C$. commersonii y P. spinipinnis, presentan valores de $\delta^{13} \mathrm{C}$ y $\delta^{15} \mathrm{~N}$ entre L. australis y los predadores offshore (G. griseus, L. peronii y P. crassidens).

Los valores más bajos de $\delta^{13} \mathrm{C}$ y $\delta^{15} \mathrm{~N}$ corresponden a L. cruciger y $P$. dioptrica, dos especies que habitan aguas offshore, observados comúnmente en aguas de la Convergencia Antártica localizada entre los $50^{\circ} \mathrm{S}$ y $60^{\circ} \mathrm{S}$. No se encontraron diferencias significativas en los valores de $\delta^{13} \mathrm{C}$ y $\delta^{15} \mathrm{~N}$ entre L. cruciger y $P$. dioptrica (Test-U, $\mathrm{P}=0,2182$ y $\mathrm{P}=0,8363$; respectivamente), pero éstas especies difirieron significativamente del resto en ambos valores isotópicos (Test-U, $\mathrm{P}<0,05)$.

Entre los habitantes offshore, las evaluaciones de stock sugieren la existencia de una única población de G. griseus que habita el Atlántico Sudoccidental, sin embargo, los datos de isótopos estables de carbono y nitrógeno revelan una distribución bimodal (Figura 9). Por lo tanto, se ha tratado a G. griseus como dos ecotipos separados (GG1 y GG2) con medias significativamente diferentes en los 
valores de $\delta^{13} \mathrm{C}$ y $\delta^{15} \mathrm{~N}$ (Test-U, $\left.\mathrm{P}<0,05\right)$ (sección 3.4.1). En general, estos dos ecotipos fueron significativamente diferentes de otras especies tanto en $\delta^{13} \mathrm{C}$ y $\delta^{15} \mathrm{~N}$ (Test-U, P < 0,05), con algunas excepciones. Se encontró que el ecotipo GG1 tiene valores de $\delta^{15} \mathrm{~N}$ similares a $L$. australis (Test-U, $\mathrm{P}=0,7430$ ), mientras que GG2 presenta valores de $\quad \delta^{13} \mathrm{C} \quad$ y $\quad \delta^{15} \mathrm{~N}$ similares a $\quad P$. spinipinnis y $L$. peronii respectivamente (U-Test, $\mathrm{P}>0,05)$.

No se evidenciaron diferencias significativas en los valores de $\delta^{13} \mathrm{C}$ entre $C$. commersonii y $P$. spinipinnis (Test-U, $\mathrm{P}=0,4825$ ), si bien ambas difirieron significativamente en $\delta^{15} \mathrm{~N}$ (Test-U, $\left.\mathrm{P}=0,0266\right)$. Tampoco se encontraron diferencias significativas entre L. peronii y P. crassidens en los valores de $\delta^{13} \mathrm{C}$ (Test$\mathrm{U}, \mathrm{P}=0,77)$, pero sí en $\delta^{15} \mathrm{~N}$ (Test-U, $\left.\mathrm{P}=0,0000\right)$.

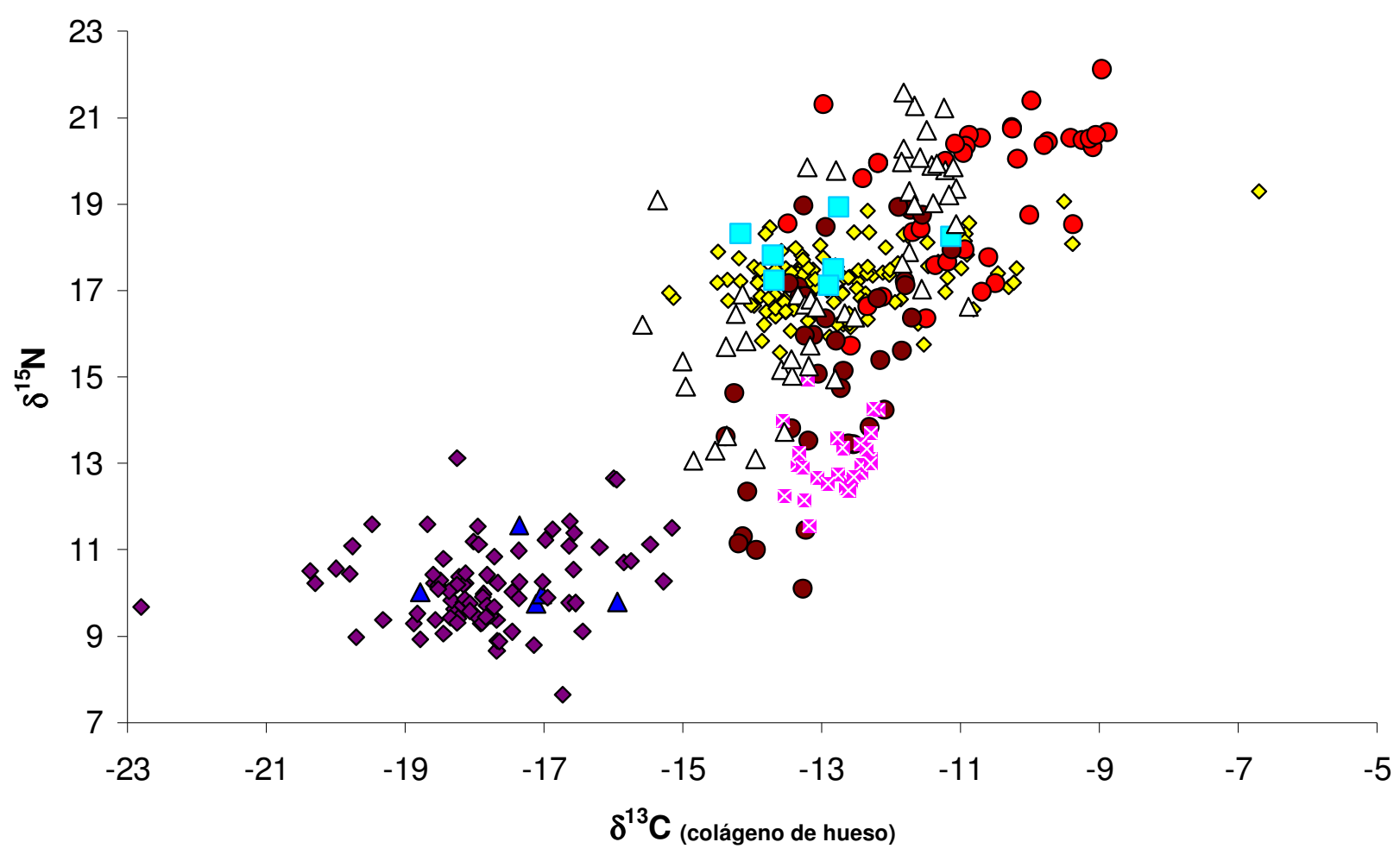

Figura 8. Valores de $\delta^{13} \mathrm{C}$ y $\delta^{15} \mathrm{~N}$ del colágeno del hueso de los cetáceos analizados. Cephalorhynchus commersonii $(\diamond)$, Grampus griseus $(\Delta)$, Lagenorhynchus australis $(\bullet)$, Lagenorhynchus cruciger $(\mathbf{\Delta})$, Lissodelphis peronii $(\bullet)$, Pseudorca crassidens $(\mathbf{\nabla})$, Phocoena dioptrica $(\diamond)$ y Phocoena spinipinnis $(\square)$. 


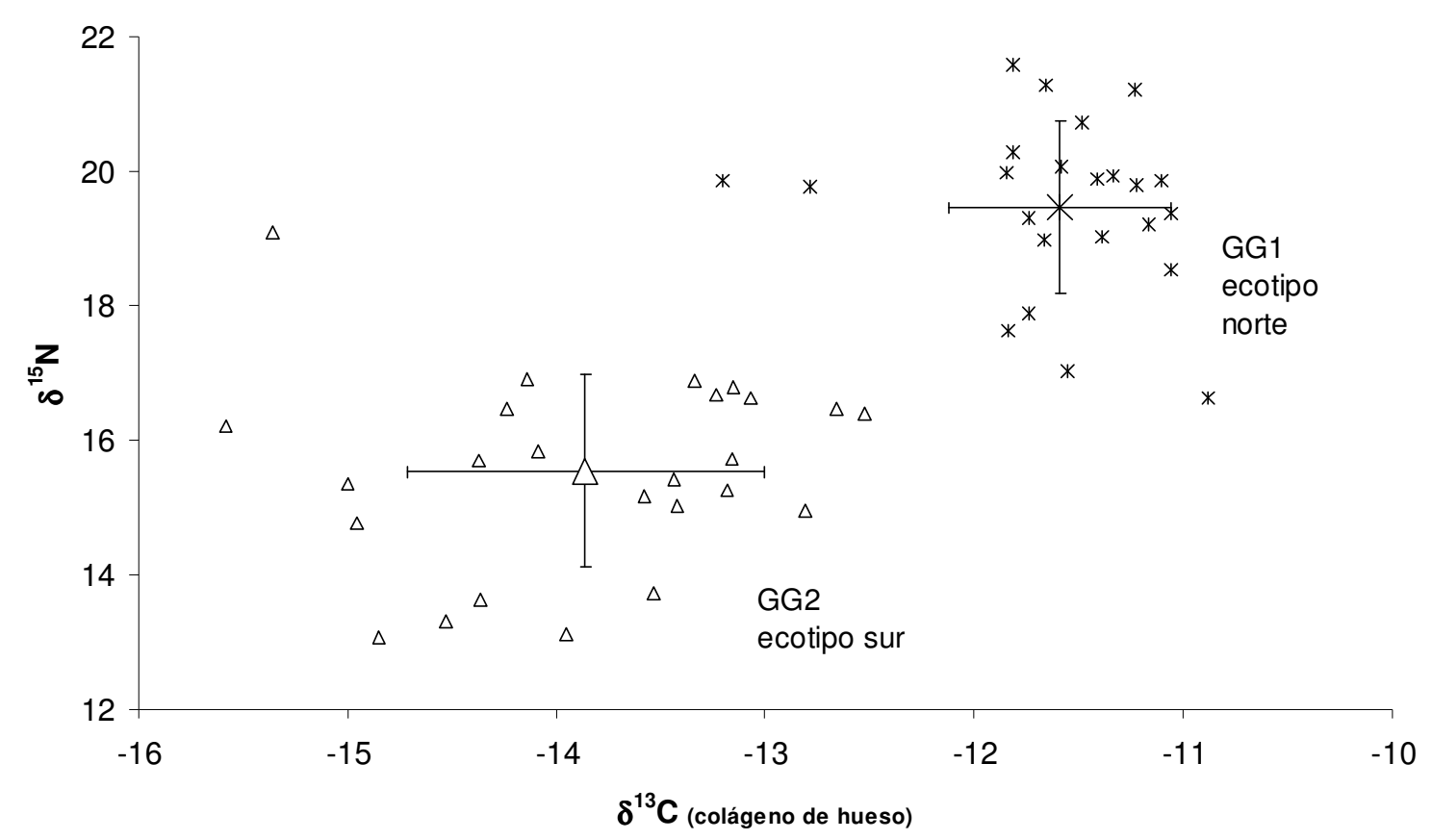

Figura 9. Valores de $\delta^{13} \mathrm{C}$ y $\boldsymbol{\delta}^{15} \mathrm{~N}$ del colágeno del hueso de los ecotipos de Grampus griseus. GG1 (*) ecotipo norte y GG2 $(\Delta)$ ecotipo sur. Ambos ecotipos son considerados predadores offshore que habitan el talud continental con movimientos hacia aguas de plataforma, pero a diferentes latitudes. Se muestran los valores para cada individuo y los valores medios ( \pm desvío estándar) de cada ecotipo.

\subsubsection{Análisis de cluster}

A partir del análisis de cluster (grupo más cercano - Nearest neighbor) se identificaron cuatro grupos entre las especies de cetáceos usando los valores de $\delta^{13} \mathrm{C}$ y $\delta^{15} \mathrm{~N}$ (Figura 10). No se registraron diferencias entre el método de cluster y la distancia métrica utilizada (distancia euclideana) y otros algoritmos de cluster. Si bien el análisis de cluster muestra un continuo isotópico desde especies costeras (Lagenorhynchus australis) con los valores más altos de $\delta^{13} \mathrm{C}$ y $\delta^{15} \mathrm{~N}$ hacia especies oceánicas con los valores isotópicos más bajos (Lagenorhynchus cruciger y Phocoena dioptrica), es posible identificar cuatro grupos de especies: (1) especies costeras ( $L$. australis y posiblemente el ecotipo norte GG1 de Grampus griseus), (2) especies costeras-de plataforma (Cephalorhynchus commersonii y Phocoena spinipinnis), (3) especies de plataforma-talud continental (ecotipo GG2 de G. griseus, Lissodelphis peronii y Pseudorca crassidens) y (4) especies oceánicas y de aguas frías (L. cruciger y $P$. dioptrica). Debido a la ubicación espacial y jerárquica de los grupos observados 
(Figura 10), los grupos 1 y 2 (con excepción de GG1) se consideran como especies inshore y los grupos 3 y 4 como especies offshore.

En el presente trabajo se registró una diferencia de $\sim 2,0 \%$ en los valores de $\delta^{13} \mathrm{C}$ entre las especies costeras (grupo 1) y las especies costeras-de plataforma (grupo 2), y una diferencia de 2,4\%o entre el grupo 1 y las especies de plataformatalud (grupo 3). Las especies oceánicas (grupo 4) mostraron las mayores diferencias en los valores de $\delta^{13} \mathrm{C}$, teniendo valores promedios de $\delta^{13} \mathrm{C}$ de $6,8 \%$, 4,7\%o y 4,4\%o más bajos que los grupos 1, 2 y 3 respectivamente.

También se observaron diferencias en los valores de $\delta^{15} \mathrm{~N}$ de $\sim 2,0 \%$ entre el grupo 1 y 2. Diferencias incluso mayores de $\sim 5,0 \%$ entre el grupo 1 y 3. Finalmente, las diferencias isotópicas más grandes se encuentran al consideraron las variaciones longitudinales y latitudinales, con diferencias de hasta $9,1 \%$, 7,4\%o, y 4,5\% en los valores de $\delta^{15} \mathrm{~N}$ entre el grupo 4 y los grupos 1, 2 y 3. 


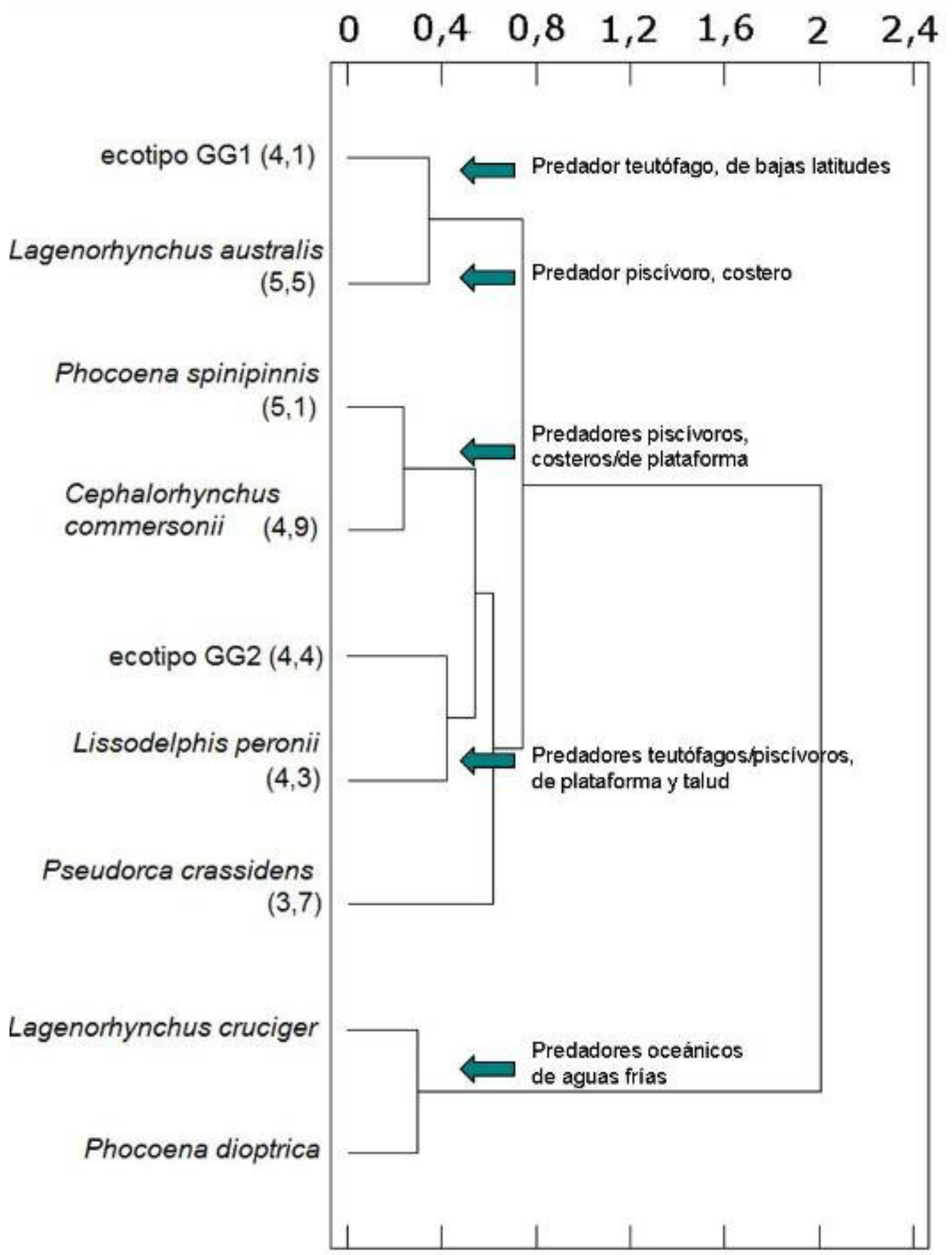

Figura 10: Análisis de cluster (vecino más cercano y distancias euclideanas) para las especies de cetáceos. Lagenorhynchus australis, Phocoena spinipinnis, Cephalorhynchus commersonii, Lissodelphis peronii, Pseudorca crassidens, Lagenorhynchus cruciger y Phocoena dioptrica y los ecotipos de Grampus griseus (GG1 y GG2). Se muestra el nivel trófico (NT) estimado en paréntesis, excepto para L. cruciger y $P$. dioptrica por falta de valores isotópicos de posibles presas o de organismos ubicados en la base de la red trófica donde se alimentan. 


\subsubsection{Niveles tróficos y varianza isotópica}

Los niveles tróficos estimados mediante la ecuación [2] (Capítulo 2, sección 2.2.5.2.2) variaron desde 3,7 a 5,5 (Tabla 4). Se calculó el nivel trófico para seis especies. No se pudo estimar los niveles tróficos para Phocoena dioptrica y Lagenorhynchus cruciger por carecer de valores isotópicos adecuados de sus posibles ítems presa o productores primarios de las zonas donde generalmente se alimentan. Para el caso especial del ecotipo GG1 se utilizaron valores de isótopos estables de la base de redes tróficas de Patagonia norte (Forero et al. 2004), por considerar a este grupo habitante de aguas de latitudes más bajas que el resto de los especímenes analizados (sección 3.4.1).

Se compararon las varianzas isotópicas y los niveles tróficos entre las especies de los grupos identificados en el análisis de cluster. No se encontró diferencias interespecíficas en la varianza isotópica para el ${ }^{13} \mathrm{C}(\mathrm{F}=0,6375 ; \mathrm{P}=0,3)$ y ${ }^{15} \mathrm{~N}(\mathrm{~F}=$ 0,9163; $\mathrm{P}=$ 0,5142) entre Cephalorhynchus commersonii y Phocoena spinipinnis, aunque sí se registraron diferencias significativas en el nivel trófico entre estas especies (Utest, $\mathrm{P}=0,0317)$. Esta diferencia debe interpretarse con precaución debido al bajo número de especímenes de P. spinipinnis analizados $(\mathrm{n}=7)$. Se hallaron diferencias significativas en el grado de variación de $\delta^{15} \mathrm{~N}$ entre las tres especies consideradas offshore (ecotipo GG2, Lissodelphis peronii y Pseudorca crassidens). En tal sentido L. peronii presentó un mayor grado de variación en los valores de $\delta^{15} \mathrm{~N}$ con respecto a GG2 y $P$. crassidens $(\mathrm{F}=0,3425, \mathrm{P}=0,0037$ para L. peronii y GG2; $\mathrm{F}=0,0892, \mathrm{P}=$ 0,0000 para L. peronii y P. crassidens). A su vez, el ecotipo GG2 también mostró mayor variación en $\delta^{15} \mathrm{~N}$ que $P$. crassidens $(\mathrm{F}=0,2604, \mathrm{P}=0,0006)$. Por otra parte, se hallaron diferencias significativas en el grado de variación de $\delta^{13} \mathrm{C}$ entre $P$. crassidens y L. peronii o GG2. Asimismo L. peronii y GG2 presentaron un mayor grado de variación en los valores de $\delta^{13} \mathrm{C}$ que $P$. crassidens $(\mathrm{F}=0,2576, \mathrm{P}=0,0003$ para L. peronii y P. crassidens; $\mathrm{F}=0,2484, \mathrm{P}=0,0004$ para GG2 y P. crassidens), aunque no hubo diferencias significativas en la variación de $\delta^{13} \mathrm{C}$ entre GG2 y $L$. peronii $(\mathrm{F}=0,9644, \mathrm{P}=0,4516)$. En cuanto a los niveles tróficos, no se evidenciaron diferencias significativas entre GG2 y L. peronii (U-test, $\mathrm{P}=0,9714$ ), pero sí entre estas especies y $P$. crassidens (U-test, $\mathrm{P}<0,05)$. Finalmente, no hubo diferencias significativas en la varianza de $\delta^{13} \mathrm{C}(\mathrm{F}=0,749, \mathrm{P}=0,4386)$ y $\delta^{15} \mathrm{~N}(\mathrm{~F}=0,702, \mathrm{P}=$ 0,4073) entre $P$. dioptrica y L. cruciger. 


\subsubsection{Modelos de mezcla - IsoSource}

Si bien se estimó la contribución isotópica de diversas presas para tres especies de cetáceos (Lagenorhynchus australis, Cephalorhynchus commersonii, Phocoena spinipinnis), mediante la utilización del software IsoSource (versión 1.3.1, http://www.epa.gov/wed/pages/models/stableisotopes/isosource/isosource.htm), no pudo estimarse la composición isotópica de la dieta para Lissodelphis peronii, Grampus griseus, Pseudorca crassidens, Phocoena dioptrica y Lagenorhynchus cruciger por carecer de posibles ítems presa necesarios para un correcto cálculo. En el resto de los casos, los resultados de las contribuciones isotópicas de cada grupo presa a los valores de $\delta^{13} \mathrm{C}$ y $\delta^{15} \mathrm{~N}$ de los cetáceos analizados se presentan resumidos en la Tabla 6. Cada solución individual representa una combinación de las proporciones de las presas que satisfacen el balance de masa isotópica en el modelo.

\section{Delfín austral (Lagenorhynchus australis)}

Para Lagenorhynchus australis, se priorizaron 5 grupos presa: costero-bentónicos (CB), costero-pelágicos 1 (CP1), demerso-pelágicos 1 (DP1), crustáceos (CR) y pulpos (OC) como mejores candidatos para calcular sus contribuciones isotópicas relativas al valor isotópico de éste. En el primer análisis el programa no generó determinaciones definidas, más bien amplios rangos de contribuciones isotópicas para cada posible presa. En base a similitudes estadísticas y ecológicas se reagruparon - a posteriori- las presas. Así, se reunió a los grupos costero-bentónicos (CB) y costero-pelágicos 1 ( $\mathrm{CP} 1)$ en presas costeras (PCO), y a los crustáceos (CR) y los pulpos (OC) en invertebrados bentónicos (IB), dejando a los demerso-pelágicos (DP1) como grupo presa individual. Este segundo análisis, que involucró tres grupos presa y permitió la delimitación más estrecha del rango de las contribuciones de estos al valor isotópico del predador (Figura 11). Se observa que las presas costeras (PCO) son las que más contribuyen al valor de isotópico de $L$. australis (con un rango de 0,62 a 0,67 y contribución media de 0,646) seguidas por los demerso-pelágicos (DP1) (rango 0,24 a 0,32 y contribución media de 0,282) y luego por crustáceos y pulpos (IB) (rango 0,06 a 0,09, y contribución media de 0,072) (Tabla 6).

Tonina overa (Cephalorhynchus commersonii)

Para Cephalorhynchus commersonii se priorizaron 8 grupos presa: costero- 
bentónicos (CB), costero-pelágicos 1 y 2 (CP1, CP2), demerso-pelágicos 1 y 2 (DP 1 , $\mathrm{DP} 2$ ), pulpos (OC), crustáceos (CR) y calamares (SQ), como los mejores candidatos para calcular las contribuciones isotópicas relativas al valor isotópico de este predador. Al igual que en el caso anterior (L. austratis), la primer corrida del programa determinó amplios y difusos rangos de contribuciones isotópicas para cada posible presa. Se mantuvo el criterio anterior para realizar agrupaciones $a$ posteriori, se respetaron los grupos creados anteriormente costero-bentónico (CB) y costero-pelágico $(\mathrm{CP} 1)$ en peces costeros $(\mathrm{PCO})$, crustáceos $(\mathrm{CR})$ y pulpos $(\mathrm{OC})$ en invertebrados bentónicos (IB) y se agruparon a demerso-pelágicos 2 (DP2), calamares (SQ) y costero-pelágicos 2 ( $(\mathrm{CP} 2)$, en presas demerso-pelágicooceanódramas (DPO), quedando nuevamente el grupo demerso-pelágicos 1 (DP1) como grupo presa individual. Este segundo análisis involucró 4 grupos presas y permitió una mejor delimitación del rango de las contribuciones de estos grupos al predador (Figura 12). En este último análisis se observa que las presas demersopelágico-oceanódramas (DPO) es el que más contribuye a sus valores isotópicos (rango 0,39 a 0,71 y contribución media de 0,553), la contribución media del resto de los grupos es menor a esta y los rangos entre ellos son similares (Tabla 6).

\section{Marsopa espinosa (Phocoena spinipinnis)}

Para Phocoena spinipinnis se priorizaron los mismos grupos presas que para $C$. commersonii, costero-bentónicos (CB), costero-pelágicos 1 y $2(\mathrm{CP} 1, \mathrm{CP} 2)$, demersopelágicos 1 y 2 (DP1, DP2), pulpos (OC), crustáceos (CR) y calamares (SQ), como mejores candidatos para calcular las contribuciones isotópicas relativas a su valor isotópico. Al igual que para L. australis y C. commersonii la primer corrida del programa determinó amplios y difusos rangos de contribuciones isotópicas para cada fuente presa. Respetando algunos grupos creados anteriormente y reagrupando otros, se realizó un segundo análisis involucrando un total de 4 grupos presas, que incluyó al grupo de peces costeros (PCO), costero-pelágicos $2(\mathrm{CP} 2)$ como presas individuales, a los demerso-pelágicos 1 (DP1) se los agrupó con los crustáceos (CR) y los pulpos (OC) en misceláneos 1 (MISC 1) y a los demerso-pelágicos 2 (DP2) y calamares se los agrupó en misceláneos 2 (MISC 2). Estas agrupaciones permitieron una mejor delimitación del rango de las contribuciones de estos grupos al predador tope (Figura 13). Las presas costero-pelágicas ( $\mathrm{CP} 2$, Sprattus fuegensis) es el que más contribuyó a la signatura isotópica de $P$. spinipinnis (rango de 0,41 a 0,55 y contribución media de 0,477). Por otra parte resultó amplio el rango de 
contribución de misceláneos 1 y 2 (MISC 1, 2), con rangos superiores mayores a los peces costeros (PCO) aunque sus contribuciones medias fueron menores que éste último grupo (Tabla 6).

A pesar de que no se logró evaluar el diferente grado de consumo de grupos de presa para todos los cetáceos analizados, la ubicación espacial de los valores isotópicos de cada uno de ellos en el conjunto de datos obtenidos (presas + cetáceos) permite definir de forma general el tipo de presas consumidas por éstos.

De esta forma, es posible la interpretación de distintos tipos de dietas a partir de la segregación de los valores isotópicos de los cetáceos y la relación que establecen con sus presas. Por lo cual, se observa 1) especies con dieta costera/inshore caracterizada por altos valores de $\delta^{13} \mathrm{C}$ y $\delta^{15} \mathrm{~N}$ y cercanos a grupos presa costeros $(L$. australis); 2) especies con dieta mixta con valores intermedios entre grupos presa costeros y de plataforma/talud (C. commersonii, $P$. spinipinnis); 3) dieta oceánica/offshore con bajos valores de $\delta^{13} \mathrm{C}$ y $\delta^{15} \mathrm{~N}$ entre grupos presa de plataforma/talud y regiones más oceánicas (ecotipo GG2 de G. griseus, L. peronii, P. crassidens) distinguiendo entre estas últimas las dietas oceánicas de altas latitudes (L. cruciger, $P$. dioptrica) caracterizadas por los valores más bajos de $\delta^{13} \mathrm{C}$ y $\delta^{15} \mathrm{~N}$ encontrados (Figura 14, 15). 


\section{Tabla 6. Contribuciones isotópicas de posibles grupos presa - IsoSource}

Presas: peces costeros-bentónicos $(\mathrm{CB})$, costeros-pelágicos ( $\mathrm{CP} 1, \mathrm{CP} 2)$, demerso-pelágicos (DP1, DP2), crustáceos (CR), pulpos (OC), calamares (SQ). Agrupaciones de presas: PCO (CB, CP1), $\mathrm{IB}(\mathrm{CR}, \mathrm{OC}), \mathrm{DPO}(\mathrm{DP} 2, \mathrm{SQ}, \mathrm{CP} 2), \mathrm{MISC} 1$ (IB, DP 1), MISC 2 (DP2, SQ)

Se muestran los resultados de dos análisis del IsoSource para cada predador analizado

\begin{tabular}{c|c|c|c|c|} 
Grupos presa corridos Presas & Rango de \\
contribución \\
isotópica
\end{tabular}

Lagenorhynchus australis

\begin{tabular}{|c|c|c|c|c|}
\hline \multirow{5}{*}{5} & $\mathrm{CB}$ & 0,395 & 0,17 & $0,00-0,67$ \\
\hline & $\mathrm{CP} 1$ & 0,235 & 0,17 & $0,00-0,64$ \\
\hline & DP 1 & 0,276 & 0,05 & $0,10-0,40$ \\
\hline & $\mathrm{OC}$ & 0,076 & 0,06 & $0,00-0,25$ \\
\hline & $\mathrm{CR}$ & 0,018 & 0,02 & $0,00-0,07$ \\
\hline \multirow{3}{*}{3} & $\mathrm{PCO}$ & 0,646 & 0,02 & $0,62-0,67$ \\
\hline & IB & 0,072 & 0,01 & $0,06-0,09$ \\
\hline & $\mathrm{DP} 1$ & 0,282 & 0,02 & $0,24-0,32$ \\
\hline \multicolumn{5}{|c|}{ Cephalorhynchus commersonii } \\
\hline \multirow{8}{*}{8} & $\mathrm{CB}$ & 0,045 & 0,05 & $0,00-0,32$ \\
\hline & $\mathrm{CP} 1$ & 0,068 & 0,05 & $0,00-0,33$ \\
\hline & $\mathrm{CP}_{2}$ & 0,164 & 0,11 & $0,00-0,53$ \\
\hline & $\mathrm{DP}_{1}$ & 0,108 & 0,09 & $0,00-0,57$ \\
\hline & $\mathrm{DP}_{2}$ & 0,198 & 0,15 & $0,00-0,81$ \\
\hline & SQ & 0,190 & 0,15 & $0,00-0,79$ \\
\hline & $\mathrm{OC}$ & 0,134 & 0,11 & $0,00-0,72$ \\
\hline & $\mathrm{CR}$ & 0,075 & 0,04 & $0,00-0,20$ \\
\hline \multirow{4}{*}{4} & $\mathrm{PCO}$ & 0,101 & 0,06 & $0,00-0,22$ \\
\hline & IB & 0,147 & 0,03 & $0,09-0,21$ \\
\hline & $\mathrm{DP} 1$ & 0,199 & 0,12 & $0,00-0,42$ \\
\hline & $\mathrm{DPO}$ & 0,553 & 0,08 & $0,39-0,71$ \\
\hline \multicolumn{5}{|c|}{ Phocoena spinipinnis } \\
\hline \multirow{8}{*}{ 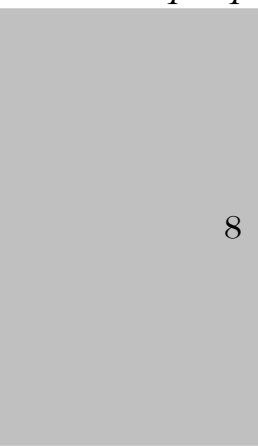 } & $\mathrm{CB}$ & 0,100 & 0,07 & $0,00-0,33$ \\
\hline & $\mathrm{CP} 1$ & 0,075 & 0,06 & $0,00-0,34$ \\
\hline & $\mathrm{CP}_{2}$ & 0,430 & 0,08 & $0,12-0,66$ \\
\hline & $\mathrm{DP} 1$ & 0,196 & 0,13 & $0,00-0,59$ \\
\hline & $\mathrm{DP}_{2}$ & 0,063 & 0,05 & $0,00-0,34$ \\
\hline & SQ & 0,080 & 0,07 & $0,00-0,43$ \\
\hline & $\mathrm{OC}$ & 0,045 & 0,04 & $0,00-0,26$ \\
\hline & $\mathrm{CR}$ & 0,010 & 0,01 & $0,00-0,07$ \\
\hline \multirow{4}{*}{4} & $\mathrm{PCO}$ & 0,226 & 0,04 & $0,12-0,31$ \\
\hline & MISC 1 & 0,177 & 0,11 & $0,00-0,44$ \\
\hline & MISC 2 & 0,120 & 0,08 & $0,00-0,30$ \\
\hline & $\mathrm{CP} 2$ & 0,477 & 0,03 & $0,41-0,55$ \\
\hline
\end{tabular}




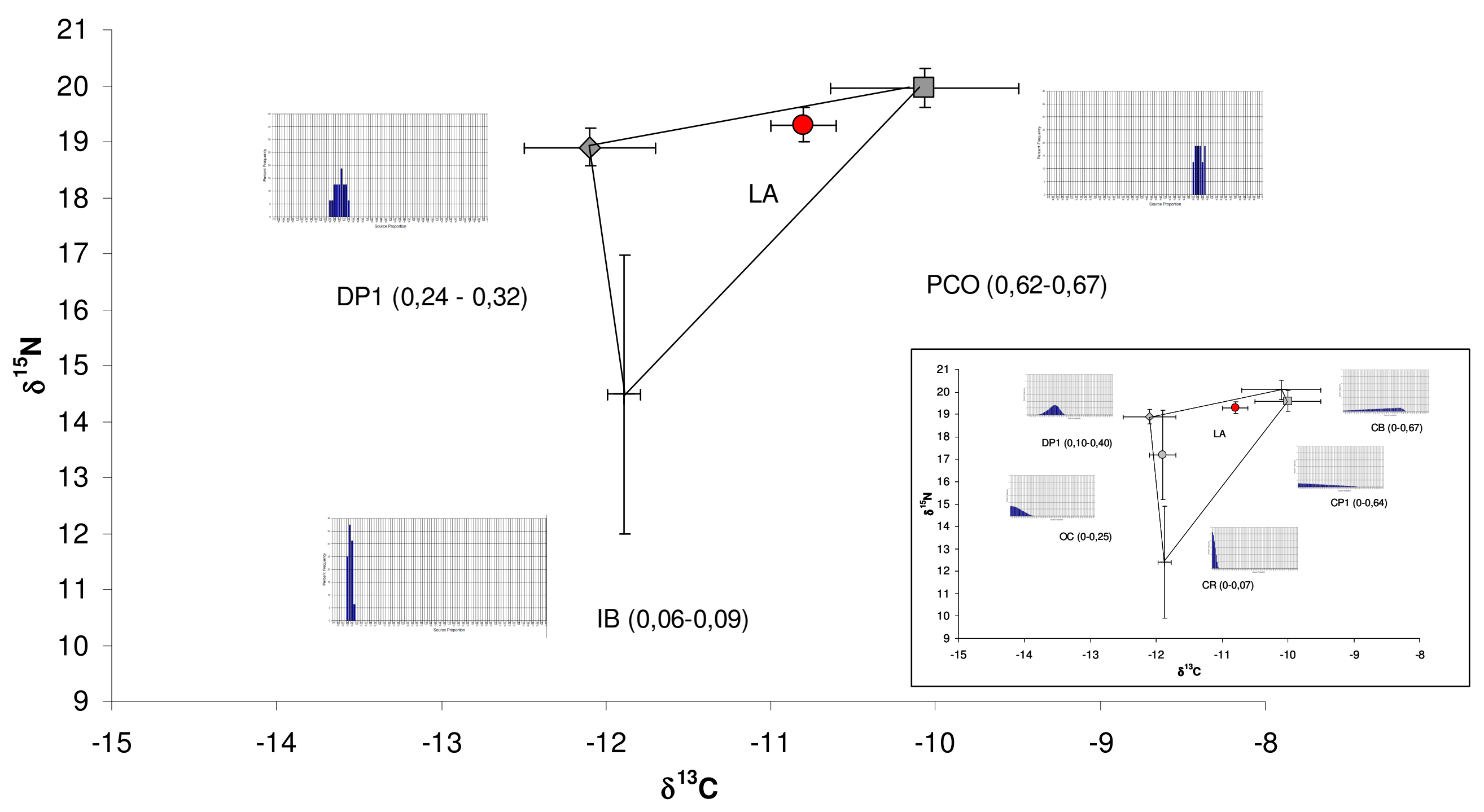

Figura 11. Contribuciones isotópicas de 3 grupos presa al valor isotópico de Lagenorhynchus australis. En el recuadro de la región inferior derecha se muestra el resultado de la contribución de los 5 grupos presa originales. Lagenorhynchus australis (○, LA). Grupo presa: peces costeros ( $₫$, PCO), invertebrados bentónicos (+, IB) y demerso-pelágicos $1(\diamond, \mathrm{DP} 1)$. 


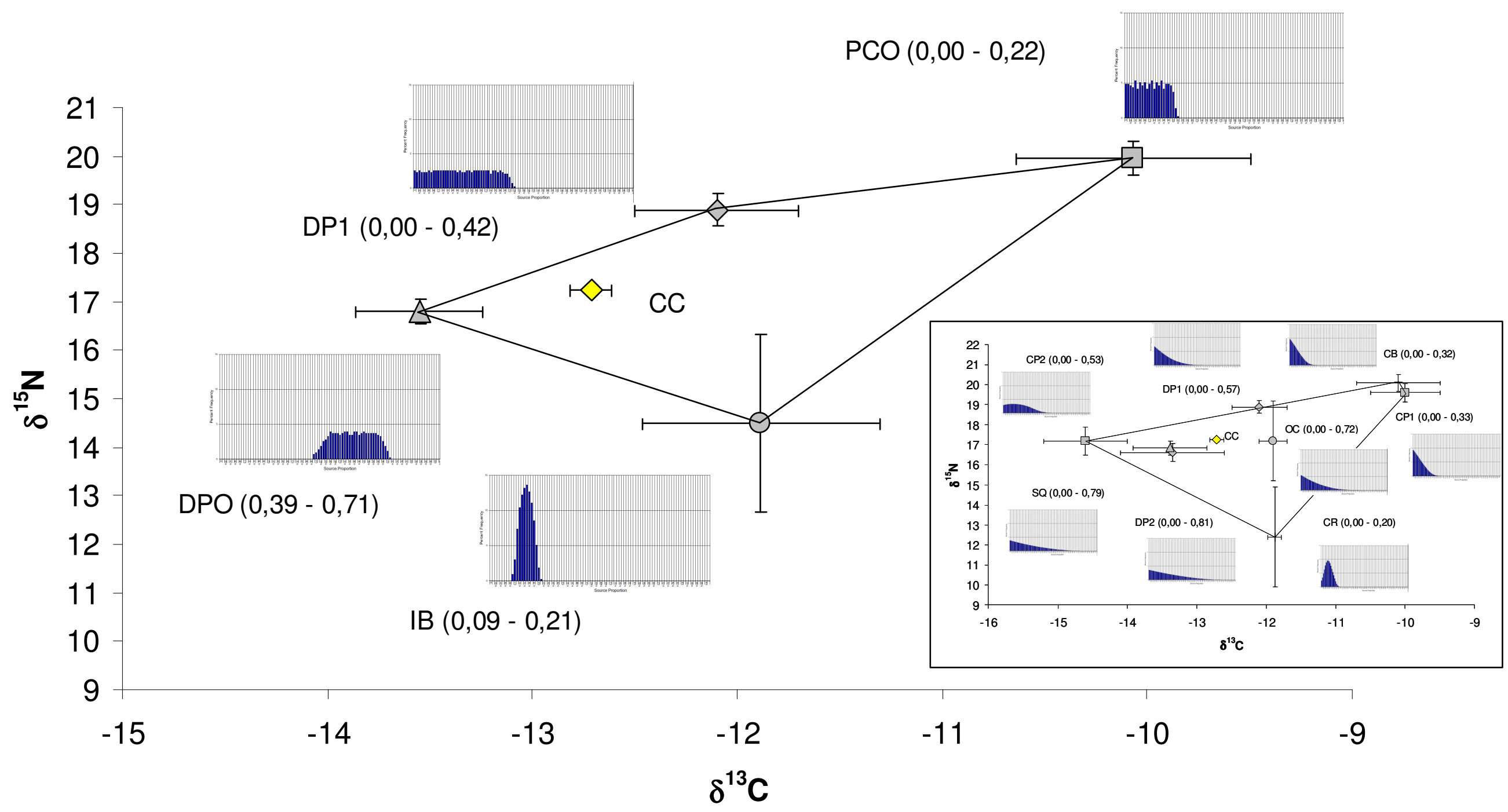

Figura 12. Contribuciones isotópicas de 4 grupos presa al valor isotópico de Cephalorhynchus commersonii. En el recuadro de la región inferior derecha se muestra el resultado de la contribución de los 8 grupos presa originales. Cephalorhynchus commersonii ( $\diamond$, $\mathrm{CC})$. Grupos presa: peces costeros ( $₫$, PCO), invertebrados bentónicos $(\bullet$, IB) y demerso-pelágicos $1(\diamond$, DP 1$)$ y demerso-pelágicooceanódromos $(\boldsymbol{\Delta}, \mathrm{DPO})$. 


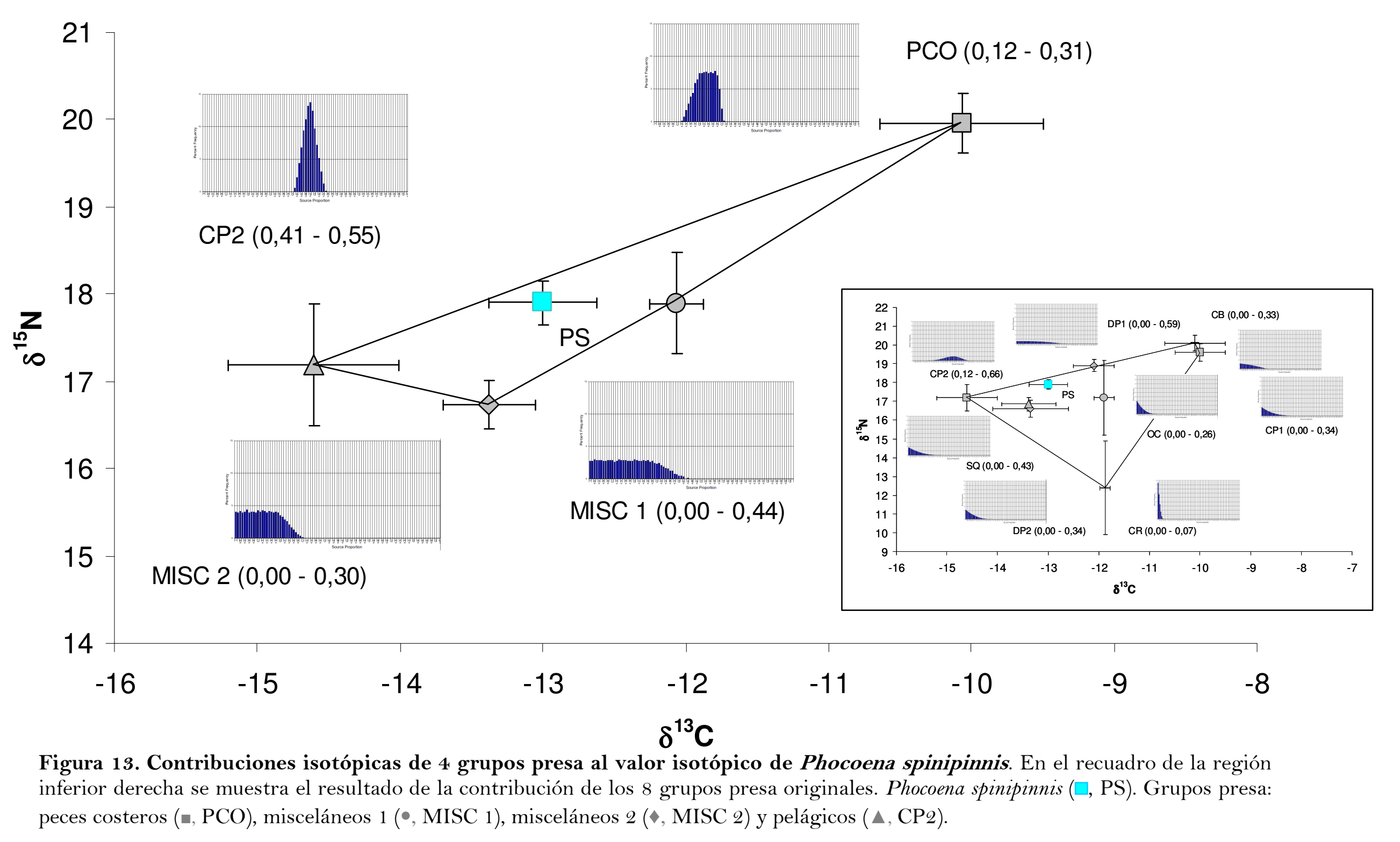




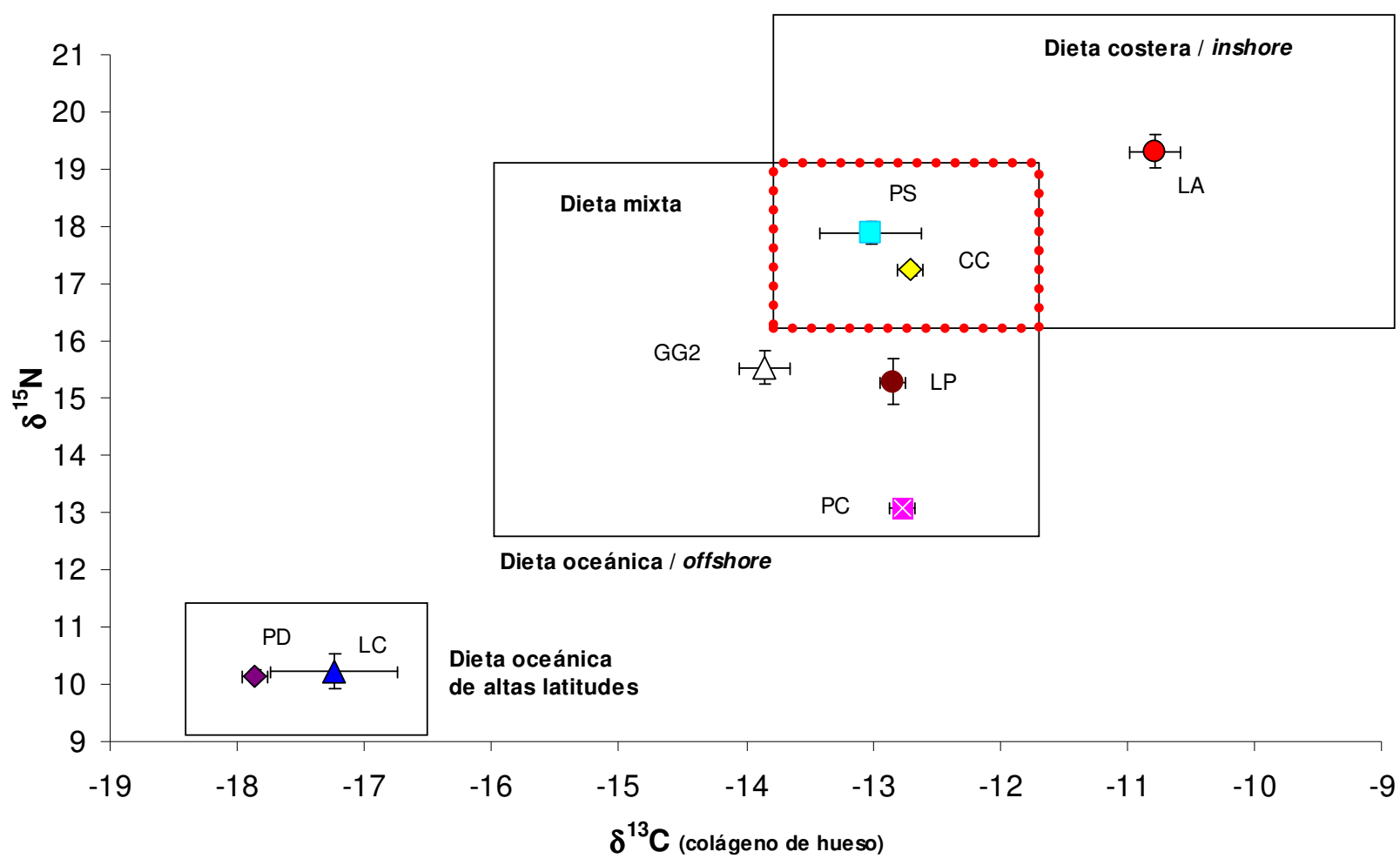

Figura 14. Dieta de las especies de cetáceos en base a la segregación de sus firmas isotópicas y la relación establecida con sus presas. Especies con dieta costera: Lagenorhynchus australis (О, LA); especies con dieta mixta: Cephalorhynchus commersonii $(\diamond, \mathrm{CC})$ y Phocoena spinipinnis ( $\square, \mathrm{PS})$; especies con dieta oceánica/offshore: ecotipo GG2

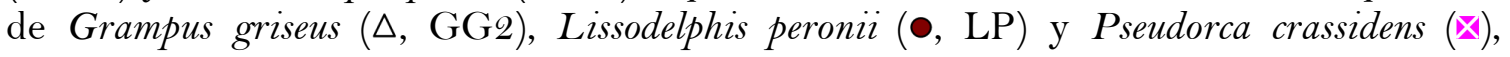
especies con dieta oceánica de altas latitudes: Phocoena dioptrica ( $\diamond$, PD) y Lagenorhynchus cruciger $(\boldsymbol{\Delta}, \mathrm{LC})$. Valores medios de $\boldsymbol{\delta}^{13} \mathrm{C}$ y $\boldsymbol{\delta}^{15} \mathrm{~N}$ ( \pm error estándar). 


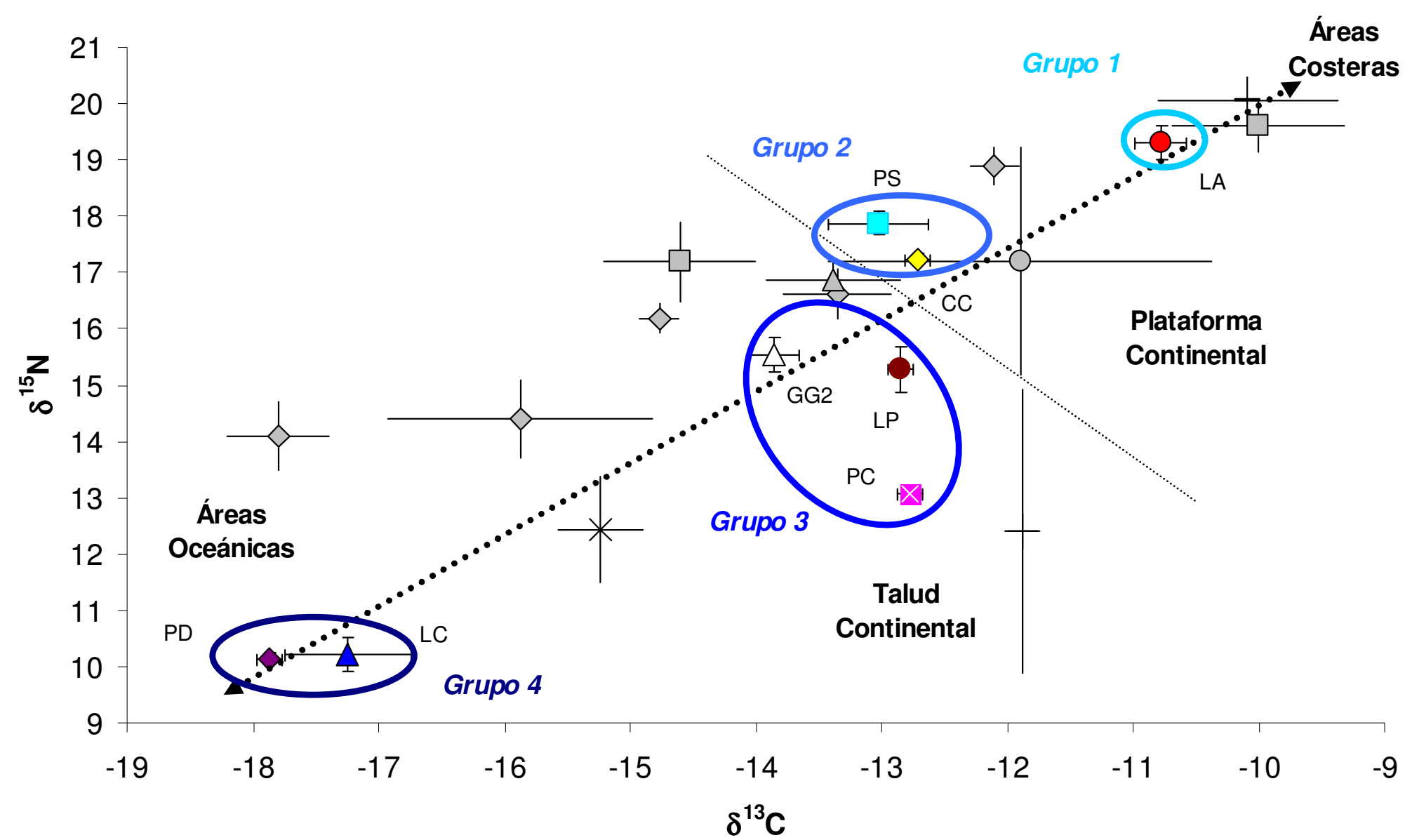

Figura 15. Comportamiento trófico principal de las ocho especies de cetáceos analizadas. Variación isotópica desde las especies costeras (ej. Lagenorhynchus australis) a las más oceánicas (Lagenorhynchus curciger y Phocoena dioptrica). Valores medios de $\delta^{13} \mathrm{C}$ y $\delta^{15} \mathrm{~N}( \pm$ error estándar) de las especies de cetáceos y posibles presas del Atlántico Sudoccidental. No se incluye el ecotipo norte de Grampus griseus (GG1, Figura 9). Los círculos indican los principales hábitats de forrajeo. Grupo 1, especies costeras: L. australis (O, LA); Grupo 2, especies costeras/de plataforma: Cephalorhynchus

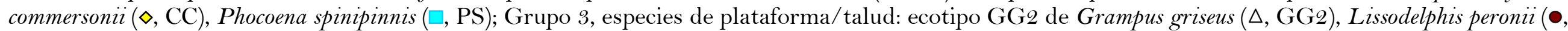
LP), Pseudorca crassidens $(\mathbb{\varangle})$, Grupo 4, especies oceánicas: L. cruciger $(\mathbf{\Lambda}, \mathrm{LC})$, P. dioptrica $(\bullet, \mathrm{PD})$. Presas: peces costero-bentónicos $(-)$, peces demersopelágicos $(\diamond)$, peces pelágicos $(\boldsymbol{\nabla})$, calamares $(\mathbf{\Delta})$, pulpos $(\bullet)$, crustáceos $(+)$ y zooplancton $(\mathbf{x})$. Los valores medios de las presas se muestran corregidos por la discriminación trófica. Línea punteada gruesa: continuo isotópico desde especies costeras a oceánicas; línea punteada fina: división entre especies inshore y offshore. 


\subsection{VARIACIONES INTRA-ESPECÍFICA EN LA DIETA}

\subsubsection{Grampus griseus}

Se evaluó la variación isotópica de $\delta^{13} \mathrm{C}$ y $\quad \delta^{15} \mathrm{~N}$ en los ecotipos de Grampus griseus, a través de su comparación con los resultados isotópicos de posibles presas en diferentes áreas espaciales de forrajeo, sus NTs estimados, y la comparación isotópica intra-específica a diferentes edades y sexos. Los especímenes muestreados incluyen 23 machos, 6 hembras y 19 individuos de sexo desconocido, haciendo un total de 48 ejemplares analizados. Todos ellos se encontraron varados a lo largo de Bahía San Sebastián, en la costa NE de Tierra del Fuego $\left(53^{\circ} 10^{\prime} \mathrm{S}-68^{\circ} 30^{\prime} \mathrm{O}\right)$, hecho que ocurrió en diferentes años.

Dado que la mayoría de los especímenes colectados en Tierra del Fuego tienen edades desconocidas, se determinó la categoría de edad por el largo total (LT), siguiendo a Amano \& Miyazaki (2004). En la determinación de la categoría de edad, los ejemplares de ambos sexos con más de $270 \mathrm{~cm}$ de LT se consideraron animales adultos (A) (sexualmente maduros) y aquellos con menos de $270 \mathrm{~cm}$ de LT como subadultos (S) (sexualmente inmaduros). Como resultado, se asignó una categoría de edad para 44 especímenes de los ecotipos de G. griseus (22 del ecotipo GG1 y 22 del ecotipo GG2). Para el primer ecotipo sólo quedó un individuo sin determinar la edad y para el segundo ecotipo fueron tres ejemplares.

Los 48 especímenes de $G$. griseus muestran una segregación isotópica significativa (Test-U, $\mathrm{P}<0,05$ ) cuando ambos valores de $\delta^{13} \mathrm{C}$ y $\boldsymbol{\delta}^{15} \mathrm{~N}$ son graficados (Figura 9). Como se mencionó anteriormente fueron tratados como dos ecotipos provenientes de diferentes áreas de alimentación y ubicados a distintas latitudes en la misma cuenca oceánica.

Para evaluar el estado trófico de los dos ecotipos de G. griseus, se consideraron los resultados obtenidos en las secciones previas (nivel trófico y la varianza isotópica). Además, se calcularon los niveles tróficos de cada ecotipo usando la ecuación [2] y se consideraron los diferentes valores de $\delta^{13} \mathrm{C}$ y $\delta^{15} \mathrm{~N}$ de la línea base establecida para cada red trófica considerada (Capítulo 2, sección 2.2.5.2.2). De este modo, se asoció al ecotipo GG1 con redes tróficas de las aguas de Patagonia norte y al ecotipo GG2 con redes tróficas de las aguas del sur de la región (Figura 16). El nivel trófico estimado del ecotipo GG2 $(\mathrm{NT}=4.4 \pm 0.4)$ resultó estadísticamente mayor con respecto a GG1 $(\mathrm{NT}=4,1 \pm 0.4)($ Test- $\mathrm{t}=2,8393 ; \mathrm{P}=$ 0,0067) (Tabla 4). 
Entre GG1 y GG2, no se encontraron diferencias estadísticas en la varianza de $\delta^{15} \mathrm{~N}(\mathrm{~F}=0,811 ; \mathrm{P}=0,3124)$, pero sí en la varianza de $\delta^{13} \mathrm{C}(\mathrm{F}=0,3688 ; \mathrm{P}=$ 0,0108) siendo mayor en GG2.

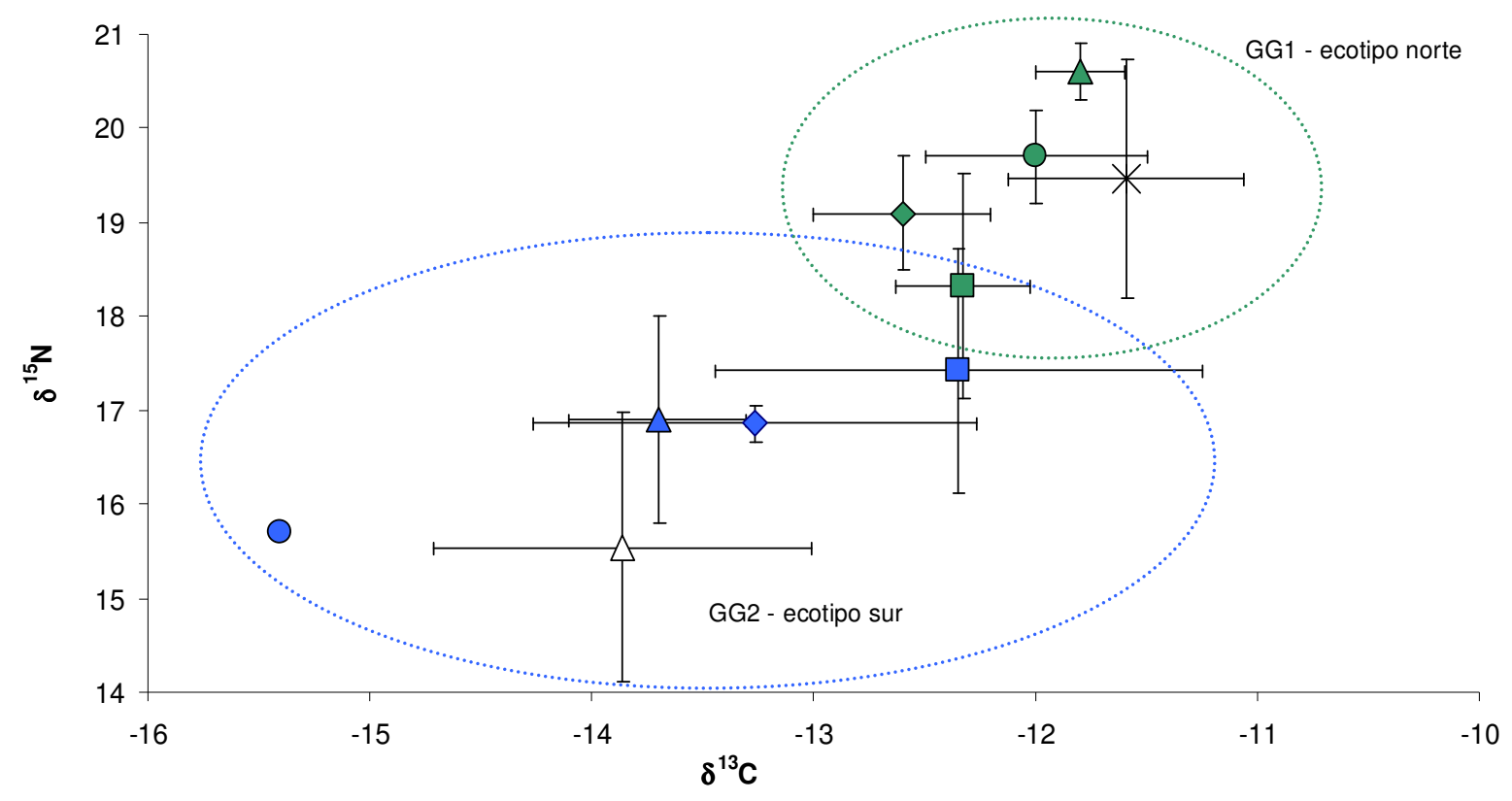

Figura 16: Valores medios de $\delta^{15} \mathrm{C}$ y $\delta^{15} \mathrm{~N}$ ( \pm desvío estándar) de los ecotipos de Grampus griseus y sus posibles presas. GG1 (*) ecotipo norte y GG2 $(\triangle)$ ecotipo sur. Los círculos con línea de puntos engloban la asociación de especies predadorpresa del norte (verde) y sur (azul) de la región patagónica. Calamares del área patagónica norte: Loligo gahi $(\diamond)$, Loligo sanpaulensis $(\Delta)$, Illex argentinus $(\square)$, Loligo sp + Illex sp (০). Calamares del área patagónica sur: Loligo gahi $(\diamond)$, Illex argentinus $(\square)$, Moroteuthis ingens $(\Delta)$, Semirrosia tenera $(\mathrm{O})$. Los valores isotópicos de los calamares se obtuvieron de Forero et al. (2004), Lewis et al. (2006), Ciancio et al. (2008), Drago et al. (2009) y de esta Tesis. Los valores de las presas se muestran corregidos por la discriminación trófica para la comparación con los ecotipos.

La comparación estadística entre las composiciones isotópicas promedio del colágeno del hueso para los diferentes sexos en GG1 y GG2 no resultó significativa en $\delta^{13} \mathrm{C}$ (Test-U, P = 0,6356 para GG 1 y $\mathrm{P}=0,6098$ para GG2) o $\delta^{15} \mathrm{~N}$ (Test-U, P $=0,5147$ para GG1 y $\mathrm{P}=0,7595$ para GG2). Tampoco se encontraron diferencias intra-específicas en la varianza asociada a los valores de $\delta^{15} \mathrm{~N}$, entre machos y hembras de ambos ecotipos $(\mathrm{F}=0,338 ; \mathrm{P}=0,0848 ; \mathrm{F}=0,7708 ; \mathrm{P}=0,5017$; respectivamente), o en $\delta^{13} \mathrm{C}(\mathrm{F}=0,3348 ; \mathrm{P}=0,2737)$ para GG2. Sin embargo, sí hubo una pequeña diferencia en la varianza de $\delta^{13} \mathrm{C}$ entre machos y hembras en 
GG1 (F = 0,0464; P = 0,0451), resultando mayor en los primeros (Tabla 7).

Los especímenes adultos y subadultos analizados no mostraron diferencias significativas para $\delta^{13} \mathrm{C}$ (Test-U, $\mathrm{P}=0,4240$ para GG1 y $\mathrm{P}=0,1381$ para GG2) o $\delta^{15} \mathrm{~N}$ (Test-U, $\mathrm{P}=0,6478$ para GG1 y $\mathrm{P}=0,2317$ para GG2) en ambos ecotipos (Tabla 7). En GG1, los subadultos mostraron una mayor varianza respecto a los adultos en los valores de $\delta^{13} \mathrm{C}(\mathrm{F}=0,097 ; \mathrm{P}=0,009)$. Mientras que no se comparó la variación en $\delta^{15} \mathrm{~N}$ entre estos, debido a que los subadultos no mostraron varianza $\left(\mathrm{S}^{2}=0\right)$. En GG2 no se halló una varianza significativa en $\delta^{13} \mathrm{C}$ y en $\delta^{15} \mathrm{~N}$ entre adultos y subadultos $\left(\mathrm{F}=0,569 ; \mathrm{P}=0,402\right.$ para $\delta^{13} \mathrm{C}$ y $\mathrm{F}=0,873 ; \mathrm{P}=0,680$ para $\left.\delta^{15} \mathrm{~N}\right)$

\section{Tabla 7. Composición isotópica del colágeno del hueso de los ecotipos de Grampus griseus en relación al sexo y categoría de edad (adultos, subadultos).}

Valores de isótopos estables de carbono y nitrógeno, desviación estándar $( \pm \mathrm{DE} \%)$ y número $(\mathrm{n})$ de especimenes analizados

\begin{tabular}{|c|c|c|c|c|c|}
\hline \multirow{2}{*}{ Ecotipo } & \multicolumn{2}{|c|}{$\boldsymbol{\delta}^{13} \mathbf{C}$} & \multicolumn{2}{|c|}{$\delta^{15} \mathbf{N}$} & \multirow{2}{*}{$\mathbf{n}$} \\
\hline & Media & $\pm \mathrm{DE}$ & Media & $\pm \mathrm{DE}$ & \\
\hline \multicolumn{6}{|c|}{ Composición isotópica en relación al sexo } \\
\hline GG 1 & & & & $\square$ & \\
\hline machos & $-11,5$ & 0,5 & 19,3 & 1,1 & 15 \\
\hline hembras & $-11,6$ & 0,1 & 18,5 & 1,9 & 3 \\
\hline \multicolumn{6}{|l|}{ GG2 } \\
\hline machos & $-13,8$ & 1,0 & 16,0 & 1,9 & 8 \\
\hline hembras & $-13,9$ & 0,5 & 15,5 & 1,7 & 3 \\
\hline \multicolumn{6}{|c|}{ Composición isotópica en relación a la categoría de edad } \\
\hline \multicolumn{6}{|c|}{ GG 1} \\
\hline adultos & $-11,5$ & 0,4 & 19,5 & 1,3 & 20 \\
\hline subadultos & $-12,3$ & 1,3 & 19,9 & 0,1 & 2 \\
\hline \multicolumn{6}{|l|}{ GG2 } \\
\hline adultos & $-18,3$ & 0,8 & 15,7 & 1,5 & 19 \\
\hline subadultos & $-14,5$ & 1,0 & 14,4 & 1,6 & 3 \\
\hline
\end{tabular}

\subsubsection{Cephalorhynchus commersonii}

Se analizó la variabilidad isotópica intra-específica en Cephalorhynchus commersonii en relación al sexo, la edad y la longitud total (LT) de los especímenes. Los machos $(\mathrm{n}=76)$ presentaron valores promedios de $\delta^{13} \mathrm{C}$ de $-12,7 \%$ o $( \pm 1,3 \%$ ) y 
valores promedio de $\delta^{15} \mathrm{~N}$ de $17,3 \%$ o $( \pm 0,6 \%$ o). Las hembras $(\mathrm{n}=33)$ presentaron valores promedio de $\boldsymbol{\delta}^{13} \mathrm{C}$ de $-12,7 \%$ o ( $\pm 1,3 \%$ ) y de $\delta^{15} \mathrm{~N}$ de $17,3 \%$ o $( \pm 0,8 \%$ o). No se encontraron diferencias significativas entre machos y hembras tanto en los valores de $\delta^{13} \mathrm{C}$ (Test-U, $\left.\mathrm{P}=0,6185\right)$ como en los de $\delta^{15} \mathrm{~N}$ (Test-T =0,15; $\left.\mathrm{P}=0,883\right)$. Las hembras mostraron una mayor variación en los valores de $\delta^{15} \mathrm{~N}$ respecto a los machos $(\mathrm{F}=1,773 ; \mathrm{P}=0,044)$, pero no difirieron en la varianza de $\delta^{13} \mathrm{C}(\mathrm{F}=0,891$; $\mathrm{P}=0,732)$.

Se analizó la variabilidad en $\delta^{13} \mathrm{C}$ y $\delta^{15} \mathrm{~N}$ en relación con la edad y el largo total (LT) de los individuos mediante un análisis de correlación por rangos de Spearman. Los especímenes de C. commersonii variaron entre 0,5 a 18 años de edad (n=91) y con longitudes totales entre 94,5 a $148 \mathrm{~cm}(\mathrm{n}=99)$. A su vez, se consideraron cuatro clases etarias para evaluar la tendencia ontogenética en los valores de $\delta^{13} \mathrm{C}$ y $\delta^{15} \mathrm{~N}$ : (1) crías, que incluyó individuos menores a 8 meses de edad, (2) juveniles, individuos con edades de 8 meses hasta a 2 años, (3) subadultos, entre 3 y 4 años, y (4) adultos, mayor a 5 años de edad. Se usaron datos de ambos sexos para calcular las medias y el desvío estándar de las clases (Tabla 8).

No hubo una correlación significativa entre los valores en $\delta^{13} \mathrm{C}$ y las edades de los especímenes $(\rho=0,0219 ; \mathrm{P}=0,8371)$ (Figura 14). No obstante, las crías presentaron valores medios de $\delta^{13} \mathrm{C}$ más enriquecidos respecto a los juveniles, subadultos y adultos $(+0,6 \%$; $+1,0 \%$ y $+0,3 \%$ o, respectivamente), pero dichas diferencias no resultaron ser significativas $(K-W, P=0,3307)$. Los valores de $\delta^{15} \mathrm{~N}$ mostraron diferencias significativas con la edad (ANOVA, $F=3,17 ; \mathrm{P}=0,0281$ ) y una correlación baja significativa de tipo positiva $(\rho=0,2721$; $\mathrm{P}=0,0091)$ (Figura 17). En la secuencia de clases se observa que las crías presentan valores medios de $\delta^{15} \mathrm{~N}$ más altos respecto a los juveniles y subadultos (+0,3\%o y $+0,2 \%$, respectivamente) aunque la diferencia no es significativa entre ellos (Tukey, $\mathrm{P}>$ 0,05). Sin embargo los adultos presentan valores medios de $\delta^{15} \mathrm{~N}$ significativamente más altos respecto a los juveniles (Tukey, $\mathrm{P}=0,024)$.

Al igual que la edad, no se encontró correlación entre la longitud total de los especímenes y los valores de $\delta^{13} \mathrm{C}(\rho=-0,1143 ; \mathrm{P}=0,26)$. Mientras que los valores de $\delta^{15} \mathrm{~N}$ mostraron una correlación significativa con la longitud total de bajo valor y de tipo positiva $(\rho=0,2405 ; \mathrm{P}=0,0165)$ (Figura 18). 
Tabla 8. Composición isotópica del colágeno del hueso de especímenes de Cephalorhynchus commersonii por clases de edades

Crías (<8meses de edad), juveniles (entre 8 meses hasta 2 años), subadultos (entre 3 y 4 años) y adultos (>5 años de edad).

Valores medios de $\delta^{13} \mathrm{C}$ y $\delta^{15} \mathrm{~N}$, desviación estándar ( $\pm \mathrm{DE} \%$ o) y número de individuos analizados (n)

\begin{tabular}{|c|c|c|c|c|c|}
\hline \multirow{2}{*}{ Clase de edad } & \multicolumn{2}{|c|}{$\delta^{13} \mathbf{C}$} & \multicolumn{2}{|c|}{$\delta^{15} \mathbf{N}$} & \multirow{2}{*}{$\mathbf{n}$} \\
\hline & Media & $\pm \mathrm{DE}$ & Media & $\pm \mathrm{DE}$ & \\
\hline Crías & $-12,1$ & 0,7 & 17,3 & 1,5 & 2 \\
\hline Juveniles & $-12,7$ & 1,0 & 17,0 & 0,6 & 30 \\
\hline Subadultos & $-13,1$ & 1,1 & 17,1 & 0,4 & 9 \\
\hline Adultos & $-12,4$ & 1,5 & 17,5 & 0,6 & 50 \\
\hline
\end{tabular}



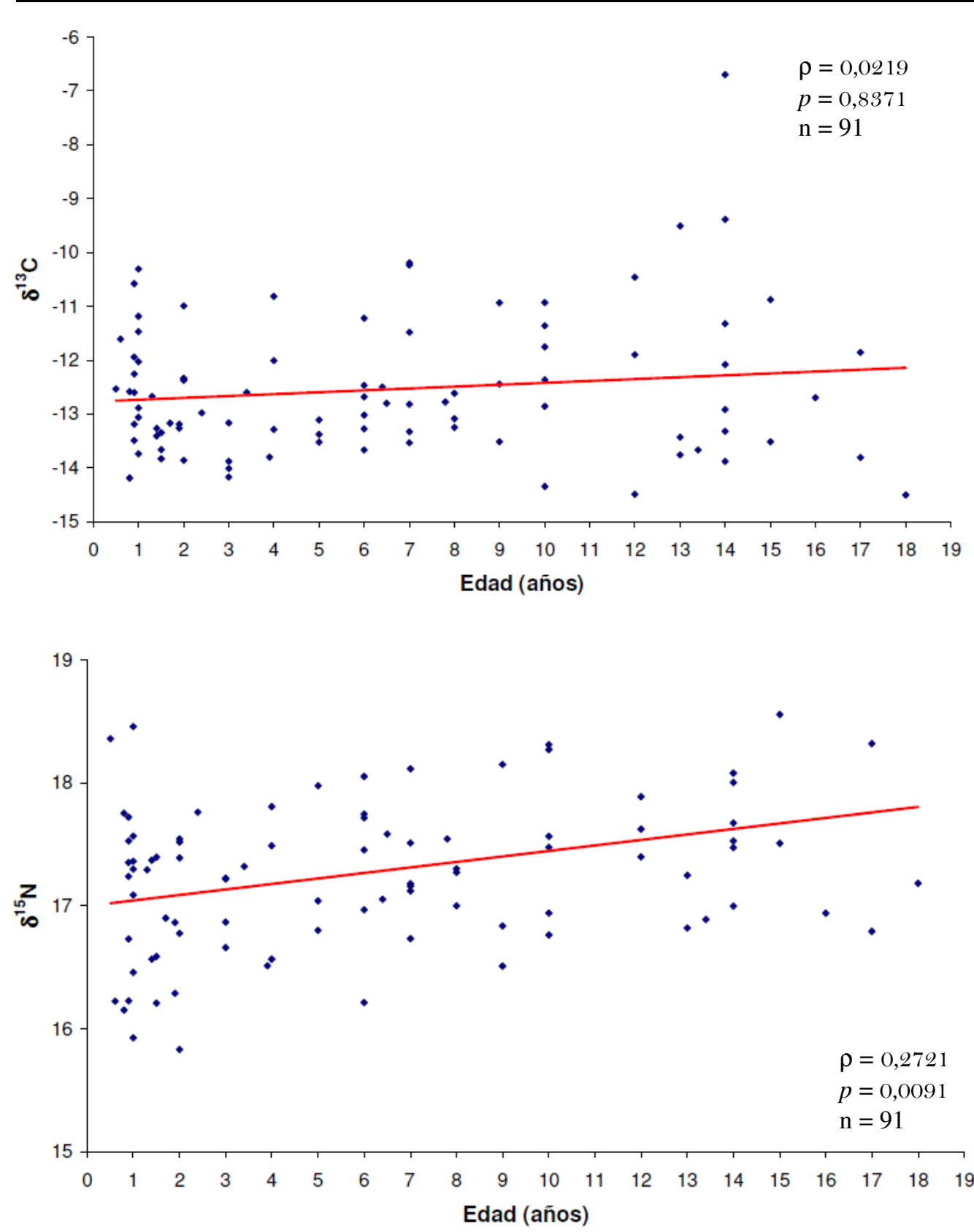

Figura 17. Variación isotópica intra-específica en Cephalorhynchus commersonii en relación con la edad de los individuos. Coeficiente de correlación por rangos de Spearman $(\rho)$, probabilidad $(p)$ y número de individuos analizados (n). 

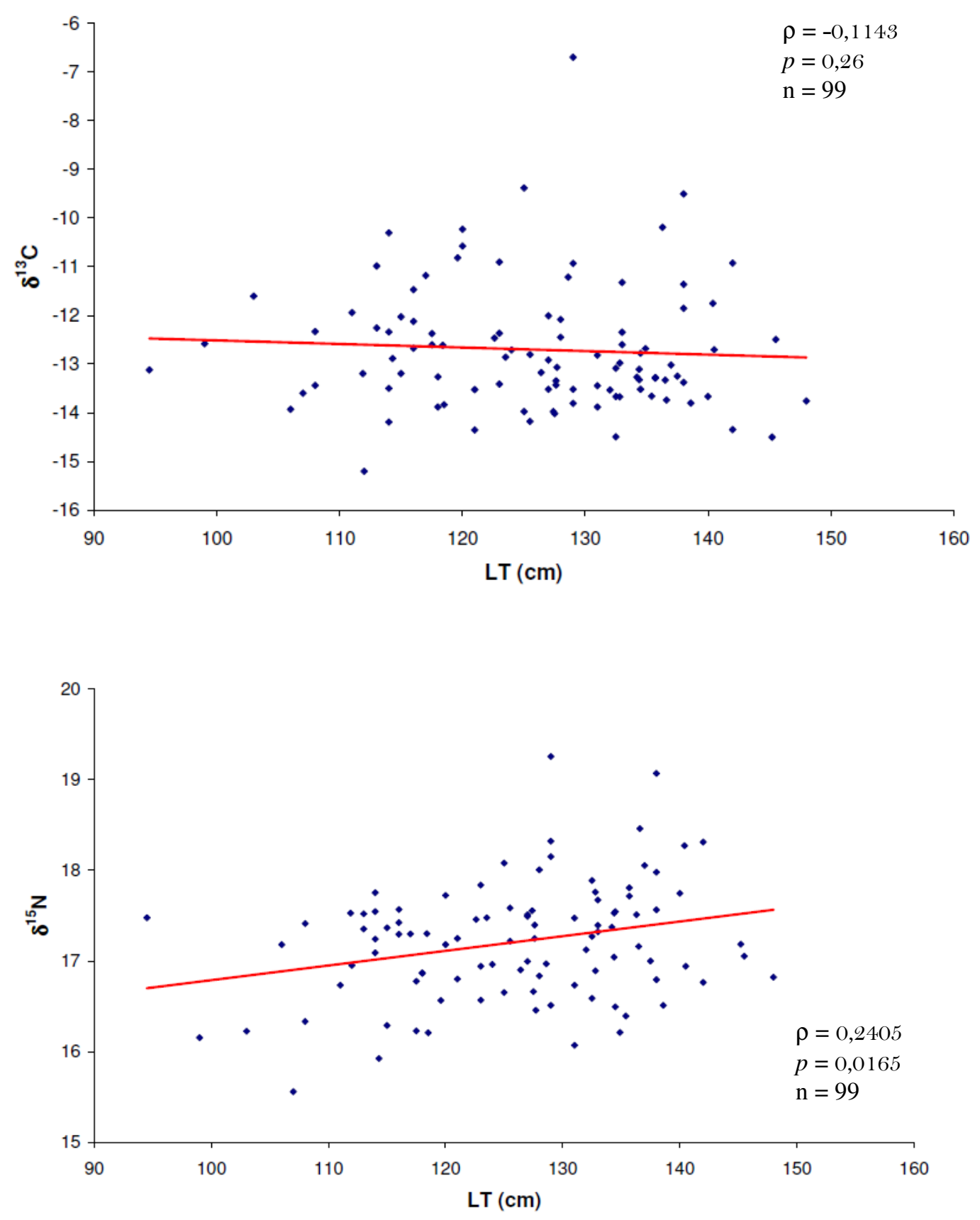

Figura 18. Variación isotópica intra-específica en Cephalorhynchus commersonii en relación con la longitud total de los individuos. Coeficiente de correlación por rangos de Spearman $(\rho)$, probabilidad $(p)$, longitud total (LT) y número de individuos analizados $(\mathrm{n})$. 


\subsection{VARIACIÓN ISOTÓPICA TEMPORAL}

Una pequeña fracción de lo registrado para los valores de $\delta^{13} \mathrm{C}$ se relaciona con la quema de combustible fósil de hace $\sim 150$ años. Para al Corrección Suess se usó una corrección tiempo-dependiente de -0.022\%o por año, encontrándose una corrección promedio de solo $0.5 \%$ o $( \pm 0.1 \%$ o para cada especie con un rango de 0.4\% a $0.7 \%$. La similar magnitud y el pequeño rango en el cálculo de la Corrección de Suess entre las especies, resulta en pequeños cambios (0.2-0.3\%o) en sus valores promedios de $\boldsymbol{\delta}^{13} \mathrm{C}$. Esto no modifica sustancialmente los valores entre ellas ni las comparaciones estadísticas, por lo que, esta corrección no se aplicó para las comparaciones generales de $\delta^{13} \mathrm{C}$. Sin embargo, para eliminar este efecto Suess sobre el análisis isotópico temporal, los valores de $\delta^{13} \mathrm{C}$ fueron previamente corregidos.

Los resultados de los análisis isotópicos temporales realizados sobre las especies de cetáceos se muestran resumidos en la Tabla 9 y Figura 19. En el caso de especial de Grampus griseus, para evaluar una posible relación entre la variabilidad isotópica encontrada y los años de varamiento, se asumió un único grupo que incluyó a los individuos de ambos ecotipos propuestos (GG1 y GG2).

\section{Tabla 9. Resultados del análisis de correlación entre los valores de $\boldsymbol{\delta}^{13} \mathrm{C}$ y $\boldsymbol{\delta}^{15} \mathrm{~N}$ y los años de varamiento de los cetáceos.}

Coeficiente de correlación de Pearson (r) o de Spearman (rho) según el caso.

$\mathrm{El} *$ denota significancia estadística a $\alpha=0,05$

\begin{tabular}{cccccc} 
Especie & \multicolumn{2}{c}{ en $\boldsymbol{\delta}^{13} \mathbf{C}$} & \multicolumn{2}{c}{ en $\boldsymbol{\delta}^{15} \mathbf{N}$} & $\mathbf{n}$ \\
& r o $\boldsymbol{\rho}$ & $\mathbf{p}$ & r o $\boldsymbol{\rho}$ & $\mathbf{p}$ & \\
LA & $-0,3410$ & $0,0336^{*}$ & 0,1456 & 0,3763 & 39 \\
CC & $-0,2539$ & $0,0164^{*}$ & $-0,3686$ & $0,0004^{*}$ & 89 \\
\hline GG & $-0,4862$ & $0,0005^{*}$ & $-0,506$ & $0,0002^{*}$ & 48 \\
PD & 0,1138 & 0,2967 & $-0,332$ & $0,0018^{*}$ & 86 \\
\hline
\end{tabular}

Se encontró una correlación significativa de tipo negativa entre los valores de $\delta^{13} \mathrm{C}$ y los años de varamiento de los especímenes en Lagenorhynchus australis, Cephalorhynchus commersonii y G. griseus. Mientras que Phocoena dioptrica no mostró correlación entre los años de varamiento y los valores de $\delta^{13} \mathrm{C}$. 
En relación a los valores de $\delta^{15} \mathrm{~N}$, también se encontró una correlación significativa con los años de varamiento de tipo negativa en C. commersonii, $G$. griseus, y P. dioptrica. Mientras que L. australis no mostró correlación entre los años de varamiento y los valores de $\delta^{15} \mathrm{~N}$. 
Riccialdelli Luciana - Ecología trófica de cetáceos subantárticos-
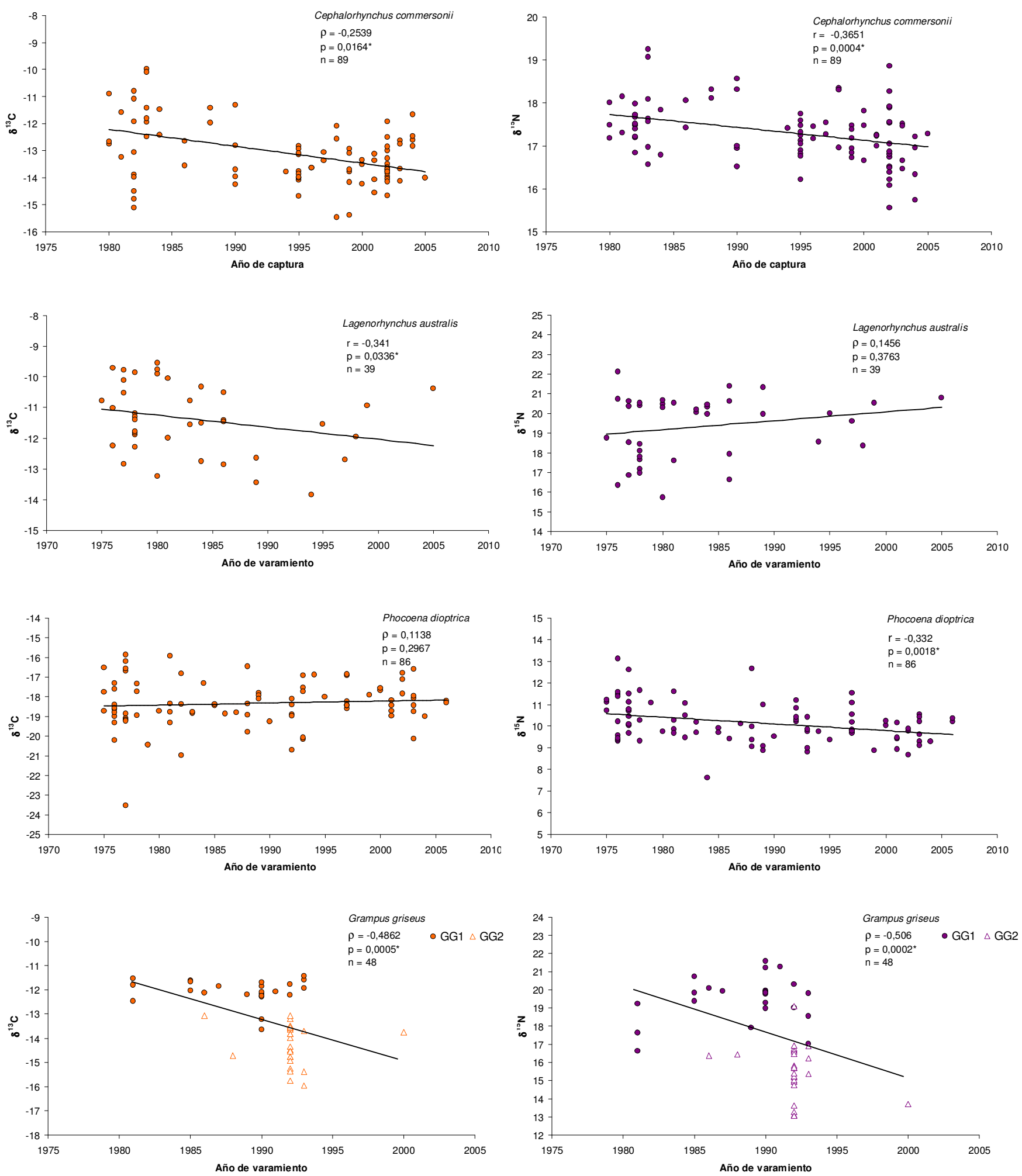

Figura 19. Variación isotópica temporal en Cephalorhynchus commersonii, Lagenorhynchus australis, Phocoena dioptrica y Grampus griseus. Tendencia en los valores de $\delta^{13} \mathrm{C}$ y $\delta^{15} \mathrm{~N}$ en las especies de cetáceos en relación con los años de captura incidental o varamiento según el caso. En G. griseus se discrimina los individuos pertenecientes al ecotipo GG1 (círculos) y a los que pertenecen a GG2 (triángulos). 


\section{CAPÍTULO 4}

\section{Discusión GENERAL}

\subsection{INTEGRIDAD DE LAS MUESTRAS}

El colágeno del hueso obtenido de los cetáceos estudiados constituye tanto colágeno propiamente dicho como otras proteínas no colágenas -encontradas también en el hueso- y que difieren en su composición isotópica (Koch et al. 2001). Cualquier alteración en la proporción de estas proteínas puede generar cambios sustanciales en sus valores de $\delta^{13} \mathrm{C}$ y $\delta^{15} \mathrm{~N}$.

Entre estas alteraciones, cabe mencionar que la exposición a diferentes factores ambientales y biológicos de los especímenes de cetáceos varados no ha comprometido seriamente la calidad de las muestras analizadas por nosotros. En otros estudios tampoco se ha encontrado una alteración en la composición isotópica original del colágeno. Ello ha quedado evidenciado en estudios isotópicos realizados por Hare et al. (1991) y Koch et al. (2001) sobre diversos restos óseos expuestos al ataque bacteriano/fúngico y a los efectos de agentes climáticos, por un período de 30 años.

Dado la estructura física y el tipo de enlaces del colágeno bajo condiciones ácidas pueden debilitarse y romperse, sin embargo la desmineralización en ácido débil generó una muy baja degradación de esta proteína obteniendo adecuadas concentraciones para el análisis de isótopos estables coincidiendo con las observaciones de Ambrose (1990).

Con la utilización de solventes orgánicos polares que remueven la mayor cantidad de lípidos de las muestras es posible la pérdida de aminoácidos y proteínas estructurales asociadas a los lípidos que se extraen. Debido a ello varios autores entre ellos Sotiropoulos et al. (2004), Post et al. (2007), Kojadinovic et al. (2008), Mintenbeck et al. (2008) han registrado incrementos indeseables en los valores de $\delta^{15} \mathrm{~N}$. La cantidad de cambio reportada difiere entre los estudios, para algunos el cambio producido fue menor que la desviación estándar, en otros de igual orden que el error analítico y en algunos casos no se ha informado efecto alguno. Sin embargo, el variable contenido lipídico de las muestras analizadas, hizo necesario esta etapa 
del procesamiento. Siendo que los lípidos están empobrecidos en ${ }^{13} \mathrm{C}$ respecto a los carbohidratos y las proteínas, son una gran fuente de variabilidad en los valores de $\delta^{19} \mathrm{C}$ cuando se comparan diferentes tipos de tejidos y de especies.

En este estudio se comparó una gran diversidad de organismos, desde invertebrados hasta vertebrados superiores, que ocupan distintas áreas espaciales (ej. áreas costeras, de plataforma y oceánicas). El diferente grado de contribución de los productores primarios (macroalgas, fitoplancton) a las redes tróficas de dichas áreas, generan valores isotópicos característicos. Esto contribuyó a la diferenciación isotópica de los niveles tróficos superiores.

De acuerdo a los valores de isótopos estables, determinados tanto en los predadores analizados como en sus posibles presas, el procesamiento general aplicado no generó serios problemas. Así el análisis de las fuentes alimentarias de los cetáceos mediante el uso de modelos de mezcla, el estudio de las preferencias de hábitat y la estimación de sus niveles tróficos a través del análisis de isótopos estables ofrece confiabilidad.

\subsection{VARIACIÓN ISOTÓPICA DE LAS PRESAS}

El análisis de isótopos estables sobre los grupos potenciales de presas de las diferentes especies de cetáceos constituyó un requisito fundamental para contribuir hacia una mejor interpretación de los valores de isótopos estables de carbono y nitrógeno obtenidos de ellos.

Aunque la base de datos lograda a partir de las presas debe completarse, los estudios realizados constituyen un avance esencial que permite definir diferentes hábitats. Las diferencias significativas encontradas entre los valores medios de $\delta^{13} \mathrm{C}$ y $\delta^{15} \mathrm{~N}$ de las presas permiten definir isotópicamente los distintos hábitats costero, de plataforma/talud y oceánico (Figura 7). Estos valores son el reflejo de los productores primarios dominantes de cada una de las regiones. Debido a que la mayoría de los sistemas costeros presentan múltiples fuentes de materia orgánica (ej. macroalgas, fitoplancton, fanerógamas intermareales, entre otros) las diferencias isotópicas que pueden obtenerse dificultan la interpretación de los datos (Michener \& Kaufman 2007). La incorporación de las macroalgas como fuente enriquecida en ${ }^{13} \mathrm{C}$ a las redes tróficas ha permitido observar diferencias con respecto a los sistemas 
offshore, en donde el fitoplancton es el único productor primario. De este modo, dado que las diferencias isotópicas de los organismos ubicados en la base de las redes tróficas repercuten en los valores isotópicos de los niveles superiores las diferencias en los valores de $\delta^{13} \mathrm{C}$ entre macroalgas y fitoplancton puede ser usada para comparar los organismos procedentes de diferentes hábitats. Más aún, el Océano Austral está caracterizado por presentar fitoplancton y materia orgánica particulada empobrecidos en ${ }^{13} \mathrm{C}$ y ${ }^{15} \mathrm{~N}$ respecto a las aguas del Atlántico Sudoccidental. Las diferencias isotópicas encontradas por Lara et al. (2010) en distintas regiones del Mar Argentino, el Pasaje de Drake y aguas Antárticas están relacionadas a cambios en las concentraciones de nutrientes y composición planctónica.

En la presente Tesis, se corrobora la influencia de las macroalgas en los ambientes costeros por los altos valores de $\delta^{13} \mathrm{C}$ y $\delta^{15} \mathrm{~N}$ que exhiben las presas costeras en relación con los bajos valores de $\delta^{13} \mathrm{C}$ y $\delta^{15} \mathrm{~N}$ de las especies de áreas oceánicas (Figura 7). Por otro lado, se han encontrado valores intermedios para especies que habitan regiones de plataforma y talud. Las presas de estas últimas zonas, en general, exhiben una importante movilidad entre los hábitats de acuerdo a la época del año (ej. Macruronus magellanicus, Illex argentinus, entre otros) en relación al movimiento de sus presas específicas o por características reproductivas. En estos casos, los valores isotópicos intermedios reflejan el acceso a múltiples fuentes de alimento, asimismo, permiten definir un ecosistema intermedio de aguas de plataforma y talud entre las zonas costeras y oceánicas (Figura 7).

La comparación en los valores de $\boldsymbol{\delta}^{15} \mathrm{~N}$ puede complicarse por el nivel trófico de los individuos. La baja diferencia encontrada entre las presas costeras y las de plataforma/talud ( $\sim, 5 \%$ ), parece reflejar este hecho, dado que la mayoría de las presas costeras analizadas ocupan niveles tróficos inferiores a la mayoría de las de plataforma. Por lo cual, la comparación de especies de igual nivel trófico permitiría observar valores de $\delta^{15} \mathrm{~N}$ más altos para los que habitan las zonas costeras con respecto a otras áreas.

El análisis sobre estas muestras fundamenta las discriminaciones isotópicas de los cetáceos en relación a sus hábitos alimentarios y usos del hábitat. 


\subsection{VARIACIÓN ISOTÓPICA INTER-ESPECÍFICA EN LOS CETÁCEOS ESTUDIADOS}

La investigación sobre el grado de solapamiento/segregación entre las poblaciones bajo estudio dependió de las grandes diferencias isotópicas encontradas entre los grupos presa y/o entre las áreas de alimentación que son explotadas por estos predadores. Para una adecuada caracterización isotópica de cada población, o especie de cetáceo, fue necesario el análisis de un alto número de individuos, dado que en la mayoría de ellas se encontró una alta variabilidad en $\delta^{13} \mathrm{C}$ y $\delta^{15} \mathrm{~N}$.

Las evidencias isotópicas sugieren que estas especies se alimentan a distintos niveles tróficos y hasta en distintos hábitats. De acuerdo al comportamiento trófico principal de cada una de ellas, y en base a sus firmas isotópicas el análisis de cluster muestra la estructura de la comunidad de cetáceos desde especies costeras (ej. Lagenorhynchus australis) hacia oceánicas (ej. Phocoena dioptrica) y de latitudes bajas (ecotipo GG1 de Grampus griseus) a altas (ej. Lagenorhynchus cruciger).

Para aquellas especies en las que se pudo estimar la composición isotópica de su dieta, el modelo IsoSource permitió determinar límites en la contribución de cada grupo presa. Sin embargo, para estas especies de cetáceos no se ha determinado experimentalmente el factor de fraccionamiento trófico entre el colágeno del hueso y la dieta, por lo que los datos isotópicos no permiten una reconstrucción precisa de la misma. No obstante, fueron útiles para detectar de forma general la contribución relativa de los diferentes grupos presa (costeras, plataforma/talud y oceánicas) en la dieta de estos predadores (Figura 14, 15). Además, también fue posible asignar a cada uno de ellos potenciales áreas de alimentación de acuerdo a la relación isotópica que establecieron con los grupos presa (Figura 15).

\section{Áreas espaciales de alimentación}

La amplia variación en los valores de $\delta^{13} \mathrm{C}$ y $\delta^{15} \mathrm{~N}$ del colágeno del hueso entre las especies de cetáceos costeros y oceánicos (Figura 8) reflejan los cambios latitudinales y longitudinales de los valores de $\delta^{19} \mathrm{C}$ y $\delta^{15} \mathrm{~N}$ de sus especies presas y productores primarios. Resultados similares han sido observados previamente en áreas del Océano Pacífico, el mar de Bering, Chukchi y Beaufort por Dunton et al. (1989), Schell et al. (1998) y Rau et al. (1982). Además, como resultado de estudios 
llevados a cabo por Lewis et al. (2006) y Drago et al. (2009), entre otros autores, en una variado grupo de organismos marinos de la región de la plataforma patagónica y por Lara et al. (2010) en la materia orgánica particulada, se ha observado un decrecimiento significativo en los valores de $\delta^{13} \mathrm{C}$ desde áreas costeras hacia áreas oceánicas (variación longitudinal) y de especies que habitan áreas del norte y sur de la Patagonia (variación latitudinal). La tendencia negativa registrada en los valores de $\delta^{13} \mathrm{C}$ desde especies costeras (grupo 1, Lagenorhynchus australis), hacia especies oceánicas (Phocoena dioptrica y Lagenorhynchus cruciger) con valores intermedios para las especies costeras-de plataforma (grupo 2, Cephalorhynchus commersonii y Phocoena spinipinnis), y las especies de plataforma-talud (grupo 3, Lissodelphis peronii, Grampus griseus y Pseudorca crassidens) reflejan las variaciones isotópicas del ambiente en función de la latitud y la longitud (Figura 15).

Sumado a la variación en los valores de $\delta^{13} \mathrm{C}$ entre las diferentes áreas de alimentación, también se ha encontrado un decrecimiento en los valores de $\delta^{15} \mathrm{~N}$ en función de la latitud y la longitud. Como se mencionó para los grupos presa los valores de $\delta^{15} \mathrm{~N}$ están fuertemente influenciados por la posición trófica de los organismos, lo cual puede complicar su uso como un indicador de hábitat. Sin embargo, se encontraron patrones geográficos similares en los valores de $\delta^{15} \mathrm{~N}$ como en los de $\delta^{13} \mathrm{C}$.

Las diferencias en ambos valores de $\delta^{13} \mathrm{C}$ y $\delta^{15} \mathrm{~N}$ entre estos grupos inshore (grupo 1 y 2) y offshore (grupo 3) confirman que los isótopos pueden ser usados para diferenciar las áreas espaciales de forrajeo de las especies de cetáceos a lo largo de un gradiente longitudinal. Se encontraron las mismas diferencias en los valores de $\delta^{13} \mathrm{C}$ y $\delta^{15} \mathrm{~N}$ entre las especies oceánicas y los otros dos grandes grupos (inshore y offshore). Esto confirma que ambos sistemas isotópicos pueden ser usados para determinar la variación latitudinal en las áreas espaciales de alimentación de estos predadores, reflejando en última instancia la variación en la base de las redes tróficas en la región más austral del Atlántico Sudoccidental (Figura 15).

En algunos casos, los valores isotópicos similares de los organismos ubicados en la base de las redes tróficas pueden complicar la interpretación de las preferencias tróficas de los predadores. Por ejemplo, en el caso de L. australis y el ecotipo GG1 de G. griseus presentan valores de $\delta^{13} \mathrm{C}$ y $\delta^{15} \mathrm{~N}$ similares, lo cual sugiere que estas 
especies consumen especies presas parecidas en el mismo hábitat. Sin embargo, se conoce que L. australis y G. griseus (en este caso el ecotipo GG1) tienen hábitos tróficos completamente diferentes y habitan diferentes hábitats. Este ejemplo demuestra que, en ciertos casos, los datos isotópicos deben ser complementados con información obtenida de otras fuentes, como la observación directa o el análisis de contenidos estomacales. Esta integración de la información disponible otorga una mejor interpretación de los datos ambiguos.

Bearhop et al. (2004) han propuesto utilizar la varianza isotópica como medida de la amplitud del nicho trófico. En este sentido, la amplitud del nicho trófico ha sido abordada mediante estudios convencionales sobre la dieta de los organismos, como el análisis de contenidos estomacales, de heces u observación directa, junto con medidas de riqueza y uniformidad (Beahorp et al. 2004, Layman et al. 2007). El análisis de isótopos estables se ha transformado en una herramienta muy útil para evaluar algunos aspectos del nicho trófico de las especies, dado que provee información ecológica tanto sobre la dieta como del hábitat en el que viven (LeeThorp et al. 2003, Syväranta \& Jones 2007, Newsome et al. 2007b, entre otros).

En algunas especies de cetáceos se encontró un solapamiento en los valores de $\delta^{13} \mathrm{C}$ y/o $\delta^{15} \mathrm{~N}$ con otras especies (ej. C. commersonii y P. spinipinnis), lo cual indica un potencial solapamiento de sus áreas de alimentación y/o sus preferencias alimentarias y por lo tanto de sus nichos tróficos. Más aún, una mayor varianza isotópica implicaría amplias áreas de alimentación y/o preferencias alimentarias, incrementando la amplitud del nicho y una tendencia al comportamiento generalista por parte de los cetáceos. Mientras que una menor varianza isotópica implicaría menor amplitud del nicho trófico y un comportamiento más especialista (ej. $P$. crassidens).

\section{Niveles tróficos y comportamiento alimentario}

\section{Especies Inshore}

Lagenorhynchus australis (delfín austral)

Lagenorhynchus australis, presenta los valores más altos de $\delta^{13} \mathrm{C}$ y $\delta^{15} \mathrm{~N}$, sugiriendo que esta especie se alimenta en ecosistemas costeros y ocupa niveles tróficos relativamente altos $(\sim 5.5)$ en comparación con otras especies inshore 
(Cephalorhynchus commersonii y Phocoena spinipinnis). L. australis habita ambientes donde las macroalgas, que típicamente tienen valores de $\delta^{13} \mathrm{C}$ de $6-8 \%$ más altos que el fitoplancton simpátrico (France 1995), son productores primarios importantes influenciando los altos valores isotópicos de los organismos costeros. La comparación de los valores isotópicos promedios de L. australis con las potenciales presas analizadas sugiere que es una especie principalmente ictiófaga, cuya dieta es típicamente costera (Figura 14, 15). De acuerdo a los resultados del modelo IsoSource, las especies presas más importantes para este cetáceo incluirían presas costero-bentónicas (ej. Zoarcidos indeterminados, Patagonotothem sima, $P$. tessellata, Eleginops maclovinus) y costero-pelágicas (e.j. Odonthestes spp.), seguidos por especies demerso-pelágicas de plataforma/talud (ej. Merluccius australis, M. hubbsi, Salilota australis, Macrucronus magellanicus, Cottoperca gobio), constituyendo los grupos que más contribuyen a la composición isotópica del colágeno del hueso de L. australis. A diferencia de las observaciones realizadas por Lescrauwaet en Schiavini et al. (1997) sobre la importancia de los pulpos que tienen en la alimentación de L. australis, ellas exhiben una muy baja contribución al valor del colágeno del hueso de esta especie.

Estos resultados están ratificando los hábitos alimentarios de L. asutralis en el sector atlántico de Tierra del Fuego, conocidos a través de estudios convencionales de dieta por Schiavini et al. (1997), Viddi \& Lescrawaet (2005) entre otros, los cuales sostienen que es un predador generalista costero y que puede extender su alimentación sobre la plataforma patagónica persiguiendo presas demerso-pelágicas como las mencionadas anteriormente.

Cephalorhynchus commersonii (tonina overa) y Phocoena spinipinnis (marsopa espinosa)

Cephalorhynchus commersonii y Phocoena spinipinnis también fueron consideradas como especies inshore. Las similitudes en los valores de $\delta^{13} \mathrm{C}$ entre estas dos especies con Lissodelphis peronii, Pseudorca crassidens y el ecotipo GG2 de Grampus griseus sugieren que estos pueden tener en común alguna parte de sus áreas de alimentación sobre la plataforma patagónica y/o en la elección de sus presas. De acuerdo al análisis de isótopos estables C. commersonii y P. spinipinnis presentan valores promedios similares de $\delta^{13} \mathrm{C}$ y $\delta^{15} \mathrm{~N}$ y ocupan niveles tróficos similares, lo cual sugiere que tienen preferencias alimentarias y de hábitat comunes, y posiblemente compitan por las mismas fuentes alimentarias en los ecosistemas 
costeros. Brownell \& Praderi (1982) sugirieron que P. spinipinnis es menos abundante en la costa Atlántica que en la Pacífica de su distribución debido a una competencia con otros cetáceos menores costeros como el tucuxi (Sotalia guianensis) y la franciscana (Pontoporia blainvillę) al norte, y con C. commersonii y Lagenorhynchus australis al sur de su distribución atlántica. No obstante, $C$. commersonii y $P$. spinipinnis no se encuentran en competencia directa por el alimento o el hábitat con L. australis en base a sus diferentes valores medios de $\delta^{13} \mathrm{C}$ y $\delta^{15} \mathrm{~N}$. Sin embargo, y de acuerdo con el análisis de su varianza isotópica, C. commersonii y P. spinipinnis pueden estar compitiendo por las presas y/o el hábitat, o pueden estar consumiendo diferentes proporciones de las mismas especies presas en la misma área de forrajeo, llevando a un solapamiento no competitivo.

Los resultados isotópicos de esta Tesis sugieren que $C$. commersonii y $P$. spinipinnis son predadores principalmente piscívoros. Esto está en concordancia con estudios convencionales sobre la dieta de estas especies realizados en distintas partes de su distribución, entre ellos los estudios realizados por Bastida et al. (1988), Corcuera (1991), Escare \& Oporto (1992), Corcuera et al. (1995), Lorenzani \& Junin (1996), Rosero Caicedo (2005) y Pedraza (2007). De acuerdo a los resultados del IsoSource especies de peces costero-pelágicos (e.j. Sprattus fuegensis), demerso-pelágicos de plataforma/talud (e.j., Merluccius hubbsi, M. australis, Salilota australis, nototenidos, Micromesistius australis, Genypterus blacodes) y calamares (e.j. Loligo gahi, Illex argentinus) constituyen las presas principales de estas especies. La baja contribución isotópica que mostraron las presas costero-bentónicas (ej. Patagonotothen spp., Eleginops maclovinus) y el grupo de crustáceos (ej. Munida gregaria, Halicarcinus planatus) al valor isotópico del colágeno del hueso de $C$. commersonii, sugiere una baja representatividad de estos grupos en su dieta, a diferencia de lo encontrado por Pedraza (2007) y Rosero Caicedo (2005) para los peces y Bastida et al. (1988) para los crustáceos.

El uso de distintos recursos costeros y de plataforma se ve reflejado en los valores medios de $\delta^{13} \mathrm{C}$ y $\delta^{15} \mathrm{~N}$ y sus varianzas isotópicas, constituyendo una dieta mixta para C. commersonii y P. spinipinnis (Figura 14, 15). Esta dualidad en su alimentación dificulta la interpretación de la amplitud de sus áreas de alimentación. Según Bastida et al. (1988), Clarke \& Goodall (1994) y Pedraza (2007), la distribución temporal y las altas concentraciones que algunos recursos alcanzan en ciertas épocas del año (ej. Sprattus fuegensis, Macruronus magellanicus, Salilota 
australis) en los sectores costeros de Tierra del Fuego, es aprovechado por $C$. commersonii dado su comportamiento oportunista. Dado las similitudes isotópicas, posiblemente P. spinipinnis presente el mismo comportamiento. De acuerdo a esto, la dieta mixta de estas especies puede estar generada por el consumo de presas de aguas más profundas de la plataforma patagónica (a demás de las costeras) sólo en aguas costeras cuando éstas se hacen disponibles en la zona o bien por el uso de ambos ambientes (costa y plataforma patagónica) donde se ofrece esta variedad de presas.

A pesar del escaso conocimiento sobre los movimientos estacionales de estas dos especies, Würsig et al. (1977), Goodall (1994) y Pedraza (2007) han sugerido que las mismas exhiben movimientos hacia aguas offshore en respuesta a los movimientos de sus presas o por la búsqueda de áreas para la protección de crías. Además, Pedraza (2007) ha registrado individuos en un amplio rango de profundidades (entre $10 \mathrm{~m}$ a $+200 \mathrm{~m}$ ), en áreas muy alejadas de la costa. Las similitudes isotópicas con especies de cetáceos offshore parecen corroborar esta idea, sugiriendo que sus áreas de alimentación pueden ser más extensas sobre la plataforma patagónica persiguiendo peces pelágicos, demerso-pelágicos y calamares (Figura 15).

Futuros análisis de isótopos estables sobre tejidos con una mayor tasa de recambio isotópico (como piel, músculo) tendrán gran utilidad para discernir movimientos tróficos diarios o estacionales de estas dos especies. A su vez, esto también podrá mejorar la resolución en las contribuciones isotópicas de grupos escasamente representados en esta Tesis (ej. crustáceos). De acuerdo a los estudios convencionales sobre la dieta de C. commersonii realizados por Bastida et al. (1988), Rosero Caicedo (2005) y Pedraza (2007), esta especie se alimentaría tanto de estadios juveniles de ciertos grupos de presas (ej. Odontesthes spp) así como de individuos que han alcanzado la madurez sexual (ej. Macruronus magellanicus y Patagonotothen cornucula). El análisis de isótopos estables sobre individuos presa a diferentes tallas mejoraría la determinación de la dieta de estas especies. 


\section{Especies Offshore}

Pseudorca crassidens (falsa orca)

Pseudorca crassidens es considerada como un predador oceánico (Best 2007), aunque las similitudes en sus valores promedios de $\delta^{13} \mathrm{C}$ con otras especies offshore (ecotipo GG2 de Grampus griseus y Lissodelphis peronii), sugieren que ocupa hábitats principalmente sobre el talud continental en la región donde estos animales vararon $\left(52^{\circ}\right.$ a $\left.55^{\circ} \mathrm{S}\right)$. Las muestras óseas de $P$. crassidens analizadas en esta Tesis pertenecieron a individuos que formaron parte de un gran varamiento masivo, formado por 181 animales, ocurrido en el Estrecho de Magallanes en el mes de marzo de 1989 comunicado por Goodall \& Schiavini (1989) y Goodall et al. (2008). Esta especie, a pesar de tener similitudes isotópicas con L. peronii y el ecotipo GG2, parece diferir de aquellas especializándose en su alimentación, basada en cefalópodos, como sugieren los análisis de contenidos estomacales realizados por Koen Alonso et al. (1999) sobre 25 individuos del varamiento mencionado. Estas presas estaban representadas principalmente por calamares neríticos-oceánicos de aguas subantárticas (ej. Illex argentinus, Martialia hyadesi, Moroteuthis ingens) y antárticas (ej. Teuthowenia megalops), y peces neríticos (ej. Macruronus magellanicus, Genypterus blacodes) comunmente encontrados en la plataforma patagónica y las aguas offshore adyacentes a esta. Su dieta especializada en cefalópodos, está siendo avalada por el NT estimado (y el valor promedio de $\delta^{15} \mathrm{~N}$ asociado), el cual fue el más bajo registrado entre todas las especies analizadas y el esperado para especies principalmente teutófagas (Tabla 4). A su vez, la baja variación isotópica relativa observada en $\delta^{13} \mathrm{C}$ y $\delta^{15} \mathrm{~N}$ para $P$. crassidens también sugiere que esta especie es un predador especialista, con un acotado nicho trófico. A pesar del análisis sobre algunas especies de calamares neríticos-oceánicos, no se ha podido identificar presas específicas para $P$. crassidens, probablemente provocado por el bajo número de calamares en nuestra base de datos. No obstante, la comparación de sus valores de $\delta^{13} \mathrm{C}$ y $\delta^{15} \mathrm{~N}$ en el conjunto de datos sugiere una dieta oceánica/offshore sobre áreas de la plataforma externa y talud continental (Figura 14, 15).

Lissodelphis peronii (delfín liso austral)

Lissodelphis peronii es considerado un predador oceánico y circumpolar (Best 2007). Nuestros resultados sugieren que esta especie de delfín tiene hábitos offshore y habita principalmente sobre el talud continental como Pseudorca crassidens y el 
ecotipo GG2 de Grampus griseus (Figura 15). Si bien existen similitudes en los valores promedios de $\delta^{13} \mathrm{C}$ con especies inshore (como, Cephalorhynchus commersonii y Phocoena spinipinnis). Los mismos sugieren que $L$. peronii hace uso de recursos alimentarios de la plataforma patagónica, como lo hace en otras partes del mundo, donde es observado frecuentemente en habitats costeros (como por ej. en las márgenes occidentales de Sudáfrica y Chile, alimentándose en los sistemas de la corriente de Benguela y Humboldt) (Best 2007). Sin embargo, no existe información sobre movimientos específicos de este delfín en el Atlántico Sudoccidental que corroboren lo sugerido por sus valores isotópicos.

Los estudios de contenidos estomacales realizados por Torres \& Aguayo (1979) y Van Waerebeek \& Oporto (1990) en ejemplares de L. peronii sugieren que esta especie preda sobre una variedad de peces principalmente mictófidos y calamares pelágicos en las aguas de Chile y Perú. El valor promedio de $\delta^{15} \mathrm{~N}$, así como el NT estimado para $L$. peronii se encontró entre aquellas especies que se alimentan principalmente de calamares ( $P$. crassidens) y las que consumen principalmente peces (P. spinipinnis y C. commersoniı), sugiriendo una dieta oceánica/offshore basada en peces (ej. Micromesistius australis, nototenidos, Coelorinchus fasciatus, Iluocoetes fimbriatus) y cefalópodos (ej., Illex argentinus, Loligo gahi, Moroteuthis ingens) colectados principalmente sobre la plataforma y el talud patagónico (Figura 14, 15).

\section{Grampus griseus (delfín gris)}

Grampus griseus es un cetáceo que puede encontrarse en el Atlántico Sudoccidental, pero poco es lo que se conoce en relación a sus hábitos alimentarios, distribución, movimientos estacionales, reproducción y estructura poblacional. Esto se debe principalmente a sus típicos hábitos offshore, sus escasos avistajes y eventos de varamientos a lo largo de la costa argentina. Las evaluaciones de stocks (a través de varamientos y registros de avistajes) son incompletas y, previo a estos análisis de isótopos estables, no existe evidencia alguna que sugiera la existencia de dos ecotipos. Por esta razón, originalmente se asumió que todos los individuos analizados provenían de la misma unidad poblacional siendo que vararon en un área relativamente acotada y en años consecutivos, la mayor parte entre los años 1990 y 1993.

La distribución bimodal en los valores de $\delta^{13} \mathrm{C}$ y $\delta^{15} \mathrm{~N}$ sobre estas muestras sugieren un escenario diferente para G. griseus. Por lo tanto se consideró a esta 
especie con dos ecotipos, GG1 y GG2, con altos valores de isótopos estables de carbono y nitrógeno para el primero y bajos para el segundo. Se consideró a GG1 como el grupo habitante de aguas del norte de la Patagonia, con valores promedios de $\delta^{13} \mathrm{C}$ y $\delta^{15} \mathrm{~N}$ similares a los de Lagenorhynchus australis, mientras que los valores para GG2 son más parecidos a especies que ocupan áreas del sur de las aguas Patagónicas (ej. Lissodelphis peronii). Los valores isotópicos de estos ecotipos parecen seguir la tendencia isotópica negativa registrada en la materia orgánica particulada por Lara et al. (2010) desde bajas hacia altas latitudes en las aguas del Atlántico Sudoccidental.

Ambos grupos (GG1 y GG2) parecen habitar aguas de plataforma externa y talud continental en el sudoeste del Atlántico Sur, lo cual contrasta con los estudios de varios autores, entre ellos Olavarría et al. (2001) y Davis et al. (2002), que han registrado a $G$. griseus ocupando aguas muy profundas y de hábitat oceánicos. No existe información sobre contenidos estomacales para esta especie en el Atlántico sudoccidental. Los valores de $\delta^{15} \mathrm{~N}$ y $\delta^{13} \mathrm{C}$ de ambos ecotipos concuerdan con valores de $\delta^{15} \mathrm{~N}$ y $\delta^{13} \mathrm{C}$ de calamares registrados por Ciancio et al. (2008) y calamares analizados en la presente Tesis sobre aguas de la Patagonia Austral, y por Forero et al (2004), Lewis et al. (2006) y Drago et al. (2009) para aguas del centro y norte de Patagonia (Figura 16). Esta alimentación principalmente teutófaga concuerda con los estudios de Sekiguchi et al. (1992) sobre contenidos estomacales de ejemplares de G. griseus de Sudáfrica. En los cuales también han encontrado que peces de aguas offshore complementan su dieta.

De acuerdo a los datos de esta Tesis, el ecotipo del sur (GG2) tiene un comportamiento trófico similar a L. peronii y Pseudorca crassidens, con una dieta principalmente oceánica/offshore (Figura 14, 15), donde presas como calamares (ej. Semirrosia tenera, Moroteuthis ingens, Loligo gahi, Illex argentinus) y peces pelágicos/demerso-pelágicos (ej. Micromesistius australis, Sprattus fuegensis, Mictófidos) constituyen potenciales presas.

\section{Especies Oceánicas}

Lagenorhynchus cruciger (delfín cruzado)

Lagenorhynchus cruciger es una especie encontrada sólo en el hemisferios sur ambos lados de la Convergencia Antártica. Sus avistajes no son raros, aunque poco 
es lo que se conoce sobre sus preferencias alimentarias. En base a las pocas muestras de contenidos estomacales analizadas por Goodall et al. (1997a) y Fernández et al. (2003) para ejemplares de L. cruciger, se conoce que esta especie se alimenta de peces y calamares que migran hacia aguas superficiales durante la noche.

Phocoena dioptrica (marsopa de anteojos)

Phocoena dioptrica es uno de los cetáceos más raros del mundo sobre el que existe muy poca información ecológica. Sin embargo se le ha atribuido un comportamiento costero-oceánico debido a los numerosos varamientos registrados por Goodall \& Schiavini (1995) y Goodall et al. (2008) en las costas adyacentes al sudoeste del Océano Atlántico, especialmente Tierra del Fuego y por los avistajes registrados en aguas oceánicas subantárticas (Goodall \& Schiavini 1995) y, de forma reciente por Sekiguchi et al. (2006) en aguas Antárticas. Sin embargo, las grandes diferencias isotópicas en $\delta^{19} \mathrm{C}$ y $\delta^{15} \mathrm{~N}$ que $P$. dioptrica mantiene con las especies inshore (Lagenorhynchus australis, Cephalorhynchus. commersonii y Phocoena spinipinnis) es una fuerte evidencia contra la hipótesis del comportamiento costero que se le ha otorgado.

Ambas especies, L. cruciger y $P$. dioptrica, tienen los valores promedios más bajos de $\delta^{13} \mathrm{C}$ y $\delta^{15} \mathrm{~N}$, los cuales se correlacionan con valores isotópicos empobrecidos del Océano Austral registrados por Rau et al. 1982, Goericke \& Fry (1994), Dehairs et al. (1997) y Lara et al. (2010). Estos datos sugieren que comúnmente habitan las aguas frías, oceánicas de la Convergencia Antártica en particular zonas empobrecidas en ${ }^{13} \mathrm{C}$ y ${ }^{15} \mathrm{~N}$ del Pasaje de Drake y el Frente Polar $\left(\sim 59^{\circ} \mathrm{S}\right)$, donde ambas especies son avistados. Desafortunadamente, dado las dificultades logísticas en el muestreo del Frente Polar, no se cuentan con suficientes datos para detectar potenciales presas de estas especies ni para estimar sus niveles tróficos. Sin embargo, la similitud en los valores medios de $\boldsymbol{\delta}^{13} \mathrm{C}$ como de $\boldsymbol{\delta}^{15} \mathrm{~N}$, indica que ambas especies tienen similares requerimientos alimentarios y de hábitats (Figura 14, 15).

Es necesario, la investigación más detallada de los gradientes espaciales de los valores isotópicos en la base de las redes tróficas de los distintos hábitats de la región (áreas costeras, de plataforma/talud y oceánicas) para confirmar los gradientes isotópicos latitudinales y longitudinales inferidos por los datos de los predadores registrados en esta Tesis. Estas muestras tendrán importancia en la determinación de los roles de varias especies de cetáceos en el Océano Austral 
(como Lagenorhunchus cruciger, Phocoena dioptrica y Pseudorca crassidens) para los que existe actualmente escasa información ecológica.

En la región de la plataforma patagónica austral, que abarca la zona de estudio Lara et al. (2010) registraron valores de $\delta^{13} \mathrm{C}$ y $\delta^{15} \mathrm{~N}$ más bajos respecto al norte de la plataforma patagónica y aguas del sur de la Provincia de Buenos Aires, con importantes diferencias de $\sim 12 \%$ y $\sim 8 \%$ on los valores de $\delta^{13} \mathrm{C}$ y $\delta^{15} \mathrm{~N}$, respectivamente, en la materia orgánica particulada. Entre $\operatorname{los} 54^{\circ}$ a $58^{\circ} \mathrm{S}$, al norte del Pasaje de Drake, ambos isótopos muestran una marcada declinación, con valores de $\delta^{15} \mathrm{~N}$ que disminuyen de $0,08 \%$ a a $-1,66 \%$ y valores medios de $\delta^{13} \mathrm{C}$ de $26,9 \%$ o $\left( \pm 0,1 \%\right.$ o). La marcada declinación en $\delta^{15} \mathrm{~N}$ está asociada a la utilización por parte del fitoplancton de amonio empobrecido en ${ }^{15} \mathrm{~N}$. Al sur del Pasaje de Drake, en el Frente Polar $\left(59^{\circ} \mathrm{S}\right)$ y hacia regiones antárticas los valores aumentan, de $1,1 \%$ o a $6,8 \%$ on $\delta^{15} \mathrm{~N}$ y de $-30,6 \%$ a $-23,9 \%$ on $\delta^{13} \mathrm{C}$.

La variación isotópica registrada en estas especies de cetáceos parece estar en concordancia con la declinación isotópica que exhibe la materia orgánica particulada registrada por Lara et al. (2010) en las aguas del Atlántico Sudoccidental y el Océano Austral. Es importante resaltar la gran diferencia en los valores de $\delta^{13} \mathrm{C}$ y $\delta^{15} \mathrm{~N}$ entre las aguas del norte y sur de la plataforma patagónica. Esto sustenta la división espacial entre el ecotipo GG1 de Grampus griseus con los grupos/especies del sur (ecotipo GG2, Cephalorhynchus commersonii, Phocoena spinipinnis, Lissodelphis peronii, Pseudorca crassidens). Así como la diferencia entre los valores isotópicos de las aguas patagónicas con las del Pasaje de Drake y el Frente Polar, sustenta la división espacial con las especies más oceánicas, L. cruciger y $P$. dioptrica, constituyendo estas zonas como principales áreas de alimentación para estas especies dado sus bajos valores de $\delta^{13} \mathrm{C}$ y $\delta^{15} \mathrm{~N}$ (Figura 15).

\subsection{VARIACIONES INTRA-ESPECÍFICA EN LA DIETA}

\subsubsection{Grampus griseus}

De los 69 especímenes varados en las costas de Tierra del Fuego comunicados por Goodall et al. (2008), 10 han sido eventos de varamientos masivos formados de 2 a 15 individuos, la mayoría de estos han estado compuestos por 3 a 4 individuos 
excepto dos eventos donde, en cada uno, vararon 15 animales juntos. Se analizó la mayor parte de los individuos de estos dos últimos varamientos y ellos definen, en gran medida los dos ecotipos ecológicos propuestos para Grampus griseus en esta región.

Ambos varamientos ocurrieron en el sector NE de Tierra del Fuego (Argentina), en Bahía San Sebastián $\left(53^{\circ} 10^{\prime} \mathrm{S}\right.$ y $\left.68^{\circ} 30^{\prime} \mathrm{O}\right)$. El primer grupo fue encontrado en la playa en el mes de diciembre de 1990 y el segundo en noviembre de 1992. Los individuos machos fueron los que predominaron en la composición sexual de ambos grupos (Goodall datos no publicados). En general, ambos ecotipos concuerdan con los dos grandes eventos de varamientos mencionados previamente. A excepción de pocos individuos, el ecotipo GG1 está compuesto mayormente por individuos varados en 1990, mientras que el ecotipo GG2 está compuesto por individuos varados en el evento de 1992. Otros casos de varamientos más pequeños terminan de definir estos grupos.

En esta especie de acuerdo a los estudios de Hartman et al. (2008) los subadultos mantienen asociaciones intra-específicas menos estables que los adultos, por lo que a partir de cierta edad abandonan sus grupos originales para unirse a otros. En estos casos, y si el tejido analizado aún registra información previa al movimiento de un grupo a otro, de acuerdo a Hobson (2007) sus firmas isotópicas reflejarán las de sus grupos originarios si los ambientes en los que éstos viven son isotópicamente distintos. En los dos eventos de varamiento se encuentran ciertos individuos cuyas firmas isotópicas reflejan las del ecotipo opuesto, por lo que es altamente probable que dichos especímenes hayan abandonado un grupo para unirse al otro.

Los valores de $\delta^{15} \mathrm{~N}$ observados sugieren que ambos grupos ocupan niveles tróficos altos cuando llegan a adultos. Los niveles tróficos estimados, 4,1 y 4,4 para GG1 y GG2 respectivamente, concuerdan con el nivel trófico (NT=4,3) estimado por Pauly et al. (1998) para G. griseus. A pesar de la falta de información sobre sus hábitos alimentarios en esta región de su distribución geográfica, los resultados isotópicos sugieren que esta especie, así como en otras partes del mundo (Baird 2009), es de hábitos principalmente teutófagos, si bien puede complementar su dieta con especies de peces de plataforma/talud. Posiblemente la diferente contribución isotópica de los distintos grupos de presas genera una mayor variabilidad en los valores de $\delta^{13} \mathrm{C}$ y un nivel trófico levemente más alto en el ecotipo GG2 respecto al ecotipo del norte. 
Los datos de avistajes sugieren que esta especie comúnmente vive en subgrupos de $\sim 10-30$ animales, sin embargo se han observado grandes agregaciones de individuos en respuesta a una abundante disponibilidad de alimento. Estos subgrupos cohesivos están formados en general por individuos del mismo sexo y edades similares. En relación a esto, Cockcroft et al. (1993) ha encontrado preferencias alimentarias relacionadas con el sexo y la edad en esta especie, lo cual puede expresarse en diferencias isotópicas como ha ocurrido en otras especies de mamíferos marinos, como lo informado por Knoff et al. (2008) para delfines nariz de botella (Tursiops truncatus), Niño Torres et al. (2006) para el delfín común (Delphinus capensis) y Drago et al. (2009) para el lobo marino de un pelo sudamericano (Otaria flavescens). A pesar de la repartición de los recursos alimentarios entre machos y hembras y entre diferentes clases de edades registrada por Cockroft et al. (1993) en esta especie, en esta Tesis no se ha encontrado diferencias isotópicas en los valores de $\delta^{15} \mathrm{~N}$ ni en los de $\delta^{13} \mathrm{C}$ relacionadas con el sexo o la edad en ninguno de los ecotipos, lo que sugiere un comportamiento trófico similar entre estas categorías para esta región.

Considerando el alto grado de homogeneidad en ambos grupos, los cuales estuvieron constituidos mayormente por individuos machos (23 machos vs. 6 hembras) y adultos (39 adultos vs 5 subadulos), es necesario realizar análisis isotópicos más exhaustivos, que cubran todas las clases de edades y una mejor proporción de sexos, para confirmar similitudes o diferencias en el comportamiento trófico en los individuos de esta especie en el Atlántico Sudoccidental.

Cuando se analiza los especímenes de G. griseus como un solo grupo (GG1 + GG2) el análisis de la variación isotópica temporal ofrece un panorama diferente al propuesto previamente.

Dado que el colágeno del hueso es un tejido con una lenta tasa de recambio isotópico, integra información de mucho tiempo ( $\sim 10$ años). De esta forma la gran variabilidad isotópica encontrada en años cercanos (1990 a 1993) y hasta en los mismos años (ej. 1992, Figura 19) cuando varó la mayoría de los ejemplares de $G$. griseus, no se atribuye a cambios isotópicos ocurridos en cortos períodos de tiempo así sean por modificaciones en las preferencias de presas y/o hábitats, o por cambios isotópicos en la base de la red trófica. La variación encontrada a través de los años podría atribuirse a una variación individual, sin embargo, parece estar 
influida en mayor medida por los gradientes naturales en los valores de $\delta^{13} \mathrm{C}$ y $\delta^{15} \mathrm{~N}$ entre latitudes bajas y altas determinadas para las aguas de la región patagónica registradas por Lara et al. (2010), confirmando la existencia de dos ecotipos para el Altántico Sudoccidental

Más aún, la existencia de diferentes ecotipos explica la gran variabilidad en los valores isotópicos del colágeno del hueso en pocos años. Considerando los valores de $\delta^{13} \mathrm{C}$ y $\delta^{15} \mathrm{~N}$ en especies de calamares analizados por Forero et al. (2004), Lewis et al. (2006), Ciancio et al. (2008) y Drago et al. (2009) en las aguas de Patagonia y los analizados en este trabajo, los valores isotópicos de los dos grupos tienden a ser diferentes, debido principalmente a una distribución latitudinal, y no por posibles especies presas en una misma localidad (Figura 16). Además, ambos ecotipos se encuentran estrechamente relacionados con los dos grandes eventos de varamientos mencionados anteriormente. Análisis futuros de $\mathrm{ADN}$ sobre estos especímenes confirmarán la presencia de uno o dos stocks biológicos que correspondan con los ecotipos ecológicos encontrados en este trabajo. Estudios de su distribución son también importantes para focalizar en un futuro las áreas de alimentación durante diferentes edades de la especie.

\subsubsection{Cephalorhynchus commersonii}

Las muestras analizadas de Cephalorhynchus commersonii provienen de individuos capturados incidentalmente en redes costeras artesanales. La mayoría de estas capturas se produjeron en la costa NE de Tierra del Fuego, entre las costas de Bahía San Sebastián $\left(53^{\circ} 10^{\prime} \mathrm{S}\right.$ y $\left.68^{\circ} 30^{\prime} \mathrm{O}\right)$ y la ciudad de Río Grande $\left(53^{\circ} 47^{\prime} \mathrm{S}\right.$ y $\left.67^{\circ} 42^{\prime} \mathrm{S}\right)$ (Goodall et al. 2008).

Se observó una baja correlación en los valores de $\delta^{15} \mathrm{~N}$ con la edad, con valores más altos en edades más avanzadas. Sin embargo, no se encontró correlación alguna en los valores de $\boldsymbol{\delta}^{13} \mathrm{C}$ con la edad. Teniendo en consideración la gran variabilidad en las tallas de los especímenes, el largo total no es una medida adecuada para determinar la edad en esta especie pero puede proveer una aproximación relativa de la edad del individuo. Los resultados para el $\delta^{13} \mathrm{C}$ y $\delta^{15} \mathrm{~N}$ en relación con el largo total corroboran lo hallado para la edad. De acuerdo a los estudios de Minagawa \& Wada (1984) y Hobson \& Clark (1992b) no habría cambios en el fraccionamiento dieta-tejido en los valores de $\delta^{13} \mathrm{C}$ y $\delta^{15} \mathrm{~N}$ en relación con la edad de los organismos, por lo que se asumió que las tendencias registradas en los isótopos estables de 
nitrógeno están generadas por cambios en los hábitos tróficos de los individuos a diferentes edades.

Diferencias isotópicas entre las crías lactantes y los adultos de varias especies de mamíferos marinos han sido registradas por varios autores, entre ellos Knoff et al. (2007) en delfín nariz de botella (Tursiops truncatus), Newsome et al. (2009) en especímenes de orca (Orcinus orca), Valenzuela et al. (2010) en ejemplares de ballena franca austral (Eubalaena australis), así como en varias especies de pinnípedos por Hobson et al. (1997) y Hobson \& Sease (1998) y Newsome et al. (2006) entre otros. De acuerdo a Jenkins et al. (2001) estas diferencias disminuyen posterior al destete de las crías causada por el aumento en la ingesta sólida de alimentos, alcanzando los valores de los adultos cuando su alimentación iguala a la de éstos. En general en estos estudios se encontraron valores de $\delta^{15} \mathrm{~N}$ más altos y valores de $\delta^{13} \mathrm{C}$ más bajos en las crías respecto a los adultos. El enriquecimiento en los valores de $\delta^{15} \mathrm{~N}$ se lo ha relacionado con el hecho de que las crías dependen de la leche materna y por lo tanto se asume que éstos se encuentran en un nivel trófico superior exhibiendo el efecto del enriquecimiento trófico ( $\sim 2-5 \%$ ). Mientras que los bajos valores en $\delta^{13} \mathrm{C}$ se atribuyen a la influencia del contenido lipídico de la leche. Como los lípidos se encuentran empobrecidos en ${ }^{13} \mathrm{C}$, presentan valores más bajos de $\delta^{13} \mathrm{C}$ respecto a otros tejidos (DeNiro \& Epstein 1978). Por lo tanto durante el periodo en que las crías dependen completamente de la leche materna, se espera que exhiban bajos valores de $\delta^{13} \mathrm{C}$. Sin embargo, Jenkins et al. (2001) y Valenzuela et al. (2010) han observado que la diferencia reportada para ambos isótopos difiere entre las especies y los tejidos analizados.

En esta especie la lactancia se extiende al menos durante 6 meses (Bastida et al. 2007). En base al estudio sobre individuos en cautiverio, Joseph et al. (1987) determinaron que la dieta ya comienza a ser mix ta a los dos meses de edad, al año de vida la lactancia cesa completamente y la cantidad de ingesta de material sólido equipara la del adulto. Por lo que se estima que en los juveniles ya hayan desaparecido los signos isotópicos de la lactancia.

Sumado al bajo número de crías analizadas $(\mathrm{n}=2)$, la ingesta de alimento sólido a tan temprana edad en esta especie, puede estar contribuyendo a la similitud en los valores de $\delta^{13} \mathrm{C}$ y $\delta^{15} \mathrm{~N}$ entre las crías y el resto de las clases de edades. Durante el periodo en que las crías están junto a sus madres, es probable que compartan el mismo tipo de presas cuando las mismas comienzan a ingerir alimento sólido, por lo 
cual es esperable que muestren composiciones isotópicas similares como las encontradas aquí para el $\delta^{13} \mathrm{C}$ y el $\boldsymbol{\delta}^{15} \mathrm{~N}$. Además, de acuerdo a Jenkins et al. (2001) existiría un balance entre la composición isotópica de los tejidos maternos, la leche y los tejidos de las crías que producirían estas bajas diferencias encontradas en los valores de $\delta^{15} \mathrm{~N}$ y de $\delta^{13} \mathrm{C}$.

Igualmente, el efecto del destete, parece evidenciarse en el leve decrecimiento en los valores de $\delta^{13} \mathrm{C}$ y $\delta^{15} \mathrm{~N}$ entre las crías y los juveniles. Durante el primer año de vida el acelerado crecimiento de los individuos lleva a un rápido remodelado óseo y por lo tanto un alta tasa de recambio isotópico lo cual contribuye a la rápida dilución del efecto de la lactancia sobre la composición isotópica del colágeno del hueso. A partir de la edad juvenil se espera que la dieta equipare a la del adulto, sin embargo, se encontró que los juveniles y los adultos difieren significativamente en sus valores de $\delta^{15} \mathrm{~N}$. Esta diferencia puede estar generada por el tipo de presas consumidas o por el uso de diferentes áreas de alimentación, lo cual puede crear diferencias isotópicas en tipos de presas similares en diferentes localidades.

Pedraza (2007) ha sugerido que podría existir una posible segregación entre las clases de edades y el sexo en C. commersonii, y en hembras maduras con crías en sectores más alejados de la costa, o cercano a éstas, pero alejadas de los grupos de machos e individuos juveniles. Sin embargo, la diferencia encontrada entre estas clases de edades (juveniles vs. adultos) es de $\sim 0,4 \%$ o, menor al desvío estándar de cada clase $(\sim 0,6 \%$ o y mucho más baja en comparación con el incremento en los valores de $\delta^{15} \mathrm{~N}$ esperados por nivel trófico ( $\sim 3,4 \%$ o). Además, no se ha encontrado diferencias en las firmas isotópicas entre los sexos. Estos resultados parecen indicar similitudes en las preferencias de hábitat y/o tipo de presas consumidas por machos y hembras a diferentes edades. No obstante, el lento recambio isotópico que caracteriza al hueso, puede ser responsable de ocultar posibles diferencias generadas por esta segregación que se sugiere que existe entre los sexos y las clases de edad de la especie. El análisis sobre muestras de otro tipo de tejido con mayor recambio isotópico (como piel, sangre o músculo) podrían llegar a revelar estas diferencias en caso que las mismas existieran. 


\subsection{Variación Isotópica Temporal}

En este trabajo se registraron cambios significativos en los valores de $\delta^{13} \mathrm{C} y$ $\delta^{15} \mathrm{~N}$ en Cephalorhynchus commersonii, sólo en $\delta^{15} \mathrm{~N}$ en Phocoena dioptrica y en $\delta^{13} \mathrm{C}$ en Lagenorhynchus australis, a lo largo de las tres últimas décadas (Figura 19).

Las posibles diferencias en la composición isotópica entre sexos y edades pueden influenciar las tendencias temporales para $P$. dioptrica y L. australis, sobre los que no se tiene una gran disponibilidad de datos sobre cada individuo. En C. commersonii, dada la similitud en la composición isotópica entre los sexos la tendencia en los datos no puede relacionarse con el género. Sin embargo, para evitar la variabilidad isotópica asociada con la edad no se incluyeron en el análisis los individuos clasificados como crías y como juveniles.

Hasta el momento no se ha podido identificar la causa exacta de los cambios observados en las firmas isotópicas de estas tres especies analizadas (C. commersonii, $P$. dioptrica y L. australis) Sin embargo, se exponen una serie de causas a ser contrastadas en futuros estudios con una mayor disponibilidad de datos.

\section{Causas de cambio en las firmas isotópicas}

El cambio temporal registrado en las firmas isotópicas de estas especies puede ser el resultado de diferentes situaciones: (1) un cambio en los valores isotópicos de toda la red trófica, que es reflejado en el colágeno del hueso de estos predadores; (2) un cambio en sus preferencias alimentarias y/o en sus áreas de alimentación.

Modificación isotópica en las redes tróficas

Cualquier cambio isotópico producido en la base de las redes tróficas tiene un efecto en los valores de los niveles superiores. Dependiendo de la plasticidad trófica de cada especie (en relación a la movilidad y la variabilidad alimentaria) estos cambios podrán expresarse en menor o mayor grado.

De acuerdo al estudio de Newsome et al. (2007) los cambios encontrados por Cullen et al. (2001) en los reservorios de carbono oceánico (efecto Suess) en el oeste del Golfo de Alaska y el este del Mar de Bering son los responsables la declinación registrada en los valores de $\delta^{13} \mathrm{C}$ de los productores primarios marinos y que ha involucrando al resto del ecosistema. Varios autores, entre ellos Leuenberger et al. 
(1992), Francey et al. (1999) y Idermühle et al. (1999) sostienen que estos cambios están generados por la incorporación de ${ }^{12} \mathrm{CO}_{2}$ antropogénico en las aguas superficiales oceánicas, generado principalmente por la quema de combustible fósil desde hace $\sim 150$ años. Parte de la declinación registrada en los valores de $\delta^{13} \mathrm{C}$ en la series de datos analizadas puede ser atribuida a este efecto Suess. Sin embargo, luego de la corrección aplicada para eliminar este efecto industrial se observa que gran parte de la variabilidad en los valores de $\delta^{13} \mathrm{C}$ queda aún sin explicar.

Modificaciones en las entradas de nitrógeno a la red trófica pueden generar cambios en los valores de $\delta^{15} \mathrm{~N}$ de los productores primarios y por lo tanto también pueden tener consecuencias en los valores isotópicos de los niveles superiores. Esto parece ser el caso de las declinaciones registradas por Lee et al. (2005) en los valores de $\delta^{15} \mathrm{~N}$ para la ballena de Groenlandia (Balaena mysticetus) en el norte de Alaska.

La disminución en los valores de $\delta^{15} \mathrm{~N}$ puede ser provocado por la fijación biológica de $\mathrm{N}_{2}$ atmosférico (atm) (Duce et al. 2008, Christensen \& Richardson 2008). Sin embargo, de acuerdo a Lara et al. (2010) las cianobacterias o cianofitas no son abundantes en la región de estudio y no existe información disponible de potenciales cambios en su abundancia a través del tiempo, además su contribución al pool de nitrógeno disponible para la fotosíntesis es también desconocida.

Los ciclos de calentamiento y enfriamiento de las aguas superficiales de los océanos alteran la producción primaria y por lo tanto podrían modificar los valores isotópicos de los productores primarios y de toda la red trófica. Eventos de este estilo puede abarcar periodos diarios y estacionales a interanuales como los que se producen a causa de El Niño-Oscilación del Sur (ENOS) recurrente cada 2 a 7 años, o bien presentarse en escalas temporales de varias décadas como la Oscilación Decadal del Pacífico (Pacific Decadal Oscillation) y la Oscilación Multidecadal del Altántico (Atlantic Multidecadal Oscillation) con períodos de 20/30 años y de 65/80 años, respectivamente.

En el Océano Austral, de acuerdo a Thompson (2007) las anomalías climáticas se encuentran asociadas principalmente a la Oscilación de la Antártida o Modo Anular del Sur (SAM, por Southern Modular Mode). Según Thompson \& Solomon (2002) y Marshall (2007) este patrón de variabilidad climática muestra una tendencia 
positiva desde la década de 1960 que permitió vincularlo con el calentamiento de la Península Antártica y el enfriamiento del resto del continente antártico.

El área bajo estudio se encuentra bajo la influencia del ENOS y el SAM, y si bien Whitehouse et al. (2008) han evidenciado relaciones de los mismos con los niveles inferiores de las redes tróficas de la región, no se conocen hasta la fecha, los efectos de los mismos sobre la productividad oceánica en Tierra del Fuego.

Resulta extremadamente difícil documentar los diversos cambios temporales que ocurren durante largo tiempo en los ecosistemas marinos, principalmente los de offshore (Christensen \& Richardson 2008). Para la región del Atlántico Sudoccidental, no existen datos sobre la variabilidad isotópica temporal de los hábitats de la plataforma patagónica y de las aguas oceánicas adyacentes. Por lo que resulta difícil contrastar las tendencias isotópicas registradas en C. commersonii, P. dioptrica y L. australis. Hasta la fecha Drago et al. (2009) han realizado el único estudio sobre la variabilidad isotópica temporal para la región, el cual incluyó el análisis de $\delta^{13} \mathrm{C}$ y $\delta^{15} \mathrm{~N}$ en individuos de lobo marino de un pelo sudamericano (Otaria flavescens) varados entre los años 1970 a 2007 en las costas de Tierra del Fuego. Estos especímenes no mostraron tendencia alguna en sus valores isotópicos a través de 37 años. Sin embargo, se analizó un bajo número de individuos varados mayormente en la última década, por lo cual ambos aspectos pueden estar ocultando una verdadera tendencia en los valores isotópicos.

La serie isotópica temporal expuesta para C. commersonii, $P$. dioptrica y $L$. australis, resulta tener mejor representatividad a lo largo del tiempo con un alto número de individuos analizados y una distribución más equitativa de especímenes a través de los años. Análisis futuros más exhaustivos, que correlacionen diferentes efectos de estos patrones de variabilidad climática sobre la fauna marina y los cambios isotópicos observados podrán esclarecer el nivel de importancia de los eventos de índole climático/oceánico en las tendencias registradas.

Modificación en las preferencias alimentarias y/o en las áreas de alimentación

La disminución observada en los valores isotópicos puede ser el resultado de cambios en la composición de la dieta de estos animales y/o en sus áreas de alimentación. Cambios en la alimentación hacia presas de menor talla parece ser responsable de la declinación isotópica registrada por Christensen \& Richardson 
(2008) en los valores de $\boldsymbol{\delta}^{15} \mathrm{~N}$ del colágeno de hueso en la marsopa común (Phocoena phocoena) del hemisferio Norte. En $P$. dioptrica, la disminución en los valores de $\delta^{15} \mathrm{~N}$ podría también estar indicando una mayor incorporación en su dieta de organismos de menor nivel trófico. Sin embargo carecemos de datos isotópicos de posibles presas de la región donde dicha especie se alimenta (áreas del Frente Polar) para poder corroborar esta alternativa.

Los valores de $\delta^{15} \mathrm{~N}$ y $\delta^{13} \mathrm{C}$ también pueden variar si se modifican las áreas de alimentación de los organismos. Una disminución en los valores isotópicos, como la tendencia encontrada en los cetáceos (C. commersonii, P. dioptrica y L. australis), implica que el cambio en las áreas de alimentación esté dirigido hacia aguas offshore en la misma latitud o bien entre hábitats similares pero a diferentes latitudes y con un movimiento hacia el sur de la región. El primer caso implicaría también un cambio en las posibles especies, de presas costeras/bentónicas con altos valores isotópicos a presas offshore/pelágicas con bajos valores. En el segundo caso, el movimiento puede estar o no relacionado con cambios en su alimentación. Cambios de este tipo han sido registrados por Drago et al. (2009) en el lobo marino de un pelo sudamericano (Otaria flavescens) en aguas del norte de Patagonia y parece estar asociado al desarrollo de la flota pesquera de la zona.

El efecto de perturbaciones externas sobre las redes tróficas, como la presión pesquera, puede tener serias consecuencias para la estructura y dinámica del ecosistema. Pauly et al. (1998b) han argumentado que una de ellas es la disminución de peces de tallas grandes con la consecuente pesca sobre especies de menor nivel trófico, ocurrida durante las últimas décadas en una gran diversidad de áreas marinas. Este efecto conocido como "Fishing down marine food webs" se basa en estadísticas pesqueras de la FAO (Food and Agriculture Organization) y ha producido mucha atención y controversias los últimos tiempos expuestas por Pauly \& Watson (2005). Dado que existe una relación positiva entre el tamaño de los peces y los valores de $\delta^{15} \mathrm{~N}$ (y en consecuencia su nivel trófico) (Jennings et al. 2002), cambios en los valores de $\delta^{15} \mathrm{~N}$ en los predadores de niveles tróficos altos puede estar reflejando un cambio temporal en la estructura de los ecosistemas pelágicos marinos por el efecto de las pesquerías sobre estos predadores. En la región estudiada en la presente Tesis, las áreas pesqueras más importantes se sitúan principalmente sobre aguas de plataforma externa y talud adyacente (alrededores de las Islas Malvinas y Banco Burdwood). Para los hábitats costeros 
propuestos como áreas principales de forrajeo de L. australis y C. commersonii y para aguas cercanas al Frente Polar como área para $P$. dioptrica, el desarrollo pesquero es escaso dado la falta de infraestructura adecuada para el primero y las complicadas condiciones oceanográficas para el segundo (Isla 2006, Martini 2006). Sin embargo, los efectos indirectos (ej. competencia por especies presa) de las pesquerías de altura y costeras sobre las poblaciones de mamíferos marinos, continúan siendo desconocidos para la región.

La investigación de la variabilidad temporal en los valores isotópicos de los productores primarios a lo largo de la región estudiada es de suma importancia para poder responder las preguntas que surgen de esta Tesis y contrastar las hipótesis que podrían estar explicando la variación isotópica encontrada a lo largo de 30 años en diferentes especies de cetáceos (C. commersonii, P. dioptrica y L. australis). Estas investigaciones serían relevantes para el estudio sobre cambios en la ecología de diversas especies de cetáceos que habitan el Atlántico Sudoccidental y el Océano Austral. 


\section{CAPÍt ULO 5}

\section{CONCLUSIONES}

Los estudios realizados durante la presente Tesis permitieron obtener un amplio espectro de conclusiones biológicas y eológicas ampliando el escaso conocimiento que se tenía, hasta el presente, sobre diversas especies de cetáceos subantárticos.

El análisis de isótopos estables de carbono y nitrógeno del colágeno del hueso permitió integrar información ecológica de varios años y, de esta forma, caracterizar el comportamiento trófico principal de las especies de cetáceos estudiadas (Lagenorhynchus australis, Lagenorhynchus cruciger, Cephalorhynchus commersonii, Grampus griseus, Lissodelphis peronii, Pseudorca crassidens, Phocoena spinipinnis y Phocoena dioptrica). La excelente preservación del colágeno del hueso lo hace un tejido altamente adecuado para el análisis de isótopos estables en estas especies de cetáceos.

Se encontraron diferencias isotópicas significativas en los valores de $\delta^{13} \mathrm{C}$ y $\delta^{15} \mathrm{~N}$ del colágeno del hueso entre las ocho especies de cetáceos. Dichas diferencias están relacionadas con el uso del hábitat y los niveles tróficos que ocupan estos predadores en las tramas tróficas del Atlántico Sudoccidental.

* Para una adecuada caracterización isotópica de cada especie de cetáceo y algunas de sus poblaciones fue necesario el análisis de un alto número de individuos, dado que en la mayoría se encontró una alta variabilidad en los valores de $\delta^{13} \mathrm{C}$ y $\delta^{15} \mathrm{~N}$.

El análisis de isótopos estables sobre potenciales presas (especies de peces, moluscos cefalópodos y crustáceos) permitieron definir isotópicamente los hábitats costeros, de plataforma/talud y oceánicos en la región del Atlántico Sudoccidental. Sus valores reflejan los atributos de los productores primarios dominantes de la región. 
Los datos isotópicos de los diferentes grupos de presas permitieron determinar, de forma general, la contribución relativa a la signatura o firma isotópica de los cetáceos analizados, lo que ayudó en la interpretación ecológica de los valores de $\delta^{13} \mathrm{C}$ y $\delta^{15} \mathrm{~N}$ de estos últimos.

El uso combinado de $\delta^{13} \mathrm{C}$ y $\delta^{15} \mathrm{~N}$ revela información espacial sobre los hábitos alimentarios y las áreas de alimentación de los cetáceos. Sin embargo, en algunos casos los datos isotópicos por sí solos no tuvieron la capacidad de discriminar entre especies que tienen diferentes comportamientos ecológicos (como el caso de Lagenorhynchus australis y el ecotipo GG1 de Grampus griseus).

* Los datos isotópicos aportan una nueva visión en la ecología de ciertas especies (como en Phocoena dioptrica, Phocoena spinipinnis y Lagenorhynchus cruciger) sobre las que existe escasa información ecológica publicada.

Las firmas isotópicas de los cetáceos reflejan la variación espacial de los valores de $\delta^{13} \mathrm{C}$ y $\delta^{15} \mathrm{~N}$ de los productores primarios de la región (macroalgas y fitoplancton) y de sus especies presas entre los tipos de hábitat (costero, nerítico y oceánico).

El grado de solapamiento/segregación trófica entre las especies de cetáceos estudiados dependió del grado de superposición entre los recursos utilizados por ellos

* La influencia de las macroalgas enriquecidas en ${ }^{13} \mathrm{C}$ en las redes tróficas costeras parece ser la responsable de los altos valores en $\delta^{13} \mathrm{C}$ en Lagenorhynchus australis en comparación con otros cetáceos (Lissodelphis peronii, Grampus griseus, y Pseudorca crassidens), que se alimentan en hábitats pelágicos donde las especies del fitoplancton constituyen los organismos dominantes en la producción primaria.

Los valores de $\delta^{15} \mathrm{~N}$ reflejan una combinación de la dieta y del uso del hábitat de los cetáceos, además de posibilitar la estimación de los niveles tróficos ocupados por estas especies. 
En hábitats offshore, sobre la plataforma y el talud continental, parece existir una compleja asociación de especies. Las similitudes encontradas en las firmas isotópicas en varias de ellas indican que ocupan nichos ecológicos similares (ej. Grampus griseus, Lissodelphis peronii y Pseudorca crassidens). Por el contrario, en las zonas inshore las grandes diferencias isotópicas, entre Lagenorhynchus australis y Cephalorhynchus commersonii/Phocoena spinipinnis, indican un bajo solapamiento en sus requerimientos tróficos y por lo tanto una diferente ocupación de nichos ecológicos.

Lagenorhynchus australis posee altos valores de $\delta^{13} \mathrm{C}$ y $\delta^{15} \mathrm{~N}$ en comparación con otras especies, hecho consistente con consumidores costeros que ocupan niveles tróficos altos.

Cephalorhynchus commersonii y Phocoena spinipinnis exhiben valores isotópicos y niveles tróficos similares, indicativos de una dieta ictiófaga principalmente en la plataforma patagónica, lo que corrobora hipótesis previas sobre una posible competencia por el alimento y/o el hábitat entre ambas especies.

Lissodelphis peronii y Grampus griseus, considerados consumidores teutófagos e ictiófagos, presentan valores de $\delta^{15} \mathrm{~N}$ similares y ocupan niveles tróficos semejantes. Estas dos especies presentan valores isotópicos intermedios entre Pseudorca crassidens y las especies inshore (Cephalorhynchus commersonii, Phocoena spinipinnis y Lagenorhynchus australis).

Pseudorca crassidens presenta una acotada variación isotópica en $\delta^{13} \mathrm{C}$ y $\delta^{15} \mathrm{~N}$, indicativo de un estrecho nicho trófico y una especialización en sus hábitos alimentarios, presumiblemente teutófago.

Los valores más bajos de $\delta^{13} \mathrm{C}$ y $\delta^{15} \mathrm{~N}$ los presentaron Phocoena dioptrica y Lagenorhyncus cruciger reflejando su hábitat oceánico, entre latitudes de la Convergencia Antártica, al norte del Frente Polar. Las similitudes isotópicas entre estas dos especies indica que ocupan nichos tróficos parecidos. 
La distribución bimodal encontrada en los valores isotópicos de los individuos de Grampus griseus sugiere que existe una división no reconocida entre poblaciones en el extremo sur del Atlántico Sudoccidental. Los ecotipos definidos (GG1 y GG2) son considerados predadores de altos niveles tróficos de áreas de plataforma externa y talud continental, con movimientos hacia aguas inshore en ciertas épocas del año, como sugieren los registros de avistajes y las similitudes en los valores isotópicos con especies inshore (Cephalorhynchus commersonii y Phocoena spinipinnis).

Los resultados obtenidos en la presente Tesis sugieren que la plataforma patagónica y el talud continental son zonas importantes de uso para varias especies de cetáceos (ej. Cephalorhynchus commersonii, Phocoena spinipinnis, Grampus griseus, Lissodelphis peronii y Pseudorca crassidens) coincidiendo con las mismas áreas donde se concentra el mayor esfuerzo pesquero de altura de la región debido a la gran producción biológica. Además, las zonas costeras de Tierra del Fuego, Santa Cruz y el este del estrecho de Magallanes, son importantes hábitats de especies que comúnmente sufren capturas incidentales en actividades pesqueras artesanales, resultando ser una de las causas de mayor mortalidad para éstas (ej. Cephalorhynchus commersonii).

* El estudio de la variabilidad isotópica intra-específica en Grampus griseus y Cephalorhynchus commersonii permitió definir el comportamiento trófico a diferentes edades y sexos.

En ambos ecotipos de Grampus griseus, el análisis isotópico intraespecífico sugiere un comportamiento trófico similar entre machos y hembras y entre individuos subadultos y adultos.

En Cephalorhynchus commersonii los datos isotópicos sugieren que no existe segregación espacial y/o alimentaria entre individuos de diferente sexo. Mayores valores de $\delta^{15} \mathrm{~N}$ en especímenes adultos y de mayor talla podrían indicar diferencias en las preferencias de presas y/o hábitat respecto a los juveniles. En las crías de esta especie no se detecta el efecto de la lactancia en el colágeno del hueso, posiblemente por la ingesta temprana de alimento sólido. El análisis de un mayor número de especímenes en edades tempranas y el uso de otros tejidos con una tasa 
de recambio isotópico más alta (piel, músculo) ayudarían a definir diferencias entre clases de edades.

Se detectaron cambios isotópicos temporales en el colágeno del hueso de especímenes de Cephalorhynchus commersonii, Lagenorhynchus australis y Phocoena dioptrica. En virtud de la integración temporal que brinda la información isotópica del tejido analizado, se descartan posibles fluctuaciones isotópicas producidas por eventos esporádicos (ej. movimientos estacionales). Si bien no se han encontrado las causas de dichos cambios, se estima que podrían ser producidos por modificaciones intrínsecas de cada especie (referidas a cambios en presas y/o hábitat) o extrínsecas a ellas (referidas a cambios producidos en los valores isotópicos de la base de las redes tróficas). 


\section{ANEXO III \\ Protocolo de Extracción de Muestras de HUESO PARA ESTUDIOS ISOTÓPICOS}

Cuando se tomen muestras de hueso, tener en consideración los siguientes puntos:

- Se necesita una muestra mínima de 50-100 mg (miligramos). De ser posible suministrar una cantidad mayor de muestra de la mínima necesaria. Los pretratamientos del laboratorio involucran siempre pérdida de material original, lo cual puede llegar a un $80 \%$ según tipo y estado de preservación de la muestra

- Anotar datos de la muestra: especie, código de identificación (ID), fecha, peso de la muestra, zona de extracción, persona que extrajo la muestra (ver Formulario A)

- Extraer el material usando herramientas metálicas y guantes de látex

- Es probable emplear las manos cuando sea necesario e imprescindible (sin cremas u otras sustancias, láveselas bien)

- No usar herramientas plásticas, ni de madera, ni de hueso

- Utilice siempre pinzas metálicas para manipular la muestra

- Para pesar la muestra, coloque un papel aluminio (de suficiente tamaño para envolverla luego) donde se apoya los materiales a pesar, tare la balanza, y coloque la muestra y pésela

- Los sedimentos u otros materiales sobre la muestra pueden eliminarse usando un cepillo metálico o lavando los materiales con agua

- Es importante sacarle con pinzas metálicas posibles raíces que hayan penetrado en estos materiales porosos, ayúdese con lupa o microscopio de ser posible

- Las muestras deben secarse en una estufa a $60^{\circ} \mathrm{C}$ para evitar el desarrollo de microorganismos, hongos, etc.

- Las muestras pueden envolverse en papel aluminio y colocarse en bolsas de polietileno de alta densidad o pueden guardarse en recipientes metálicos o de vidrio con tapa de interior de aluminio (no usar cualquier tapa). En caso de no tener tapas con interior de aluminio, se puede hacer una tapa con papel aluminio y ajustarla con una gomita o cinta adhesiva

- No usar bolsas de papel o de tejido

- No colocar protectores o separadores de algodón, lana, aserrín de madera, papel u otro material orgánico

- No deben tener sustancias orgánicas para conservar o preservarlas porque las contaminan. En el caso de tener muestras de tejido blando (músculo, piel etc) la mejor forma de preservarlas es en freezer. Si no puede séquelas en estufa (No utilice alcohol o formol)

- No colocar dentro del recipiente que contenga la muestra los datos de la misma, adherir un papel con los datos de la muestra por fuera del recipiente que la contiene

- No deben usarse adhesivos orgánicos para recomponer las formas originales de las muestras 


\section{FORMULARIO A}

\section{Formulario de EXTRACCión DE MUESTRAS DE HUESo}

Fecha:

Responsable:

Institución:

\begin{tabular}{|c|c|c|c|c|}
\hline Especie & ID & Fecha & Peso (mg) & $\begin{array}{c}\text { Zona } \\
\text { extracción }\end{array}$ \\
\hline & & & & \\
\hline & & & & \\
\hline & & & & \\
\hline & & & & \\
\hline & & & & \\
\hline & & & & \\
\hline & & & & \\
\hline & & & & \\
\hline & & & & \\
\hline & & & & \\
\hline & & & & \\
\hline & & & & \\
\hline & & & & \\
\hline & & & & \\
\hline & & & & \\
\hline & & & & \\
\hline & & & & \\
\hline & & & & \\
\hline & & & & \\
\hline & & & & \\
\hline & & & & \\
\hline & & & & \\
\hline & & & & \\
\hline & & & & \\
\hline & & & & \\
\hline & & & & \\
\hline & & & & \\
\hline
\end{tabular}




\section{ANEXO IV \\ Protocolo de Pretratamiento DE MUESTRAS ÓSEAS PARA ESTUDIOS ISOTÓPICOS}

\section{Preparación de la muestra (utilizar Planilla A)}

1. Pese $\sim 100 \mathrm{mg}$ (miligramos) de hueso (previamente limpio como se mencionó en el Protocolo de extracción de muestras de hueso)

2. Coloque cada muestra en viales de vidrio de $20 \mathrm{ml}$ con tapas de interior de aluminio

3. Etapa de Descalcificación: colocar $\sim 15 \mathrm{ml}$ de $\mathrm{HCl} 0.2 \mathrm{~N}$, agitar por 10 minutos en un agitador magnético o ultrasónico. Puede elegir por dejar reposar la muestra a temperatura ambiente o en refrigerador sin la tapa, hasta el otro día. El colocarlo en refrigerador se logra que el ácido actúe más lentamente, por lo que la muestra necesitará más tiempo para desmineralizarse. Para chequear si la descalcificación se completó, con un par de pinzas fijese cuán flexible está la muestra, si ésta sigue rígida, recambie la solución ácida, y vuelva a repetir el procedimiento tantas veces hasta que la descalcificación sea total

4. Una vez que la descalcificación sea completa, remueva del vial el $\mathrm{HCl}$ usando una pipeta de vidrio. Remoje la muestra en agua destilada hasta lograr la neutralidad. Luego proceda a sacar la mayor cantidad de agua posible de la muestra para prepararla para el siguiente paso

5. Etapa de Extracción de Lípidos: preparar la mezcla de extracción de lípidos de cloroformo:metanol en proporciones 2:1, respectivamente. Deberá añadir $\sim 13 \mathrm{ml}$ de mezcla de extracción de lípidos a cada muestra

6. Luego de añadir la mezcla, agitar la muestra por 30 minutos en un agitador magnético o ultrasónico

7. Añadir $4 \mathrm{ml}$ de agua destilada a la solución y dejar reposar. La muestra se separará en 2 fases: una capa superior de metanol y agua destilada y una inferior de cloroformo que contendrá los lípidos. Una gran cantidad de lípidos en la fase de cloroformo dará una apariencia lechosa

8. Dejar decantar la solución. Repetir la extracción de lípidos hasta que la fase de cloroformo se muestre clara. Para materiales extremadamente grasosos (como los huesos de los mamíferos marinos) es necesario repetir esta etapa 4 o 5 veces. Nota: durante esta etapa las muestras podrán dejarse durante la noche en la mezcla de extracción de lípidos, sólo recuerde tapar el recipiente

9. Una vez que todos los lípidos hayan sido removidos, remover la mezcla de extracción de lípidos y remojar la muestra en agua destilada hasta que llegue hasta la neutralidad. Luego proceda a sacar la mayor cantidad de agua posible de la muestra y séquelas en estufa de secado a $60^{\circ} \mathrm{C}$ o en vacío por $\sim 24$ hs mínimo

10. La muestra estará lista para ser analizada en el analizador elemental y el espectrómetro de masa de relaciones isotópicas

Nota1: planifique el trabajo de laboratorio antes de iniciarlo. Use instrumentos y equipo de protección personal adecuado de acuerdo a la tarea que esté realizando.

Nota2: evite tirar el $\mathrm{HCl}$ y la mezcla de extracción de lípidos en el resumidero, elimine las soluciones dentro de un tarro de desecho adecuado, uno para el $\mathrm{HCl}$ y otro para la mezcla de lípidos. El descarte de estos desechos es responsabilidad de quien lo genera, asegurarse que éstos sean neutralizados adecuadamente para prevenir contaminación ambiental. 


\section{Análisis de la muestra (utilizar Planilla B)}

1. Tare una cápsula de estaño (tin capsule) en la balanza

2. Cuidadosamente corte con una gillette o un bisturí pequeños pedazos de la muestra y pese $0,5-0,6 \mathrm{mg}$ dentro de la cápsula

3. Mientras aún se encuentra en la balanza apriete y doble la abertura de la cápsula con unas pinzas metálicas

4. Coloque la cápsula sobre un papel de aluminio y con pinzas ayúdese a comprimir la cápsula en una bolita pequeña tratando de eliminar todo el aire de la muestra como sea posible

5. Si durante la compresión la cápsula se rompe, coloque la muestra en una nueva cápsula y proceda nuevamente a comprimirla

6. Una vez comprimida coloque la muestra en una bandeja de muestras y anote la posición que ocupa en ella en la planilla de datos

7. Finalizado, coloque la bandeja de muestras en un recipiente desecador hasta que esté listo para hacer correr las muestras en el analizador elemental y el espectrómetro de masas de relaciones isotópicas (IRSM) 
Planilla A

Datos de muestras - Pretratamiento

Fecha:

Responsable:

Institución:

\begin{tabular}{|c|c|c|c|c|}
\hline ID & $\begin{array}{l}\text { Tipo de } \\
\text { Muestra }\end{array}$ & $\begin{array}{l}\text { Peso inicial } \\
\text { (pre- } \\
\text { tratamiento) }\end{array}$ & $\begin{array}{l}\text { Peso final } \\
\text { (post- } \\
\text { tratamiento) }\end{array}$ & $\begin{array}{l}\% \text { Total } \\
\text { colágeno }\end{array}$ \\
\hline & & & & \\
\hline & & & & \\
\hline & & & & \\
\hline & & & & \\
\hline & & & & \\
\hline & & & & \\
\hline & & & & \\
\hline & & & & \\
\hline & & & & \\
\hline & & & & \\
\hline & & & & \\
\hline & & & & \\
\hline & & & & \\
\hline & & & & \\
\hline & & & & \\
\hline & & & & \\
\hline & & & & \\
\hline & & & & \\
\hline & & & & \\
\hline & & & & \\
\hline & & & & \\
\hline & & & & \\
\hline & & & & \\
\hline & & & & \\
\hline & & & & \\
\hline & & & & \\
\hline & & & & \\
\hline & & & & \\
\hline & & & & \\
\hline & & & & \\
\hline & & & & \\
\hline & & & & \\
\hline & & & & \\
\hline & & & & \\
\hline
\end{tabular}




\section{Planilla B}

\section{Datos de muestras para el análisis de isótopos estables}

Fecha:

Responsable:

Institución:

\begin{tabular}{|c|c|c|c|c|c|c|c|}
\hline Lugar & ID & Peso & Obs. & Lugar & ID & Peso & Obs. \\
\hline A1 & & & & E1 & & & \\
\hline A2 & & & & E2 & & & \\
\hline A3 & & & & E3 & & & \\
\hline A4 & & & & $\mathrm{E} 4$ & & & \\
\hline A5 & & & & E5 & & & \\
\hline A6 & & & & E6 & & & \\
\hline A7 & & & & E7 & & & \\
\hline A8 & & & & E8 & & & \\
\hline A9 & & & & E9 & & & \\
\hline A10 & & & & E10 & & & \\
\hline A11 & & & & E11 & & & \\
\hline A12 & & & & E12 & & & \\
\hline B1 & & & & F1 & & & \\
\hline B2 & & & & F2 & & & \\
\hline B3 & & & & F3 & & & \\
\hline B4 & & & & F4 & & & \\
\hline B5 & & & & F5 & & & \\
\hline B6 & & & & F6 & & & \\
\hline B7 & & & & F7 & & & \\
\hline B8 & & & & F8 & & & \\
\hline B9 & & & & F9 & & & \\
\hline B10 & & & & F10 & & & \\
\hline B11 & & & & F11 & & & \\
\hline B12 & & & & F12 & & & \\
\hline $\mathrm{C} 1$ & & & & G1 & & & \\
\hline C2 & & & & $\mathrm{G} 2$ & & & \\
\hline C3 & & & & G3 & & & \\
\hline $\mathrm{C} 4$ & & & & G4 & & & \\
\hline C5 & & & & G5 & & & \\
\hline C6 & & & & G6 & & & \\
\hline $\mathrm{C} 7$ & & & & G7 & & & \\
\hline $\mathrm{C} 8$ & & & & G8 & & & \\
\hline C9 & & & & G9 & & & \\
\hline C10 & & & & G10 & & & \\
\hline C11 & & & & G11 & & & \\
\hline C12 & & & & G12 & & & \\
\hline D1 & & & & H1 & & & \\
\hline $\mathrm{D} 2$ & & & & $\mathrm{H} 2$ & & & \\
\hline D3 & & & & $\mathrm{H} 3$ & & & \\
\hline D4 & & & & $\mathrm{H} 4$ & & & \\
\hline D5 & & & & H5 & & & \\
\hline D6 & & & & H6 & & & \\
\hline D7 & & & & $\mathrm{H} 7$ & & & \\
\hline D8 & & & & H8 & & & \\
\hline D9 & & & & H9 & & & \\
\hline D10 & & & & H10 & & & \\
\hline D11 & & & & H11 & & & \\
\hline D12 & & & & H12 & & & \\
\hline
\end{tabular}

La Planilla A y B resultaron apropiadas para esta investigación, pueden ser modificadas o mejoradas de acuerdo a la información necesaria para otros trabajos. Luciana Riccialdelli 


\section{REFERENCIAS}

Amano M, Miyazaki N (2004) Composition of a school of Risso's dolphins, Grampus griseus. Marine Mammal Science 20:152-160

Ambrose SH (1990) Preparation and characterization of bone and tooth collagen for isotopic analysis. Journal of Archaeological Science 17:43 1-451

Ames AL, Van Vleet ES, Sackett WM (1996) The use of stable carbon isotope analysis for determining the dietary habits of the Florida manatee, Trichechus manatus latirostris. Marine Mammal Science 12:555-563

Aurioles D, Koch PL, Le Boeuf BJ (2006) Differences in foraging location of Mexican and California elephant seals: evidence from stable isotopes in pups. Marine Mammal Science 22:326-338

Baird RW (2002a) Risso's dolphin. En: Perrin WF, Würsig B, Thewissen JGM (eds) Encyclopedia of Marine Mammals. Academic Press, San Diego, pp 137-139

Baird RW (2002b) False killer whale Pseudorca crassidens. En: Perrin WF, Würsig B, Thewissen JGM (eds) Encyclopedia of Marine Mammals. Academic Press, San Diego, pp 411-412

Baird RW (2009) Risso's dolphin Grampus griseus. En: Perrin WF, Würsig B, Thewissen JGM (eds) Encyclopedia of Marine Mammals. Academic Press, Amsterdam, p 975-976

Baker AN (1981) The southern right whale dolphin Lissodelphis peronii (Lacépède) in Australasian waters. National Museum of New Zealand 2:17-34

Bastida R, Lichtschein V, Goodall RNP (1988) Food habits of Cephalorhynchus commersonii off Tierra del Fuego. En: Brownell RL, Donovan GP (eds) The Biology of the Genus Cephalorhynchus. Reports of the International Whaling Commission, Special Issue 9, pp 143-160

Bastida R, Rodríguez D (2006) Orden Cetacea. En: Barquéz RM, Díaz MM, Ojeda RA (eds) Mamíferos de Argentina, Sistemática y distribución. SAREM, Tucumán, 122-144pp

Bastida R, Rodríguez D, Secchi E, da Silva V (2007) Mamíferos acuáticos de Sudamérica y Antártida. Vazquez Mazzini Editores, Buenos Aires, 366pp 
Baumgartner MF (1997) The distribution of Risso's dolphin (Grampus griseus) with respect to the physiography of the northern Gulf of Mexico. Marine Mammal Science 13:614-638

Bearhop S, Adams CE, Waldron S, Fuller RA, Macleod H (2004) Determining trophic niche width: a novel approach using stable isotope analysis. Journal of Animal Ecology 73:1007-1012

Berón Vera B, Pedraza SN, Raga JA, Gil de Pertierra A, Crespo EA, Koen Alonso M, Goodall RNP (2001) Gastrointestinal heminths of Commerson's dolphins Cephalorhynchus commersonii from central Patagonia and Tierra del Fuego. Diseases of Aquatic Organisms 47:201-208

Bertolotti MI, Verazay GA, Akselman R (2001) El mar Argentino y sus recursos pesqueros. En: Boschi E (ed) Evolución de la Flota Pesquera Argentina, Artes de Pesca y Dispositivos Selectivos. Publicación Especial INIDEP, Mar del Plata, Argentina

Best PB (2007) Whales and Dolphins of the Southern African Subregion. Cambridge University Press, Cambridge, England

Best PB, Schell DM (1996) Stable isotopes in southern right whale (Eubalaena australis) baleen as indicators of seasonal movements, feeding and growth. Marine Biology 124:483-494

Bligh EG, Dyer WJ (1959) A rapid method of total lipid extraction and purification. Canadian Journal of Biochemistry and Physiology 37:911-917

Bowen WD (1997) Role of marine mammals in aquatic ecosystems. Marine Ecology Progress Series 158:267-274

Brownell RL, Praderi R (1982) Status of Burmeister's porpoise, Phocoena spinipinnis, in southern South American waters. En: Mammals in the Seas. FAO Fisheries Series, pp 91-96

Brownell RL, Praderi R (1984) Phocoena spinipinnis. Mammalian Species 217:1-4

Bujalesky G (2007) Coastal geomorphology and evolution of Tierra del Fuego (Southern Argentina). Geologica Acta 5:337-362

Burton RK, Koch PL (1999) Isotopic tracking of foraging and long-distance migration in northeastern Pacific pinnipeds. Oecologia 119:578-585

Cabana G, Rasmussen JB (1994) Modelling food chain structure and contaminant bioaccumulation using stable nitrogen isotopes. Nature 372:255-257 
Cabana G, Rasmussen JB (1996) Comparison of aquatic food chains using nitrogen isotopes. Proceedings of National Academy of Science of the United State of America 93:10844-10847

Campagna C, Verona C, Falabella V (2006) Situación ambiental en la ecorregión del Mar Argentino. En: Brown A, Martínez Ortiz U, Acerbi M, Corcuera J (eds) La situación ambiental argentina 2005. Fundación Vida Silvestre Argentina, Buenos Aires, pp 323-336

Cañadas A, Sagarminaga R, García-Tiscar S (2002) Cetacean distribution related with depth and slope in the Mediterranean waters off southern Spain. Deep Sea Research 49:2053-2073

Carreon-Martinez L, Heath D (2010) Revolution in food web analysis and trophic ecology: diet analysis by DNA and stable isotope analysis. Molecular Ecology 19:25-27

Caut S, Angulo E, Courchamp F (2009) Variation in discrimination factors $\left(\Delta^{15} \mathrm{~N}\right.$ and $\Delta{ }^{13} \mathrm{C}$ ): the effect of diet isotopic values and applications for diet reconstruction. Journal of Applied Ecology 46:443-453

Chang R (1992) Química. McGraw-Hill Interamericana de México, México, 1064pp

Christensen JT, Richardson K (2008) Stable isotope evidence of long-term changes in the North Sea food web structure. Marine Ecology Progress Series 368:1-8

Christensen V, Pauly D (2004) Placing fisheries in their ecosystem context, an introduction. Ecological Modelling 172:103-107

Ciancio JE, Pascual MA, Botto F, Frere E, Iribarne O (2008) Trophic relationships of exotic anadromous salmonids in the southern Patagonian Shelf as inferred from stable isotope. Limnology and Oceanography 53:788-779

Clarke M, Goodall RNP (1994) Cephalopods in the diets of three odontocete cetacean species stranded at Tierra del Fuego, Globicephala melaena (Traill, 1809), Hyperoodon planifrons Flower, 1882 and Cephalorhynchus commersonii (Lacépède, 1804). Antarctic Science 6:149-154

Cockroft VG, Haschick SL, Klages NTW (1993) The diet of Risso's dolphin, Grampus griseus (Cuvier, 1812), from the east coast of South Africa. Zeitschrift für Säugetierkunde 58:286-293

Corcuera J (1991) Marsopa espinosa Phocoena spinipinnis (Burmeister, 1865). En: Capozzo HL, Junin M (eds) Estado de Conservación de los Mamíferos Marinos 
del Atlántico Sudoccidental. Informes y estudios del programa de Mares Regionales del PNUMA, p 250

Corcuera J, Monzón F, Aguilar A, Borrell A, Raga JA (1995) Life history data, organochlorine pollutants and parasites from eight Burmeister's porpoises, Phocoena spinipinnis, caught in northern Argentine waters. En: Biology of Phocoenids. Reports of the International Whaling Commission, Special Issue 16, pp 349-363

Cousseau MB, Perrota RG (2000) Peces marinos de Argentina: biología, distribución, pesca. INIDEP, Mar del Plata, 167pp

Crespo EA, Pedraza SN, Coscarella M, García NA, Dans SL, Iñíguez MA, Reyes LM, Koen Alonso M, Schiavini ACM, Gonzalez R (1997b) Distribution and school size of dusky dolphins, Lagenorhynchus obscurus (Gray, 1828), in the southwestern South Atlantic Ocean. Reports of the International Whaling Commission 47:693-697

Crespo EA, Pedraza SN, Dans SL, Koen Alonso M, Reyes LM, García NA, Coscarella M (1997a) Direct and indirect effects of the highseas fisheries on the marine mammal populations in the Northern and central Patagonian coast. Journal of Northwest Atlantic Fisheries Science 22:189-207

Culik BM (2004) Review of small cetaceans. Distribution, behaviour, migration and threats. UNEP / CMS Secretariat, Bonn, Germany

Cullen JT, Rosenthal Y, Falkowsky PG (2001) The effect of anthropogenic $\mathrm{CO} 2$ on the carbon isotope composition of marine phytoplankton. Limnology \& Oceanography 46:996-998

Das K, Beans C, Holsbeek L, Mauger G, Berrow SD, Rogan E, Bouquegneau JM (2003) Marine mammals from northeast Atlantic: relationship between trophic status as determined by $\delta^{13} \mathrm{C}$ and $\delta^{15} \mathrm{~N}$ measurements and their trace metal concentrations. Marine Environmental Research 56:349-365

Davis RW, Ortega-Ortiz JG, Ribic CA, Evans WE, Biggs DC, Ressler PH, Cady RB, Leben RR, Mullin KD, Würsig B (2002) Cetacean habitat in the northern oceanic gulf of Mexico. Deep Sea Research 49:121-142

Dawson T, Mambelli S, Plamboeck A, Templer P, Tu K (2002) Stable isotopes in plant ecology. Annual Review of Ecology and Systematics 33:507-559

Dawson T, Siegwolf R (2007) Using stable isotopes as indicators, tracers, and recorders of ecological changes: some context and background. En: Dawson T, 
Siegwolf R (eds) Stable Isotopes as Indicators of Ecological Changes. Elsevier, USA, pp 3-18

de Haro JC, Iñíguez MA (1997) Ecology and behaviour of the Peale's dolphin, Lagenorhynchus australis (Peale, 1848), at Cabo Virgenes $\left(52^{\circ} 30^{\prime} \mathrm{S}, 68^{\circ} 28^{\prime} \mathrm{W}\right)$, in Patagonia, Argentina. Reports of the International Whaling Commission 47:723-727

Deagle BE, Tollit DJ, Jarman SN, Hindell MA, Trites AW, Gales Nj (2005) Molecular scatology as a tool to study diet: analysis of prey DNA in scats from captive Steller sea lions. Molecular Ecology 14:1831-1842

Dehairs F, Kopczynska E, Nielsen P, Lancelot C, Bakker DCE, Koeve W, Goeyens L (1997) $\delta^{13} \mathrm{C}$ of Southern Ocean suspended organic matter during spring and early summer: regional and temporal variability. Deep Sea Research 44:129142

DeNiro MJ, Epstein S (1978) Influence of diet on the distribution of carbon isotopes in animals. Geochimica et Cosmochimica Acta 42:495-506

DeNiro MJ, Epstein S (1981) Influence of diet on the distribution of nitrogen isotopes in animals. Geochimica et Cosmochimica Acta 45:341-351

Drago M, Crespo EA, Aguilar A, Cardona L, García N, Dans SL, Goodall N (2009) Historic diet change of the South American sea lion in Patagonia as revealed by isotopic analysis. Marine Ecology Progress Series 384:273-286

Dunton KH, Saupe SM, Golikov AN, Schell DM, Schonberg SV (1989) Trophic relationships and isotopic gradients among arctic and subartic marine fauna. Marine Ecology Progress Series 56:89-97

Eder EB, Lewis MN, Campagna C, Koch PL (2010) Evidence of demersal foraging from stable isotope analysis of juvenile elephant seals from Patagonia. Marine Mammal Science 26:430-442

Escare L, Oporto JA (1992) Alimentación de la marsopa espinosa, Phocoena spinipinnis (Burmeister, 1865). (Cetacea: Phocoenidae) en Queuele, IX Región - Chile 5ta Reunión de Trabajo de Especialistas en Mamíferos Acuáticos de América del Sur. SOLAMAC, Buenos Aires, Argentina, p 23

Estes JA (1996) Predators and ecosystem management. Wildlife Society Bulletin 24:390-396

Fajardo-Mellor L, Berta A, Brownell RL, Boy CC, Goodall RNP (2006) The phylogenetic relationships and biogeography of true porpoises (Mammalia: 
Phocoenidae) based on morphological data. Marine Mammal Science 22:910932

Fawcett D (1995) Tratado de Histología. MacGrawHill Interamericana, Madrid, España

Fernández M, Berón-Vera B, García NA, Raga JA, Crespo EA (2003) Food and parasites from two hourglass dolphins, Lagenorhynchus cruciger (Quoy and Gaimard, 1824), from Patagonian waters. Marine Mammal Science 19:832-836

Flores MA, Moraga R, Pérez MJ, Hanshing E, Olavarría C (2003) New sightings of false killer whales Pseudorca crassidens (Owen, 1846) in Chile. Revista de Biología Marina y Oceanografía 32:81-85

Fogel ML, Turros N (2002) Extending the limits of paleodietary studies of humans with compound specific carbon isotope analysis of amino acids. Journal of Archaeological Science 30:535-545

Folch J, Lees M, Stanley GHS (1957) A simple method for the isolation and purification of total lipids from animal tissues. Journal of Biological Chemistry 226:497-509

Forero MG, Bortolotti GR, Hobson KA, Donázar JA, Bertellotti M, Blanco G (2004) High trophic overlap within the seabird community of Argentinean Patagonia: a multiscale approach. Journal of Animal Ecology 73:789-801

France RL (1995) Carbon-13 enrichment in benthic compared to planktonic algae: foodweb implications. Marine Ecology Progress Series 124:307-312

Francey R, Allison C, Etheridge D, Trudinger C, Enting I, Leuenberger M, Langenfelds R, Michel E, Steel L (1999) A 1000-year precision record of $\delta^{13} \mathrm{C}$ in atmospheric $\mathrm{CO}_{2}$. Thellus B 51:170-193

Fry B (2006) Stable Isotope Ecology. Springer Science and Business Media, New York, USA, 308pp

Garcia AM, Hoeinghaus DJ, Vieira JP, Winemiller KO, Motta Marques DML, Bemvenutti MA (2006) Preliminary examination of food web structure of Nicola lake (Taim hydrological system, south Brazil) using dual C and N stable isotope analyses. Neotropical Ichthyology 4:279-284

Gendron D, Aguíñiga S, Carriquiry JD (2001) $\delta^{15} \mathrm{~N}$ and $\delta^{13} \mathrm{C}$ in skin biopsy samples: a note on their applicability for examining the relative trophic level in three rorqual species. Journal of Cetacean Research and Management 3:41-44 
Goericke R, Fry B (1994) Variations of marine plankton $\delta^{13} \mathrm{C}$ with latitude, temperature, and dissolve $\mathrm{CO}_{2}$ in the world ocean. Global Biogeochemical Cycles 8:85-90

Goodall RNP (1978) Report in the small cetaceans stranded on the coasts of Tierra del Fuego. The Scientific Reports of the Whales Research Institute, Tokyo 30:197230

Goodall RNP (1989) The lost whales of Tierra del Fuego. Oceanus 32:89-95

Goodall RNP (1994) Commerson's dolphin Cephalorhynchus commersonii (Lacépède 1804). En: Ridgway SH, Harrison SR (eds) Handbook of Marine Mammals. Vol 5: The First Book of Dolphins. Academic Press, London, pp 241-267

Goodall RNP (1997) Review of sightings of the hourglass dolphin, Lagenorhynchus cruciger, in the South American sector of the Antarctic and Sub-Antarctic. Reports of the International Whaling Commission 47:1001-1013

Goodall RNP (2002a) Spectacled porpoise Phocoena dioptrica. En: Perrin WF, Würsig B, Thewissen JGM (eds) Encyclopedia of Marine Mammals. Academic Press, San Diego, pp 1158-1161

Goodall RNP (2002b) Peale's dolphin Lagenorhynchus australis. En: Perrin WF, Würsig B, Thewissen JGM (eds) Encyclopedia of Marine Mammals. Academic Pres, San Diego, pp 890-894

Goodall RNP (2002c) Hourglass dolphin Lagenorhynchus cruciger. En: Perrin WF, Würsig B, Thewissen JGM (eds) Encyclopedia of Marine Mammals. Academic Press, San Diego, pp 583-585

Goodall RNP, Baker AN, Best PB, Meyer M, Miyazaki N (1997a) On the biology of the hourglass dolphin, Lagenorhynchus cruciger (Quoy and Gaimard, 1824). Reports of the International Whaling Commission 47:895-999

Goodall RNP, Benegas LG, Boy CC, Dellabianca N, Pimper L, Riccialdelli L (2008) Review of small cetaceans stranded or incidentally captured on the coast of Tierra del Fuego, Argentina, over 33 years. Paper SC/60/SM2 1 presented to the Scientific Committee, International Whaling Commission, Junio 2008, 14pp. Available from www.iwcoffice.org

Goodall RNP, de Haro JC, Fraga F, Iñíguez MA, Norris KS (1997b) Sightings and behaviour of Peale's dolphins, Lagenorhynchus australis, with notes on dusky dolphins, L. obscurus, off southernmost South America. Reports of the International Whaling Commission 47:757-775 
Goodall RNP, Galeazzi AR (1985) A review of the food habits of the small cetaceans of the Antartic and Sub-Antarctic. En: Siegfried WR, Condy PR, Laws RM (eds) Antarctic Nutrient Cycles and Food Webs. Springer-Verlag, Berlin, p 566-572

Goodall RNP, Galeazzi AR, Leatherwood S, Miller KW, Cameron IS, Kastelein RK, Sobral AP (1988) Studies of Commerson's dolphins, Cephalorhynchus commersonii, off Tierra del Fuego, 1976-1984, with a review of information on the species in the South Atlantic. En: Brownell RL, Donovan GP (eds) The Biology of the Genus Cephalorhynchus. Reports of the International Whaling Commission, Special Issue 9, p 3-70

Goodall RNP, Norris KS, Harris G, Oporto JA, Castello HP (1995a) Notes on the biology of Burmeister's porpoise, Phocoena spinipinnis, off southern South America. En: Bjorge A, Donovan GP (eds) Biology of the Phocoenids. Reports of the International Whaling Commission, Special Issue 16, pp 317-347

Goodall RNP, Norris KS, Scheville WE, Fraga F, Praderi R, Iñíguez MAJ, de Haro JC (1997c) Review and update on the biology of Peale's dolphin, Lagenorhynchus australis. Reports of the International Whaling Commission 47:777-796

Goodall RNP, Schiavini A (1992) Varamientos de delfín gris, Grampus griseus, en las costas del extremo sur sudamericano. 5ta Reunión de Trabajo de Especialistas en Mamíferos Acuáticos de América del Sur. SOLAMAC, Buenos Aires, Argentina, p 31

Goodall RNP, Schiavini ACM (1989) Preliminary report on a mass stranding of false killer whales, Pseudorca crassidens, along the Strait of Magellan. 8th Biennial Conference on the Biology of Marine Mammals. Society for Marine Mammology, Pacific Grove, California, p. 23 (no publicado)

Goodall RNP, Schiavini ACM (1995) On the biology of the spectacled porpoise, Australophocaena dioptrica. En: Bjorge A, Donovan GP (eds) Biology of the Phocoenids. Reports of the International Whaling Commission, Special Issue 16 , pp $411-453$

Goodall RNP, Schiavini ACM, Fermani C (1994) Net fisheries and net mortality of small cetaceans off Tierra del Fuego, Argentina. En: Perrin WF, Donovan GP, Barlow J (eds) Gillnets and Cetaceans. Reports of the International Whaling Commission, Special Issue 15, pp 295-304

Goodall RNP, Würsig B, Würsig M, Harris G, Norris KS (1995b) Sightings of Burmeister's porpoise, Phocoena spinipinnis, off southern South America. En: 
Bjorge A, Donovan GP (eds) Biology of the Phocoenids. Reports of the International Whaling Commission, Special Issue 16, pp 297-316

Graham BS, Koch PL, Newsome SD, McMahon KW, Aurioles D (2010) Using isoscapes to trace the movements and foraging behavior of top predators in oceanic ecosystems. En: West J (ed) Isoscapes: Understanding Movement, Pattern, and Process on Earth Through Isotope Mapping. Springer Science + Business Media BV, pp 299-318

Hare PE, Fogel ML, Stafford Jr. TW, Mitchell AD, Hoering TC (1991) The isotopic composition of carbon and nitrogen in individual amino acids isolated from modern and fossil proteins. Journal of Archaeological Science 18:277-292

Hartman KL, Visser F, Hendriks AJE (2008). Social structure of Risso's dolphins (Grampus griseus) at the Azores: a stratified community based on highly associated social units. Canadian Journal of Zoology, 86:294-306

Hedges REM, Stevens RE, Koch PL (2005) Isotopes in bones and teeth. En: Leng MJ (ed) Isotopes in Palaeoenvironmental Research. Springer, Netherlands, p 117145

Hobson KA (1999) Tracing origins and migration of wildlife using stable isotopes: a review. Oecología 120:314-326

Hobson KA (2007) Isotopic tracking of migrant wildlife. En: Michener R, Lajtha K (eds) Stable Isotopes in Ecology and Environmental Science. Blackwell Publishing, Malden, MA, p 155-175

Hobson KA, Alisauskas RT, Clark RG (1993) Stable-nitrogen isotope enrichment in avian tissues due to fasting and nutritional stress: implications for isotopic analyses of diet. The Condor 95:388-394

Hobson KA, Clark RG (1992a) Assessing avian diets using stable isotopes I: turnover of ${ }^{13} \mathrm{C}$ in tissues. The Condor 94:181-188

Hobson KA, Clark RG (1992b) Assessing avian diets using stable isotopes II: factors influencing diet-tissue fractionation. The Condor 94:189-197

Hobson KA, Sease JL (1998) Stable isotope analyses of tooth annuli reveal temporal dietary records: an example using Steller sea lion. Marine Mammal Science $14: 116-129$

Hobson KA, Sease JL, Merrick RL, Piatt JF (1997) Investigating trophic relationships of pinnipeds in Alaska and Washington using stable isotope ratios of nitrogen and carbon. Marine Mammal Science 13:1 14-132 
Hoffman JC, Sutton TT (2010) Lipid correction for carbon stable isotope analysis of deep-sea fishes. Deep Sea Research 57:956-964

Idermühle A, Stocker T, Joos F, Fisher H, Smith H, Wahlen M, Deck B, Mastroianni D, Tschumi J, Blunier T, Meyer R, Stauffer B (1999) Holoce carbon-cycle dynamics based in $\mathrm{CO} 2$ trapped in ice at Taylor Dome, Antarctica. Nature 398:121-126

Iñíguez MA, de Haro JC (1994) Preliminary report on the feeding habits of the Peale's dolphin (Lagenorhynchus australis) in southern Argentina. Aquatic Mammals 20:35-37

Iñíguez MA, Tossenberger VP (2007) Commerson's dolphins (Cephalorhynchus commersonii) off Ría Deseado, Patagonia, Argentina. Aquatic Mammals 33:276285

Isla MS (2006) Pesca marítima en Tierra del Fuego con especial énfasis en la pesca costera y artesanal. Dirección de Pesca y Acuicultura, Subsecretaría de Recursos Naturales, Ushuaia, Argentina

Iverson SJ, Field C, Bowen WD, Blanchard W (2004) Quantitative fatty acid signature analysis: a new method of estimating predator diets. Ecological Monographs 72:211-235

Jefferson TA, Newcomer MW, Leatherwood S, Van Waerebeek K (1994) Right whale dolphins Lissodelphis borealis (Peale, 1848) and Lissodelphis peronii (Lacépède, 1804). En: Ridgway SH, Harrison SR (eds) Handbook of Marine Mammals. Vol 5: The First Book of Dolphins. Academic Press, London, pp 335-361

Jenkins SG, Partridge ST, Stephenson TR, Farley SD, Robbins CT (2001) Nitrogen and carbon isotope fractionation between mothers, neonates and nursing offspring. Oecología 129:336-341

Jennings S, Greenstreet SPR, Hill L, Piet GL, Pinnegar JK, Warr KJ (2002) Longterm trends in the trophic structure of the North Sea fish community: evidence from stable-isotope analysis, size-spectra and community metrics. Marine Biology 141:1085-1097

Joseph BE, Antrim JE, Cornell LH (1987) Commerson's dolphin (Cephalorhynchus commersonii): A discussion of the first live birth within a marine zoological park. Zoo Biology 6:69-77

Kelly JF (2000) Stable isotopes of carbon and nitrogen in the study of avian and mammalian trophic ecology. Canadian Journal of Zoology 78:1-27 
Kemper C, Hill M (2001) First records of the spectacled porpoise Phocoena dioptrica in continental Australian waters. Marine Mammal Science 17:161-170

Kiszka J, Oremus M, Richard P, Poole M, Ridoux V (2010) The use of stable isotope analyses from skin biopsy samples to assess trophic relationships of sympatric delphinids off Moorea (Frech Polynesia). Journal of Experimental Marine Biology and Ecology 395:48-54

Knoff A, Hohn A, Macko SA (2008) Ontogenetic diet changes in bottlenose dolphins (Tursiops truncatus) reflected through stable isotopes. Marine Mammal Science 24:128-137

Koch PL (2007) Isotopic study of the biology of modern and fossil vertebrates. En: Michener R, Lajtha K (eds) Stable Isotopes in Ecology and Environmental science. Blackwell Publishing, Malden, MA, pp 99-154

Koch PL, Beherensmeyer AK, Stott AW, Turros N, Evershed RP, Fogel ML (2001) The effects of weathering on the stable isotope composition of bones. Ancient Biomolecules 3:117-134

Koen Alonso M, Pedraza SN, Schiavini ACM, Goodall RNP, Crespo EA (1999) Stomach contents of false killer whales (Pseudorca crassidens) stranded on the coasts of the Strait of Magellan, Tierra del Fuego. Marine Mammal Science $15: 712-724$

Kojadinovic J, Richard P, Le Corre M, Cosson RP, Bustamente P (2008) Effects of lipid extraction on $\delta^{13} \mathrm{C}$ and $\delta^{15} \mathrm{~N}$ values in seabird muscle, liver and feathers. Waterbirds 31:169-178

Kruse S, Caldwell DK, Caldwell MC (1999) Risso’s dolphin Grampus griseus (G. Cuvier, 1812). En: Ridgway S (ed) Handbook of Marine Mammals. Vol. 6. Academic press, New York, p 183-212

Lara RJ, Alder V, Franzosi CA, Kattner G (2010) Characteristics of suspended particulate organic matter in the southwestern Atlantic: influence of temperature, nutrient and phytoplankton features on the stable isotope signature. Journal of Marine Systems 79:199-209

Layman CA, Arrington DA, Montaña CG, Post DM (2007) Can stable isotope ratios provide for community-wide measures of trophic structure? Ecology 88:42-48

Leatherwood S, Grove JS, Zuckerman AE (1991) Dolphins of the genus Lagenorhynchus in the tropical South Pacific. Marine Mammal Science 7:194197 
Leatherwood S, Perrin WF, Kirby VL, Hubbs CL, Dahlheim ME (1980) Distribution and movements of Risso's dolphin, Grampus griseus, in the eastern North Pacific. Fishery Bulletin 77:951-963

LeDuc RG, Perrin WF, Dizon AE (1999) Phylogenetic relationships among the delphinid cetaceans based on full cytochrome b sequences. Marine Mammal Science 15:619-648

Lee SH, Schell DM, McDonald TL, Richardson WJ (2005) Regional and seasonal feeding by bowhead whales Balaena mysticetus as indicated by stable isotope ratios. Marine Ecology Progress Series 285:271-287

Lee-Thorp JA, Sponheimer M, Van Der Merwe NJ (2003) What do stable isotopes tell us about hominid dietary and ecological niches in the Pliocene? International Journal of Osteoarchaeology 13:104-113

Lescrauwaet AK (1997) Notes on the behaviour and ecology of Peale's dolphin, Lagenorhynchus australis, in the Strait of Magellan, Chile. Reports of the International Whaling Commission 47:747-755

Lescrauwaet AK, Gibbons J (1994) Mortality of small cetaceans and the crab bait fisheries in the Magallanes area of Chile since 1980. En: Perrin WF, Donovan GP, Barlow J (eds) Gillnets and Cetaceans. Reports of the International Whaling Commission, Special Issue 15, pp 485-494

Leuenberger M, Siegenthaler U, Langway C (1992) Carbon isotope composition of atmospheric $\mathrm{CO}_{2}$ during the last ice age from an Antarctic ice core. Nature 357:488-490

Lewis R, O'Connell TC, Lewis M, Campagna C, Hoelzel AR (2006) Sex-specific foraging strategies and resource partitioning in the southern elephant seal (Mirounga leonina). Proceedings of The Royal Society B 273:2901-2907

Lipsky JD (2002) Right whale dolphins Lissodelphis borealis and L. peronii. En: Perrin WF, Würsig B, Thewissen JGM (eds) Encyclopedia of Marine Mammals. Academic Press, San Diego, pp 1030-1033

Logan JM, Jardine TD, Miller TJ, Bunn SE, Cunjak R, A, Lutcavage ME (2008) Lipid corrections in carbon and nitrogen stable isotope analyses: comparison of chemical extraction and modelling methods. Journal of Animal Ecology $77: 838-846$

Lorenzani J, Junin M (1996) Nuevo registro de Phocoena spinipinnis para la provincia de Buenos Aires. 7ma Reunión de Trabajo de Especialistas en Mamíferos Acuáticos de América del Sur. SOLAMAC, Viña del Mar, Chile, p 87 
Marshall GJ (2007) Half-century seasonal relationships between the Southern Annular Mode and Antarctic temperatures. International Journal of Climatology 27:373-383.

Martinez del Río C, Wolf BO (2005) Mass-balance models for animal isotopic ecology. En: Starck JM, Wang T (eds) Physiological and Ecological Adaptations to Feeding in Vertebrates. Science Publishers, Enfield, New Hampshire, pp 141174

Martinez del Río C, Wolf N, Carleton SA, Gannes LZ (2009) Isotopic ecology ten years after a call for more laboratory experiments. Biological Reviews 84:91111

Martini LW (2006) Artes y Métodos de Pesca. Nivel 1. Armada Argentina, Mar del Plata, Argentina, 163pp

McCutchan JHJ, Lewis WMJ, Kendall C, McGrath CC (2003) Variation in trophic shift for stable isotope ratios of carbon, nitrogen, and sulfur. Oikos 102:378-390

Merrick RL (1997) Current and historical roles of apex predators in the Bering Sea ecosystem. Journal of Northwest Atlantic Fishery Science 22:342-355

Michener R, Kaufman L (2007) Stable isotope ratios as tracers in marine food webs: an update. En: Michener R, Lajtha K (eds) Stable Isotopes in Ecology and Environmental Science. Blackwell Publishing, Malden, MA, pp 238-282

Minagawa M, Wada E (1984) Stepwise enrichment of ${ }^{15} \mathrm{~N}$ along food chains: Further evidence and the relation between $\delta^{15} \mathrm{~N}$ and animal age. Geochimica et Cosmochimica Acta 48:1135-1140

Mintenbeck K, Brey T, Jacob U, Knust R, Struck U (2008) How to account for lipid effect on carbon stable-isotope ratio $\left(\boldsymbol{\delta}^{13} \mathrm{C}\right)$ : sample treatment effects and model bias. Journal of Fish Biology 72:815-830

Montoya JP (2007) Natural abundance of ${ }^{15} \mathrm{~N}$ in marine planktonic ecosystems. En: Michener R, Lajtha K (eds) Stable Isotopes in Ecology and Environmental Science. Blackwell Publishing, Malden, MA, pp 176-201

Mucchio Z, Jackson G (2009) Isotope ratio mass spectrometry. Analyst 134:213-222

Newcomer MW, Jefferson TA, Brownell RLJ (1996) Lissodelphis peronii. Mammalian Species 531:1-5

Newsome SD, Clementz MT, Koch PL (2010) Using stable isotope biogeochemistry to study marine mammal ecology. Marine Mammal Science 26:509-572

Newsome SD, Etnier MA, Kurle CM, Waldebauer JR, Chamberlain CP, Koch PL (2007a) Historic decline in primary productivity in western Gulf of Alaska and 
eastern Bering Sea: isotopic analysis of northern fur seal teeth. Marine Ecology Progress Series 332:211-224

Newsome SD, Etnier MA, Monson DH, Fogel ML (2009b) Retrospective characterization of ontogenetic shifts in killer whale diets via $\delta^{13} \mathrm{C}$ and $\delta^{15} \mathrm{~N}$ analysis of teeth. Marine Ecology Progress Series 374:229-242

Newsome SD, Koch PL, Etnier MA, Aurioles-Gamboa D (2006) Using carbon and nitrogen isotope values to investigate maternal strategies in Northeast Pacific otariids. Marine Mammal Science 22:556-572

Newsome SD, Martinez del Río C, Bearhop S, Phillips DL (2007b) A niche for isotopic ecology. Frontiers in Ecology and the Environment 5:429-436

Newsome SD, Tinker MT, Monson DH, Oftedal OT, Ralls K, Staedler MM, Fogel ML, Estes JA (2009a) Using stable isotopes to investigate individual diet specialization in California sea otters (Enhydra lutris nereis). Ecology 90:961-974

Niño-Torres CA, Gallo-Reynoso JP, Galván-Magaña F, Escobar-Briones E, Macko SA (2006) Isotopic analysis of $\delta^{13} \mathrm{C}, \delta^{15} \mathrm{~N}$ and $\delta^{34} \mathrm{~S}$ "A feeding tale" in teeth of the longbeaked common dolphin, Delphinus capensis. Marine Mammal Science 22:831-846

Olavarría C, Aguayo-Lobo A, Bernal R (2001) Distribution of Risso's dolphin (Grampus griseus, Cuvier 1812) in Chilean waters. Revista de Biología Marina y Oceanografía 36:111-116

Pauly D, Christensen V (2002) Ecosystem models. En: Hart P, Reynolds J (eds) Handbook of Fish Biology and Fisheries. Blackwell Science Ltd, UK, pp 211227

Pauly D, Christensen V, Dalsgaard J, Froese R, Torres F (1998b) Fishing down marine food webs. Science 279:860-863

Pauly D, Christensen V, Guenette S, Pitcher TJ, Sumaila UR, Walters CJ, Watson R, Zeller D (2002) Towards sustainability in world fisheries. Nature 418:689-695

Pauly D, Trites AW, Capuli E, Christensen V (1998a) Diet composition and trophic levels of marine mammals. ICES Journal of Marine Science 55:467-481

Pauly D, Watson R (2005) Background and interpretation of the 'marine trophic index' as a measure of biodiversity. Philosophical Transactions of The Royal Society B, 360:415-423. 
Pedraza SN (2007) Ecología poblacional de la tonina overa Cephalorhynchus commersonii (Lacépède, 1804) en el litoral patagónico. Tesis Doctoral, Universidad de Buenos Aires, Argentina, 225pp

Phillips DL (2001) Mixing models in analyses of diet using multiple stable isotopes: a critique. Oecologia 127:166-170

Phillips DL, Gregg JW (2001) Uncertainty in source partitioning using stable isotopes. Oecologia 127:171-179

Phillips DL, Gregg JW (2003) Source partitioning using stable isotopes: coping with too many sources. Oecologia 136:261-269

Phillips DL, Koch PL (2002) Incorporating concentration dependence in stable isotope mixing models. Oecologia 130:1 14-125

Phillips DL, Newsome SD, Gregg JW (2005) Combining sources in stable isotope mixing models: alternative methods. Oecologia 144:520-527

Pichler FB, Robineau D, Goodall RNP, Meÿer MA, Olavarría C, Baker CS (2001) Origin and radiation of Southern Hemisphere coastal dolphins (genus Cephalorhynchus). Molecular Ecology 10:2215-2223

Pierce GJ, Begoña Santos M, Learmonth JA, Mente E, Stowasser G (2004) Methods for dietary studies on marine mammals. En: Briand F (ed) Investigating the Roles of Cetaceans in Marine Ecosystems. CIESM Publisher, Venice, p 29-36

Pierce GJ, Boyle PR (1991) A review of methods for diet analysis in piscivorous marine mammals. Oceanography and Marine Biology Annual Review 29:409486

Pinedo MC, Barreto AS, Lammardo MP, Andrade ALV, Geracitano L (2002) Northernmost records of the spectacled porpoise, Layard's beaked whale, Commerson's dolphin, and Peale's dolphin in the southwestern Atlantic Ocean. Aquatic Mammals 28:32-37

Pinedo MC, Rosas FCW (1989) Novas ocorrências de Pseudorca crassidens (Cetacea, Delphinidae) para o atlântico sul ocidental, com observações sobre medidas cranianas e alimentação. Atlántica 11:77-83

Pinela AM, Borrell A, Cardona L, Aguilar A (2010) Stable isotope analysis reveals habitat partitioning among marine mammals off the NW African coast and unique trophic niches for two globally threatened species. Marine Ecology Progress Series 416:295-306 
Pinnegar J, Polunin NVC (1999) Differential fractionation of $\delta^{13} \mathrm{C}$ and $\delta^{15} \mathrm{~N}$ among fish tissues: implications for the study of trophic interactions. Functional Ecology $13: 225-231$

Porras-Peters H, Aurioles-Gamboa D, Cruz-Escalona VH, Koch PL (2008) Trophic level and overlap of sea lions (Zalophus carlifornianus) in the Gulf of California, Mexico. Marine Mammal Science 24:554-576

Post DM (2002) Using stable isotopes to estimate trophic position: models, methods, and assumptions. Ecology 83:703-718

Post DM, Layman CA, Arrington DA, Takimoto G, Quattrochi JP, Montaña CG (2007) Getting to the fat of the matter: models, methods and assumptions for dealing with lipids in stable isotope analyses. Oecologia 152:179-189

Rau GH, Mearns AJ, Young DR, Olson RJ, Schafer HA, Kaplan IR (1983) Animal ${ }^{13} \mathrm{C} /{ }^{12} \mathrm{C}$ correlates with trophic level in pelagic food webs. Ecology 64:13141318

Rau GH, Sweeney RE, Kaplan IR (1982) Plankton ${ }^{13} \mathrm{C}:{ }^{12} \mathrm{C}$ ratio changes with latitude: differences between northern and southern oceans. Deep-Sea Research 29:1035-1039

Rayment W, Dawson SM, Slooten E (2010) Seasonal changes in distribution of Hector's dolphin at Banks Peninsula, New Zealand: implications for protected area design. Aquatic Conservation: Marine and Freshwater Ecosystems 20:106116

Rayment W, Dawson SM, Slooten E, Bräger S, DuFresne S, Webster T (2009) Kernel density estimates of alongshore home range of Hector's dolphins (Cephalorhynchus hectori) at Banks Peninsula. Marine Mammal Science 25:537556

Reeves RR, Smith BD, Crespo EA, Notarbartolo di Siara G (2003) Dolphins, whales and porpoises: 2002-2010 Conservation action plan for the world's cetaceans. IUCN/SSC Cetacean Specialist Group. IUCN, Gland, Switzerland and Cambridge, UK.

Reyes JC, Van Waerebeek K (1995) Aspects of the biology of Burmeister's porpoise from Peru. En: Bjorge A, Donovan GP (eds) Biology of Phocoenids. Reports of the International Whaling Commission, Special Issue 16, p 349-364

Reyes L (2006) Cetaceans of central Patagonia, Argentina. Aquatic Mammals 32:20-30

Robineau D, Goodall RNP, Pichler F, Baker AN (2007) Description of a new subspecies of Commerson's dolphin, Cephalorhynchus commersonii (Lacépède, 
1804), inhabiting the coastal waters of the Kerguelen Islands. Mammalia $71: 172-180$

Rosa S, Milinkovitch MC, Van Waerebeek K, Berck J, Oporto JA, Alfaro-Shigueto J, Van Bressem MF, Goodall RNP, Cassens I (2005) Population structure of nuclear and mitochondrial DNA variation among South American Burmeister's porpoises (Phocoena spinipinnis). Conservation Genetics 6:431-443

Rosero Caicedo DM (2005) Dieta de la tonina overa, Cephalorhynchus commersonii (Lacépède, 1804) en Tierra del Fuego, Argentina. Tesis de Licenciatura, Pontificia Universidad Javeriana, Colombia, 57pp

Ross GJB (1984) The smaller cetaceans of the southeast coast of southern Africa. Annals of the Cape Provincial Museums (Natural History) 15:173-411

Rubenstein DR, Hobson KA (2004) From birds to butterflies: animal movement patterns and stable isotopes. Trends in Ecology and Evolution 19:256-263

Schell DM, Barnett BA, Vinette KA (1998) Carbon and nitrogen isotope ratios in zooplankton of the Bearing, Chukchi and Beafourt Seas. Marine Ecology Progress Series 162:11-23

Schell DM, Saupe SM, Haubenstock N (1989) Natural isotope abundances in Bowhead whale (Balaena mysticetus) baleen: markers of aging and habitat usage. En: Rundel PW, Ehleringer JR, Nagy KA (eds) Stable Isotopes in Ecological Research. Springer-Verlag New York, Inc., New York, USA, p 260-269

Schiavini ACM, Goodall RNP, Lescrauwaet AK, Koen Alonso M (1997) Food habits of Peale's dolphin, Lagenorhynchus australis; review and new information. Reports of the International Whaling Commission 47:827-834

Schoeller DA (1999) Isotope fractionation: why aren't we what we eat? Journal of Archaeological Science 26:667-673

Schoeninger MJ, DeNiro MJ (1984) Nitrogen and carbon isotopic composition of bone collagen from marine and terrestrial animals. Geochimica et Cosmochimica Acta 48:625-639

Sekiguchi K, Klages NTW, Best PB (1992) Comparative analysis of the diets of smaller odontocete cetaceans along the coast of Southern Africa. South African Journal of Marine Science 12:843-861

Sekiguchi K, Olavarría C, Morse L, Olson P, Ensor P, Matsuoka K, Pitman R, Findlay K, Gorter U (2006) The spectacled porpoise (Phocoena dioptrica) in Antarctic waters. Journal of Cetacean Research and Management 8:265-271 
Servicio de Hidrografía Naval (1981) Derrotero Argentino. Parte III: Archipiélago

Fueguino e Islas Malvinas. Armada Argentina, Publicación H203

Servicio de Hidrografía Naval (2006) Tablas de Marea para el Año 2006. Puertos de la

República Argentina y Puertos Principales de Brasil, Uruguay y Chile. Armada

Argentina, Publicación H610, 494pp

Sharp ZD (2007) Principles of Stable Isotopes Geochemistry. Pearson Prentice Hall, New Jersey, EEUU, 344pp

Sheffield G, Fay FH, Feder H, Kelly BP (2001) Laboratory digestion of prey and interpretation of walrus stomach contents. Marine Mammal Science 17:310330

Sheffield G, Grebmeier JM (2009) Pacific walrus (Odobenus rosmarus divergens): differential prey digestion and diet. Marine Mammal Science 25:761-777

Sheppard S, Harwood J (2005) Advances in molecular ecology: tracking trophic links through predator-prey food-webs. Functional Ecology 19:75 1-762

Slooten E, Rayment W, Dawson S (2006) Offshore distribution of Hector's dolphins at Banks Peninsula, New Zealand: is the Banks Peninsula Marine Mammal sanctuary large enough? New Zealand Journal of Marine and Freshwater Research 40:333-343

Smith DS, Whitehead H (1999) Distribution of dolphins in Galápagos waters. Marine Mammal Science 15:550-555

Sotiropoulos MA, Tonn WM, Wassenaar LI (2004) Effects of lipid extraction on stable carbon and nitrogen isotope analyses of fish tissues: potential consequences for food web studies. Ecology of Freshwater Fish 13:155-160

Sponheimer M, Robinson T, Ayliffe L, Passey B, Roeder B, Shipley L, Lopez E, Cerling TE, Dearing D, Ehleringer J (2003) An experimental study of carbonisotope fractionation between diet, hair, and feces of mammalian herbivores. Canadian Journal of Zoology 81:871-876

Stacey PJ, Leatherwood S, Baird RW (1994) Pseudorca crassidens. Mammalian Species $456: 1-5$

Stainland I (2002) Investigating the biases in the use of hard prey remains to identify diet composition using Antarctic fur seals (Arctocephalus gazelle) in captive feeding trials. Marine Mammal Science 18:223-243

Sulzman EW (2007) Stable isotope chemistry and measurement: a primer. En: Michener R, Lajtha K (eds) Stable Isotopes in Ecology and Environmental Science. Blackwell Publishing, Malden, MA, pp 1-21 
Syväranta J, Jones RI (2007) Changes in feeding niche widths of perch and roach following biomanipulation, revealed by stable isotope analysis. Freshwater Biology 53:425-434

Tezanos Pinto G, Gasparrou C, Iñíguez MA, Goodall RNP (2000) Observaciones preliminares de marsopas espinosas (Phocoena spinipinnis) en el Canal Beagle (Tierra del Fuego, Argentina). 9na Reunión de Trabajo de Especialistas en Mamíferos Acuáticos de América del Sur. SOLAMAC, Buenos Aires, Argentina, pp 129-130

Thiemann GW, Budge SM, Iverson SJ (2004) Determining bubbler fatty acid composition: a comparison of in situ direct and traditional methods. Marine Mammal Science 20:284-295

Thompson DWJ (2007) A brief introduction to the Annular Modes and Annular Mode research. Disponible en www.atmos.colostate.edu/ao/introduction. Último acceso el 6-7-2010

Thompson DWJ, Solomon S (2002) Interpretation of recent Southern Hemisphere climate change. Science 296:895-899.

Tollit D, Heaslip S, Deagle B, Iverson S, Joy R, Rosen D, Trites A (2006) Estimating diet composition in sea lion: which technique too choose? En: Trites AW, Atkinson SK, DeMarten DP, Fritz LW, Gellat TS, Rea LD, Wynne KM (eds) Sea Lions of the World. AK-SG-06-01. Alaska Sea Grant College Program, pp 293-307

Torres D, Aguayo A (1979) Hábitos alimentarios de Lissodelphis peronii (Lacepede, 1804) en Chile central (Cetacea: Delphinidae). Revista de Biología Marina y Oceanografía 16:22 1-224

Trites AW (2001) Marine mammal trophic levels and interactions. En: Steele J, Thorpe S, Turekian K (eds) Encyclopedia of Ocean Sciences. Academic Press, London, pp 1628-1633

Trites AW (2002) Pedator-prey relationships. En: Perrin WF, Würsig B, Thewissen HGM (eds) Encyclopedia of Marine Mammals. Academic Press, San Diego, pp 994-997

Trites AW (2003) Food webs in the ocean: who eats whom and how much? En: Sinclair M, Valdimarsson G (eds) Responsible Fisheries in the Marine Ecosystem. FAO, Rome and CABI Publishing, Wallingford, pp 125-141

Trites AW, Christensen V, Pauly D (2006) Effects of fisheries on ecosystems: just another top predator? En: Boyd I, Wanless S, Camphusyen CJ (eds) Top 
Predators in Marine Ecosystems. Cambridge University Press, Cambridge, pp $11-27$

Tykot RH (2004) Stable isotopes and diet: you are what you eat. En: Martini M, Milazzo M, Piacentini M (eds) Physics Methods in Archaeometry Proceedings of the International School of Physics "Enrico Fermi" Course CLIV, Bologna, Italy: Societá Italiana di Fisica, pp 433-444

Valenzuela LO, Sironi M, Rowntree V (2010) Interannual variation in th estable isotope differences between Mathers and their calves in southern right whales (Eubalaena australis). Aquatic Mammals 36:138-147

Van Waerebeek K, Canto J, Gonzalez J, Oporto JA, Brito JL (1991) Southern right whale dolphins, Lissodelphis peronii off the Pacific coast of South America. Zeitschrift für Säugetierkunde 56:284-295

Van Waerebeek K, Goodall RNP, Best PB (1997) A note on evidence for pelagic warm-water dolphins resembling Lagenorhynchus. Report of the International Whaling Commission 47:1015-1017

Van Waerebeek K, Oporto JA (1990) Observaciones preliminares sobre la biología de Lissodelphis peronii (Delphinidae) en el Pacífico Sureste. 4ta Reunión de Trabajo de Especialistas en Mamíferos Acuáticos de América del Sur. SOLAMAC, Valdivia, Chile, pp 73

Van Waerebeek K, Santillán L, Reyes JC (2002) An unusually large aggregation of Burmeister's porpoise Phocoena spinipinnis off Perú, with a review of sightings from the eastern South Pacific. Noticiario Mensual 350:12-17

Vander Zanden MJ, Rasmussen JB (1996) A trophic position model of pelagic food webs: impact on contaminant bioaccumulation in lake trout. Ecological Monographs 66:451-477

Vanderklift MA, Ponsard S (2003) Sources of variation in consumer-diet $\delta^{15} \mathrm{~N}$ enrichment: a meta-analysis. Oecologia 136:169-182

Viddi FA, Lescrauwaet AK (2005) Insights on habitat selection and behavioural patterns of Peale's dolphins (Lagenorhynchus australis) in the Strait of Magellan, southern Chile. Aquatic Mammals 31:176-183

Walker JL, Macko SA (1999) Dietary studies of marine mammals using stable carbon and nitrogen isotopic ratios of teeth. Marine Mammal Science 15:314-334

Walker JL, Potter CW, Macko SA (1999) The diets of modern and historic bottlenose dolphin populations reflected through stable isotopes. Marine Mammal Science $15: 335-350$ 
Whitehouse MJ, Rothery MP, Atkinson A, Ward P, Korb RE (2008) Rapid warming of the ocean around South Georgia, Southern Ocean, during the 20th century: forcings, characteristics and implications for lower trophic levels. Deep-Sea Research I 55(10):1218-1228.

Wolf N, Carleton SA, Martinez del Río C (2009) Ten years of experimental animal isotopic ecology. Functional Ecology 23:17-26

Würsig M, Würsig B, Mermoz JF (1977) Desplazamientos, comportamiento general y un varamiento de la marsopa espinosa, Phocoena spinipinnis, en el Golfo San José (Chubut, Argentina). Physis 36:71-79 